Fernanda Miranda Mendes

\title{
Produção e Caracterização de Bioplásticos a partir de Amido de Batata
}

\author{
Dissertação apresentada ao Instituto de Química \\ de São Carlos, da Universidade de São Paulo \\ para obtenção do título de Mestre em Química \\ (Físico-Química)
}

Orientador: Prof. Dr. Antonio Aprigio da Silva Curvelo

São Carlos

2009 
Dedicatória

À minha família 


\section{Agradecimentos}

À Deus, por ter me ajudado a chegar neste momento da minha vida com saúde e com muita perseverança.

Ao prof. Antonio Aprigio da Silva Curvelo pela amizade, dedicação e disposição na orientação deste trabalho.

A minha família que sempre me deu forças para continuar minha jornada passo a passo.

Aos colegas do laboratório e ex-alunos do grupo pela colaboração, amizade e boa convivência.

As minhas amigas de república pelo apoio e incentivo e a todos as pessoas com as quais convivi durante o período de execução do meu trabalho.

Ao Instituto de Química, Física e Geotecnia da USP de São Carlos e ao Departamento de Engenharia de Metalurgia e de Materiais da Escola Politécnica da USP pela infra-estrutura.

À Biomater pelo fornecimento dos materiais empregados neste estudo.

À FAPESP pelo suporte financeiro. 


\section{Resumo}

O presente trabalho teve por objetivo estudar 0 amido termoplástico (TPS) proveniente de batata e suas blendas com os polímeros biodegradáveis da classe dos poli (hidroxialcanoatos), como o homopolímero Poli ( $\beta$-hidroxibutirato) (PHB) e o copolímero Poli ( $\beta$-hidroxibutirato-co-valerato) (PHBV). Para tanto, foram desenvolvidas formulações de TPS, TPS/PHB, TPS/PHBV, TPS/PHBV, TPS/PHB/PHBV e dos próprios polímeros. Os teores de poli(hidroxialcanoatos) nas misturas foram iguais a 25, 50 e $75 \%$. O TPS e as blendas foram preparados via mistura física dos polímeros base com água e glicerol. O estudo da plasticização do amido com $30 \%$ de glicerol foi realizado em um misturador intensivo e os parâmetros de processo determinados $\left(160^{\circ} \mathrm{C}, 10 \mathrm{~min}\right.$ e $\left.60 \mathrm{rpm}\right)$ mostraram-se eficientes para a obtenção do termoplástico TPS. Os ensaios de absorção de água revelaram que o TPS pode apresentar ganho de massa de até $37 \%$. As blendas preparadas com maiores teores do polímero (PHB e/ou PHBV) apresentaram maior resistência à absorção de água. A análise termogravimétrica (TG) das blendas revelou a existência de dois estágios de perda de massa, correspondentes à degradação do TPS e aos poliestéres. Dados de calorimetria demonstraram que o amido de batata possui teor de amilose de $23,6 \%$. A curva DSC das blendas foram observados dois eventos térmicos endotérmicos, sendo o primeiro relacionado à saída de água e glicerol do TPS e o segundo correspondente à fusão do PHB e/ou PHBV. A análise por microscopia eletrônica de varredura evidenciou a presença de grãos de amido residuais nas formulações contendo maiores conteúdos de PHB e/ou PHBV. A análise térmica dinâmico-mecânica do TPS revelou a ocorrência de dois picos em tan $\delta$, sendo o primeiro correspondente a transições na fase rica do plasticizante glicerol e um segundo pico definido como $T_{g}$ do amido plasticizado. Os Ensaios Mecânicos de Tração mostraram para a amostra TPS o maior valor de deformação máxima, menor valor de módulo de elasticidade e baixo valor de tensão máxima, quando comparado às blendas TPS/PHB, TPS/PHBV e TPS/PHB/PHBV. O comportamento do TPS mostrou-se fortemente influenciado pelo teor de água presente na amostra. 


\begin{abstract}
The aim of this work was the study of thermoplastic starch (TPS) prepared from potato and its blends with biodegradable polyhydroxyalcanoates as homopolymer Poly ( $\beta$-hydroxibutirate) (PHB) and/or copolymer - Poly ( $\beta$-hydroxybutirate-covalerate) (PHBV). To reach the objectives of this study, there were developed formulations of TPS, TPS/PHB, TPS/PHBV, TPS/PHBV, TPS/PHB/PHBV and of the polymers themselves. The content of polyhydroxyalcanoates in the mixtures were 25, 50 and $75 \%$. The TPS and the blends were prepared by physical mixture of the polymers with water and glycerol. The study of starch'plasticization, performed with $30 \%$ of glycerol, was carried out in an intensive mixer and the determined parameters of the process $\left(160^{\circ} \mathrm{C}, 10 \mathrm{~min}\right.$ and $\left.60 \mathrm{rpm}\right)$ were effective for the production of the parent thermoplastic starch. The water absorption tests showed that the TPS can present gain of mass up to $37 \%$. The blends prepared with higher amounts of the polymer (PHB and/or PHBV) presented higher resistance to the absorption of water. Thermogravimetric analysis (TG) of the blends revealed the existence of two mass loss stages, correspondents to the degradation of TPS and the polyesters. Data from calorimetry (DSC) demonstrated that the potato starch present $23.6 \%$ of amylose. The traces of DSC from TPS revealed only events related to the elimination of water and glycerol. For the blends two thermal endothermic events were observed. The first one corresponds to the elimination of water and glycerol from TPS and the second to the melting of the PHB and/or PHBV. The analysis performed by using scanning electron microscopy showed the presence of residual grains of starch in the formulations containing $50 \%$ or higher amounts of PHB and/or PHBV. The Dynamic Mechanical Thermal Analysis of TPS revealed the occurence of two tan $\delta$ peaks, being the first one correspondent to transitions in the glycerol rich phase and a second peak described as $\mathrm{Tg}$ of the plasticized starch. The Mechanical Tests showed for the TPS sample the highest value of elongation, the lower value of tensile strength and a low value of Young's modulus, when compared to the blends TPS/PHB, TPS/PHBV and TPS/PHB/PHBV. The behaviour of the TPS appeared strongly influenced by the content of water in the samples.
\end{abstract}




\section{Lista de Figuras}

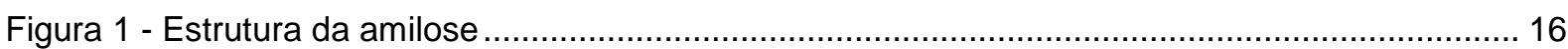

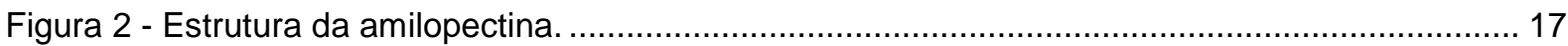

Figura 3 - Gelatinização do amido (PALMA; CICHELLO; PAVANELLI, 2009).................................... 19

Figura 4 - Retrogradação do amido (PALMA; CICHELLO; PAVANELLI, 2009).................................. 20

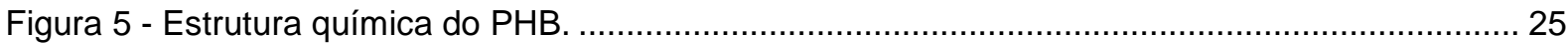

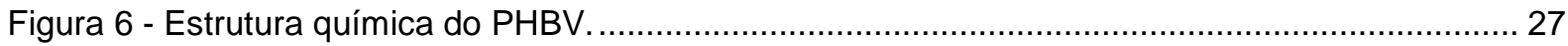

Figura 7- Misturador intensivo Haake (A) e detalhes da câmara de processamento e rotores tipo roller.

Figura 8 - Prensa utilizada para formação dos corpos de prova. .................................................. 39

Figura 9 - Exemplo do gráfico de $\left(M_{t}-M_{0}\right) / M_{\infty}$ em função de $\left(t^{1 / 2}\right) / L$ utilizado para calcular 0

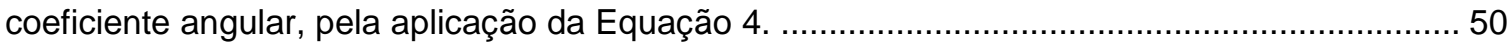

Figura 10 - Perfil de difração de raios-x exibindo os picos característicos e o método de Hulleman para determinação do índice de cristalinidade.

Figura 11 - Perfil de difração de raios-x exibindo os picos característicos e o halo amorfo para determinação do índice de cristalinidade

Figura 12 - Curvas do torque em função do tempo de processamento para diferentes temperaturas e

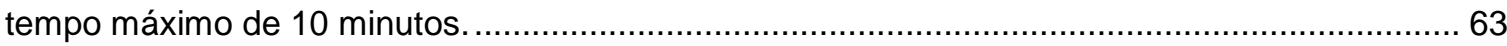

Figura 13 - Blendas PHB50 com diferentes temperaturas de processamento, $150^{\circ} \mathrm{C}(\mathrm{A}) ; 155^{\circ} \mathrm{C}(\mathrm{B})$;

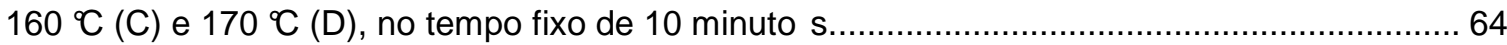

Figura 14 - Curvas de torque em função do tempo de mistura dos PHB50 a $160{ }^{\circ} \mathrm{C}$..........................65

Figura 15 - Blendas PHB50 obtidas em diferentes tempos de processamento, 4 minutos (A); 6 minutos (B); 8 minutos (C) e 10 minutos (D), na temperatura fixa de $160{ }^{\circ} \mathrm{C} \ldots \ldots \ldots \ldots \ldots \ldots \ldots \ldots \ldots . . . . . . . . . . . . . . .65$

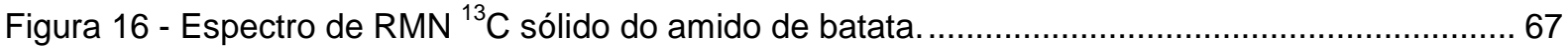

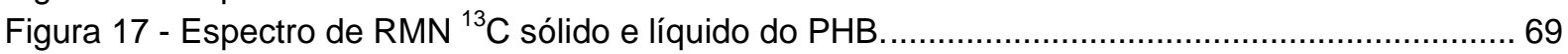

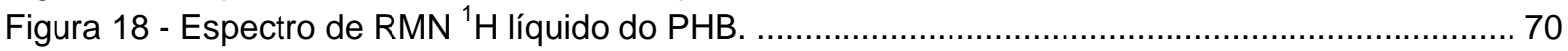

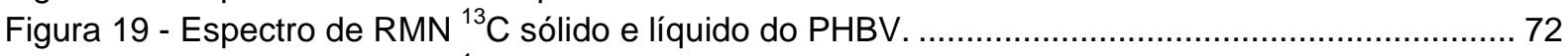

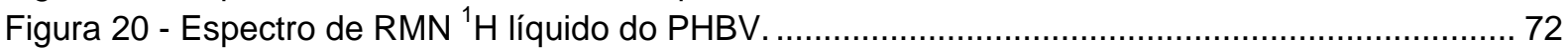

Figura 21 - Cromatograma do amido de batata e da amostra TPS............................................... 74

Figura 22 - Curvas de absorção de água (\%) em função do tempo (h) para as amostras TPS condicionadas em umidades controladas em 22,5, 43, 53, 75 e 84 \%. ..................................... 77

Figura 23 - Absorção de água (\%) em função da quantidade de PHB (\%) para a amostra TPS, blendas TPS/PHB e amostras de PHB, condicionadas em diferentes umidades relativas. .......... 79

Figura 24 - Absorção de água (\%) em função da quantidade de PHBV (\%) para a amostra TPS, blendas TPS/PHBV e amostras de PHBV, condicionadas em diferentes umidades relativas...... 80

Figura 25 - Absorção de água (\%) em função da quantidade de PHB/PHBV (\%) para a amostra TPS, blendas TPS/PHB/PHBV e amostras de PHB e PHBV, condicionadas em diferentes umidades relativas.

Figura 26 - Curvas de absorção de água (\%) em função do tempo (h) para a amostra TPS, blendas TPS/PHB e amostras com PHB, condicionadas em $53 \%$ de umidade.

Figura 27 - Curvas de absorção de água (\%) em função do tempo (h) para a amostra TPS, blendas TPS/PHBV e amostras com PHBV, condicionadas em $53 \%$ de umidade.

Figura 28 - Curvas de absorção de água (\%) em função do tempo (h) para a amostra TPS, blendas TPS/PHB/PHBV e amostras com PHB/PHBV, condicionadas em $53 \%$ de umidade................... 83

Figura 29 - Curvas TG e DTG para o amido de batata, PHB, PHBV e glicerol. Porta amostra de platina, atmosfera $\mathrm{N} 2$ (fluxo: $20 \mathrm{~mL} \mathrm{~min}^{-1}$ ); razão de aquecimento: $10{ }^{\circ} \mathrm{C} \mathrm{min}^{-1}$......................... 89

Figura 30 - Curvas TG e DTG para o amido de batata, glicerol e TPS. Porta amostra de platina, atmosfera $\mathrm{N}_{2}$ (fluxo: $20 \mathrm{~mL} \mathrm{~min}^{-1}$ ); razão de aquecimento: $10{ }^{\circ} \mathrm{C} \min ^{-1}$................................... 92

Figura 31- Curvas TG para amostra TPS, blendas TPS/PHB e para amostras de PHB. Porta amostra de platina, atmosfera $\mathrm{N}_{2}$ (fluxo: $20 \mathrm{~mL} \mathrm{~min}^{-1}$ ); razão de aquecimento: $10{ }^{\circ} \mathrm{C} \mathrm{min}^{-1}, 53 \%$ de umidade relativa. 
Figura 32 - Curvas TG para amostra TPS, blendas TPS/PHBV e amostras de PHBV. Porta amostra de platina, atmosfera $\mathrm{N}_{2}$ (fluxo: $20 \mathrm{~mL} \mathrm{~min}^{-1}$ ); razão de aquecimento: $10{ }^{\circ} \mathrm{C} \min ^{-1}, 53 \%$ de umidade relativa.

Figura 33 - Curvas TG para amostra TPS, blendas TPS/PHB/PHBV e para amostras de PHB/PHBV.

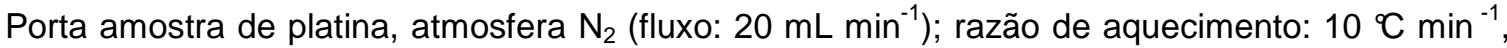
$53 \%$ de umidade relativa

Figura 34 - Curvas TG e DTG das amostras PHB antes e após o processamento, amostras com glicerol e o próprio glicerol. Porta amostra de platina, atmosfera N2 (fluxo: $20 \mathrm{~mL} \mathrm{~min}^{-1}$ ); razão de aquecimento: $10{ }^{\circ} \mathrm{C} \mathrm{min}^{-1}$

Figura 35 - Curvas TG e DTG das amostras PHBV antes e após o processamento, amostras com glicerol e o próprio glicerol. Porta amostra de platina, atmosfera $\mathrm{N}_{2}$ (fluxo: $20 \mathrm{~mL} \mathrm{~min}{ }^{-1}$ ); razão de aquecimento: $10{ }^{\circ} \mathrm{C} \mathrm{min}^{-1}$

Figura 36 - Curvas TG e DTG das amostras PHB e/ou PHBV antes e após o processamento, amostras com glicerol e o próprio glicerol. Porta amostra de platina, atmosfera N2 (fluxo: $20 \mathrm{~mL}$ $\left.\min ^{-1}\right)$; razão de aquecimento: $10{ }^{\circ} \mathrm{C} \min ^{-1}$.

Figura 37 - Curva DSC para o amido de batata sem a presença de água. Porta amostra hermético com furo no centro, atmosfera $\mathrm{N} 2$ (fluxo: $20 \mathrm{~mL} \mathrm{~min}^{-1}$ ); razão de aquecimento: $10{ }^{\circ} \mathrm{C} \mathrm{min}^{-1}$, massa de $10 \mathrm{mg}$ e temperatura ambiente até $250^{\circ} \mathrm{C}$

Figura 38 - Curva DSC para a gelatinização do amido de batata. Porta amostra de alumínio de alta pressão, atmosfera $\mathrm{N} 2$ (fluxo: $20 \mathrm{~mL} \min ^{-1}$ ); razão de aquecimento: $10{ }^{\circ} \mathrm{C} \mathrm{min}^{-1}$, massa $1: 2 /$ amido: $\mathrm{H}_{2} \mathrm{O}$ e temperatura ambiente até $120^{\circ} \mathrm{C}$.

Figura 39 - Curva DSC para a determinação do teor de amilose do amido de batata. Porta amostra de alumínio de alta pressão, atmosfera $\mathrm{N} 2$ (fluxo: $20 \mathrm{~mL}$ min-1); razão de resfriamento: $5{ }^{\complement} \mathrm{C} \mathrm{min}{ }^{-1} \mathrm{e}$ razão de aquecimento: $10^{\circ} \mathrm{C} \mathrm{min}^{-1}$.

Figura 40 - Curvas DSC ( $1^{\circ}$ aquecimento, resfriament o, $2^{\circ}$ aquecimento) para o PHB (A) e PHBV (B).

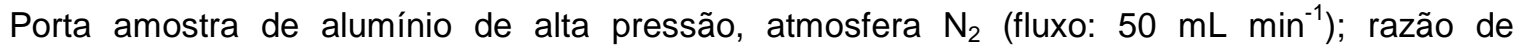
resfriamento e aquecimento: $10^{\circ} \mathrm{C} \mathrm{min}^{-1}$, massa: $10 \mathrm{mg}$, temperatura ambiente a $200{ }^{\circ} \mathrm{C}$. ...... 106

Figura 41 - Curva DSC para amostra TPS. Porta amostra de alumínio, atmosfera $\mathrm{N}_{2}$ (fluxo: $20 \mathrm{~mL}$ $\min ^{-1}$ ); razão de aquecimento: $10{ }^{\circ} \mathrm{C} \mathrm{min}^{-1}$, massa de $10 \mathrm{mg}$ e temperatura ambiente até $250{ }^{\circ} \mathrm{C}$.

Figura 42 - Curvas DSC para a amostra TPS, blendas TPS/PHB e amostras de PHB.................... 111

Figura 43 - Curvas DSC para a amostra TPS, blendas TPS/PHBV e amostras de PHBV. .............. 112

Figura 44 - Curvas DSC para a amostra TPS, blendas TPS/PHB/PHBV e amostras de PHB e/ou PHBV. 112

Figura 45 - Microscopia eletrônica de varredura do amido de batata com ampliações de 1000x e

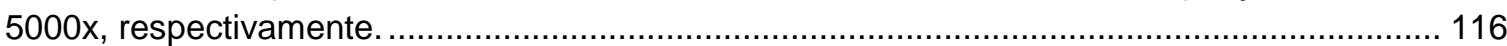

Figura 46 - Histograma das quantidades e tamanhos dos grânulos de amido de batata. ................. 118

Figura 47 - Microscopia eletrônica de varredura do PHB (A) e PHBV (B) com ampliações de 5.000x.

Figura 48 - Microscopia Eletrônica de Varredura do TPS com aumentos de 500x (A1) e 1000x (A2).

Figura 49 - Microscopia Eletrônica de Varredura das blendas PHB25 (A), PHB50 (B), PHB75 (C), PHB70G30 (D) e PHB (E), com aumentos de 1000x....................................................... 120

Figura 50 - Microscopia Eletrônica de Varredura das blendas PHBV25 (A), PHBV50 (B), PHBV75 (C), PHBV70G30 (D) e PHBV (E), com aumentos de 1000x.................................................... 121

Figura 51 - Microscopia Eletrônica de Varredura das blendas PHB12,5PHBV12,5 (A), PHB25PHBV25 (B), PHB37,5PHBV37,5 (C), PHB35PHBV35G30 (D) e PHB50PHBV50 (E), com aumento de $1000 \mathrm{x}$ 122

Figura 52 - Microscopia Eletrônica de Varredura das amostras PHB, PHBV e PHB50PHBV50, respectivamente, com aumento de 500x (A). Amostras PHB70G30, PHBV50G30 e

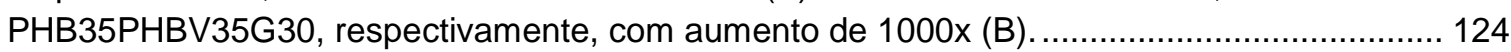

Figura 53 - Espectro na região de infravermelho do amido de batata........................................... 126 
Figura 54 - Espectro na região de infravermelho do PHB e PHBV, respectivamente....................... 127

Figura 55 - Espectro na região de infravermelho das amostras amido de batata e TPS,

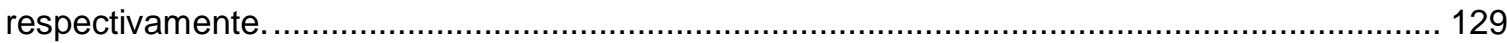

Figura 56 - Espectros de FTIR na região de 4000 a $650 \mathrm{~cm}^{-1}$, para a amostra TPS, blendas TPS/PHB e amostras de PHB.

Figura 57 - Espectros de FTIR na região de 4000 a $650 \mathrm{~cm}^{-1}$, para a amostra TPS, blendas TPS/PHBV e amostras de PHBV

Figura 58 - Espectros de FTIR na região de 4000 a $650 \mathrm{~cm}^{-1}$, para a amostra TPS, blendas

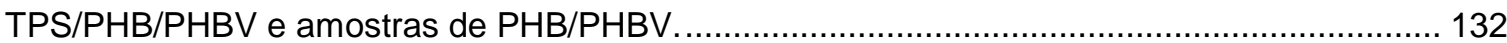

Figura 59 - Difratogramas de raios-X para o amido de batata, PHB e PHBV ................................... 135

Figura 60 - Difratogramas de Raios-X do amido de batata e amostra TPS. ................................... 138

Figura 61 - Difratogramas de raios-X para a amostra TPS, blendas TPS/PHB e para amostras de

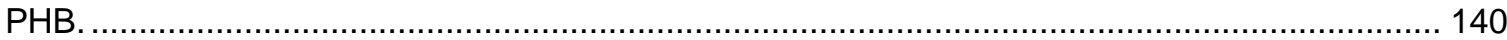

Figura 62 - Difratogramas de Raios-X para a amostra TPS, blendas TPS/PHBV e para amostras de PHBV

Figura 63 - Difratogramas de Raios-X para a amostra TPS, blendas TPS/PHB/PHBV e para amostras de PHB/PHBV.

Figura 64 - Difratogramas de Raios-X das amostras PHB antes e após o processamento e amostras de PHB com glicerol

Figura 65 - Difratogramas de Raios-X das amostras PHBV antes e após o processamento e amostras de PHBV com glicerol.

Figura 66 - Difratogramas de Raios-X das amostras PHB e/ou PHBV antes e após o processamento e amostras com glicerol.

Figura 67 - Curvas de módulo de armazenamento (E') e tangente de perda (tan $\delta$ ) em função da temperatura $\left({ }^{\circ} \mathrm{C}\right)$ para a amostra TPS

Figura 68 - Gráficos de tan $\delta$ em função da temperatura e gráficos de módulo de armazenamento (E') em função da temperatura para a amostra TPS, blendas TPS/PHB e amostras de PHB.

Figura 69 - Gráficos de tan $\delta$ em função da temperatura e gráficos de módulo de armazenamento (E') em função da temperatura para a amostra TPS, blendas TPS/PHBV e amostras de PHBV..... 149

Figura 70 - Gráficos de tan $\delta$ em função da temperatura e gráficos de módulo de armazenamento (E') em função da temperatura para a amostra TPS, blendas TPS/PHB/PHBV e amostras de $\mathrm{PHB} / \mathrm{PHBV}$.

Figura 71 - Curvas representativas de tensão em função da deformação para a amostra TPS. ...... 155

Figura 72 - Gráficos representativo da tensão máxima (MPa) (A), deformação máxima (\%) (B) e módulo de elasticidade (MPa) (C) em função do teor de PHB (\%) para a amostra TPS, blendas TPS/PHB e amostras de PHB.

Figura 73 - Gráficos representativo da tensão máxima (MPa) (A), deformação máxima (\%) (B) e módulo de elasticidade (MPa) (C) em função do teor de PHBV (\%) para a amostra TPS, blendas TPS/PHBV e amostras de PHBV.

Figura 74 - Gráficos representativo da tensão máxima (MPa) (A), deformação máxima (\%) (B) e módulo de elasticidade (MPa) (C) em função do teor de PHBV (\%) para a amostra TPS, blendas TPS/PHB/PHBV e amostras de PHB/PHBV.

Figura 75 - Gráficos representativo da tensão máxima (MPa) para a amostra TPS, blendas PHB25, PHBV25 e PHB12,5PHBV12,5 e amostras PHB e PHB50PHBV50.

Figura 76 - Gráficos representativo da deformação máxima (\%) para a amostra TPS, blendas PHB25, PHBV25 e PHB12,5PHBV12,5 e amostras PHB e PHB50PHBV50.

Figura 77 - Gráficos representativo do módulo de elasticidade (MPa) para a amostra TPS, blendas PHB25, PHBV25 e PHB12,5PHBV12,5 e amostras PHB e PHB50PHBV50. 


\section{Lista de Tabelas}

Tabela 1 - Composições do TPS, das blendas TPS/PHB e das amostras de PHB.......................... 42

Tabela 2 - Composições do TPS, das blendas TPS/PHB e das misturas de PHB e PHBV. ............... 43

Tabela 3 - Condições de processamento empregadas no reômetro de torque. .................................. 44

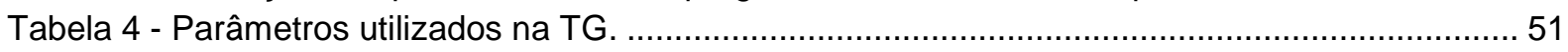

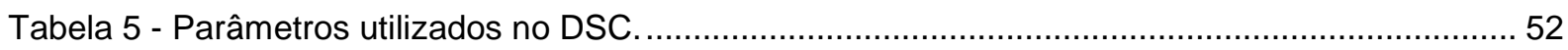

Tabela 6 - Parâmetros utilizados para a determinação da melhor condição de análise nos diferentes

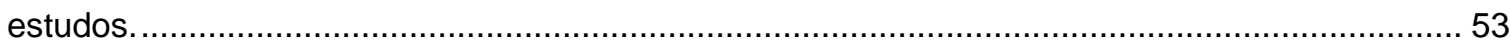

Tabela 7 - Programação de temperatura na determinação do teor de amilose empregando DSC. ....54

Tabela 8 - Principais posições das bandas mais significativas do amido de batata. …....................... 67

Tabela 9 - Valores de Mn, Mw e Mw/Mn para as amostras de amido de batata e TPS...................... 75

Tabela 10 - Valores de absorção máxima de água para as amostras TPS em diferentes umidades

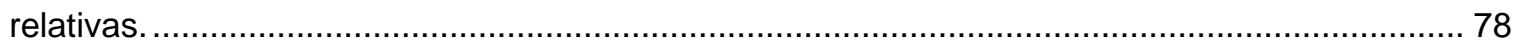

Tabela 11 - Absorção máxima de água (\%) em ambientes de 22,5, 43, 53, 75 e $84 \%$ de umidades relativas para a amostra TPS, blendas TPS/PHB, TPS/PHBV e TPS/PHB/PHBV e amostras de

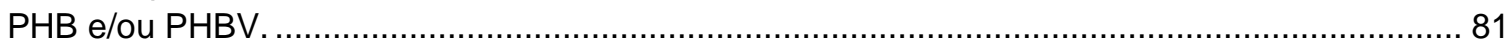

Tabela 12 - Valores de absorção máxima de água para a amostra TPS, blendas TPS/PHB, TPS/PHBV e TPS/PHB/PHBV e as amostras de PHB e/ou PHBV............................................. 84

Tabela 13 - Parâmetros $n, k$ e $D\left(\mathrm{~cm}^{2} . s^{-1}\right)$ para a amostra TPS, blendas TPS/PHB, TPS/PHBV,

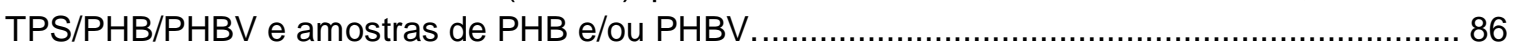

Tabela 14 - Eventos térmicos com os respectivos intervalos de temperatura e perda de massa (\%)

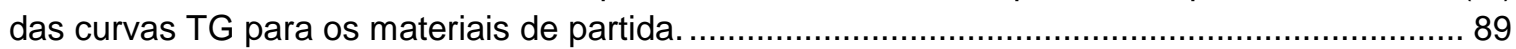

Tabela 15 - Intervalos de temperatura e perda de massa (\%) do TPS, blendas TPS/PHB, TPS/PHBV e TPS/PHB/PHBV e amostras de PHB e/ou PHBV................................................................... 95

Tabela 16 - Características térmicas (intervalo de temperatura, temperatura de cristalização (Tc) e temperatura de fusão $\left(T_{m}\right)$, entalpia de cristalização $\left(\Delta \mathrm{H}_{c}\right)$ e de fusão $\left(\Delta \mathrm{H}_{m}\right)$ e grau de

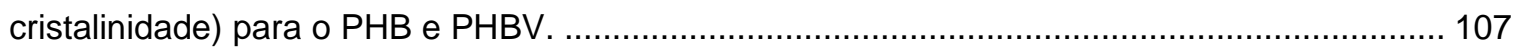

Tabela 17 - Características térmicas (intervalo de temperatura, temperatura de pico e onset e entalpias) para $\circ 1^{\circ} \mathrm{e} \circ 2^{\circ}$ evento para a amostra T PS, blendas TPS/PHB, TPS/PHBV e TPS/PHB/PHBV e amostras de PHB e/ou PHBV e grau de cristalinidade para as amostras com $\mathrm{PHB}$ e/ou PHBV.

Tabela 18 - Principais atribuições para as bandas de absorção no IV para o amido de batata. ....... 126

Tabela 19 - Principais atribuições para as bandas de absorção no IV para os polímeros PHB e PHBV.

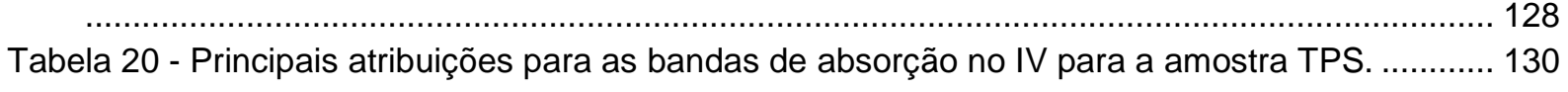

Tabela 21 - Grau de cristalinidade (\% C) obtido por Difração de Raios-X para os polímeros PHB (pó) e PHBV (pellet), amostras de PHB e/ou PHBV e amostras de PHB e/ou PHBV com glicerol. ..... 144

Tabela 22 - Valores das temperaturas de transições, a partir das curvas de tan $\delta$ em função da temperatura para a amostra TPS, blendas TPS/PHB, TPS/PHBV e TPS/PHB/PHBV e as

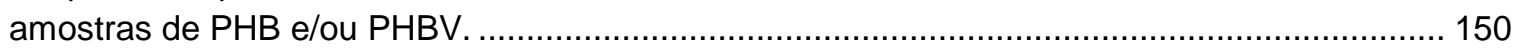

Tabela 23 - Valores de tensão máxima $(\sigma)$ em MPa, deformação máxima $(\varepsilon)$ em \% e módulo de elasticidade (E) em MPa, apresentados no ensaio de tração (Figuras de 72 a 74) para as amostras TPS, blendas TPS/PHB, TPS/PHBV e TPS/PHB/PHBV e amostras de PHB e/ou PHBV.

159

Tabela 24 - Valores de tensão máxima $(\sigma)$ em MPa, deformação máxima $(\varepsilon)$ em \% e módulo de elasticidade (E) em MPa, apresentados no ensaio de tração (Figuras 75 a 77) para as amostras TPS, blendas PHB25, PHBV25 e PHB12,5PHBV12,5 e amostras PHB e PHB50PHBV50....... 164 


\section{Lista de Abreviaturas e Siglas}

AA - Água Absorvida

ASTM - Sociedade Americana para Ensaio de Materiais

DTG - Termogravimetria Derivada

DSC - Calorimetria Exploratória Diferencial

DMTA - Análise Térmica Dinâmico-Mecânica

FT - Transformada de Fourier

FTIR - Espectroscopia de Absorção na Região do Infravermelho com Transformada de Fourier

HB - Hidroxibutirato

HPSEC - Cromatografia de Exclusão por Tamanho de Alta Eficiência

HV - Hidroxivalerato

IR - Radiação Infravermelha

ISO - Organização Internacional para Padronização

LPC - L- $\alpha$-lisofosfatidilcolina

MEV - Microscopia Eletrônica de Varredura

PHA - Poli (hidroxialcanoato)

PHB - Poli ( $\beta$-hidroxibutirato)

PHBV - Poli ( $\beta$-hidroxibutirato-co-valerato)

RMN - Ressonância Magnética Nuclear

$\mathrm{RMN}{ }^{13} \mathrm{C}$ - Ressonância Magnética Nuclear de ${ }^{13} \mathrm{C}$

RMN ${ }^{1} \mathrm{H}$ - Ressonância Magnética Nuclear de ${ }^{1} \mathrm{H}$

TG - Termogravimetria

TPS - Amido Termoplástico

TPS/PHB - Blenda de Amido Termoplástico e PHB

TPS/PHBV - Blenda de Amido Termoplástico e PHBV

TPS/PHB/PHBV - Blenda de Amido Termoplástico, PHB e PHBV. 


\section{Lista de Símbolos}

D - Coeficiente de Difusão

E - Módulo de elasticidade ou Módulo de Young

E’ - Módulo de armazenamento ou Módulo elástico

E“ - Módulo de perda ou Módulo de Dissipação Viscosa

G - Coeficiente angular da reta

$\mathrm{H}_{\mathrm{a}}$ - Altura correspondente à fase amorfa

$\mathrm{H}_{\mathrm{c}}$ - Altura corresponde ao pico cristalino

$\mathrm{I}_{\mathrm{cr}}$ - Índice de Cristalinidade

$\mathrm{I}_{\mathrm{a}}$ - Área sob o halo amorfo

$\mathrm{I}_{\mathrm{C}}$ - Área dos picos cristalinos

$\mathrm{L}$ - Espessura do filme polimérico

$M_{0}$ - Massa da amostra antes da exposição a um ambiente de umidade relativa.

$\mathrm{M}_{\mathrm{t}}$ - Massa da amostra depois da exposição a um ambiente de umidade relativa.

$M_{t}$ - Massa de água no tempo $t$

$M_{\infty}$ - Massa de água absorvida no equilíbrio

Mn - Massa molar numérica média

Mw - Massa molar ponderal média

$M_{w} / M_{n}$ - Polidispersividade

tan $\delta$ - Tangente de perda ou Amortecimento mecânico

$T_{g}$ - Temperatura de Transição Vítrea

$\mathrm{T}_{\mathrm{c}}$ - Temperatura de Cristalização

$\mathrm{T}_{\mathrm{m}}$ - Temperatura de Fusão

$\mathrm{K}$ - Constante de proporcionalidade

k - Coeficiente de Afinidade

$\mathrm{n}$ - Coeficiente de Fick

o - Tensão Máxima

\% C - Grau de Cristalinidade

$\varepsilon$ - Deformação Máxima

$\Delta \mathrm{H}_{\mathrm{f}}$ - Entalpia de Fusão

$\Delta \mathrm{H}_{\mathrm{f}}{ }^{\circ}$ - Entalpia de Fusão para polímero $100 \%$ cristalin o

$\Delta \mathrm{H}_{\mathrm{c}}$ - Entalpia de Cristalização

$\Delta \mathrm{H}_{\mathrm{m}}$ - Entalpia de Fusão

$2 \theta$ - Ângulo de Bragg 


\section{Sumário}

Resumo

Abstract

Lista de Figuras

Lista de Abreviaturas e Siglas

Lista de Símbolos

CAPÍTULO 1

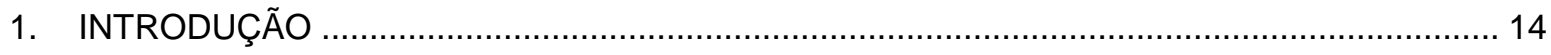

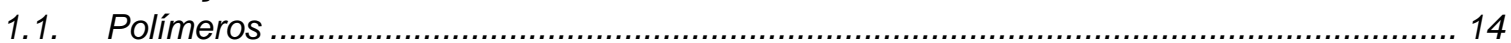

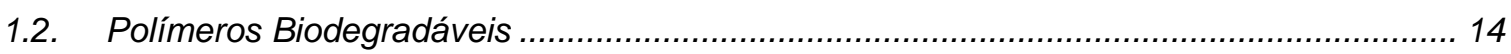

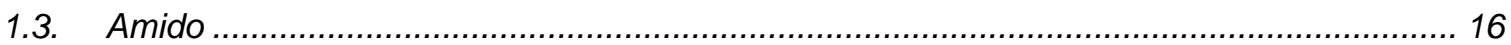

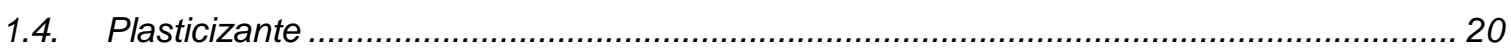

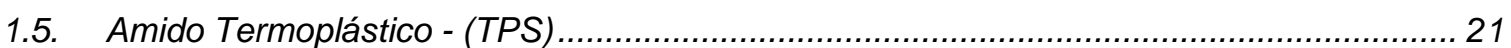

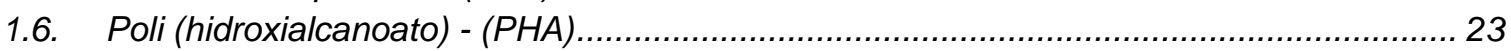

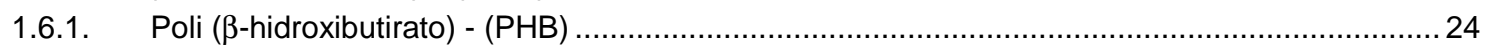

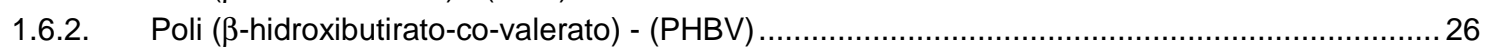

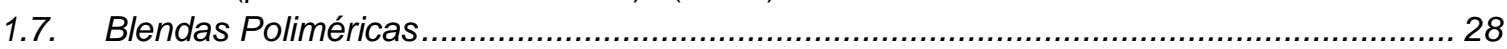

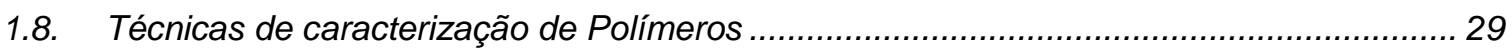

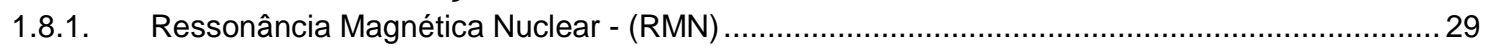

1.8.2. Cromatografia de Exclusão por Tamanho de Alta Eficiência - (HPSEC) ………………...........2 29

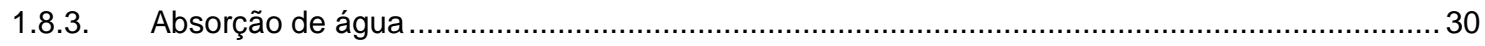

1.8.4. Termogravimetria (TG) / Termogravimetria derivada (DTG) …......................................... 30

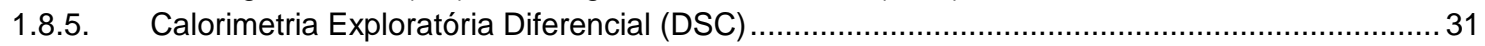

1.8.6. Microscopia Eletrônica de Varredura - (MEV) ................................................................... 32

1.8.7. Espectroscopia de Absorção na Região do Infravermelho com Transformada de Fourier -

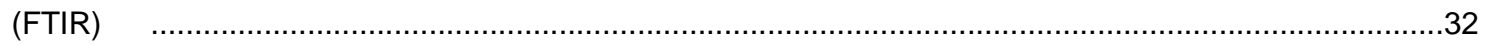

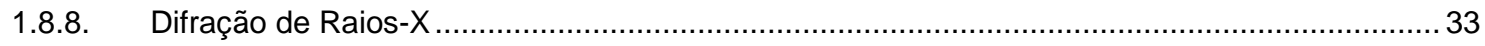

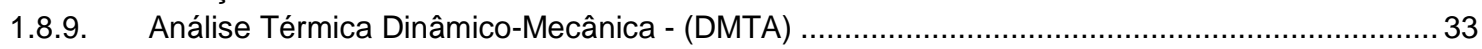

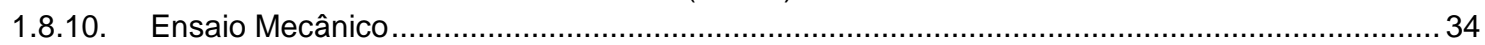

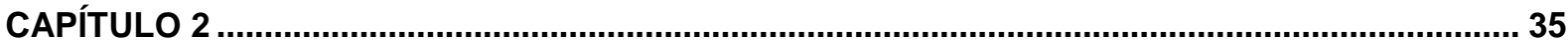

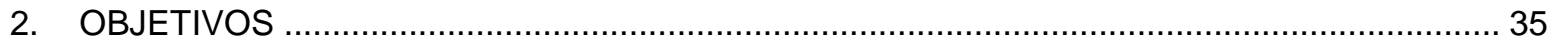

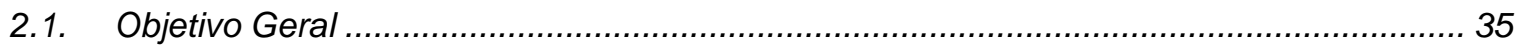

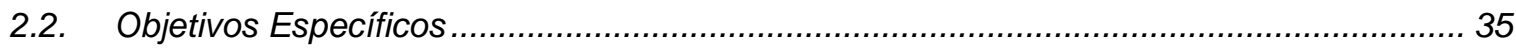

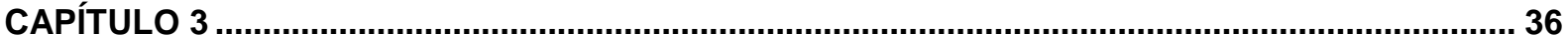

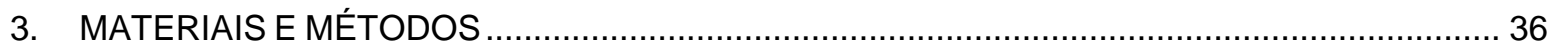

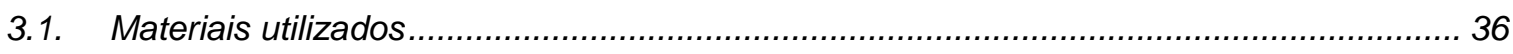

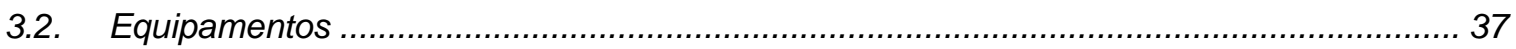

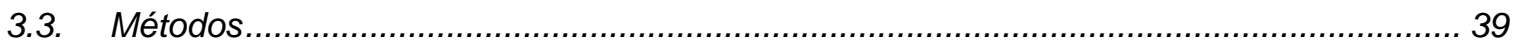

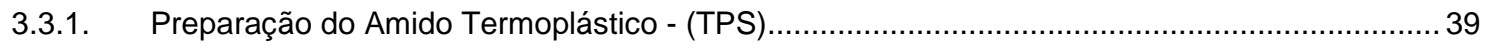

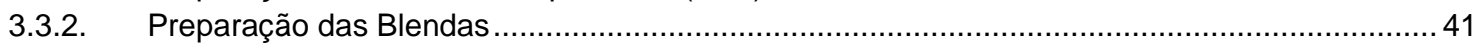

3.3.3. Composição das blendas e variáveis de processamento ........................................................... 42

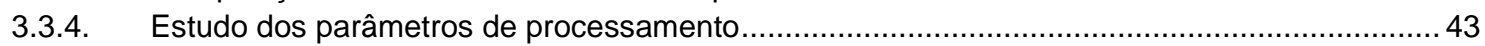

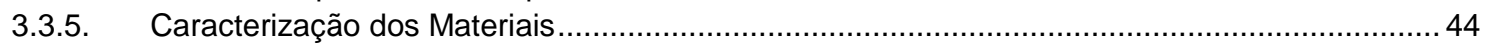

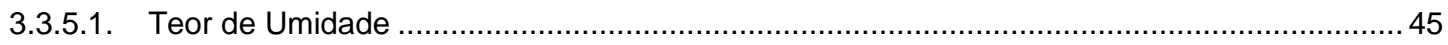

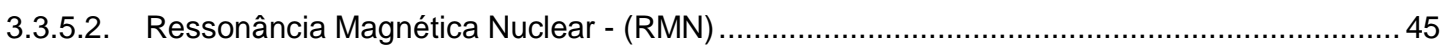

3.3.5.3. Cromatografia de Exclusão por Tamanho de Alta Eficiência - (HPSEC) …….......................47

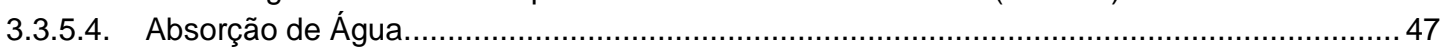

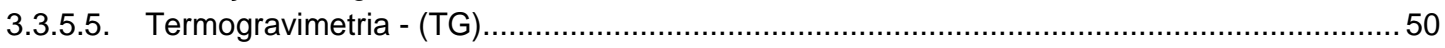

3.3.5.6. Calorimetria Exploratória Diferencial - (DSC) .............................................................. 51

3.3.5.7. Microscopia Eletrônica de Varredura - (MEV) …………………………………………..... 55 
3.3.5.8. Espectroscopia de Absorção na Região do Infravermelho com Transformada de Fourier -

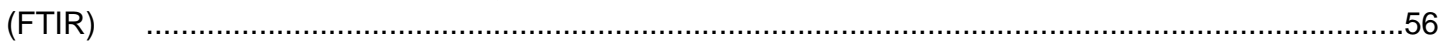

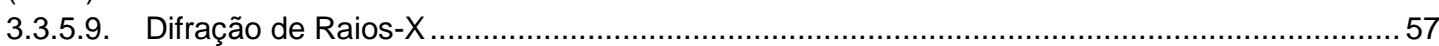

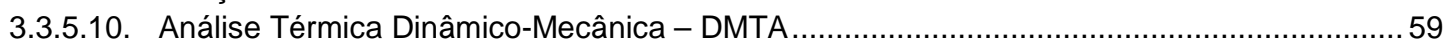

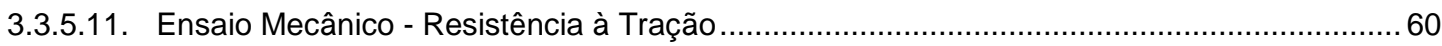

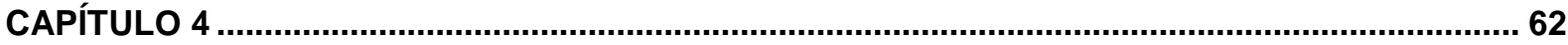

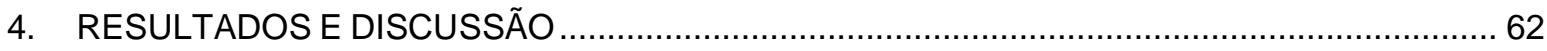

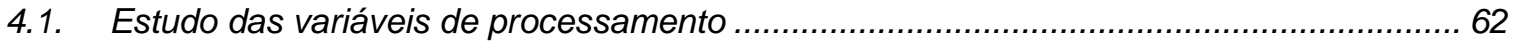

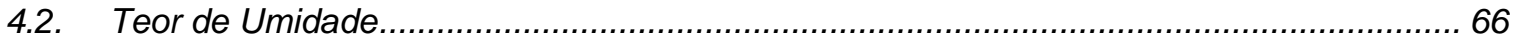

4.3. Ressonância Magnética Nuclear - (RMN) ......................................................6 66

4.4. Cromatografia de Exclusão por Tamanho de Alta Eficiência - (HPSEC) ......................... 73

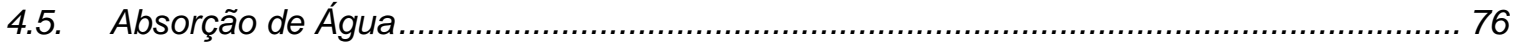

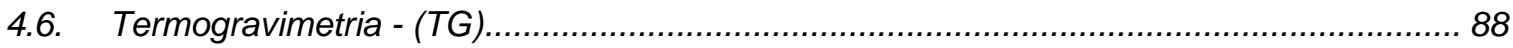

4.7. Calorimetria Exploratória Diferencial - (DSC) ..................................................... 101

4.8. Microscopia Eletrônica de Varredura - (MEV) ........................................................ 115

4.9. Espectroscopia de Absorção na região do Infravermelho com Transformada de Fourier -

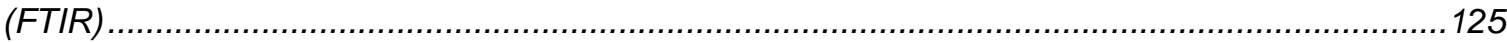

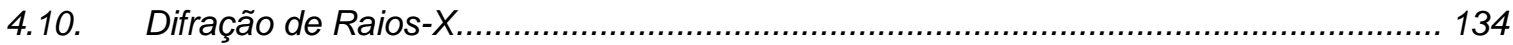

4.11. Análise Térmica Dinâmico-Mecânica (DMTA) ................................................. 145

4.12. Ensaio Mecânico - Ensaio de Tração.......................................................... 154

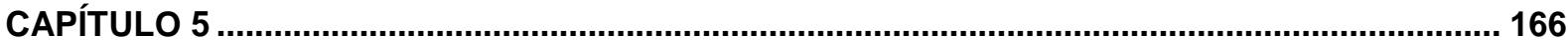

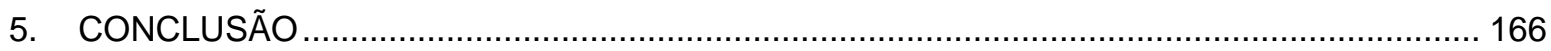

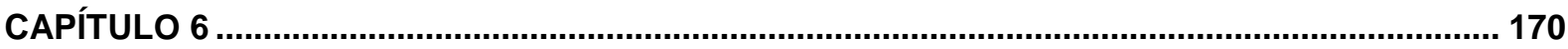

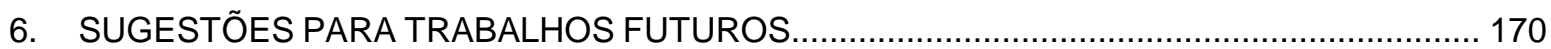

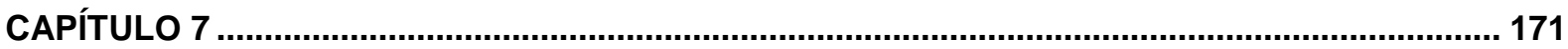

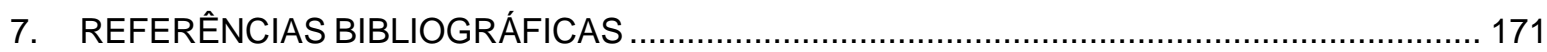




\section{CAPÍTULO 1}

\section{INTRODUÇÃO}

\subsection{Polímeros}

As moléculas dos polímeros, em virtude de seu tamanho, são chamadas freqüentemente de macromoléculas. Essas moléculas longas são compostas por entidades estruturais conhecidas como mero, as quais se repetem ao longo da cadeia. O termo polímero significa muitos meros.

Quando todas as unidades repetidas ao longo de uma cadeia são do mesmo tipo, o polímero é chamado homopolímero. Os copolímeros são cadeias compostas por duas ou mais unidades de meros diferentes.

Possivelmente, o maior número de materiais poliméricos se enquadra na classificação dos plásticos. Como definição, segundo a norma ASTM, plástico é um material que contém como componente essencial uma ou mais substâncias poliméricas orgânicas de alta massa molar, sendo processado no estado fundido e sendo sólido no estado final (ASTM D 6400).

\subsection{Polímeros Biodegradáveis}

Com o crescimento do consumo de polímeros tem-se tornado necessária a produção de substitutos ambientalmente sustentáveis, os chamados polímeros ou plásticos biodegradáveis, importantes no gerenciamento de resíduos. Assim, há um grande interesse na pesquisa e desenvolvimento de materiais de embalagens 
biodegradáveis no sentido de diminuir o acúmulo desses resíduos no meio ambiente.

A degradação polimérica pode ser causada por diversos fatores ambientais (INNOCENTINI-MEI; MARIANI, 2005). Os mais comuns são calor, luz solar, oxigênio, água, micro-organismos, macro-organismos, ação mecânica, vento, chuva, entre outros. Dependendo do fator ambiental ativo, a degradação pode ser classificada em categorias como fotodegradação (por luz), termo-degradação (por temperatura), biodegradação (por microorganismos), hidrólise (reação com água), degradação oxidativa (reação com oxigênio), entre outras.

A biodegradação de um polímero é um processo intrínseco pelo qual microorganismos e suas enzimas consomem este material como fonte de nutrientes, em condições normais de umidade, temperatura e pressão.

O desenvolvimento de materiais biodegradáveis tem como meta produtos que apresentem um tempo de degradação não muito diferente dos materiais naturais e cujos resíduos sejam compatíveis com o meio ambiente. Por isso, os institutos normatizadores têm apresentado normas (ASTM D 6400, ASTM D 5338, ISO 14851, ISO 14852, ISO 14855, DIN EN 13432) que tratam especificamente dos critérios que definem um material como sendo biodegradável e os ensaios para se proceder a essa avaliação.

Assim, a busca de novas tecnologias de materiais total ou parcialmente biodegradáveis, como o amido termoplástico, é um atraente campo de pesquisa que concilia mercado consumidor e preservação ambiental. 


\subsection{Amido}

Os polissacarídeos são os mais abundantes carboidratos na natureza e servem como substância de reserva e como componente estrutural das células das plantas. Pela Legislação Brasileira, dentre os polissacarídeos de reserva dos vegetais podem ser encontrados os amido ou féculas.

Amido refere-se à substância extraída dos grãos de cereais, e fécula refere-se à substância amilácea extraída das raízes e tubérculos. Em relação às propriedades gerais, denomina-se simplesmente amido (CEREDA, 2001).

O amido é constituído por uma mistura de dois polissacarídeos, amilose e amilopectina em proporções que variam com a espécie e o grau de maturação. A amilose e a amilopectina apresentam diferentes estruturas como mostrada na Figura 1 e 2 , respectivamente.

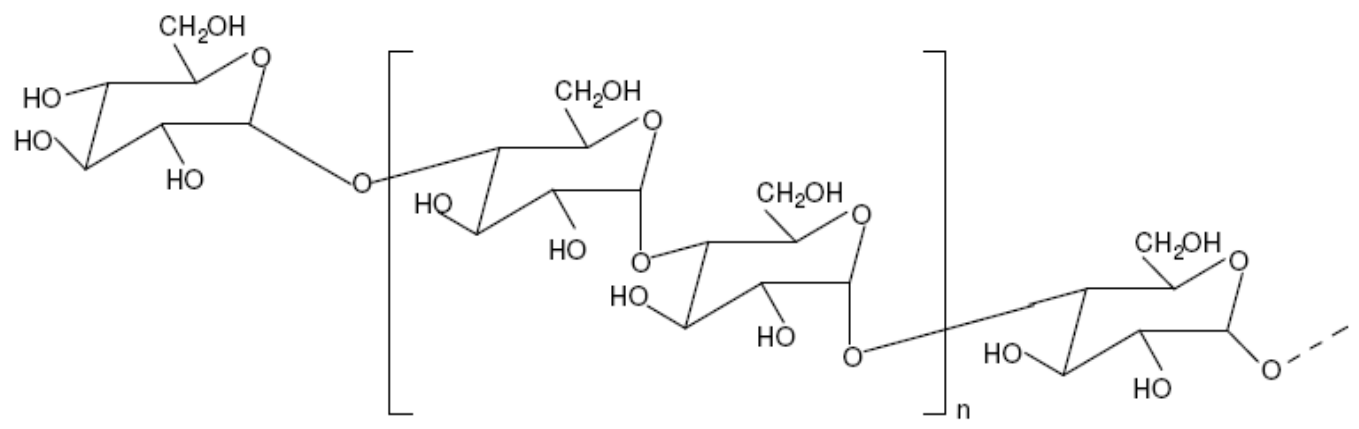

Figura 1 - Estrutura da amilose 


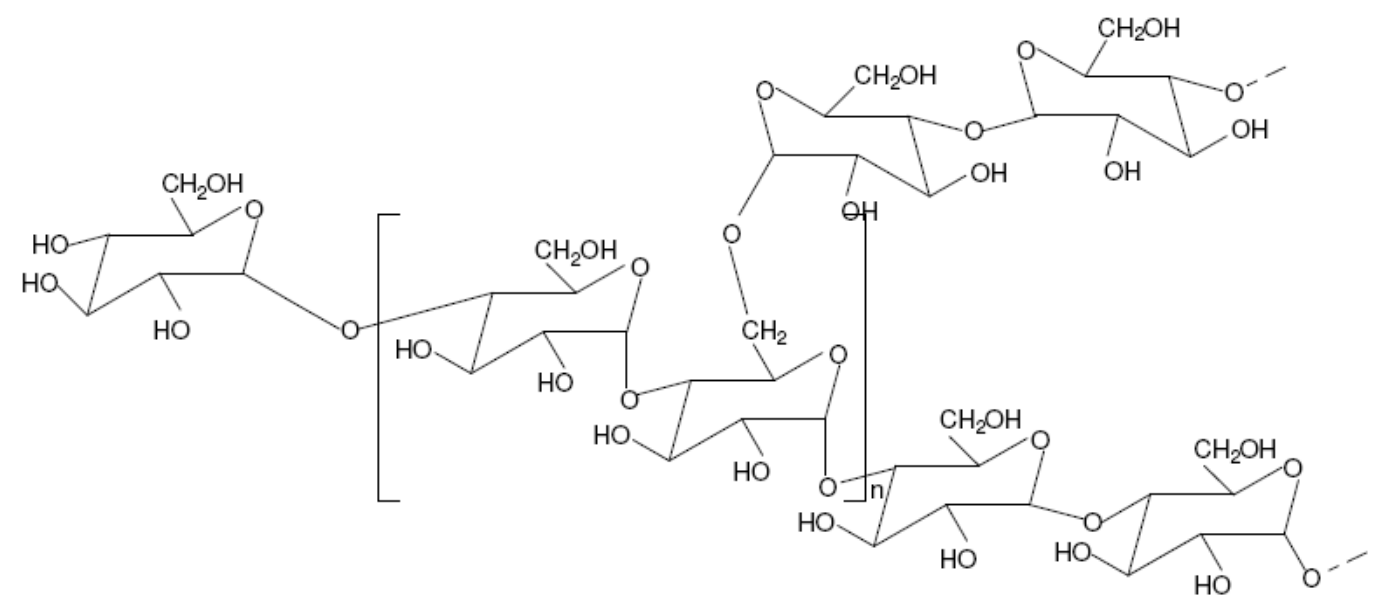

Figura 2 - Estrutura da amilopectina.

A amilose é uma molécula essencialmente linear de unidades de $\alpha$-Dglicopiranose unidas por ligações glicosídicas $\alpha-1,4$, com um pequeno número de ramificações. Apresenta estrutura helicoidal, $\alpha$-hélice, formada por pontes de hidrogênio entre as hidroxilas das moléculas de glicose e possui massa molar variando entre $10^{5}$ a $10^{6} \mathrm{~g} \cdot \mathrm{mol}^{-1}$.

A amilopectina apresenta uma estrutura ramificada, constituída por cadeias lineares de $\alpha$-D-glicopiranose unidas entre si por ligações $\alpha-1,4$ e cadeias ramificadas iniciadas por ligações $\alpha-1,6$. Sua massa molar situa-se em torno de $10^{8}$ g.mol ${ }^{-1}$ e apresenta configuração tipo dupla hélice (CEREDA, 2001).

Além da amilose e amilopectina, o grânulo de amido apresenta compostos nitrogenados, lipídeos e minerais, sendo que os dois polissacarídeos são responsáveis por aproximadamente $98 \%$ da massa do amido (base seca).

Outro parâmetro importante na caracterização do amido é o tamanho e a forma dos grânulos que são próprios da planta de origem, podendo influenciar no rendimento industrial e nas aplicações tecnológicas. 
Estes grânulos são armazenados pelas plantas em suas sementes, raízes ou em seus vasos condutores, com diâmetros granulares que variam de 2 a $100 \mu$ e formas esféricas, ovais, poliédricas, dentre outras (MOORTHY, 2002). As cinco espécies consideradas como principais fontes de amido comercial são o milho, trigo, arroz, batata e mandioca.

A cristalinidade dos grânulos de amidos, de 15 a 45 \%, deve-se basicamente à amilopectina, e pode ser caracterizada por difração de raios-X em três padrões principais: $A, B$ e $C$, como conseqüência do empacotamento em dupla hélice das cadeias ramificadas desse polímero.

O padrão A é característico do amido de cereais, apresentando um arranjo monoclínico. O padrão B é encontrado em amido de tubérculos e de frutas. Possui ramificações longas, sendo a estrutura mais altamente hidratada, consistindo de dupla hélice empacotada em arranjo hexagonal. O padrão $C$, uma mistura de $A$ e $B$, é característico do amido de vagens. As variações estão relacionadas com a origem botânica, com o comprimento e a abundância das cadeias longas e curtas, e com a forma de distribuição dos constituintes das cadeias (CEREDA, 2001; MYLLARINEN et al., 2002).

Os grãos nativos de amido incham quando absorvem água devido à formação de ligações de hidrogênio entre a água e os grupos hidroxilas do amido. Apesar disso, o grão ainda preserva a sua ordem e cristalinidade. Entretanto, quando estes grãos previamente inchados são aquecidos, estas ligações são rompidas e, conseqüentemente, a cristalinidade é também progressivamente reduzida. Este processo é conhecido como gelatinização do amido e pode ser visualizado na Figura 3. 
Diferentes amidos exibem diferentes densidades granulares que afetam a facilidade com que estes grânulos absorvem água. A escala de gelatinização referese à faixa de temperatura acima da qual todos os grânulos são inchados inteiramente (em torno de $60{ }^{\circ} \mathrm{C}$ a $75{ }^{\circ}$ C) dependendo da origem do amido (PARKER; RING, 2001; ST-PIERRE et al., 1997).

Grânulo de Amido

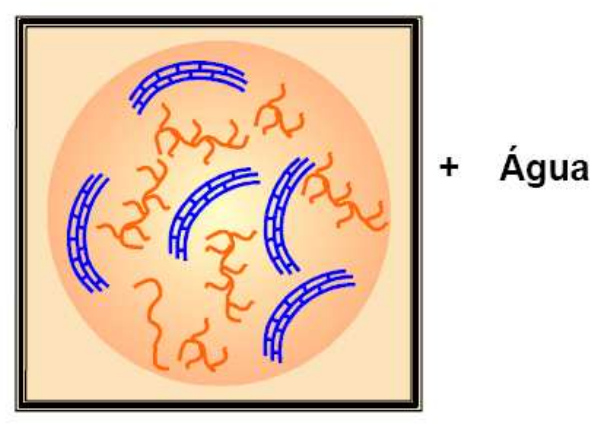

Amido Gelatinizado

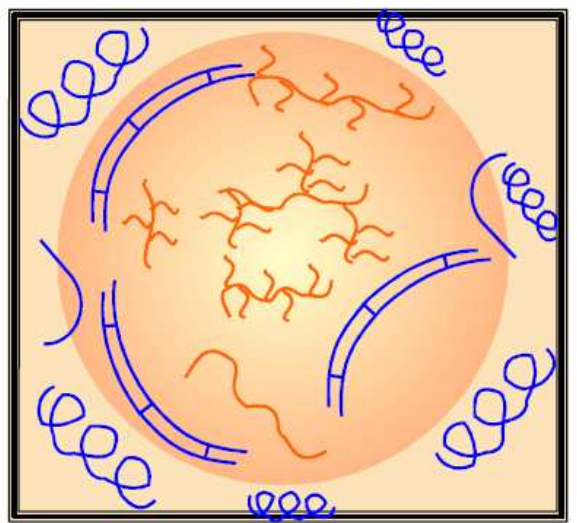

Figura 3 - Gelatinização do amido (PALMA; CICHELLO; PAVANELLI, 2009).

Após a gelatinização, as moléculas de amilose, em função de sua estrutura linear, tendem a se orientar paralelamente, aproximando-se o suficiente para que se formem pontes de hidrogênios intermoleculares. Este processo é chamado de retrogradação do amido. As moléculas de amilose são as principais responsáveis pela ocorrência do fenômeno, enquanto na amilopectina o fenômeno ocorre somente na periferia de sua molécula (CEREDA, 2001; RIBEIRO; SERAVALLI, 2003).

A retrogradação resulta na redução de volume, aumento da firmeza do gel e redução da afinidade do polímero pela água, fenômeno conhecido como sinérese (expulsão da água existente entre as moléculas). Isso explica a formação de filmes estáveis e flexíveis pelo amido gelatinizado. O processo de retrogradação pode ser visualizado na Figura 4. 

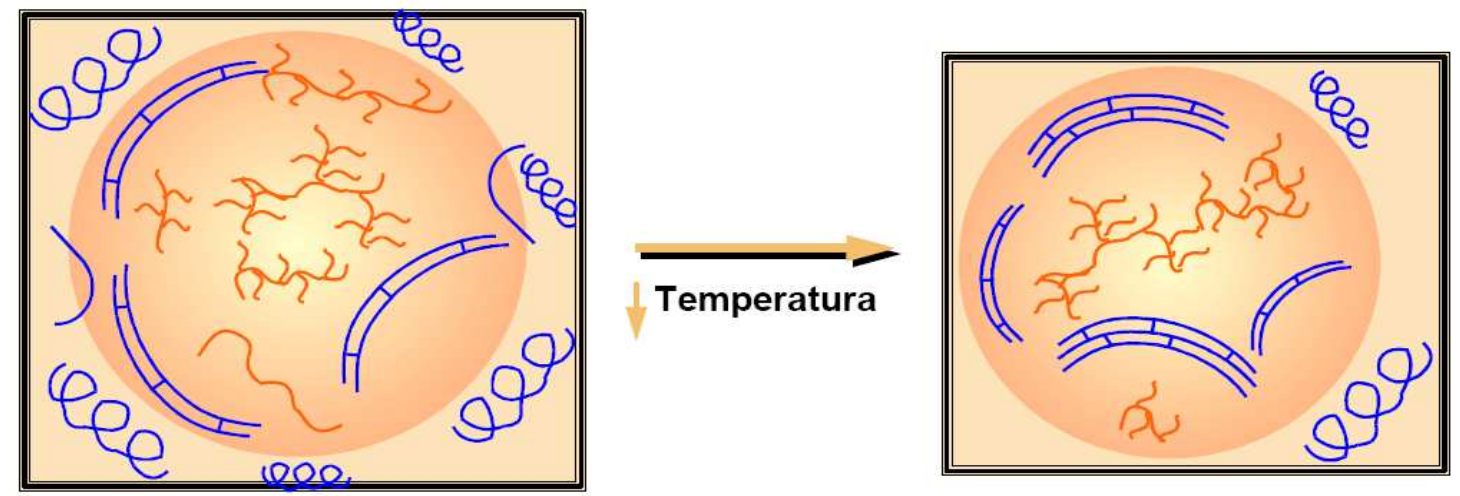

Figura 4 - Retrogradação do amido (PALMA; CICHELLO; PAVANELLI, 2009).

Inúmeros estudos (SHI et al., 2007; TALJA, 2007; MALI et al., 2004; MA; YU; KENNEDY, 2005; CARVALHO et al., 2003b; MA; YU, 2004; FORSSEL et al., 1997; FORSSEL et al.,1999; KOENIG; HUANG, 1995; VAN SOEST et al., 1996a,c) têm sido publicados sobre caracterização das propriedades funcionais de filmes a base de amido ou amido termoplástico.

\subsection{Plasticizante}

As amostras de amido puro, por si só, são frágeis devido as fortes interações de hidrogênio intramoleculares e intermoleculares das macromolecular de amilose e amilopectina. Assim necessitam de um plasticizante para torná-las flexíveis, aumentando a mobilidade das cadeias macromoleculares.

O plasticizante deve ser polar, hidrofílico e compatível com a base de formação do filme polimérico. Outra exigência importante de um plasticizante é que o seu ponto de ebulição deve ser alto, o suficiente para evitar a sua evaporação nos 
materiais durante o processamento e secagem. Portanto, alguns plasticizantes trabalham de forma mais eficaz do que outros, devido às suas características estruturais e da interação resultante com as moléculas do amido.

A água adicionada à formulação tem duas funções: agente desestruturante do grânulo nativo, com rompimento das ligações de hidrogênio entre as cadeias, e agente plasticizante de processo. No entanto, é necessária a adição de um plasticizante adicional além da água, tal como um poliol, que permitirá a obtenção de um material maleável com características termoplásticas e com melhor desempenho mecânico. Glicerol é um dos poliois mais comumente utilizado para a produção de amido termoplástico (MA; YU, 2004; PUSHPADASS; MARX; HANNA, 2008).

A proporção de plasticizante utilizado e a sua natureza química influenciam fortemente nas propriedades físico-químicas, térmicas e mecânicas dos mesmos, devido a diminuição das interações entre as cadeias, aumento da mobilidade e flexibilidade do material e diminuição da temperatura de transição vítrea.

\subsection{Amido Termoplástico - (TPS)}

A transformação do amido em grânulos, com sua estrutura semicristalina, em um material amorfo ou parcialmente amorfo, denominado de amido termoplástico, envolve pelo menos duas etapas. Primeiro ocorre intumescimento do grânulo na presença de água ou de outro agente plasticizante (gelatinização do amido), depois em temperaturas mais elevadas, sob efeito de forças de cisalhamento e pressão, em equipamentos de processamento de polímeros, ocorre a total desorganização do grânulo. 
Enquanto termoplástico, o amido é um material que, quando sujeito à ação de calor, tem sua maleabilidade aumentada e endurece quando é resfriado, sendo este um processo totalmente reversível. Em nível molecular, e à medida que a temperatura é elevada, as forças de ligação de van der Waals são diminuídas (devido ao aumento do movimento molecular), de modo tal que o movimento relativo de cadeias adjacentes é facilitado quando uma tensão é aplicada (CALLISTER JUNIOR, 2002).

O TPS é um material relativamente novo para aplicação como plástico biodegradável e é um dos principais polímeros atualmente estudados nessa área. Apresenta duas limitações principais quando comparado à maioria dos plásticos em uso: apresenta elevada higroscopicidade e baixo desempenho quanto a propriedades mecânicas.

Para comprovar a grande absorção de água quando a amostra é plasticizada com glicerol, Dufrene e coloboradores (2000) compararam a matriz de amido sem glicerol e com glicerol e verifica que a matriz preparada sem glicerol absorve duas vezes menos água do que a matriz plasticizada. Em intervalos de tempos menores (até 100 h), a cinética de absorção é rápida, enquanto a cinética de absorção em tempos maiores é lenta (DUFRESNE; DUPEYRE; VIGNON, 2000).

De acordo com Pontes (2008), não foi possível obter corpos de prova para as amostras de amido de batata plasticizadas com 15 e $20 \%$ de glicerol devido à alta fragilidade destas composições. Para as amostras plasticizadas com 30 e $40 \%$ de glicerol, o pico de $\tan \delta$ de maior temperatura, referente ao amido, deslocou para temperaturas mais baixas com o aumento do teor de glicerol, indicando uma diminuição da temperatura de transição vítrea (PONTES, 2008). Isso ocorre porque 
com o aumento do conteúdo de plasticizante, as intensidades das forças de interação entre as cadeias do polímero diminuem e a mobilidade aumenta.

\subsection{Poli (hidroxialcanoato) - (PHA)}

Os Poli (hidroxialcanoatos) são poliésteres biodegradáveis sintetizados por via bacteriana, a partir de matérias-primas renováveis. O polímero é acumulado por inúmeras bactérias na forma de grânulos intracelulares, que podem representar até $90 \%$ da massa seca celular e tem como principal função a reserva de carbono e energia.

Os PHAs são polímeros facilmente atacados por fungos através de hidrólise. Eles podem oferecer uma grande variedade de propriedades, desde plásticos rígidos altamente cristalinos a polímeros dúcteis. Apresentam como propriedades, elevado ponto de fusão, baixa rigidez, resistência ao alongamento antes da ruptura e forte resistência ao impacto. As propriedades físicas e mecânicas destes materiais dependem da composição monomérica e da distribuição de massa molar dos polímeros, as quais estão diretamente relacionadas às condições de crescimento e aos microorganismos que os produzem (REDDY et al., 2003).

O primeiro PHA descoberto, em 1926, por Lemoigne foi o poli (3hidroxibutirato) (PHB), um polímero extremamente frágil devido ao seu elevado grau de cristalinidade. No entanto, a introdução de diferentes monômeros HA como o 3hidroxivalerato (3HV) na cadeia modifica as propriedades do PHB (ROSSELL et al., 2006). Deste modo, muitos estudos têm sido orientados para caracterizar a produção, morfologia, propriedades mecânicas e biodegradabilidade cinética do PHB e PHBV. 
El-Hadi e colaboradores (2002) estudaram a correlação entre cristalinidade, morfologia, temperatura de transição vítrea, propriedades mecânicas e de biodegradação de PHAs, mais especificamente o PHB, e suas blendas. Segundo o autor, o PHB e PHBV são muito frágeis e algumas das razões que contribuem para tal comportamento são: cristalização secundária da fase amorfa na temperatura ambiente, temperatura de transição vítrea próxima a temperatura ambiente, baixa densidade de nucleação, o que promove o surgimento de esferulitos "grandes" entre as lamelas.

Vários estudos da cristalização secundária, a qual aparece durante o armazenamento do polímero, tem sido relatado e observa-se que com a adição de um plasticizante o movimento molecular é realçado, há um abaixamento da temperatura de transição vítrea $\left(T_{g}\right)$ e um menor grau de degradação das cadeias poliméricas (EL-HADI et al., 2002).

PHAs podem ser utilizados em embalagens, produtos agrícolas, médicos, veterinários e aplicações marítimas, pois comportam-se de forma similar aos termoplásticos convencionais com a vantagem de apresentarem completa biodegradação.

\subsubsection{Poli ( $\beta$-hidroxibutirato) - (PHB)}

O PHB é um poliéster semicristalino, de cadeia linear (Figura 5), hidrofóbico, possui boa resistência química e pode ser processado como termoplástico. Sua massa molar varia entre 10.000 a 3.000 .000 g.mol ${ }^{-1}$, dependendo do microorganismo, da fonte de carbono e das condições de purificação (ROSA; PANTANO FILHO, 2003; BELEM, 2008). 
Industrialmente, tem atraído bastante atenção por sua biocompatibilidade e biodegradabilidade. Porém, devido a sua alta cristalinidade, estreita janela de processamento, elevada rigidez e comportamento frágil, tornam o seu uso relativamente limitado.

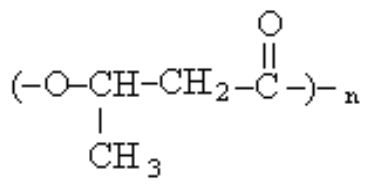

Figura 5 - Estrutura química do PHB.

O arranjo destes grupos na molécula polimérica pode dar origem a três diferentes configurações: isotática, sindiotática e atática. O PHB isotático é o mais comum e de uso comercial, enquanto a obtenção das formas sindiotática e atática são possíveis apenas em sínteses laboratoriais.

O PHB isotático é um polímero altamente cristalino (acima de $80 \%$ ) muito rígido e frágil, com propriedades de barreira e resistência química a hidrólise, possui uma temperatura de transição vítrea entre -5 e $9{ }^{\circ} \mathcal{C}$ e uma temperatura de fusão cristalina de aproximadamente $178{ }^{\circ} \mathrm{C}$. É um polímero totalmente biodegradado por fungos e bactérias, dando como produtos finais aeróbicos $\mathrm{CO}_{2}$ e água e resíduos orgânicos, enquanto a biodegradação anaeróbica têm como produtos finais metano, água e resíduos orgânicos (BELEM, 2008).

A produção em grande escala do $\mathrm{PHB}$ acontece por um processo de fermentação bacterial: bactérias como a Alcaligenes eutrophus, produzem até $90 \%$ do seu peso seco de PHB de cristalinidade superior a $80 \%$.

Este polímero apresenta uma boa resistência ao vapor da água e à umidade, além de ser estável sob circunstâncias de armazenamento normais e durante o seu 
uso, podendo durar mais de quatro anos em prateleiras e armários. Mas, quando depositado em ambientes ricos em bactérias (aterros sanitários) sofre biodegradação, transformando-se em gás carbônico e água, sem a geração de resíduos tóxicos. A sua decomposição por meios biológicos vai depender de um número de fatores tais como a atividade microbial do ambiente e da área de superfície exposta. Outros fatores são também importantes, como a temperatura, $\mathrm{pH}$, peso molecular e cristalinidade do material, presença de oxigênio, umidade e nutrientes minerais (HUANG; SHETTY; WANG ,1990).

\subsubsection{Poli ( $\beta$-hidroxibutirato-co-valerato) - (PHBV)}

O PHBV é um poliéster semicristalino, também de cadeia linear (Figura 6) e pode ser encontrado com um percentual de valerato bastante variável. Apresenta como característica, menor dureza, menor resistência à tração (conseqüentemente, maior ductibilidade e elasticidade) que o PHB puro.

O PHBV é um copolímero constituído por unidades aleatórias de (R)-3hidroxibutirato $(\mathrm{HB})$ e $(\mathrm{R})$-3-hidroxivalerato $(\mathrm{HV})$. Apresenta um menor ponto de fusão e maior flexibilidade quando comparado com o homopolímero PHB. O menor ponto de fusão de PHBV amplia a janela de processamento. A porcentagem de hidroxivalerato (HV) no copolímero PHBV influencia fortemente nas propriedades deste polímero, tais como cristalinidade, ponto de fusão e cristalização (AVELLA et al., 2000a,b; BHARDWAJ et al., 2006). 


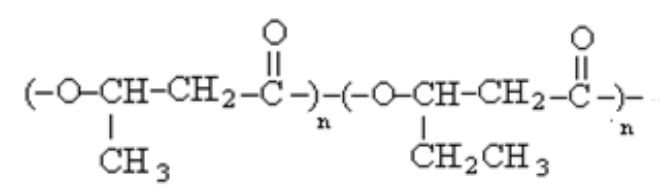

Figura 6 - Estrutura química do PHBV.

Assim como no caso do homopolímero, o processo de produção do copolímero é bacteriano. Os microrganismos alimentam-se de açúcares e os transformam em grânulos intracelulares que são poliésteres. Para as bactérias, esses poliésteres servem como uma reserva de energia. As etapas seguintes do processo produtivo são a extração e a purificação do polímero acumulado dentro das bactérias. Sua produção diferencia-se da observada para o PHB pela adição concomitante de ácido propiônico ao meio de cultivo bacteriano. No final da fermentação é formado o copolímero do hidroxibutirato com segmentos aleatórios de hidroxivalerato.

A concentração de valerato no copolímero pode provocar mudança do tempo de degradação, de algumas semanas a vários anos, variações em algumas propriedades físicas, como massa molar, grau de cristalinidade, temperatura de fusão, dentre outras (ROSSELL et al., 2006).

Para Brunel (2008), teores de hidroxivalerato nos copolímeros PHBV com 3,5 \% de $\mathrm{HV}$ e com $8,6 \%$ de HV, tornaram-se possíveis comparações entre os efeitos do aumento da mobilidade molecular ocasionado por dois fatores: a plasticização interna (teor de HV no copolímero) e plasticizante externo (presença de plasticizante). Comparando as curvas de tensão em função da deformação dos copolímeros puros, observa-se que a adição de plasticizante no PHBV com 3,5 \% de HV proporciona um leve aumento na deformação na ruptura e uma pequena redução na rigidez; enquanto que para o PHBV com 8,6 \% de HV estas alterações 
são mais marcantes sugerindo maior interação entre o copolímero com maior quantidade de HV e o plasticizante (BRUNEL, 2008).

\subsection{Blendas Poliméricas}

A mistura de dois ou mais polímeros, com características constitucionais ou configuracionais diferentes, forma uma blenda polimérica. As blendas têm atraído muita atenção dos pesquisadores que estudam o desenvolvimento de novos materiais. Isto se deve principalmente a possibilidade de obter materiais com desempenhos diferentes e, em muitos casos, melhores que os dos polímeros puros, sem investimentos em novas rotas de síntese de polímeros.

A possibilidade de misturar diferentes polímeros aumenta consideravelmente o seu espectro de uso, reduzindo custos e obtendo materiais com melhores valores em suas propriedades físicas e com aplicações em vários segmentos industriais.

Blendas poliméricas podem ser miscíveis, imiscíveis ou parcialmente miscíveis. A miscibilidade relaciona-se com a capacidade de dois ou mais componentes se misturarem em nível molecular, resultando numa mistura homogênea. Já os componentes das blendas imiscíveis são essencialmente independentes. Este tipo de blenda apresenta um número de fases relacionado ao número de seus componentes. As blendas parcialmente miscíveis devem apresentar misturas parcialmente homogêneas.

Blendas de amido termoplástico e outros polímeros biodegradáveis como o Poli ( $\beta$-hidroxibutirato) - (PHB) e o copolímero Poli ( $\beta$-hidroxibutirato-co-valerato) (PHBV) oriundos de fontes renováveis têm recebido bastante atenção nos últimos anos, fazendo desses materiais produtos comerciais importantes (AVÉROUS, 2004; 
WANG; SUN; SEIB, 2002; AMASS; AMASS; TIGHE, 1998; BASTIOLI, 2001; YANG;

LIU, 2004; THIRE'; RIBEIRO; ANDRADE, 2006; RAMSAY et al., 1993; VINHAS; 2007).

\subsection{Técnicas de caracterização de Polímeros}

\subsubsection{Ressonância Magnética Nuclear - (RMN)}

A Espectroscopia de Ressonância Magnética Nuclear (RMN) é uma técnica que se vale da capacidade de certos núcleos absorverem energia na região de radiofreqüência, quando submetidos a um campo magnético. A absorção é função do próprio núcleo e dos átomos ligados a estes. Um espectro de RMN é um registro gráfico de intensidade versus freqüências de absorção

Com essa técnica é possível a determinação da taticidade em homopolímeros, a determinação das sequências em copolímeros e o cálculo das razões de reatividade assim como a determinação de mecanismos de reação.

\subsubsection{Cromatografia de Exclusão por Tamanho de Alta Eficiência - (HPSEC)}

Cromatografia de Exclusão por Tamanho de Alta Eficiência (HPSEC) é uma técnica de fracionamento das cadeias poliméricas de um polímero, com relação ao volume hidrodinâmico que cada uma delas ocupa em solução. 
O fracionamento dessa técnica envolve a separação do polímero a ser analisado em um número muito grande de frações com diferentes massas moleculares. Ao final da coluna de separação, cadeias de massa molecular maior serão eluidas primeiro, sendo seguidas pelas cadeias menores (CANEVAROLO JUNIOR, 2004; LUCAS, E. F.; SOARES, B. G.; MONTEIRO, 2001).

\subsubsection{Absorção de água}

Em materiais termoplásticos, a natureza hidrofílica do amido (conseqüência principalmente das hidroxilas presentes) aumenta a capacidade de absorção de água do material. Considerando que este material pode ser exposto a umidade quando em uso, estudos referentes à absorção de água se revestem de interesse acadêmico e prático.

Estudos realizados com materiais termoplásticos mostraram que o modelo de difusão fickiano pode ser válido para o estudo de difusão de água nestes materiais. As características da difusão fickiana são descritas como curvas de absorção lineares nos estágios iniciais e acima da parte linear do gráfico de $\left(M_{t}-M_{0}\right) / M_{\infty}$ em função de $\left(\mathrm{t}^{1 / 2}\right) /$ L. (POTHAN; THOMAS, 2004; ESPERT; VILAPLANA; KARLSSON, 2004; COMYN, 1985; TEIXEIRA, 2007; CARVALHO, 2002).

\subsubsection{Termogravimetria (TG) / Termogravimetria derivada (DTG)}

A técnica é utilizada para determinar a variação da massa da amostra em função da temperatura e/ou tempo, enquanto a amostra é submetida a uma programação controlada de temperatura (CANEVAROLO JUNIOR, 2004). Na DTG 
as curvas são registradas a partir das curvas TG e correspondem à derivada primeira da variação de massa em relação à temperatura ou ao tempo.

Dada a natureza dinâmica da variação de temperatura da amostra para originar curvas TG/DTG, fatores instrumentais (razão de aquecimento, atmosfera do forno, tipo de cadinho) e relacionados às características da amostra (massa da amostra, tamanho das partículas) podem influenciar a natureza, a precisão e a exatidão dos resultados experimentais.

\subsubsection{Calorimetria Exploratória Diferencial (DSC)}

Através da técnica DSC é possível medir a variação de entalpia entre a amostra e uma referência em função da temperatura, além de vários eventos térmicos que podem ser observados por meio de transições exotérmicas e endotérmicas.

Exemplos de eventos térmicos que podem ser citados são temperatura de gelatinização; temperatura de transição vítrea $\left(T_{g}\right)$, aquela na qual se inicia o movimento de segmentos longos da cadeia polimérica; temperatura de fusão $\left(T_{m}\right)$ e entalpia de fusão $\left(\Delta \mathrm{H}_{\mathrm{f}}\right)$, as quais dependem da distribuição de tamanho das regiões cristalinas presentes nas amostras e temperatura de cristalização $\left(T_{c}\right)$, a qual é acompanhada da liberação de calor latente e gera um pico exotérmico bem definido na curva de DSC. 


\subsubsection{Microscopia Eletrônica de Varredura - (MEV)}

A Microscopia Eletrônica de Varredura (MEV) aparece como uma ferramenta importante nos estudos das características de grânulos de amido, acompanhamento de desenvolvimento de plantas amiláceas, análise de produtos, estudo de estruturas superficiais dos materiais, entre outros.

Esta técnica pode ser utilizada para o estudo da morfologia dos grânulos de amido, em particular na análise da forma dos grânulos e distribuição de tamanho dos mesmos.

\subsubsection{Espectroscopia de Absorção na Região do Infravermelho com Transformada de Fourier - (FTIR)}

A técnica FTIR pode ser empregada para a identificação, a determinação de grupos funcionais e em estudos de conformação e estrutura de macromoléculas.

A radiação infravermelha $(\mathrm{IR})$ corresponde à parte do espectro situada entre as regiões do visível e das microondas. Embora o espectro de infravermelho seja característico da molécula, certos grupos de átomos dão origem a bandas que ocorrem na mesma freqüência, independente da estrutura da molécula.

Existem dois tipos de vibrações moleculares: as deformações axiais e as deformações angulares. Uma vibração de deformação axial é o movimento em que a distância interatômica aumenta e diminui alternadamente ao longo do eixo da ligação. As vibrações de deformação angular correspondem à variação de ângulos de ligação, em um conjunto de átomos (SILVERSTEIN; BASSLER; MORRILL, 1994). 


\subsubsection{Difração de Raios-X}

A Difração de Raios-X é uma técnica muito utilizada na investigação de estruturas poliméricas. O princípio da difração depende do fenômeno de interferência que ocorre quando uma onda em movimento é espalhada a partir de um número de centros. Esses centros, no caso de polímeros, têm relação com os domínios cristalinos e amorfos presentes em sua estrutura.

A técnica baseia-se nos princípios da lei de Bragg, na qual um cristal é apresentado como um conjunto de planos refletores, com espaçamento uniforme, de onde os raios-x incidentes a um ângulo $\theta$ são refletidos a um mesmo ângulo (CANEVAROLO JUNIOR, 2004).

No estudo da cristalinidade de amidos, a difração de raios-X é usualmente realizada em materiais hidratados. A hidratação é um fator que interfere na análise, uma vez que mantém a ordem estrutural e aumenta a resolução da medida.

\subsubsection{Análise Térmica Dinâmico-Mecânica - (DMTA)}

Essa técnica é associada a processos de relaxações de cadeias quando se submete a amostra a uma tensão senoidal e cuja deformação resposta se apresenta fora de fase em relação à solicitação inicialmente empregada. Fornece informações a respeito do módulo de armazenamento ou módulo elástico (E’), do módulo de perda ou módulo de dissipação viscosa (E") e da tangente de perda ou amortecimento mecânico (tan $\delta)$. Das curvas de DMTA obtém-se uma representação destas propriedades em função da temperatura (CANEVAROLO JUNIOR, 2004). Os 
picos em tan $\delta$ geralmente definem a temperatura de transição vítrea e são um indicativo do impedimento e/ou facilidade de movimentos moleculares.

\subsubsection{Ensaio Mecânico}

As propriedades mecânicas dos materiais poliméricos são de grande importância e interesse científico e tecnológico, devido aos requisitos e/ou exigências que os diversos polímeros existentes devem atender na maior parte de suas aplicações. Valores de propriedades mecânicas, tais como resistência à tensão, módulo de elasticidade e elongação, entre outros, podem servir como base de comparação do desempenho mecânico dos diferentes polímeros, assim como para a avaliação dos efeitos decorrentes da modificação do polímero-base (reforços, cargas, aditivos, plasticizantes). 


\section{CAPÍTULO 2}

\section{OBJETIVOS}

\subsection{Objetivo Geral}

O objetivo deste trabalho contempla a preparação e a caracterização de materiais termoplásticos e biodegradáveis preparados a partir do Amido de Batata e dos poliésteres Poli ( $\beta$-hidroxibutirato) - PHB e Poli ( $\beta$-hidroxibutirato-co-valerato) PHBV, utilizando-se o glicerol como agente plasticizante.

\subsection{Objetivos Específicos}

$\checkmark \quad$ Estudar os efeitos das variáveis de composição e variáveis de processamento sobre o desempenho dos materiais obtidos.

$\checkmark \quad$ Investigar a influência do plasticizante glicerol sobre as propriedades das blendas TPS/PHB, TPS/PHBV e TPS/PHB/PHBV e determinar se existe interação entre o glicerol e os poliésteres (PHB e PHBV).

$\checkmark$ Determinar as influências dos poliésteres (tipo e composição) nas propriedades finais das blendas TPS/PHB e TPS/PHBV. 


\section{CAPÍTULO 3}

\section{MATERIAIS E MÉTODOS}

\subsection{Materiais utilizados}

\section{Amido}

O Amido utilizado neste trabalho foi Amido de Batata, industrializado e comercialmente especificado como Fécula de Batata. Esse material em forma de pó foi fabricado pela Yoki, com lote $\mathrm{C} 7 \mathrm{KH}$.

Poli ( $\beta$-hidroxibutirato) - PHB

O Poli ( $\beta$-hidroxibutirato), homopolímero em forma de pó utilizado neste trabalho foi fornecido pela Biomater.

\section{Poli ( $\beta$-hidroxibutirato-co-valerato) - PHBV}

O Poli ( $\beta$-hidroxibutirato-co-valerato), copolímero utilizado neste trabalho foi de procedência da Tianan Biologic Material Company, Ltd (Ningbo, China), em forma de pellet (grânulo). O PHBV em pellet é constituído de 3 a $12 \%$ de HV (dado fornecido pela empresa). Sendo o material produzido por fermentação bacteriana, suas propriedades podem variar de lote para lote. 


\section{Plasticizante}

O plasticizante utilizado foi o glicerol fabricado pela Tec-Lab (Hexis Científica S.A), denominada também de glicerina bidestilada, com teor mínimo de $99 \%$ e ponto de ebulição de $290^{\circ} \mathrm{C}$.

\section{Ácido Esteárico}

O Ácido Esteárico foi fabricado pela Oxiteno com Grau III.

Os materiais de partida foram utilizados neste trabalho sem nenhum tipo de tratamento prévio.

\subsection{Equipamentos}

Foi utilizado na preparação dos materiais (blendas e misturas) um misturador intensivo e na preparação dos corpos de prova uma prensa com aquecimento.

\section{Reômetro de Torque HAAKE:}

Foi utilizado um misturador de batelada intensivo acoplado a um reômetro de torque, modelo Thermo Haake, marca Reômetro de Torque /Mixer R-600, software de análise Polylab monitor (Figura 7 A), com rotor tipo Roller (Figura 7 B) e com capacidade total da câmara de processamento (sem os rotores) de $120 \mathrm{~cm}^{3}$. 
O equipamento foi disponibilizado pelo Departamento de Materiais, da Escola Politécnica da Universidade de São Paulo - USP.

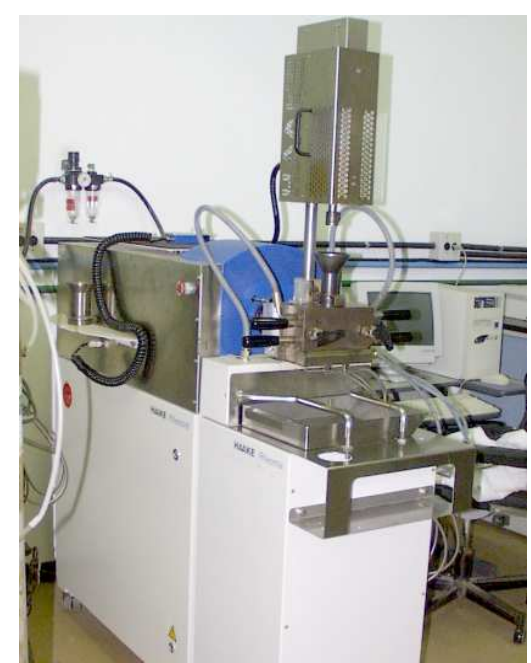

A

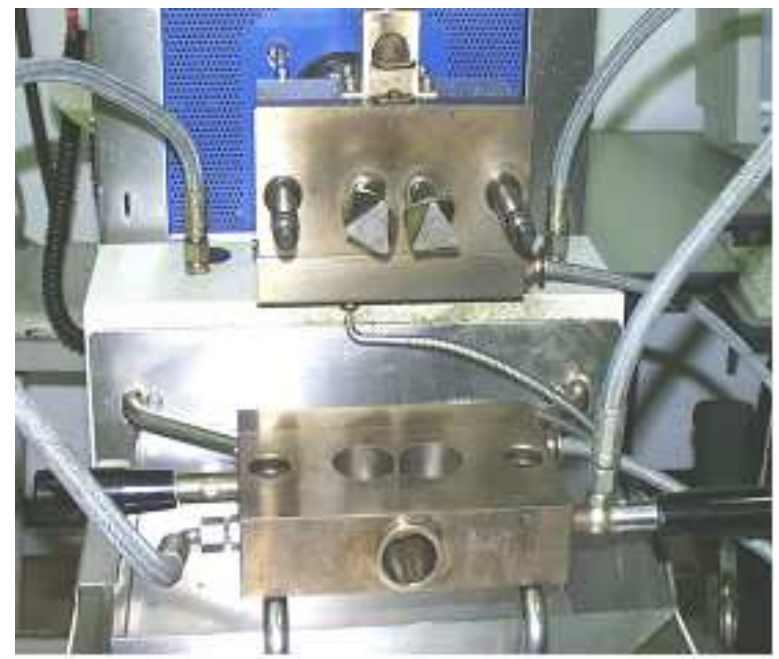

B

Figura 7- Misturador intensivo Haake $(A)$ e detalhes da câmara de processamento e rotores tipo roller.

\section{Prensa}

Foi utilizada uma prensa (termoprensa) Carver (Figura 8) para a formação dos corpos de prova, a qual contém duas placas de aquecimento (mesmas dimensões das placas para moldagem) com controle de aquecimento de $\pm 2,5{ }^{\circ}$. 


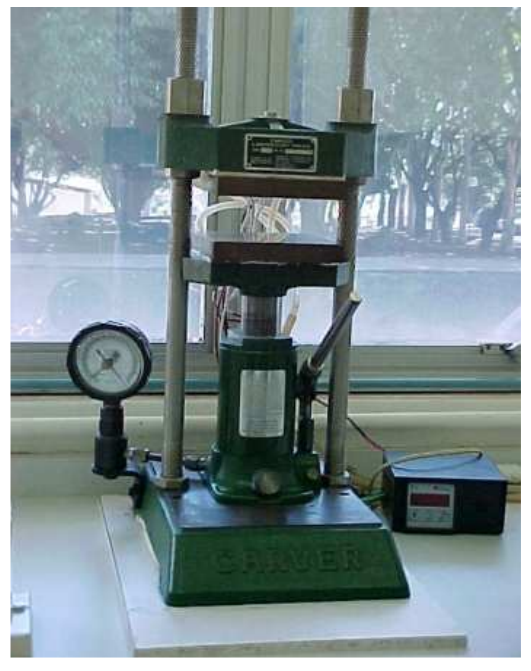

Figura 8 - Prensa utilizada para formação dos corpos de prova.

\subsection{Métodos}

\subsubsection{Preparação do Amido Termoplástico - (TPS)}

No processo de preparação do Amido Termoplástico (TPS) foi realizada uma pré-mistura do amido com os plasticizantes (água e glicerol) e em seguida a preparação da mistura termoplástica. Essas etapas estão detalhadas abaixo.

\section{Etapa 1 - Pré-mistura do amido com os plasticizantes:}

Em um saco de polietileno foram misturados, manualmente, o amido, glicerol, água e ácido esteárico até a obtenção de um pó ou massa, denominada de prémistura. Para obter uma mistura eficiente no reômetro de torque foram necessárias $60 \mathrm{~g}$ de amostra.

Estudos já realizados no grupo de pesquisa mostraram bons resultados com o uso de $50 \%$ de plasticizante total (glicerol e água), sendo $30 \%$ devido ao glicerol 
(CARVALHO et al., 2003b; DA RÓZ, 2004; TEIXEIRA, 2007). As misturas foram preparadas a partir de $60 \mathrm{~g}$ de amido (16,6 \% de umidade), $18 \mathrm{~g}$ de glicerol, $3,65 \mathrm{~g}$ de água e $0,5 \mathrm{~g}$ de ácido esteárico. A água é normalmente utilizada como plasticizante de processo para o amido, podendo ou não ser eliminada no produto acabado e o ácido esteárico é utilizado como agente desmoldante a fim de facilitar a remoção do material processado do misturador.

\section{Etapa 2 - Preparação da mistura termoplástica:}

A pré-mistura (amido/plasticizantes) foi adicionada diretamente na câmara do misturador (Figura $7 \mathrm{~B}$ ), na temperatura de $160^{\circ} \mathrm{C}$ e imediatamente fechada com o embolo do equipamento. A rotação dos rotores foi de $60 \mathrm{rpm}$ e o tempo de processamento de 10 minutos. $O$ embolo foi aberto ocasionalmente para eliminação de vapor de água gerado.

Os materiais após o processamento no misturador foram prensados à quente para obtenção dos corpos de prova (Figura 8). O molde utilizado para controle de espessura é formado por três placas de metal, duas maciças e uma vazada. $\mathrm{Na}$ placa vazada foram colocadas externamente folhas de PET para evitar aderência com o filme e as placas metálicas. As superfícies destas folhas foram borrifadas com desmoldante (silicone em spray). As amostras foram colocadas no interior da placa vazada e entre as duas placas maciças.

Durante a termoprensagem a temperatura utilizada foi de $165 \pm 5^{\circ} \mathrm{C}$ e o tempo de prensagem de 10 minutos. Foi realizada uma pré-prensagem à pressão de 2 toneladas métricas, por 6 minutos, em seguida foi aumentada a pressão para 4 toneladas métricas, por 2 minutos e subseqüentemente a pressão foi elevada para 
10 toneladas métricas, por mais 2 minutos. A placa de aquecimento foi então resfriada lentamente com fluxo de ar comprimido até a temperatura de aproximadamente $40^{\circ} \mathrm{C}$ e posteriormente os corpos-de -prova foram desmoldados.

\subsubsection{Preparação das Blendas}

Para a preparação das blendas foram realizadas pré-misturas com amido, plasticizantes e os polímeros PHB e/ou PHBV, seguido do processamento no reômetro de torque. Essas etapas, similares as realizadas para a preparação do TPS estão detalhadas abaixo.

\section{Etapa 1 - Pré-mistura feita com amido, plasticizantes e polímero:}

Em um saco de polietileno foram misturados, manualmente, o amido, glicerol, água e ácido esteárico até completa homogeneização. Em seguida foram acrescentados os polímeros (PHB e/ou PHBV), em diferentes proporções.

\section{Etapa 2 - Preparação das blendas poliméricas:}

Os procedimentos para a preparação das blendas poliméricas foram semelhantes à amostra TPS. 


\subsubsection{Composição das blendas e variáveis de processamento}

As blendas preparadas foram TPS/PHB, TPS/PHBV e TPS/PHB/PHBV. Conhecendo-se previamente o teor de umidade do amido, a proporção de glicerol definida para todas as misturas foi de $30 \%$ sobre o valor da massa de amido (base seca).

As amostras de TPS e PHB foram denominadas como: TPS; PHB25; PHB50; PHB75; PHB70G30 e PHB. A amostra TPS é constituída somente da mistura de amido e plasticizantes. As blendas denominadas PHB25; PHB50; PHB75 são constituídas de PHB nas proporções indicadas e de TPS. A mistura PHB70G30, com denominação diferente das demais, além do PHB é constituída também de glicerol (esta mistura não tem TPS). A última amostra, PHB é constituída somente do polímero PHB.

As composições das blendas de PHB são mostradas na Tabela 1.

Tabela 1 - Composições do TPS, das blendas TPS/PHB e das amostras de PHB.

\begin{tabular}{cccc}
\hline Amostra & $\begin{array}{c}\text { TPS } \\
(\%)\end{array}$ & $\begin{array}{c}\text { Polímero } \\
(\%)\end{array}$ & $\begin{array}{c}\text { Glicerol } \\
(\%)\end{array}$ \\
\hline TPS & 100 & - & - \\
PHB25 & 75 & 25 & - \\
PHB50 & 50 & 50 & - \\
PHB75 & 25 & 75 & - \\
PHB70G30 & - & 70 & 30 \\
PHB & - & 100 & - \\
\hline
\end{tabular}

As amostras de TPS e PHBV foram denominadas: PHBV25; PHBV50; PHBV75; PHBV70G30 e PHBV. As amostras TPS/PHBV foram constituídas com as mesmas proporções das amostras de PHB (citadas anteriormente). 
As amostras de TPS, PHB e PHBV foram denominadas: PHB12,5PHBV12,5, PHB25PHBV25, PHB37,5PHBV37,5, PHB35PHBV35G30 e PHB50PHBV50. As blendas denominadas PHB12,5PHBV12,5, PHB25PHBV25, PHB37,5PHBV37,5 são constituídas de PHB e PHBV nas proporções indicadas e de TPS. A mistura PHB35PHBV35G30, com denominação diferente das demais, além do PHB e PHBV é constituída também de glicerol (esta mistura não tem TPS). A última amostra, PHB50PHBV50 é constituída somente pelos polímeros PHB e PHBV.

As composições das blendas de TPS/PHB/PHBV são mostradas na Tabela 2.

Tabela 2 - Composições do TPS, das blendas TPS/PHB e das misturas de PHB e PHBV.

\begin{tabular}{ccccc}
\hline Amostra & $\begin{array}{c}\text { TPS } \\
(\%)\end{array}$ & \multicolumn{2}{c}{$\begin{array}{c}\text { Polímero } \\
(\%)\end{array}$} & $\begin{array}{c}\text { Glicerol } \\
(\%)\end{array}$ \\
\hline TPS & 100 & - & & - \\
PHB12,5PHBV12,5 & 75 & 12,5 & 12,5 & - \\
PHB25PHBV25 & 50 & 25 & 25 & - \\
PHB37,5PHBV37,5 & 25 & 37,5 & 37,5 & - \\
PHB35PHBV35G30 & - & 35 & 35 & 30 \\
PHB50PHBV50 & - & 50 & 50 & - \\
\hline
\end{tabular}

\subsubsection{Estudo dos parâmetros de processamento}

Para definir o tempo e a temperatura de processamento das amostras no reômetro de torque foram realizados alguns estudos com as blendas PHB50. Esta composição foi determinada por ser uma mistura com proporções iguais de TPS e PHB e a escolha do polímero foi feita pelo grande número de trabalhos encontrados na literatura. 
No primeiro estudo foi fixado a rotação dos rotores em $60 \mathrm{rpm}$, variou-se a temperatura de 150 a $170{ }^{\circ} \mathrm{C}$ e o tempo de processame nto de 4 a 10 minutos como mostrado na Tabela 3.

Tabela 3 - Condições de processamento empregadas no reômetro de torque.

\begin{tabular}{ccc}
\hline Amostra & $\begin{array}{c}\text { Temperatura } \\
\left({ }^{\circ} \mathbf{C}\right)\end{array}$ & $\begin{array}{c}\text { Tempo } \\
\text { (minuto) }\end{array}$ \\
\hline PHB50 & 150 & 10 \\
PHB50 & 155 & 10 \\
PHB50 & 160 & 10 \\
PHB50 & 170 & 10 \\
PHB50 & 160 & 4 \\
PHB50 & 160 & 6 \\
PHB50 & 160 & 8 \\
\hline
\end{tabular}

No tempo de 10 minutos, os materiais foram processados nas temperaturas de 150 a $170{ }^{\circ} \mathrm{C}$. Depois de definir a melhor tempera tura partiu-se para o segundo estudo, do melhor tempo, entre 4 a 10 minutos, como representado na Tabela 3.

\subsubsection{Caracterização dos Materiais}

Os materiais de partida (Amido de Batata, PHB e PHBV) foram caracterizados quanto ao teor de umidade, comportamento térmico, morfologia, cristalinidade, empregando-se as seguintes técnicas: Ressonância Magnética Nuclear (RMN); Cromatografia de Exclusão por Tamanho de Alta Eficiência (HPSEC); Termogravimetria (TG); Calorimetria Exploratória Diferencial (DSC); Microscopia Eletrônica de Varredura (MEV); Espectroscopia de Absorção na Região do Infravermelho com Transformada de Fourier (FTIR) e Difração de Raios-X. 
A amostra TPS, as blendas TPS/PHB, TPS/PHBV e TPS/PHB/PHBV e as amostras de PHB e/ou PHBV foram caracterizadas quanto à absorção de umidade, propriedades mecânicas, propriedades térmicas e propriedades morfológicas. Para as caracterizações de algumas dessas propriedades foram utilizadas as seguintes técnicas: Ensaio Mecânico (Resistência a Tração) e Análise Térmica DinâmicoMecânica (DMTA), dentre todas as outras técnicas utilizadas com os materiais de partida.

O TPS, as blendas TPS/PHB, TPS/PHBV e TPS/PHB/PHBV e as amostras de PHB e/ou PHBV foram condicionados a $53 \%$ de umidade relativa, antes da realização dos estudos de caracterização pelas técnicas TG, DSC, FTIR, Difração de Raios-X, DMTA e Ensaio Mecânico. As amostras foram obtidas a partir de corpos de prova após a termoprensagem.

\subsubsection{Teor de Umidade}

Os teores de umidade do Amido de Batata, PHB e PHBV foram determinados em uma balança de determinação de umidade OHAUS modelo MB200. Foi pesada aproximadamente $1,0 \mathrm{~g}$ da amostra, a qual foi aquecida à $106^{\circ} \mathrm{C}$, por 180 minutos. As análises foram realizadas em duplicata.

\subsubsection{Ressonância Magnética Nuclear - (RMN)}

As medidas de $\mathrm{RMN}{ }^{13} \mathrm{C}$ e $\mathrm{RMN}{ }^{1} \mathrm{H}$ com as amostras de Amido de Batata, PHB e PHBV, como materiais de partida, foram utilizadas para caracterizar o amido 
de batata, determinar as diferenças entre os polímeros (PHB e PHBV) e para verificar a quantidade de hidroxivalerato no copolímero PHBV.

Para as amostras de amido, PHB e PHBV foram feitas as análises de RMN 13C sólido e para as amostras PHB e PHBV as análises de RMN 13C líquido e RMN $1 \mathrm{H}$ líquido.

As análises de RMN 13C sólido foram realizadas no laboratório de RMN do IFSC-USP, utilizando-se um espectrômetro Varian-Inova de 9,4 T, com freqüências de ressonância de 100,5 MHz para o $13 \mathrm{C}$ e 400,0 MHz para o $1 \mathrm{H}$. Foi utilizada uma sonda MAS (Magic Angle Spinning) de $5 \mathrm{~mm}$ de dupla ressonância, com estabilidade de rotação de $\pm 2 \mathrm{~Hz}$. Os pulsos de $90^{\circ}$ típicos de 3,6 e 3,8 microsegundos foram aplicados para $13 \mathrm{C}$ e $1 \mathrm{H}$, respectivamente. $\mathrm{O}$ campo de desacoplamento heteronuclear $(1 \mathrm{H}-13 \mathrm{C})$ aplicado foi de $80 \mathrm{kHz}$, relativo à seqüência TPPM (Two Pulse Phase Modulation). Polarização cruzada com rampa foi realizada com tempo de contato de $1 \mathrm{~ms}$ e tempo de reciclo de $5 \mathrm{~s}$ para promediação dos espectros, seguido da sequência TOSS (Total Supression of Spinning Sidebands) de 4 pulsos para retirada das bandas laterais, e velocidade de rotação em torno do ângulo mágico de $5 \mathrm{kHz}$.

Para as medidas de RMN líquido, aproximadamente $0,5 \mathrm{~g}$ de amostra foi previamente dissolvida em clorofórmio sob agitação constante no ultra-som por duas horas. O solvente utilizado foi clorofórmio deuterado. As medidas foram realizadas num espectrômetro Bruker-AC-200, com freqüências de ressonância de 50,32 MHz para o $13 \mathrm{C}$ e $200,132 \mathrm{MHz}$ para o $1 \mathrm{H}$. Os números de varreduras foram de 73.600 e 64 para $13 \mathrm{C}$ e $1 \mathrm{H}$, respectivamente. Os pulsos de $60^{\circ}$ e $55^{\circ}$ típicos de 4,0 microsegundos e as larguras espectrais aplicadas foram de 15.000 e $2600 \mathrm{~Hz}$ para $13 \mathrm{C}$ e $1 \mathrm{H}$, respectivamente. 


\subsubsection{Cromatografia de Exclusão por Tamanho de Alta Eficiência - (HPSEC)}

A distribuição de massa molar do material de partida, antes do processamento (amido de batata) e após o processamento (TPS) foram determinadas por Cromatografia de Exclusão por Tamanho de Alta Eficiência (HPSEC).

O equipamento utilizado para as amostras foi um cromatógrafo Shimadzu, com uma pré-coluna Ultrahydrogel A e 3 colunas Ultrahydrogel Linear em série. Como eluente foi preparada uma solução aquosa $0,1 \mathrm{~N}$ de $\mathrm{NaNO}_{3}$ com pH de 11,5 ajustado com solução $1 \mathrm{M}$ de $\mathrm{NaOH}$. Foi utilizado fluxo de $0,8 \mathrm{~mL} \cdot \mathrm{min}^{-1}$, pressão de $22 \mathrm{Kgf} / \mathrm{cm}^{2}$, temperatura de $35 \mathrm{C}$, detector de índice de refra ção e volume de injeção de $20 \mu \mathrm{L}$.

As amostras foram preparadas a partir da dissolução de $450 \mathrm{mg}$ de amido em $15 \mathrm{~mL}$ de solução $\mathrm{NaOH} 1 \mathrm{M}$ seguido de agitação e aquecimento de $70-80{ }^{\circ} \mathrm{C}$ por 2 horas. À $2 \mathrm{~mL}$ desta solução foram adicionados $4 \mathrm{~mL}$ do eluente e, em seguida as amostras foram filtradas em membrana de fibra de vidro de porosidade de 1,0 $\mu \mathrm{m}$. A curva de calibração foi construída empregando-se soluções padrões de Pullulan.

\subsubsection{Absorção de Água}

Como os compostos de TPS são parcialmente solúveis em água, não foi possível realizar os ensaios de absorção de água por imersão dos materiais, o que comprometeria os resultados do ensaio. Para contornar este problema, as medidas 
foram realizadas através da exposição do material a um ambiente de umidade controlado (DUFRESNE; DUPEYRE; VIGNON, 2000).

Os ensaios de absorção de água foram realizados em ambientes com 22,5; 43; 53; 75 e $84 \%$ de umidade relativa controladas, obtidas através do uso de soluções saturadas de sais, que foram respectivamente $\mathrm{CH}_{3} \mathrm{COOK} ; \mathrm{K}_{2} \mathrm{CO}_{3}$; $\mathrm{Mg}\left(\mathrm{NO}_{3}\right)_{2} \cdot 6 \mathrm{H}_{2} \mathrm{O} ; \mathrm{NaCl} ; \mathrm{KCl}$ e $\mathrm{K}_{2} \mathrm{SO}_{4}$.

O procedimento de condicionamento foi realizado de acordo com a norma ASTM E 104. Os corpos de prova da amostra TPS, das blendas TPS/PHB, TPS/PHBV e TPS/PHB/PHBV e das amostras de PHB e/ou PHBV foram cortados com um vazador de $8 \mathrm{~mm}$ de diâmetro, a partir de placas moldadas à quente com espessura de aproximadamente $2 \mathrm{~mm}$.

Os materiais foram secos a $70{ }^{\circ} \mathrm{C}$ por 72 horas, numa estufa a vác uo (Marconi, Salvis Lab, Vacucenter), pesados em uma balança analítica (modelo Bolco, Germany) e colocados nos recipientes com umidades relativas préestabelecidas. As amostras foram pesadas em sucessivos intervalos de tempo até atingir o equilíbrio ou a absorção máxima. As medidas foram feitas em duplicatas para todas as amostras.

A quantidade de água absorvida (AA) por cada amostra, em um tempo t, foi calculada pela Equação 1:

$$
A A(\%)=\frac{(M t-M 0)}{M 0} \times 100 \quad \text { Equação } 1
$$


Onde $M_{0}$ e $M_{t}$ são as massas da amostra antes da exposição a um ambiente de umidade relativa controlada e após um tempo t de exposição do referido ambiente, respectivamente.

Para analisar se a absorção de água segue comportamento de Difusão Fickiana, os dados obtidos foram tratados em curvas de log $\left(M_{t} / M_{\infty}\right)$ em função de $\log$ t, como indicado pela Equação 2 (COMYN, 1985; ESPERT, A.; VILAPLANA, F.; KARLSSON, 2004):

$$
\frac{M_{t}}{M_{\infty}}=k t^{n} \quad \text { Equação } 2
$$

Sendo $M_{t}$ o conteúdo de água no tempo $t ; M_{\infty}$ o conteúdo de água no equilíbrio, $k$ e $n$ constantes.

O coeficiente de difusão (D) da água foi determinado a partir das medidas de absorção de água a 53 \% de umidade relativa, segundo a aproximação de Comyn (1985), baseada na Equação 3:

$$
\frac{M_{t}}{M_{\infty}}=\frac{4}{L}\left(\frac{D t}{\pi}\right)^{1 / 2} \quad \text { Equação } 3
$$

Onde $M_{\infty}$ é a massa de água absorvida no equilíbrio, $L$ é a espessura do filme polimérico e D é o coeficiente de Difusão. 
Segundo Comyn (1985), a equação 2 é válida para $\left(M_{t}-M_{0}\right) / M_{\infty} \leq 0,5$ com erro de $0,1 \%$. O coeficiente de difusão de água foi calculado a partir do coeficiente angular da reta obtido pelo gráfico de $\left(M_{t}-M_{0}\right) / M_{\infty}$ em função de $\left(t^{1 / 2}\right) / L$, como ilustrado na Figura 9 e expresso pela Equação 4 (Comyn, 1985):

$$
D=\frac{G^{2} \times \Pi}{16} \quad \text { Equação } 4
$$

Sendo $G$ o coeficiente angular da reta.

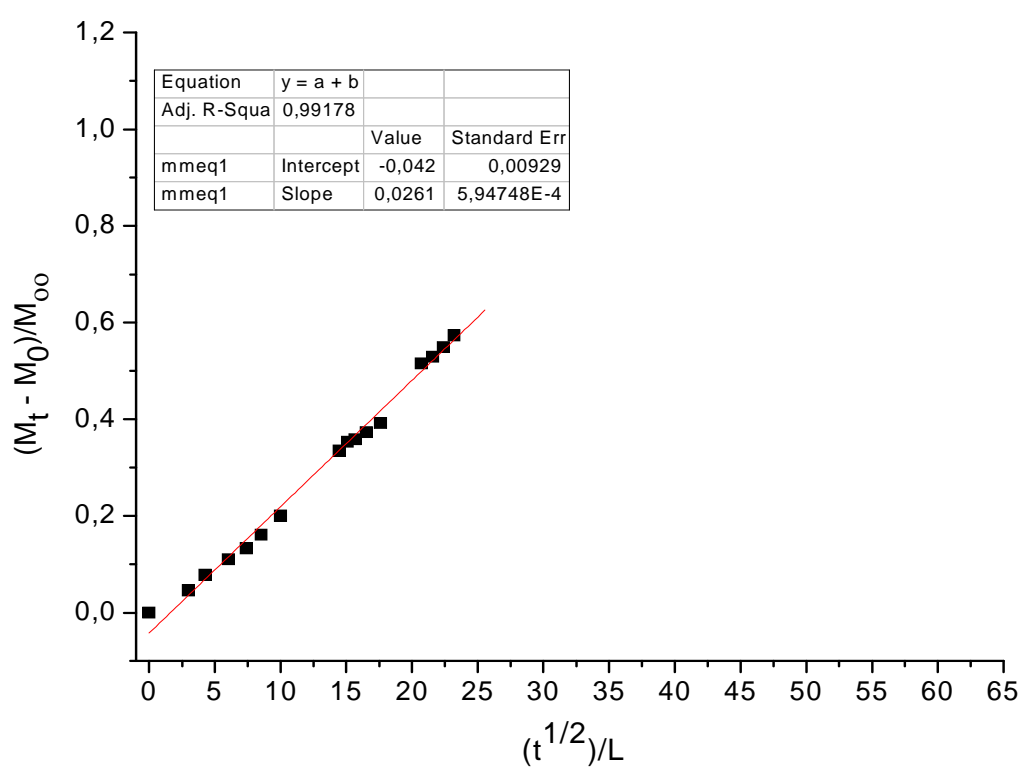

Figura 9 - Exemplo do gráfico de (Mt - M0)/Mœ em função de (t1/2)/L utilizado para calcular o coeficiente angular, pela aplicação da Equação 4.

\subsubsection{Termogravimetria - (TG)}

A temperatura de decomposição térmica, assim como a determinação do teor de umidade das amostras, entre outros eventos térmicos foram avaliados através da técnica Termogravimetria (TG), utilizando um equipamento da Shimadzu TA-50 WSI Thermal Analyser equipado com os módulos TGA-50. 
Para todos os materiais de partida foram utilizados atmosfera de $\mathrm{N}_{2}$, vazão de $20 \mathrm{~mL} \cdot \mathrm{min}^{-1}$, razão de aquecimento de $10^{\circ} \mathrm{C} \cdot \mathrm{min}^{-1}$ e porta amostra de platina. As análises foram realizadas em duplicatas.

A Tabela 4 representa as condições utilizadas na TG para os materiais de partida, sendo que o amido e o PHB foram analisados na forma de pó e o PHBV na forma de pellet.

Tabela 4 - Parâmetros utilizados na TG.

\begin{tabular}{ccc}
\hline Amostra & $\begin{array}{c}\text { Massa } \\
(\mathbf{m g})\end{array}$ & $\begin{array}{c}\text { Faixa de } \\
\text { temperatura } \\
\left({ }^{\circ} \mathbf{C}\right)\end{array}$ \\
\hline Amido & $15,0 \pm 0,5$ & $25-900$ \\
PHB & $9,0 \pm 0,5$ & $25-600$ \\
PHBV & $9,0 \pm 0,5$ & $25-600$ \\
Glicerol & $19 \pm 0,5$ & $25-500$ \\
\hline
\end{tabular}

Para a amostra TPS, blendas TPS/PHB, TPS/PHBV e TPS/PHB/PHBV e amostras de PHB e/ou PHBV foram utilizadas atmosfera de $\mathrm{N}_{2}$, vazão de $20 \mathrm{~mL}$.min ${ }^{1}$, razão de aquecimento de $10^{\circ} \mathrm{C} \cdot \mathrm{min}^{-1}$ e porta amostra de platina. Para todas as amostras foram usadas $15,0 \pm 0,5 \mathrm{mg}$ de massa e faixa de temperatura de $25-900$ C. Antes das análises, os corpos de prova foram co ndicionados em $53 \%$ de umidade relativa.

\subsubsection{Calorimetria Exploratória Diferencial - (DSC)}

Através da técnica Calorimetria Exploratória Diferencial (DSC) foi possível medir a variação de entalpia entre a amostra e uma referência em função da temperatura, além de vários eventos térmicos. 
O equipamento utilizado foi da TA Instruments com o módulo DSC Q10 e acessório de resfriamento DSC Refrigerated Cooling System (RCS 90). Para todos os materiais de partida foram utilizadas as seguintes condições no equipamento: atmosfera de $\mathrm{N}_{2}$ e razão de aquecimento de $10{ }^{\circ} \mathrm{C} \cdot \mathrm{min}^{-1}$.

Para o amido de batata foi utilizado fluxo de gás de $20 \mathrm{~mL} \cdot \mathrm{min}^{-1}$ e porta amostra hermético com furo no centro. Para os polímeros PHB e PHBV foram utilizados fluxos de gás de $50 \mathrm{~mL} \cdot \mathrm{min}^{-1}$ e porta amostra de alumínio de alta pressão, sendo que com esses dois materiais foram realizadas duas corridas de aquecimento e uma de resfriamento, nas razões de $10{ }^{\mathrm{C}} \mathrm{C} \cdot \mathrm{min}^{-1}$.

A Tabela 5 representa as condições utilizadas no DSC para os materiais de partida, sendo que o amido e o PHB foram analisados na forma de pó e o PHBV na forma de pellet.

Tabela 5 - Parâmetros utilizados no DSC.

\begin{tabular}{ccc}
\hline Amostra & $\begin{array}{c}\text { Massa } \\
(\mathbf{m g})\end{array}$ & $\begin{array}{c}\text { Faixa de temperatura } \\
\left({ }^{\mathbf{C}}\right)\end{array}$ \\
\hline Amido & $10,0 \pm 0,5$ & $25-250$ \\
PHB & $10,0 \pm 0,5$ & $-60-200$ \\
PHBV & $10,0 \pm 0,5$ & $-60-200$ \\
\hline
\end{tabular}

As cristalinidades das blendas TPS/PHB, TPS/PHBV e TPS/PHB/PHBV e das amostras PHB e/ou PHBV foram determinadas por DSC e calculada a partir da equação 5 :

$\% \mathrm{C}=\frac{\Delta \mathbf{H}_{\mathrm{f}}}{\Delta \mathbf{H}_{\mathrm{f}}^{\circ}} \times 100 \quad$ Equação 5 
Onde \% C é a cristalinidade em porcentagem, $\Delta \mathrm{H}_{\mathrm{f}}$ é a entalpia de fusão obtida por DSC, $\Delta \mathrm{H}_{\mathrm{f}}{ }^{\circ}$ é a entalpia de fusão para polímero $100 \%$ cristal ino (PACHEKOSKI, 2005).

Para a determinação da temperatura de gelatinização do amido também foi utilizado o DSC. A análise foi realizada nas mesmas condições da amostra de amido (Tabela 5), acrescentando-se no porta-amostra de alumínio de alta pressão 10,0 mg de amido e 20,0 mg de água, mantendo uma proporção de 1/2 mm amido:água. A mistura foi previamente mantida em repouso por uma hora para a posterior realização da análise (NDIFE; SUMNU; BAYINDIRLI, 1998).

Para a amostra TPS, as blendas TPS/PHB, TPS/PHBV e TPS/PHB/PHBV e as amostras de PHB e/ou PHBV foram utilizadas o equipamento Shimadzu TA-50 WSI Thermal Analyser equipado com os módulos DSC-50. Vários estudos para a determinação da condição ideal de análise foram realizados. A Tabela 6 representa os três estudos com as diferentes condições utilizadas durante as medidas de DSC.

Tabela 6 - Parâmetros utilizados para a determinação da melhor condição de análise nos diferentes estudos.

\begin{tabular}{lccc}
\hline Estudo & $\begin{array}{c}\text { Faixa de } \\
\text { temperatura } \\
\left({ }^{\complement} \mathbf{C}\right)\end{array}$ & $\begin{array}{c}\text { Fluxo de gás } \\
\left(\mathbf{m L}^{\left.-\mathbf{m i n}^{-1}\right)}\right.\end{array}$ & Porta amostra \\
\hline Primeiro & $-55-250$ & 70 & Alumínio de alta pressão \\
Segundo & $-55-250$ & 70 & Alumínio aberta \\
Terceiro & $25-200$ & 20 & Alumínio aberta \\
\hline
\end{tabular}

Para os três estudos foram utilizadas as condições de 10,0 \pm 0,5 $\mathrm{mg}$ das amostras e taxa de aquecimento de $10^{\circ} \mathrm{C} \cdot \mathrm{min}^{-1}$. Para obter a temperatura de $-55^{\circ} \mathrm{C}$ 
foi utilizado nitrogênio líquido no DSC. Antes das análises, as amostras foram condicionadas em $53 \%$ de umidade relativa.

Para quantificar os teores de amilose na amostra de amido de batata foi utilizado também a técnica de DSC e um método proposto por Mestres (MESTRES et al., 1996) que consiste na complexação entre a amilose e a enzima L- $\alpha$ lisofosfatidilcolina (LPC), (SIGMA).

Para a preparação da amostra, foram pesados $5,00 \mathrm{mg}$ de amido em um porta amostra de alta pressão e $25 \mu \mathrm{L}$ de solução $2 \%$ de LPC. A mistura permaneceu em repouso por $1 \mathrm{~h}$. Posteriormente, a medida foi realizada empregando-se um equipamento da TA Instrumento, módulo DSC Q10 com as condições de atmosfera de $\mathrm{N}_{2}$ e fluxo de $20 \mathrm{~mL} \cdot \mathrm{min}^{-1}$. A referência consistiu de $20 \mu \mathrm{L}$ de água. A Tabela 7 representa a programação de temperatura.

Tabela 7 - Programação de temperatura na determinação do teor de amilose empregando DSC.

\begin{tabular}{ccc}
\hline $\begin{array}{c}\text { Etapa/ } \\
\left.\text { Faixa de temperatura ( }{ }^{\circ} \mathrm{C}\right)\end{array}$ & $\begin{array}{c}\text { Razão de aquecimento (+) } \\
\text { ou de resfriamento (-) } \\
\left({ }^{\circ} \mathbf{C} . \text { min }^{-1}\right)\end{array}$ & $\begin{array}{c}\text { Isoterma } \\
\text { (minuto) }\end{array}$ \\
\hline Aquecimento (1): $25^{\circ} \mathrm{C}-160$ & +10 & 2 \\
Resfriamento (1):160 ${ }^{\circ} \mathrm{C}-25$ & -5 & 5 \\
Aquecimento (2): $25^{\circ} \mathrm{C}-160$ & +10 & 2 \\
Resfriamento (2):160 ${ }^{\circ} \mathrm{C}-25$ & -5 & 5 \\
\hline
\end{tabular}

Para determinar a porcentagem de amilose foi aplicada a Equação 6:

$$
\% \text { amilose }=\frac{\Delta_{\mathrm{H}} \text { amostra }}{\Delta_{\mathrm{H}} \text { padrão }} \times 100 \quad \text { Equação } 6
$$

$\mathrm{O}$ valor adotado de $\Delta \mathrm{H}$ padrão da amilose de amido de batata foi de 28,50 J.g $\mathrm{g}^{-1}$ (MESTRES et al., 1996). 


\subsubsection{Microscopia Eletrônica de Varredura - (MEV)}

Com a técnica de Microscopia Eletrônica de Varredura (MEV) foram realizados estudos da estrutura superficial e da morfologia dos materiais de partida (Amido de Batata, PHB e PHBV), da amostra TPS, blendas TPS/PHB, TPS/PHBV e TPS/PHB/PHBV e amostras de PHB e/ou PHBV.

As amostras de amido, PHB e PHBV, como materiais de partida, foram colocadas sobre suportes metálicos com fitas adesivas de carbono utilizadas como adesivos condutivos e recobertas com $10 \mathrm{~nm}$ de ouro. $\mathrm{O}$ recobrimento foi realizado em um metalizador Coating System BAL-TEC MED 020. As amostras foram mantidas em dessecador até o momento das análises.

As amostras $\mathrm{e}$ as blendas citadas anteriormente, na forma de filmes (espessura de $3 \mathrm{~mm}$ ), foram submetidas à fratura frágil após congelamento em nitrogênio líquido por aproximadamente 10 minutos. Em seguida as amostras foram secas a vácuo, a $70^{\circ} \mathrm{C}$, por 1 hora. Todas as amostr as foram colocadas sobre uma fita adesiva e recobertas com ouro. As fotomicrografias foram obtidas em um equipamento LEO (modelo 440) com detector OXFORD, operando com feixe de elétrons de $20 \mathrm{keV}$.

O revestimento das amostras por filmes condutores, como o ouro, foi feito para evitar o acúmulo de carga negativa, pois as mesmas são formadas por materiais não condutores. 


\subsubsection{Espectroscopia de Absorção na Região do Infravermelho com Transformada de Fourier - (FTIR)}

A técnica FTIR foi utilizada na caracterização da estrutura química dos materiais poliméricos, para comparação das absorções dos materiais de partida e das amostras.

$\mathrm{Na}$ obtenção dos espectros dos materiais de partida (Amido de Batata, PHB e PHBV), foi utilizado um espectrômetro BOMEM, modelo MB-102, na região de 300 a $4000 \mathrm{~cm}^{-1}$. As amostras na forma de pó foram misturadas com $\mathrm{KBr}$ previamente seco, numa proporção de 1:100 (g/g) e a partir delas foram confeccionadas pastilhas por prensagem. A mistura amostra/KBr foi seca em estufa a vácuo por 2 horas, na temperatura de $100^{\circ} \mathrm{C}$, antes de ser prensada. Os es pectros foram obtidos no modo transmitância, $4 \mathrm{~cm}^{-1}$ de resolução e 16 scans. $\mathrm{min}^{-1}$.

As análises de FTIR para a amostra TPS, blendas TPS/PHB, TPS/PHBV e TPS/PHB/PHBV e amostras de PHB e/ou PHBV foram realizadas utilizando um espectrômetro no laboratório de Polímeros do IFSC-USP, marca NEXUS e modelo 470, com um suporte de Cristal de Seleneto de Zinco (ZnSe) - modo ATR. Os espectros foram obtidos no modo reflectância, $4 \mathrm{~cm}^{-1}$ de resolução e 64 scans.min ${ }^{-1}$ e na região de 650 a $4000 \mathrm{~cm}^{-1}$. Antes de iniciar as medidas, os corpos de prova (filmes com $1 \mathrm{~mm}$ de espessura) foram secos a $70^{\circ} \mathrm{C}$, por 72 horas, numa estufa a vácuo. 


\subsubsection{Difração de Raios-X}

A técnica de Difração de Raios-X através do espalhamento coerente da radiação $\mathrm{X}$, por estruturas organizadas (cristais), permitiu realizar estudos morfológicos em materiais, determinando sua estrutura cristalina e sua fração (percentual) cristalina.

As análises das amostras foram realizadas à temperatura ambiente, no intervalo angular $2 \theta$ de 5 a $40^{\circ}$ em um difratômetro Universal de raios-X RIGAKU, com eletrodo de cobre operando com potência de $50 \mathrm{kV} / 100 \mathrm{~mA}$, a uma velocidade de $2^{\circ} \mathrm{C} \cdot \mathrm{min}^{-1}$, no laboratório de Cristalografia do IFSC-USP.

O amido e PHB foram analisados na forma de pó e o PHBV na foram de pellet. As amostras TPS, blendas TPS/PHB, TPS/PHBV e TPS/PHB/PHBV e amostras de PHB e/ou PHBV foram analisadas na forma de filmes (espessura de 3 $\mathrm{mm}$ ). Antes das análises, as amostras foram condicionadas em ambiente de umidade relativa controlada em $53 \%$.

Os cálculos do índice ou grau cristalinidade do amido e da amostra TPS foram determinadas empregando-se o método utilizado por Hulleman e colaboradores (1999), (HULLEMAN et al.,1999), através da Equação 7:

$$
I c r=\frac{H c}{(H c+H a)} \quad \text { Equação } 7
$$

Onde $\mathrm{I}_{\mathrm{cr}}$ é $\mathrm{o}$ índice de cristalinidade, $\mathrm{H}_{\mathrm{a}}$ é a altura correspondente à fase amorfa em relação à linha base e $\mathrm{H}_{\mathrm{c}}$ é a altura corresponde ao pico cristalino. 
A Figura 11 representa uma curva analisada pelo método estabelecido por Hulleman, o qual propõe a altura dos picos de difração para determinação do índice de cristanilidade.

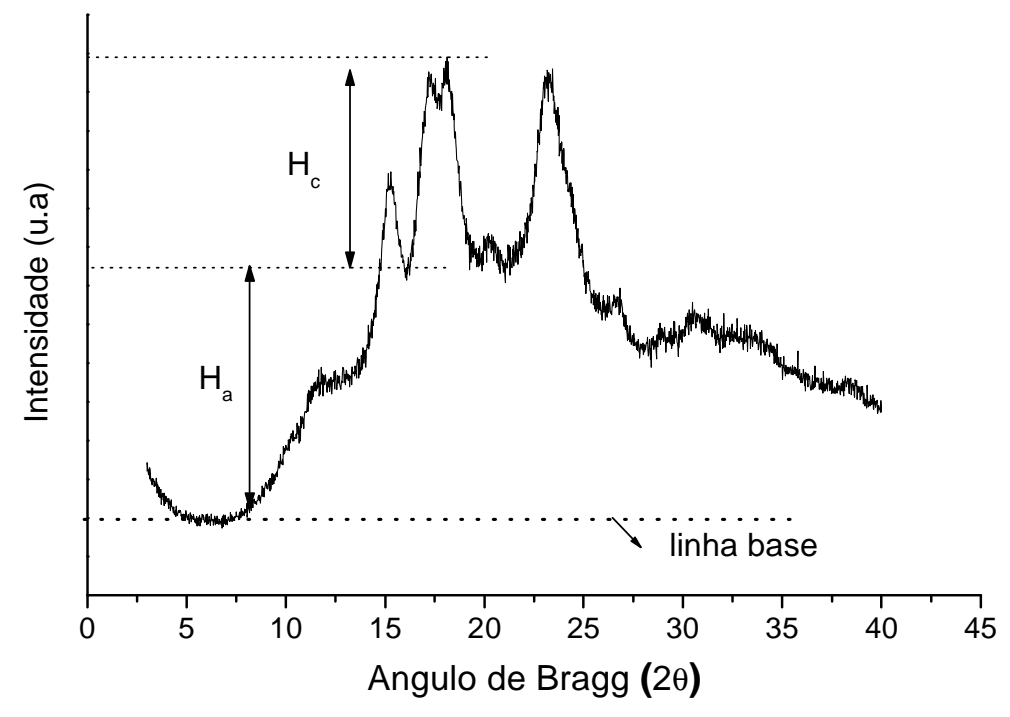

Figura 10 - Perfil de difração de raios-x exibindo os picos característicos e o método de Hulleman para determinação do índice de cristalinidade.

Para as blendas e as amostras de PHB e/ou PHBV, o cálculo do grau de cristalinidade foi realizado pelo método estabelecido por Ruland (1974) (RULAND,1974). Esse método permite calcular a cristalinidade de um polímero pela

\section{Equação 8:}

$\% \mathrm{C}=\frac{\mathrm{I}_{\mathrm{c}}}{\left(\mathrm{I}_{\mathrm{c}}+\mathrm{KI}_{\mathrm{a}}\right)} \times 100 \quad$ Equaçäo 8

Onde \%C é a cristalinidade em porcentagem, $\mathrm{I}_{\mathrm{a}}$ é a área sob o halo amorfo, $\mathrm{I}_{\mathrm{c}}$ é o resultado da integração dos picos de difração ou as áreas dos picos cristalinos e K é uma constante de proporcionalidade para cada polímero. 
A Figura 11 representa uma curva analisada pelo método estabelecido por Ruland (1974), o qual a propõe a deconvolução dos picos de difração para determinação do grau de cristanilidade. Com o auxílio de um software aplicativo foi calculado a área sob o pico difratado sem a contribuição do halo amorfo na avaliação.

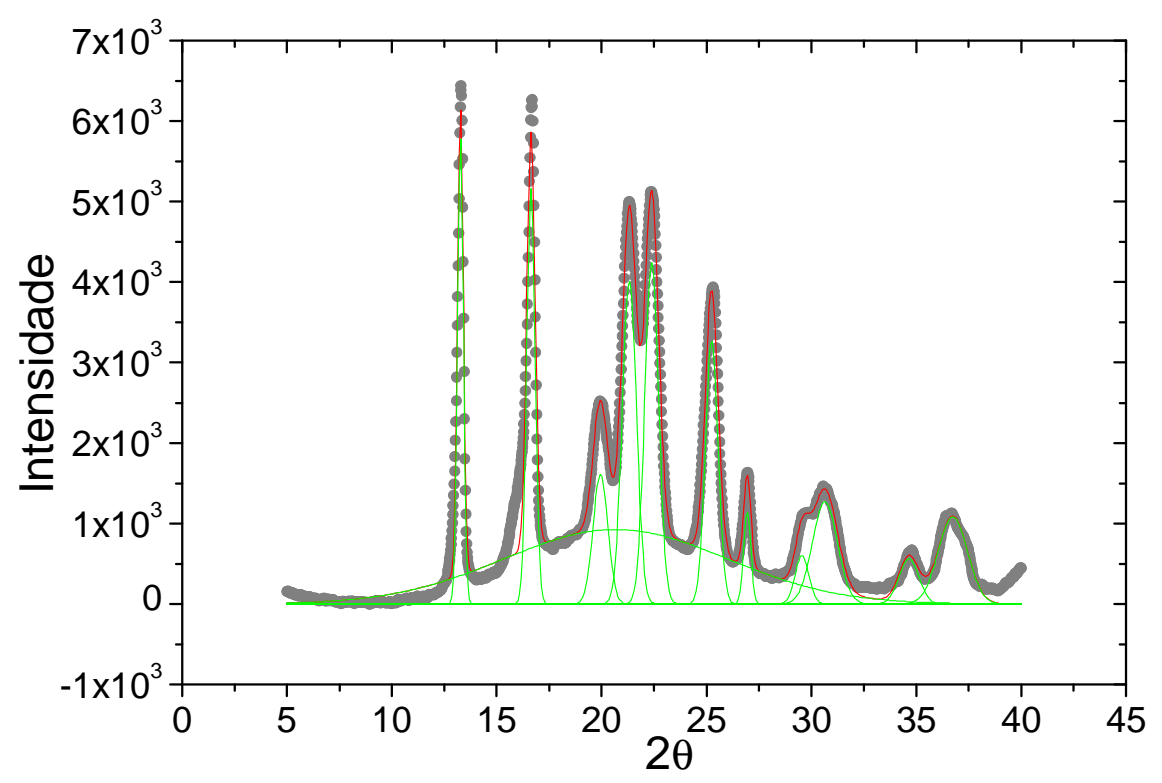

Figura 11 - Perfil de difração de raios-x exibindo os picos característicos e o halo amorfo para determinação do índice de cristalinidade.

\subsubsection{Análise Térmica Dinâmico-Mecânica - DMTA}

A Análise Térmica Dinâmico-Mecânica (DMTA) foi utilizada para verificação do efeito plasticizante do glicerol e da adição dos polímeros PHB e/ou PHBV sobre as amostras TPS, a partir da determinação da temperatura de transição vítrea $\left(T_{g}\right)$, da miscibilidade dos materiais, dentre outras propriedades.

Os métodos dinâmicos mecânicos são mais sensíveis às relaxações associadas à transição vítrea quando comparadas com as análises feitas por DSC. 
Visto que por DSC não foi possível a observação da $T_{g}$ para a amostra TPS e as blendas de PHB e/ou PHBV, tal determinação foi realizada por DMTA.

As análises de DMTA foram realizadas no laboratório de Polímeros do IFSCUSP, em um equipamento NETZSCH modelo DMTA 242C, no modo tensão, equipado com um sistema de resfriamento por suprimento de nitrogênio líquido. Foi determinado no equipamento para todas as amostras, freqüência de $1 \mathrm{~Hz}$, em atmosfera de ar, amplitude de $16 \mu \mathrm{m}$ e razão de $2{ }^{\circ} \mathrm{C} \cdot \mathrm{min}^{-1}$.

Para a amostra TPS o intervalo de temperatura foi de -120 a $110^{\circ} \mathrm{C}$ e para as blendas de PHB e/ou PHBV de -130 a 150 `C. Para as análises, utilizaram corpos de prova retangulares de largura/comprimento/espessura $6 \times 20 \times 1 \mathrm{~mm}$ e condicionados em $53 \%$ de umidade relativa.

\subsubsection{Ensaio Mecânico - Resistência à Tração}

Algumas propriedades poliméricas como rigidez, fragilidade, ductibilidade, dentre outras são importantes indicadoras da resistência mecânica de um material, sendo usualmente utilizadas para especificar e determinar limites de aplicação. Nesse ensaio os corpos de prova com dimensões padronizadas foram submetidos a esforços crescentes na direção axial.

Para a realização dos ensaios de tração, foram empregados seis corpos-deprova para a amostra TPS, blendas TPS/PHB, TPS/PHBV e TPS/PHB/PHBV e as amostras de PHB e/ou PHBV. As amostras foram preparadas com molde, em forma de halteres, via termoprensagem. As amostras foram previamente condicionadas em ambiente de umidade relativa de $53 \%$. 
Os ensaios foram realizados segundo a norma ASTM D638 M-96, utilizandose uma máquina EMIC DL3000, célula de carga de 200 Kgf, com velocidade de 50 mm. $\mathrm{min}^{-1}$, no laboratório de Geotecnia da EESC - USP. 


\section{CAPÍtULO 4}

\section{RESULTADOS E DISCUSSÃo}

\subsection{Estudo das variáveis de processamento}

Estudos foram realizados com as blendas PHB50, no reômetro de torque, para determinação das variáveis de processamento (temperatura e tempo). Manteve-se fixada a rotação dos rotores em 60 rpm, variando a temperatura de 150 a $170{ }^{\circ} \mathrm{C}$ e o tempo de processamento de 4 a 10 minut os.

No tempo de 10 minutos os materiais foram processados nas temperaturas de $150,155,160$ e $170{ }^{\circ}$. Depois de definir a melhor temperatura através das curvas de torque e de análises visuais das amostras (cor, massa homogênea, material totalmente plasticizado) partiu-se para o estudo do melhor tempo, variando de 4, 6, 8 e 10 minutos.

A Figura 12 representa a curvas de torque em função do tempo de processamento para a blenda PHB50, variando a temperatura de 150 a $170{ }^{\circ} \mathrm{C}$, mantendo o tempo máximo em 10 minutos. 


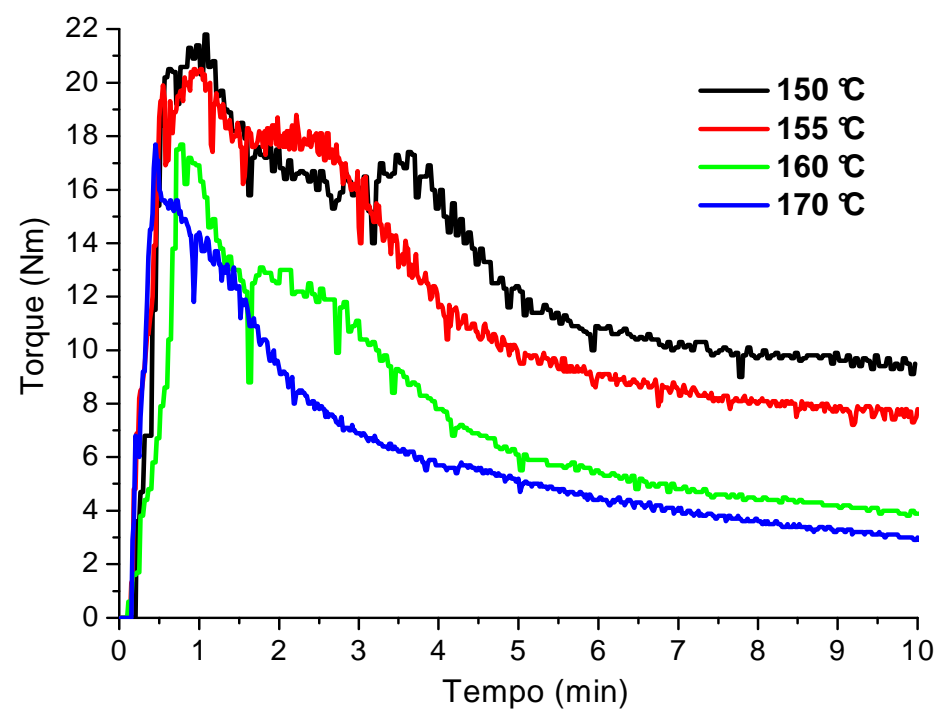

Figura 12 - Curvas do torque em função do tempo de processamento para diferentes temperaturas e tempo máximo de 10 minutos.

A Figura 12 revela uma variação das curvas de torque, com o aumento da temperatura. À medida que aumenta a temperatura de processamento de 150 a 170 ${ }^{\circ}$, o torque diminui de aproximadamente 22 a $16 \mathrm{Nm}$ e a curva se torna constante em um tempo menor.

A Figura 13 apresenta as blendas PHB50 depois de serem processadas em diferentes temperaturas $\left(150,155,160,170{ }^{\circ} \mathrm{C}\right)$.

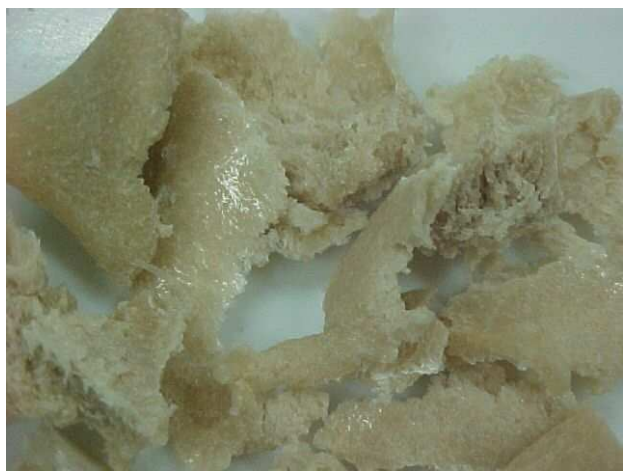

A

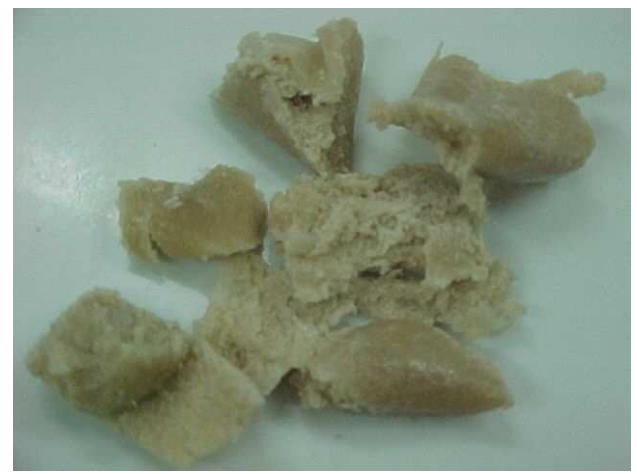

B 


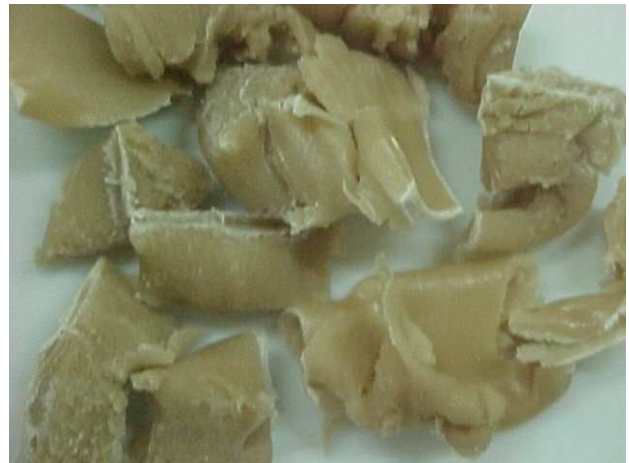

C

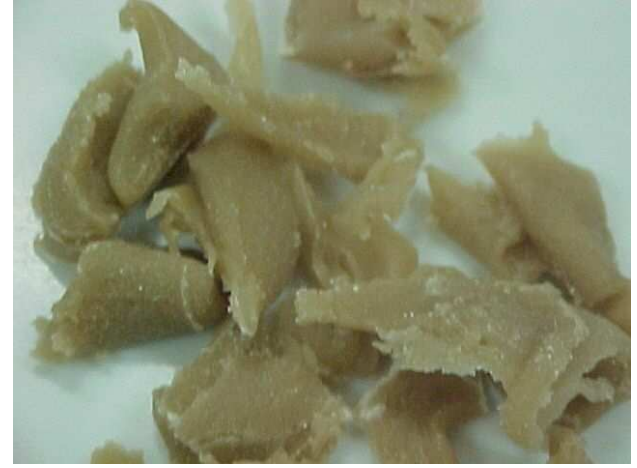

D

Figura 13 - Blendas PHB50 com diferentes temperaturas de processamento, $150^{\circ} \mathrm{C}(\mathrm{A}) ; 155^{\circ} \mathrm{C}(\mathrm{B})$; $160^{\circ} \mathrm{C}(\mathrm{C})$ e $\left.170{ }^{\circ} \mathrm{(D}\right)$, no tempo fixo de 10 minuto s.

A Figura 13 (A e B) revela que não foram obtidas misturas homogêneas, pois observou grande quantidade de pó na superfície, além de coloração marrom, com regiões esbranquiçadas, podendo concluir que não aconteceu fusão total dos materiais. Durante o processamento a temperatura máxima da amostra observada na Figura $13 \mathrm{~A}$ foi de $160^{\circ} \mathrm{C}$ e da amostra da Figura $13 \mathrm{~B}$ foi de $170{ }^{\circ} \mathrm{C}$. Na Figura $13 \mathrm{C}$ observou uma mistura homogênea sem a presença de pó na superfície e com uma coloração marrom escuro. Aparentemente ocorreu fusão dos materiais e formaram blendas rígidas, atingindo temperatura máxima de $170{ }^{\circ} \mathrm{C}$ durante 0 processamento. Na Figura $13 \mathrm{D}$, observou uma mistura bastante homogênea e uma coloração mais escura que as outras amostras, mas a temperatura máxima atingiu $178^{\circ}$; para o amido é uma temperatura muito alta, podendo ocorrer degradação.

A Figura 14 representa a curvas de torque em função dos tempos de processamento para o PHB50, mantendo a temperatura fixa em $160^{\circ} \mathrm{C}$. 


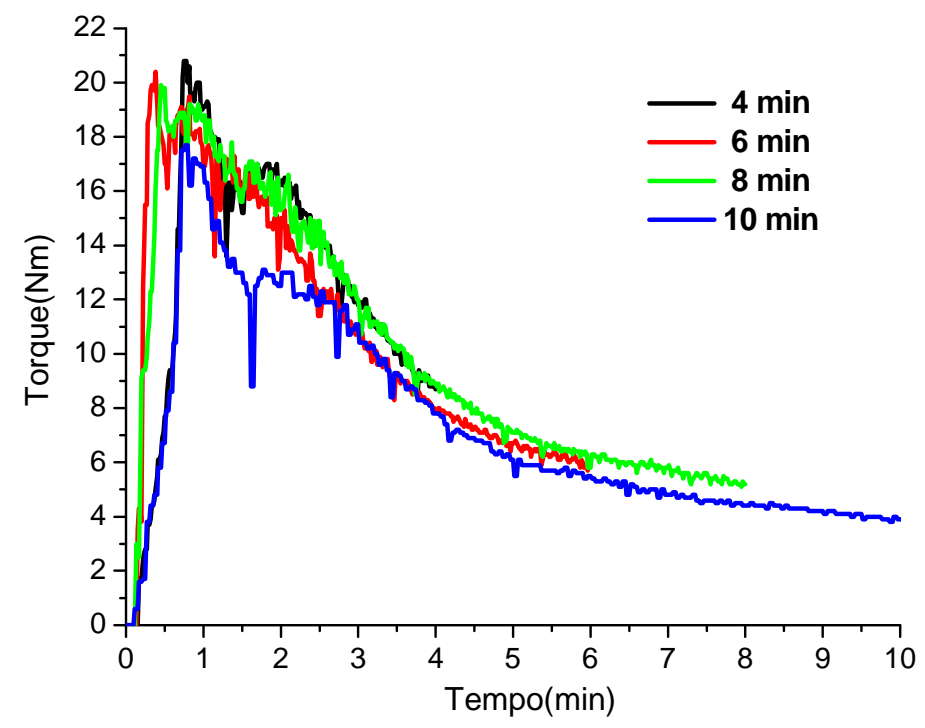

Figura 14 - Curvas de torque em função do tempo de mistura dos PHB50 a $160{ }^{\circ} \mathrm{C}$.

A Figura 15 representa as amostras de PHB50 depois de serem processadas em diferentes tempos (4, 6, 8 e 10 minutos).

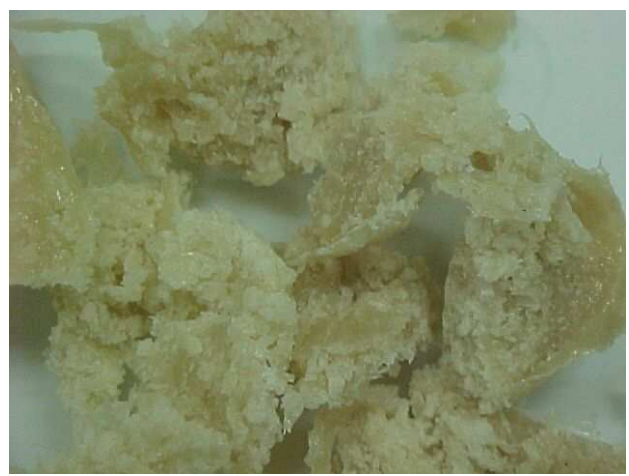

A

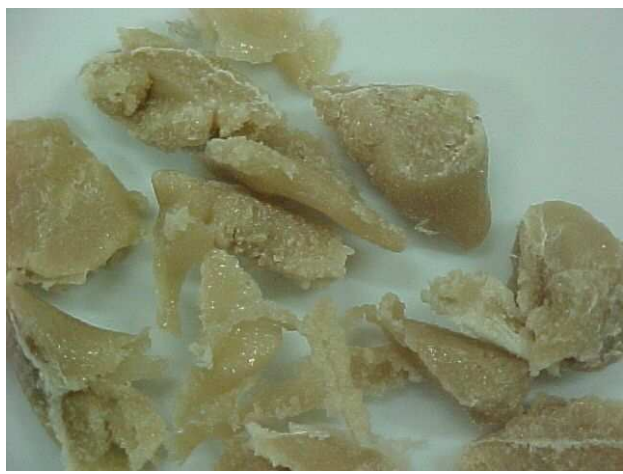

C

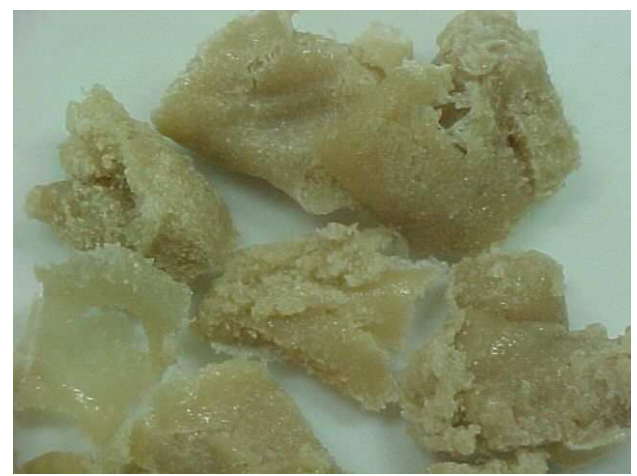

B

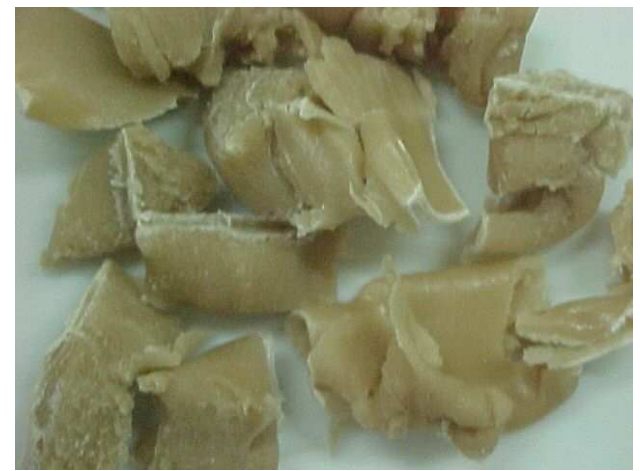

D

Figura 15 - Blendas PHB50 obtidas em diferentes tempos de processamento, 4 minutos (A); 6 minutos (B); 8 minutos (C) e 10 minutos (D), na temperatura fixa de $160{ }^{\circ} \mathrm{C}$. 
Na Figura 15 (A e B) foi observado que as blendas não fundiram e não produziram misturas homogêneas, apresentando coloração marrom e regiões esbranquiçadas. Na Figura 15 C, observou-se que ocorreu fusão dos materiais, mas não obtiveram misturas totalmente homogêneas, pois se observou pó na superfície das mesmas.

Assim, determinou-se que as melhores condições para o processamento das amostras corresponderam a uma temperatura de $160^{\circ} \mathrm{C}$ e o tempo de 10 minutos (Figura $15 \mathrm{D}$ ).

\subsection{Teor de Umidade}

Os teores de umidade do amido, PHB e PHBV foram determinados em uma balança de determinação de umidade. A balança determina a porcentagem de perda de massa relativa ao teor de umidade das amostras. Para o amido de batata o teor de umidade foi de $18 \%$ e para os polímeros PHB (pó) e PHBV (pellet) o teor de umidade foi de $1 \%$.

\subsection{Ressonância Magnética Nuclear - (RMN)}

A técnica RMN foi utilizada na identificação dos compostos orgânicos dos materiais de partida (Amido de Batata, PHB e PHBV). Para o amido de batata foi realizada a análise de RMN $13 \mathrm{C}$ sólido. Para as amostras PHB e PHBV foram feitas as análises de $\mathrm{RMN} 13 \mathrm{C}$ sólido e líquido e $\mathrm{RMN} 1 \mathrm{H}$ líquido. A técnica foi utilzada no presente trabalho apenas para a caracterização dos materiais de partida. 


\section{Amido de Batata}

Foi realizada a análise de $\mathrm{RMN}{ }^{13} \mathrm{C}$ sólido para a amostra de amido de batata.

A Figura 16 e a Tabela 8 ilustram as características do espectro para a amostra.

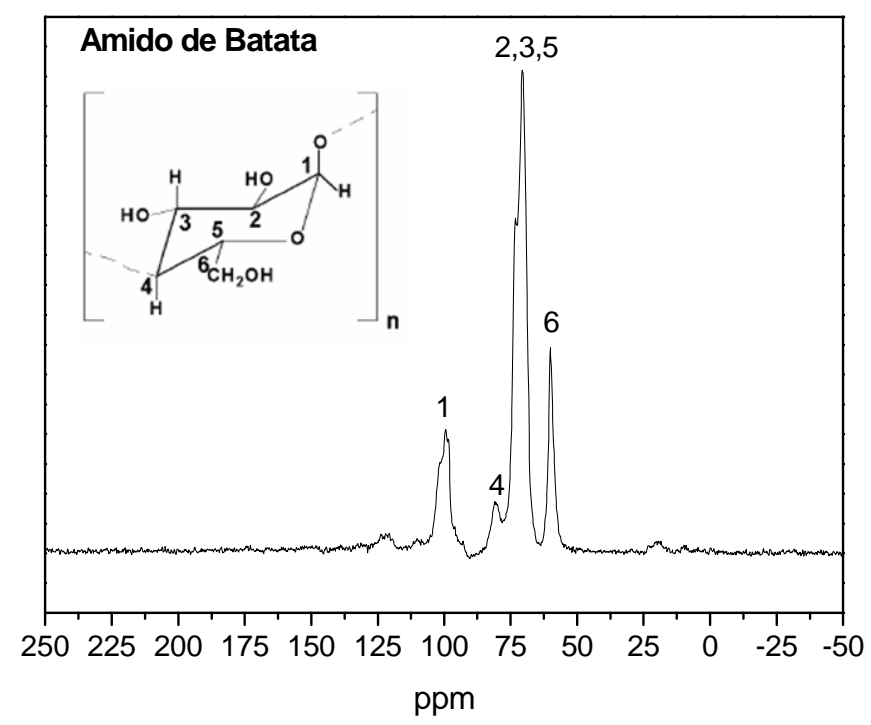

Figura 16 - Espectro de RMN 13C sólido do amido de batata.

Tabela 8 - Principais posições das bandas mais significativas do amido de batata.

\begin{tabular}{cccc}
\hline Amostra & $\begin{array}{c}\text { Deslocamento } \\
\text { químico } \\
(\mathbf{p p m})^{\mathbf{a}}\end{array}$ & $\begin{array}{c}\text { Deslocamento } \\
\text { químico } \\
(\mathbf{p p m})^{\mathbf{b}}\end{array}$ & Tipo de Carbono \\
\hline 99,101 & 99,102 & $\mathrm{C} 1:\left(\mathrm{CH}(\mathrm{OR})_{2}\right)$ \\
Amido & 81 & 81 & $\mathrm{C} 4:(\mathrm{CH}-\mathrm{OR})$ \\
& 71,73 & 71,74 & $\mathrm{C} 2, \mathrm{C} 3, \mathrm{C} 5:(\mathrm{CH}-\mathrm{OH})$ \\
& 60 & 61 & $\mathrm{C} 6$ \\
\hline a. Dados obtidos & \multicolumn{3}{c}{ Dados da literatura (KAZIMIERCZAK et al., 2007). }
\end{tabular}

Na técnica de RMN no estado sólido os sinais são mais alargados que em solução (Figura 16) devido à pequena movimentação molecuar e ao alto peso 
molecular das moléculas que constituem o material (CANEVAROLO JUNIOR, 2004).

A multiplicidade do C1 (Figura 16 e Tabela 8) corresponde ao tipo de empacotamento dos grânulos de amido e pode revelar a natureza de sua cristalinidade. Como o amido de batata, possui um cristal do tipo B, o pico do C1 é um dupleto na região de 99 e 101 ppm , indicando que este amido possui dois resíduos de açúcar não idênticos. Este pico está relacionado aos grupos $\mathrm{CH}(\mathrm{OR})_{2}$.

O C4 corresponde aos grupos $\mathrm{CH}-\mathrm{OR}$, como ilustrado na Figura 16. Como o C1 está ligado a dois átomos de oxigênio e o C4 está ligado apenas a um oxigênio, o deslocamento químico para o carbono dos grupos $\mathrm{CH}(\mathrm{OR})_{2}$ foi maior.

Os $\mathrm{C} 2$, $\mathrm{C} 3$ e $\mathrm{C} 5$ relacionados aos grupos $\mathrm{CH}-\mathrm{OH}$, apresentaram os sinais de maior intensidade em todo o espectro. E o 66 em 60 ppm, correspondendo ao grupo $\mathrm{CH} 2 \mathrm{OH}$, apresentando o menor deslocamento. Kazimierczak e colaboradores observaram os mesmos picos para a amostra de amido de batata, corroborando assim com o presente trabalho (KAZIMIERCZAK et al., 2007).

\section{PHB}

A Figura 17 (A e B) e a Figura 18 ilustram as características dos espectros de RMN ${ }^{13} \mathrm{C}$ sólido e líquido e RMN ${ }^{13} \mathrm{H}$ líquido, respectivamente, para a amostra PHB. 


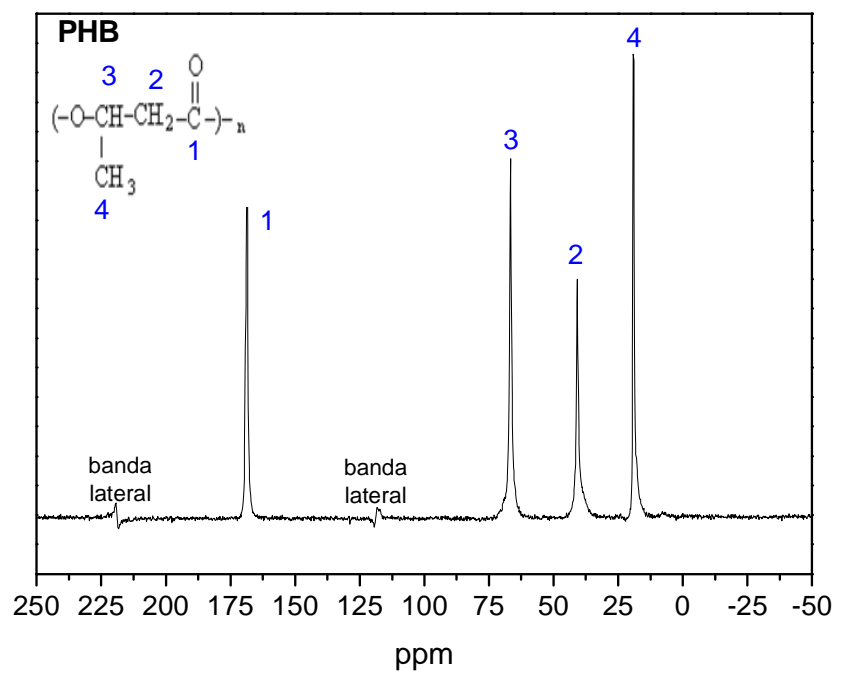

A

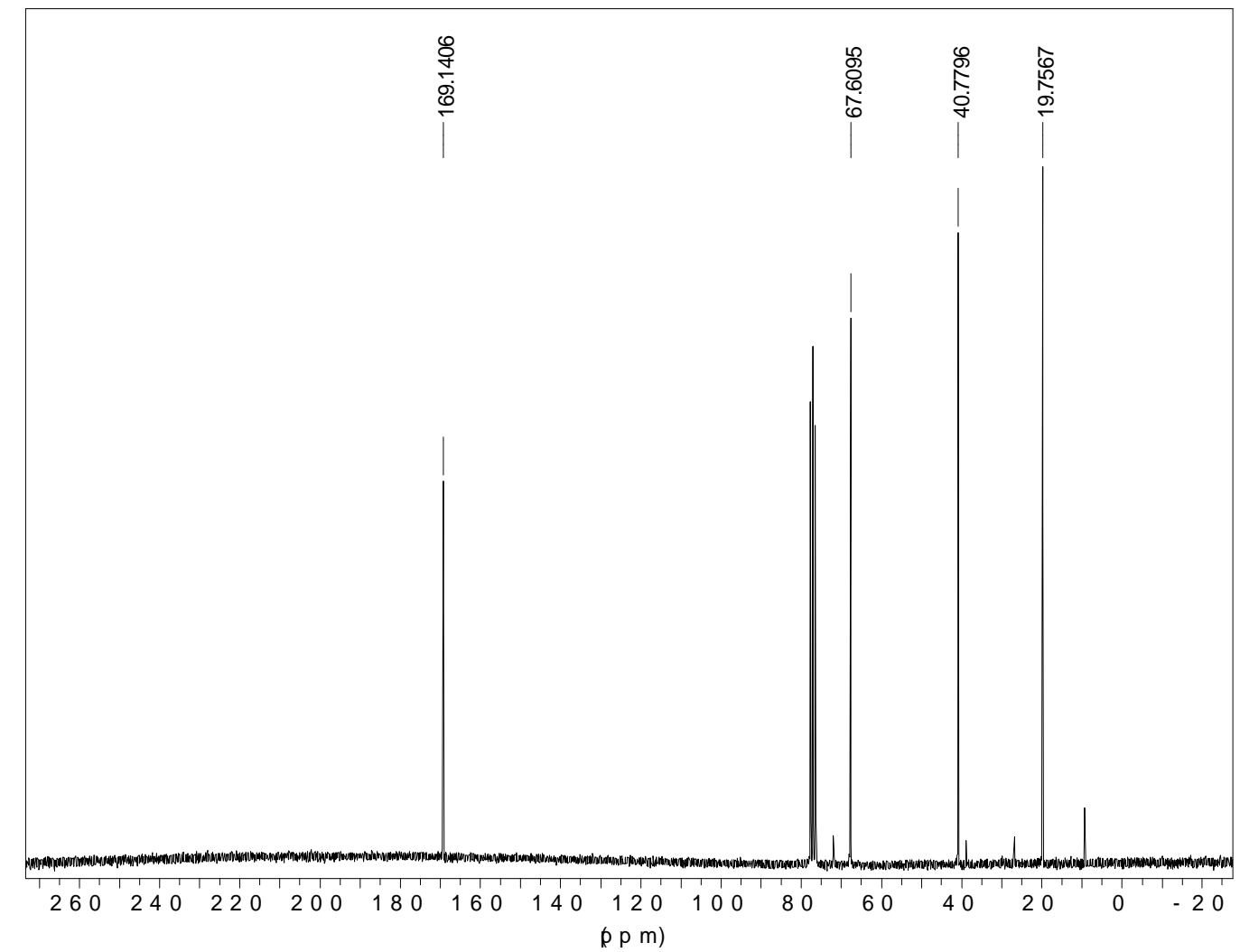

B

Figura 17 - Espectro de RMN 13C sólido e líquido do PHB. 


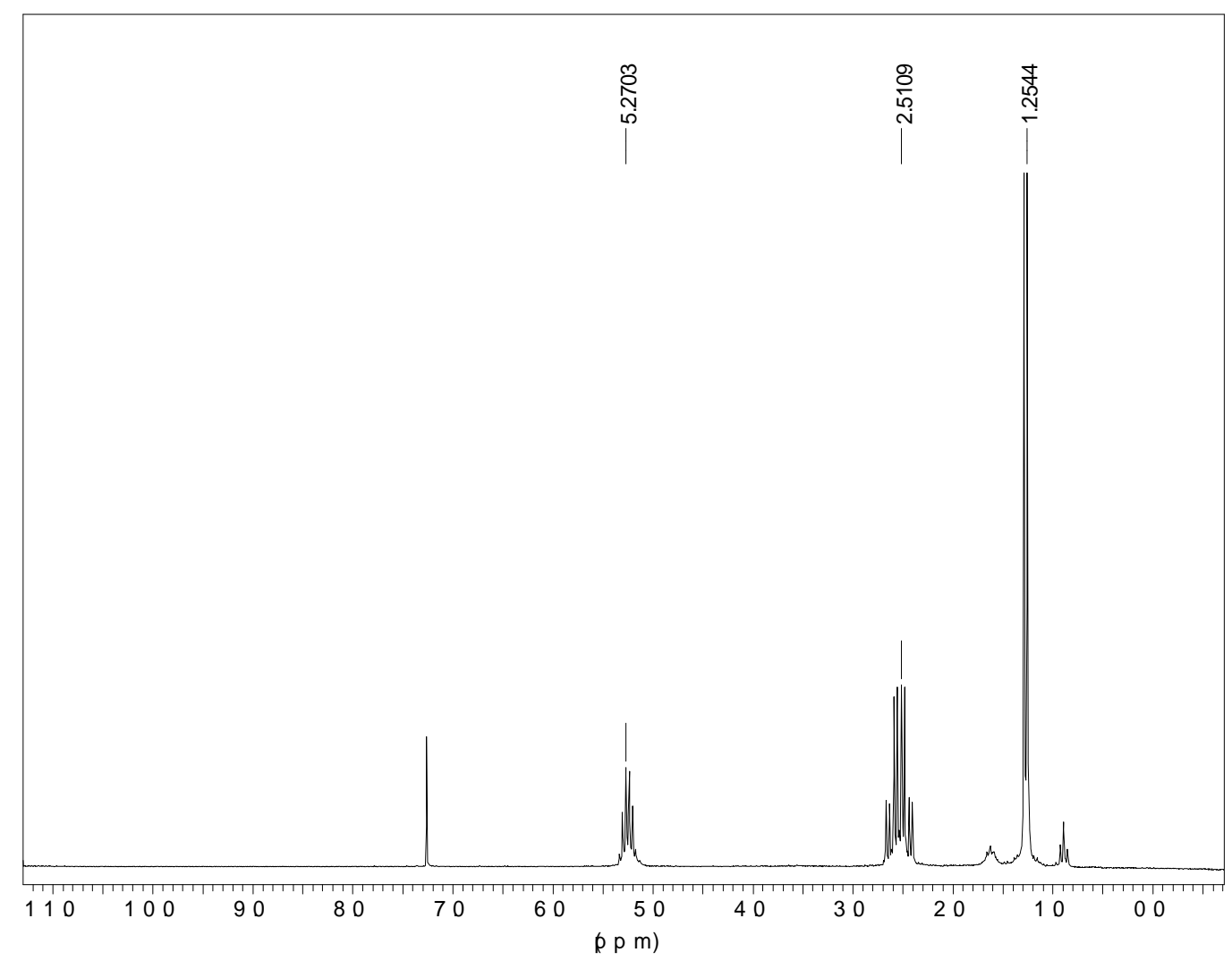

Figura 18 - Espectro de RMN 1H líquido do PHB.

Foram observados nas análises de $\mathrm{RMN}{ }^{13} \mathrm{C}$ sólido e líquido da amostra PHB, Figura 17 ( $A$ e B), espectros com picos praticamente nas mesmas posições. Para o espectro de RMN ${ }^{13} \mathrm{C}$ sólido, picos em 19, 41, 67 e 169 ppm foram relatados para os grupos $\mathrm{CH}_{3}, \mathrm{CH}_{2}, \mathrm{CH}$ e C=O, respectivamente. Em relação ao espectro de $\mathrm{RMN}{ }^{13} \mathrm{C}$ líquido os picos observados para os mesmos grupos foram em aproximadamente 20, 41, 68 e 169 ppm. Sendo que, para este espectro especificamente, o pico em 77,23 ppm foi referente ao solvente clorofórmio. Os dados de Saito e colaboradores (2001) corroboraram com o presente trabalho (SAITO; INOUE; YOSHIE, 2001).

Foi observado na Figura 18, RMN de ${ }^{1} \mathrm{H}$ para a amostra PHB um dupleto em 1,2 ppm que é atribuído ao grupo $\mathrm{CH}_{3}$, um multipleto em 2,5 ppm referente ao grupo $\mathrm{CH}_{2}$ e um multipleto em 5,3 ppm atribuído a ressonância do grupo $\mathrm{CH}$. O sinal em 1,6 ppm é devido a água que foi utilizada na preparação da amostra. E como a 
análise foi feita em solução, o pico em 7,26 foi correspondente ao solvente clorofórmio. Ramachander e colaboradores (2002) observou os mesmos picos para a amostra PHB (RAMACHANDER et al., 2002).

\section{PHBV}

A Figura 19 (A e B) e a Figura 20 ilustram as características dos espectros de RMN ${ }^{13} \mathrm{C}$ sólido e líquido e $\mathrm{RMN}{ }^{13} \mathrm{H}$ líquido, respectivamente, para a amostra PHBV.

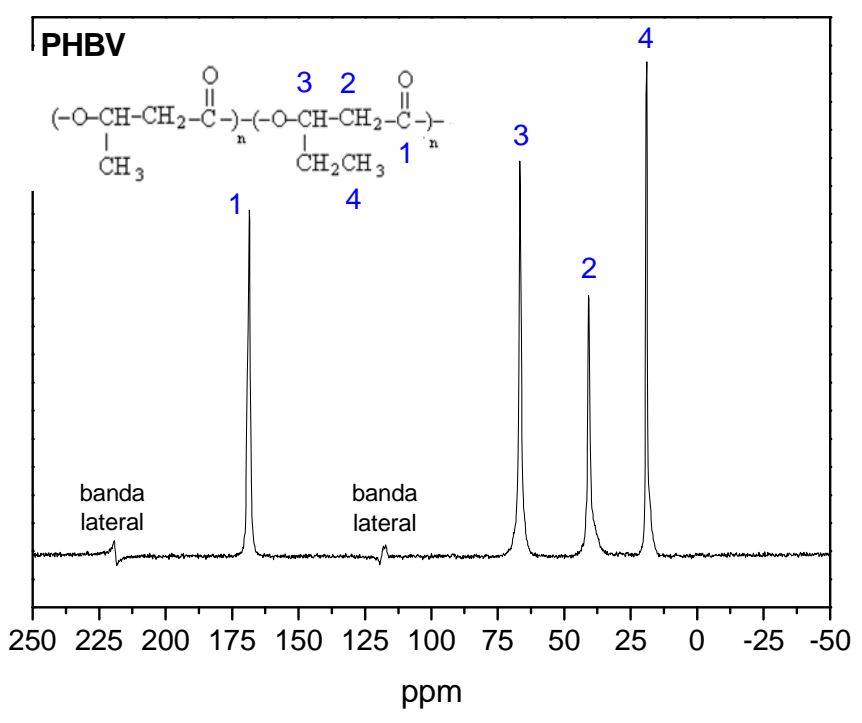

A 


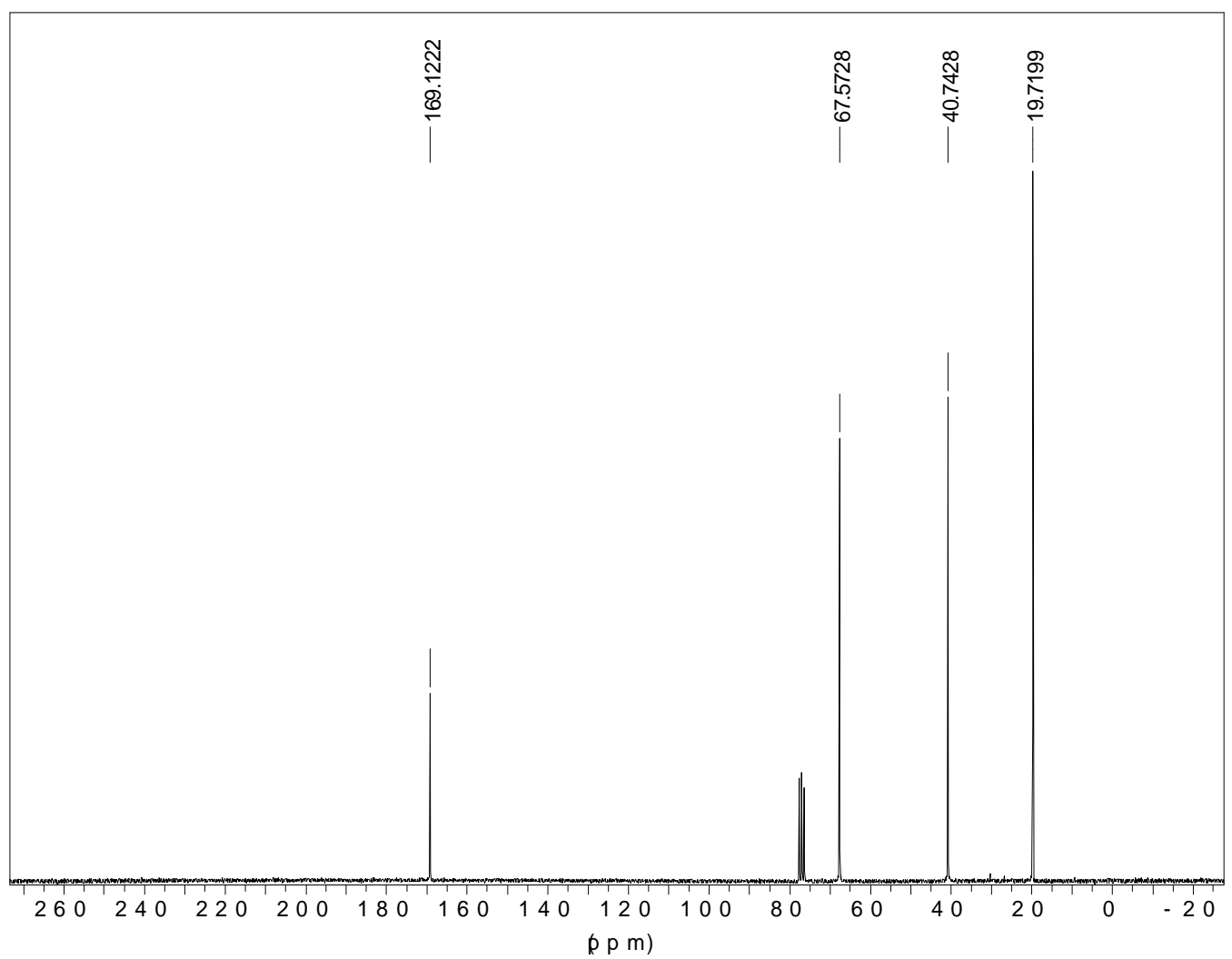

$B$

Figura 19 - Espectro de RMN 13C sólido e líquido do PHBV.

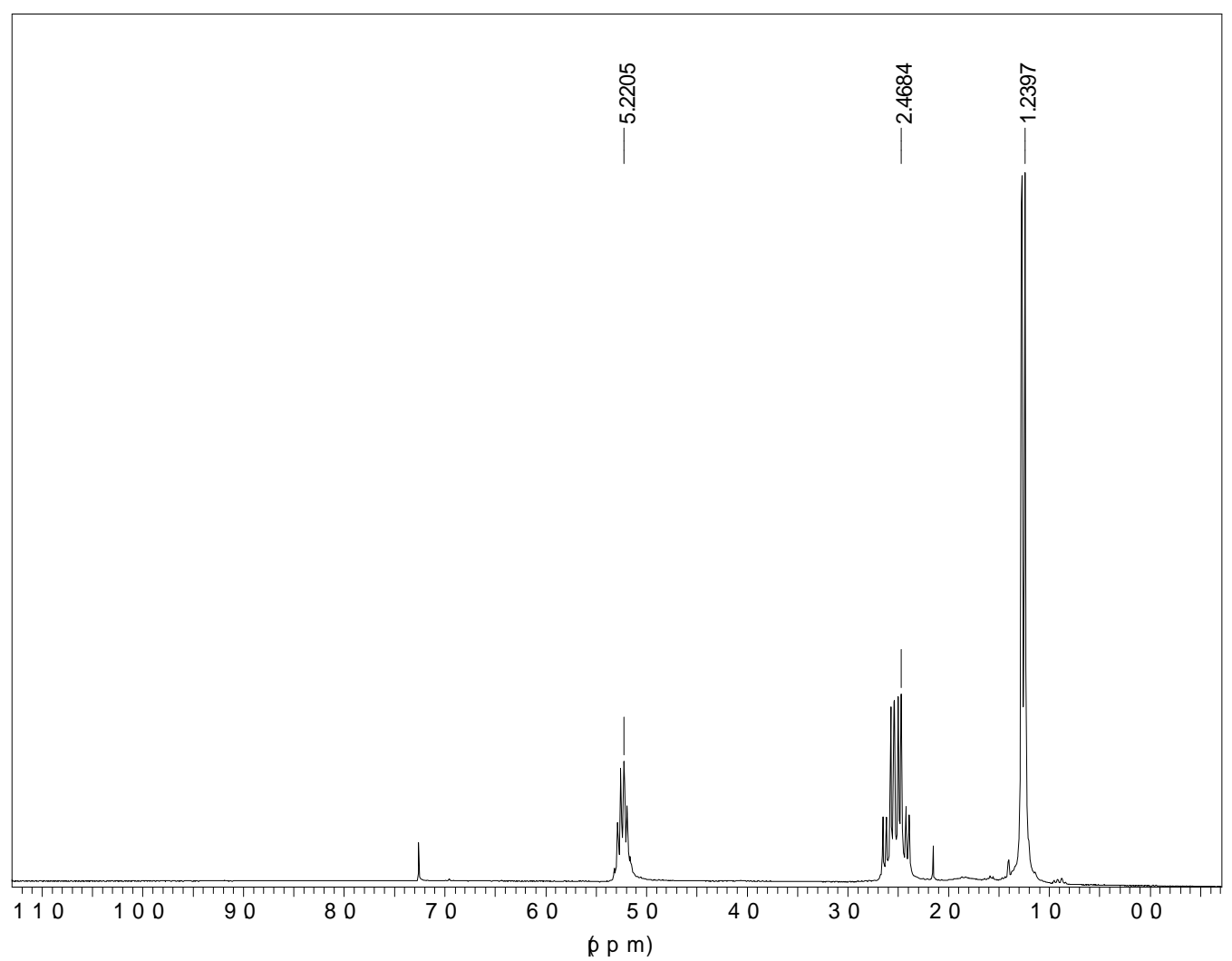

Figura 20 - Espectro de RMN 1H líquido do PHBV. 
Foram observados nas análises de $\mathrm{RMN}{ }^{13} \mathrm{C}$ sólido e líquido da amostra PHBV, Figura 19 (A e B). Para o espectro de RMN ${ }^{13} \mathrm{C}$ sólido, picos em 19, 41, 67 e 168 ppm foram relatados para os grupos $\mathrm{CH}_{3}, \mathrm{CH}_{2}, \mathrm{CH}$ e $\mathrm{C}=\mathrm{O}$, respectivamente. Em relação ao espectro de $\mathrm{RMN}{ }^{13} \mathrm{C}$ líquido os picos observados para os mesmos grupos foram em aproximadamente 20, 41, 68 e 169 ppm. Sendo que, para este espectro especificamente, o pico em 77,23 ppm foi referente ao solvente clorofórmio.

Os mesmos picos observados para o polímero PHB foram observados para o PHBV, concluindo que a quantidade de HV nesta amostra é baixa. Assim não foi possível visualizar as diferenças entre os dois componentes, principalmente com a molécula $\mathrm{CH}_{2}$ do grupo etil presente no PHBV.

Na Figura 20, RMN de ${ }^{1} \mathrm{H}$ para a amostra PHBV foram observados os mesmos picos quando comparado com a amostra PHB, ou seja, um dupleto em 1,2 ppm que é atribuído ao grupo metil, um multipleto em 2,5 ppm referente ao grupo metileno $\left(\mathrm{CH}_{2}\right)$ e um multipleto em 5,2 ppm atribuído ao grupo metino $(\mathrm{CH})$. O sinal em 2,1 ppm é devido a água que doi utilizada na preparação da amostra.

\subsection{Cromatografia de Exclusão por Tamanho de Alta Eficiência - (HPSEC)}

Utilizando-se a técnica de Cromatografia por Exclusão de Tamanho de Alta Eficiência (HPSEC) foram obtidos os cromatogramas com o perfil da distribuição da massa molar, referentes à amilose e amilopectina do amido de batata e do amido plasticizado (TPS). A técnica foi utilzada no presente trabalho apenas para a caracterização dos materiais (amido e TPS). 
A Figura 21 ilustra o cromatograma das amostras de amido e TPS, sendo possível uma comparação do amido como material de partida com o amido depois do processamento.

A partir da curva de distribuição das massas molares obteve-se os valores da massa molecular média numérica $(\mathrm{Mn})$, massa molecular média ponderal $(\mathrm{Mw})$ e da polidispersividade (Mn/Mw). Estes valores estão apresentados na Tabela 9.

No entanto, para calcular os valores de Mn e Mw a partir de uma curva de distribuição de massas molares, é necessário a curva de calibração com padrões de massas molecular definida e estrutura similar a estrutura da amostra. A curva de calibração está ilustrada também na Figura 21.

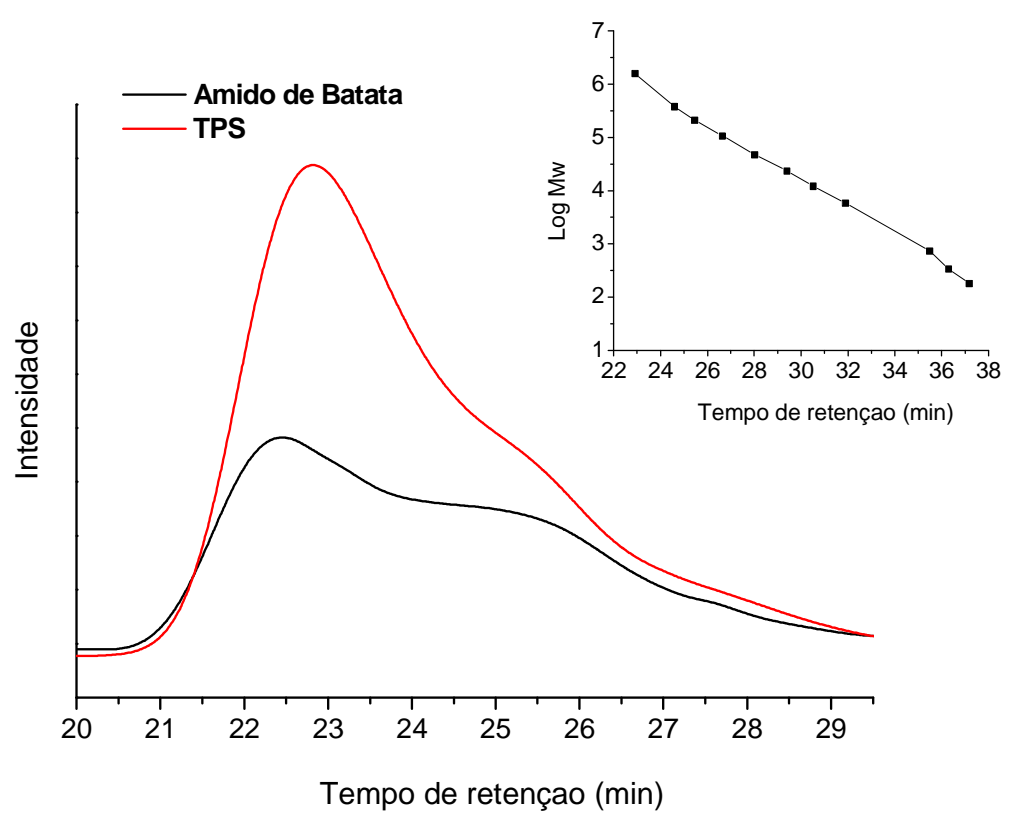

Figura 21 - Cromatograma do amido de batata e da amostra TPS. 
Tabela 9 - Valores de Mn, Mw e Mw/Mn para as amostras de amido de batata e TPS.

\begin{tabular}{ccccc}
\hline Material & $\begin{array}{c}\text { Intervalo de Eluição } \\
(\mathbf{m i n})\end{array}$ & $\begin{array}{c}\text { Massa Molar Média } \\
\left(\mathbf{g} \cdot \mathbf{m o l}^{-1}\right)\end{array}$ & Polidispersividade \\
\hline \multirow{2}{*}{ Amido de } & $17-29,5$ & $\mathbf{M n}$ & $\mathbf{M w}$ & $\mathbf{M n} / \mathbf{M w}$ \\
Batata & $17-24$ & $1,62 \times 10^{6}$ & $2,58 \times 10^{6}$ & 6,23 \\
& $24-29,5$ & 121.638 & 237.995 & 1,60 \\
TPS & $17-29,5$ & 285.205 & $1,38 \times 10^{6}$ & 4,85 \\
& $17-24$ & $1,47 \times 10^{6}$ & $2,17 \times 10^{6}$ & 1,47 \\
& $24-29,5$ & 132.579 & 262.296 & 1,98 \\
\hline
\end{tabular}

Devido a dificuldade de solubilização das amostras de amido, os dados apresentados no presente trabalho são representativos apenas das frações dissolvidas.

Foi obervado na Figura 21 que a amilopectina, componente de maior massa molar, apresentou o menor tempo de eluição, enquanto que a amilose, de menor massa molar, eluiu em tempos maiores.

A amilose e a amilopectina presentes no amido levaram a ocorrência de um padrão cromatográfico bimodal. Esse perfil de eluição das amostras de amido é coerente com o esperado para as misturas dos dois componentes (amilose e amilopectina) (CARVALHO et al., 2003a).

No cromatograma da amostra TPS não apareceu uma distinção nítida entre os dois componentes, amilose e amilopectina, apresentando um único pico principal na região atribuída a amilopectina com um ombro na região atribuída a amilose. Os pesos molares foram analisados para verificar possíveis ocorrências de degradação das cadeias do amido, devido ao processamento por cizalhamento.

Segundo Carvalho e colaboradores (2003), o processo de desestruturação com quebra das cadeias maiores pode provocar uma homogeneidade, resultando 
em uma mistura com massas molares de amilose e amilopectina mais similares. Essa homogeneidade pode ser observada na amostra TPS, devido o comportamento da curva, o qual apresenta dois picos, sendo o segundo menos definido e também pelo menor valor da polidispersividade quando comparada com a amostra de amido como material de partida (CARVALHO et al., 2003a).

\subsection{Absorção de Água}

A capacidade de absorção de água da amostra TPS, das blendas TPS/PHB, TPS/PHBV e TPS/PHB/PHBV e das misturas de PHB e/ou PHBV foi determinada com o intuito de verificar a quantidade total de água abvorvida, a cinética de absorção e a estabilidade das amostras frente a umidades relativas controladas de 22,$5 ; 43 ; 53 ; 75$ e $84 \%$.

\section{TPS}

A Figura 22 apresenta os resultados dos ensaios de absorção de água em função do tempo para as amostras TPS, condicionadas a diferentes umidades relativas. 


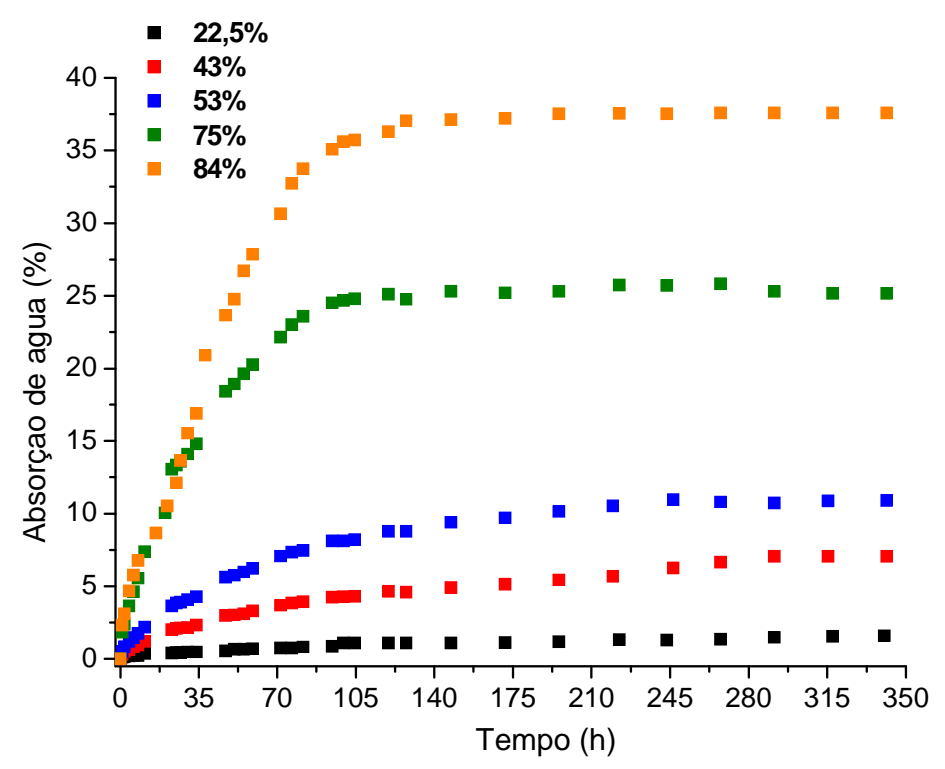

Figura 22 - Curvas de absorção de água (\%) em função do tempo (h) para as amostras TPS condicionadas em umidades controladas em $22,5,43,53,75$ e $84 \%$.

As amostras TPS foram condicionadas em ambientes de umidade relativa controlada de 22,5, 43, 53, 75 e $84 \%$ por aproximadamente 340 h até o equilíbrio de absorção máximo, sendo que as amostras começaram a estabilizar após $94 \mathrm{~h}$ de condicionamento.

A permeabilidade de amostras pelo vapor d'água pode ser afetada por uma série de fatores tais como temperatura do ensaio, espessura do corpo de prova e conteúdo de plasticizante (PUSHPADASSA; MARX; HANNA, 2008). Para minimizar estas variáveis as amostras TPS foram condicionadas em temperaturas de $23 \pm 1$ ${ }^{\circ} \mathrm{C}$, com corpos de provas de $2 \mathrm{~mm}$ de espessura e co $\mathrm{m} 30 \%$ de plasticizante.

Na Tabela 10 estão apresentados os valores de absorção máxima de água no equilíbrio. 
Tabela 10 - Valores de absorção máxima de água para as amostras TPS em diferentes umidades relativas.

\begin{tabular}{cc}
\hline $\begin{array}{c}\text { Umidade } \\
(\%)\end{array}$ & $\begin{array}{c}\text { Absorção máxima } \\
(\%)\end{array}$ \\
\hline $\mathbf{2 2 , 5}$ & 1,6 \\
$\mathbf{4 3}$ & 8,1 \\
$\mathbf{5 3}$ & 10,9 \\
$\mathbf{7 5}$ & 25,6 \\
$\mathbf{8 4}$ & 36,9 \\
\hline
\end{tabular}

Todas as amostras TPS (Figura 22 e Tabela 10) apresentaram ganhos de massa em função do tempo. Em tempos menores de condicionamento (até 105 h), a absorção de água pelos corpos de prova ocorreu mais rapidamente, enquanto que em tempos maiores (acima de 105 h) com a proximidade do equilíbrio da absorção, a cinética de absorção tornou-se mais lenta. Van Soest e colaboradores (1997) observaram as mesmas características em relação a cinética de absorção do material (VAN SOEST; ESSER, 1997; CARVALHO, 2002).

Foi possível realizar as medidas de absorção de umidade em todos os ambientes condicionados, mas acima de $53 \%$ verificou-se a formação de gotículas de líquido sobre a superfície dos corpos de prova (exudação). Em função desse problema as caracterizações e as determinações dos coeficientes de difusão de água nas amostras foram realizadas em ambiente com umidade relativa de $53 \%$.

A absorção de água está diretamente relacionada também ao meio condicionado aos quais as amostras foram submetidas, assim foi observado que 0 aumento máximo de água nas amostras TPS foi mais significativo nos ambientes de umidades relativas altas (75 e $84 \%$ ). Os grupos hidroxilas do amido e dos 
plasticizantes utilizados participam do processo de absorção pela formação de ligações de hidrogênio com a água.

Segundo Teixeira (2007) e Carvalho (2002) as amostras TPS quando condicionadas em diferentes ambientes de umidades relativas apresentam aspectos diferenciados em relação às propriedades mecânicas, as temperaturas de transição vítrea, dentre outras (TEIXEIRA, 2007; CARVALHO, 2002).

\section{Blendas TPS/PHB, TPS/PHBV e TPS/PHB/PHBV}

As Figuras 23, 24 e 25 e a Tabela 11 apresentam os resultados dos ensaios de absorção de água (\%) em função da quantidade de PHB, PHBV e PHB/PHBV (\%), respectivamente para a amostra TPS, blendas TPS/PHB, TPS/PHBV, TPS/PHB/PHBV e amostras de PHB e/ou PHBV em umidades relativas controladas de $22,5,43,53,75$ e $84 \%$.

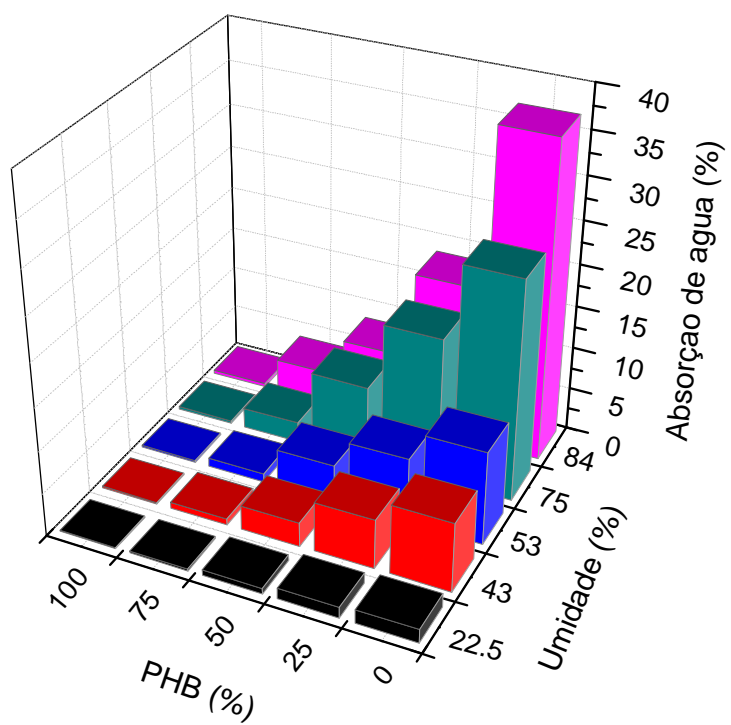

Figura 23 - Absorção de água (\%) em função da quantidade de PHB (\%) para a amostra TPS, blendas TPS/PHB e amostras de PHB, condicionadas em diferentes umidades relativas. 


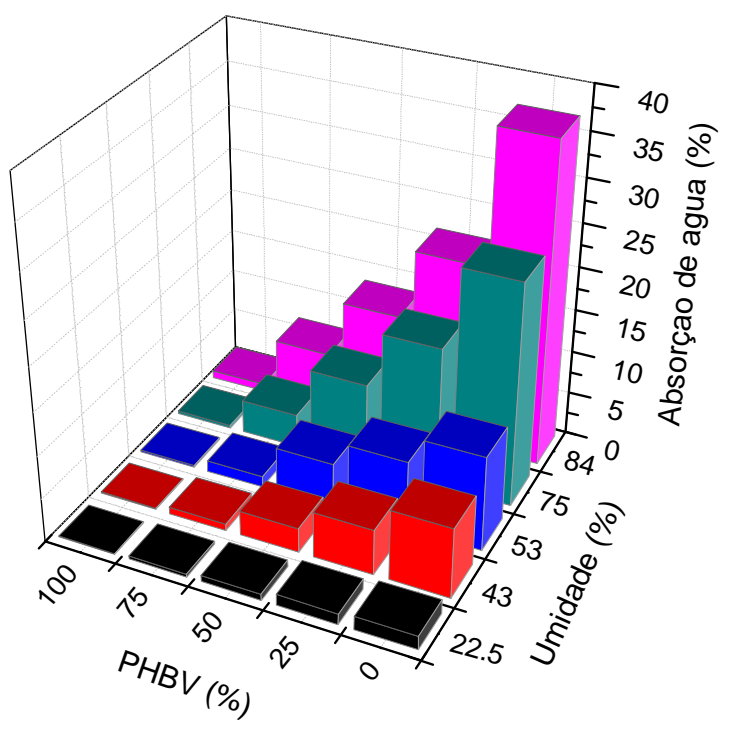

Figura 24 - Absorção de água (\%) em função da quantidade de PHBV (\%) para a amostra TPS, blendas TPS/PHBV e amostras de PHBV, condicionadas em diferentes umidades relativas.

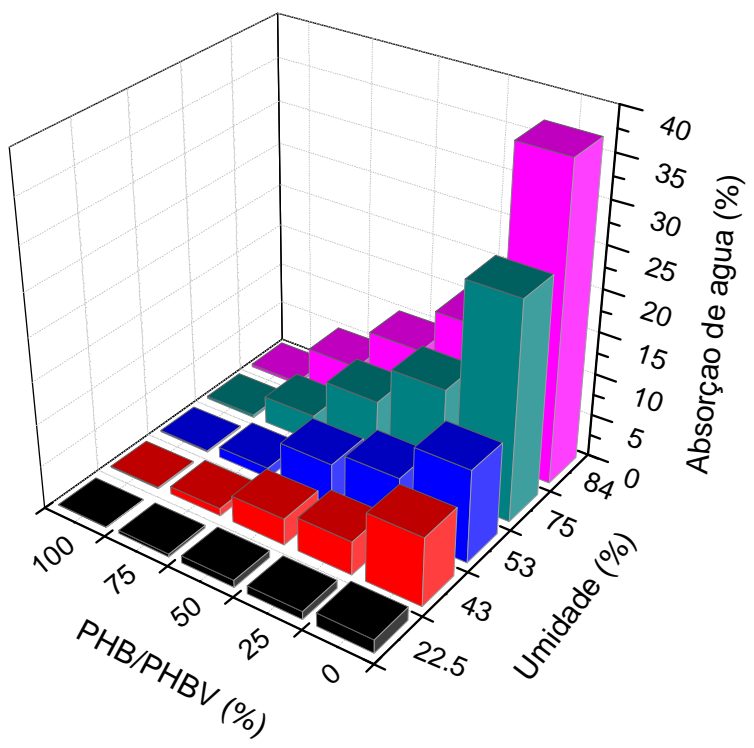

Figura 25 - Absorção de água (\%) em função da quantidade de PHB/PHBV (\%) para a amostra TPS, blendas TPS/PHB/PHBV e amostras de PHB e PHBV, condicionadas em diferentes umidades relativas. 
Tabela 11 - Absorção máxima de água (\%) em ambientes de 22,5, 43, 53, 75 e $84 \%$ de umidades relativas para a amostra TPS, blendas TPS/PHB, TPS/PHBV e TPS/PHB/PHBV e amostras de PHB e/ou PHBV.

\begin{tabular}{|c|c|c|c|c|c|}
\hline \multicolumn{6}{|c|}{$\begin{array}{c}\text { Absorção máxima de água (\%) em diferentes } \\
\text { umidades }\end{array}$} \\
\hline$\%$ PHB & 22,5 & 43 & 53 & 75 & 84 \\
\hline 0 & 1,6 & 8,1 & 10,9 & 25,6 & 36,9 \\
\hline 25 & 1,3 & 5,8 & 7,6 & 16,8 & 18,5 \\
\hline 50 & 0,7 & 2,8 & 4,4 & 8,9 & 8,4 \\
\hline 75 & 0,2 & 0,7 & 1,0 & 2,4 & 3,9 \\
\hline 70/G30 & 0,3 & 0,8 & 1,0 & 2,8 & 3,6 \\
\hline 100 & 0,1 & 0,2 & 0,2 & 0,3 & 0,4 \\
\hline \multicolumn{6}{|l|}{$\%$ PHBV } \\
\hline 25 & 1,3 & 5,3 & 7,9 & 16,2 & 21,6 \\
\hline 50 & 0,8 & 2,8 & 5,2 & 9,8 & 13,5 \\
\hline 75 & 0,4 & 0,8 & 1,3 & 3,9 & 6,8 \\
\hline 70/G30 & 0,53 & 1,19 & 2,04 & 2,97 & 5,51 \\
\hline 100 & 0,1 & 0,1 & 0,2 & 0,3 & 0,9 \\
\hline \multicolumn{6}{|c|}{ \% PHB/PHBV } \\
\hline 25 & 1,0 & 4,0 & 6,6 & 12,5 & 15,5 \\
\hline 50 & 0,8 & 3,2 & 4,9 & 8,1 & 10,2 \\
\hline 75 & 0,3 & 0,9 & 1,2 & 3,2 & 5,2 \\
\hline 70/G30 & 0,3 & 1,4 & 1,7 & 3,8 & 3,7 \\
\hline 100 & 0,1 & 0,1 & 0,2 & 0,3 & 0,4 \\
\hline
\end{tabular}

Um aumento significativo na absorção de água para a amostra TPS foi observado em todas as umidades relativas controladas, devido o caráter hidrofílico deste material e as interações de hidrogênio com a água.

Essa característica também foi relatada para as blendas TPS/PHB, TPS/PHBV e TPS/PHB/PHBV (Figuras 23, 24 e 25 e Tabela 11), visto que com a adição de PHB e/ou PHBV foi observada uma redução na absorção de água, 
proporcionalmente à quantidade de PHAs adicionados. E comparando as blendas TPS/PHB e TPS/PHBV observou-se que a adição de PHBV levou a uma redução de absorção de água ligeiramente menor que a adição de PHB.

Por outro lado, as amostras PHB e/ou PHBV (Figuras 23, 24 e 25), que não contém TPS e nem glicerol, apresentaram um grau de absorção de água bastante limitado em qualquer ambiente de umidade relativa controlada, já que o PHB e PHBV são menos hidrofílicos. Estas observações também foram relatadas por Lai e colaboradores (2005) (LAl; DON; HUANG, 2006).

Como todas as análises para as caracterizações dos materiais foram realizadas em umidade relativa controlada em $53 \%$, foram ilustrados a seguir os resultados da absorção de água e coeficiente de difusão de todas as amostras.

As Figuras 26, 27 e 28 apresentam as curvas de absorção de água (\%) em função do tempo (h) para a amostra TPS, blendas TPS/PHB, TPS/PHBV e TPS/PHB/PHBV e misturas com PHB e/ou PHBV, em ambiente com $53 \%$ de umidade relativa.

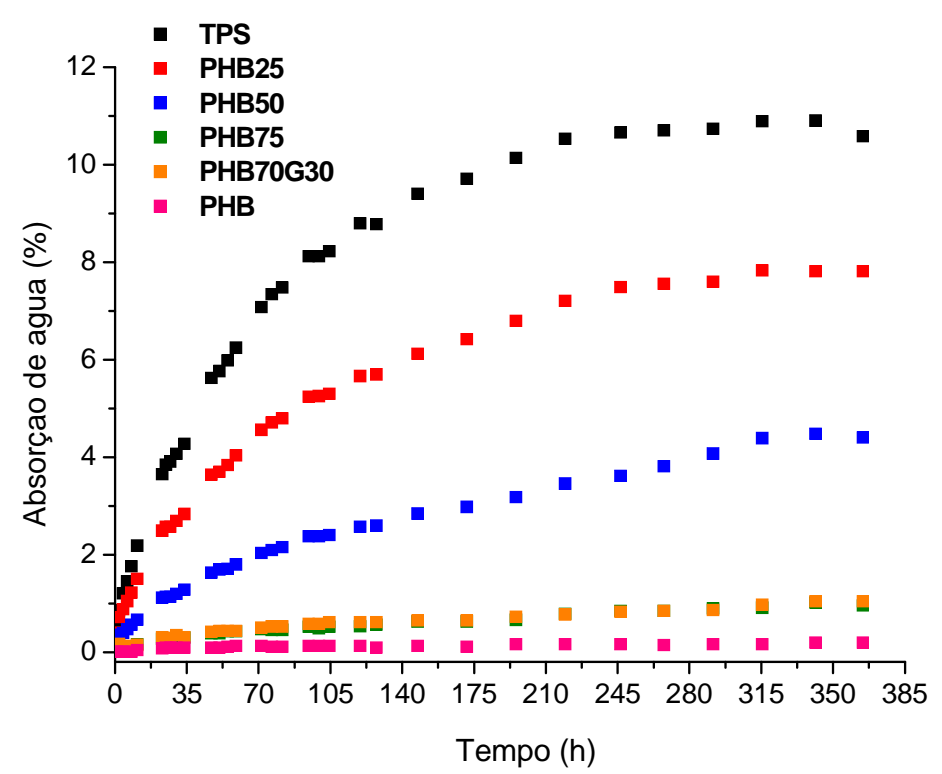

Figura 26 - Curvas de absorção de água (\%) em função do tempo (h) para a amostra TPS, blendas TPS/PHB e amostras com PHB, condicionadas em $53 \%$ de umidade. 


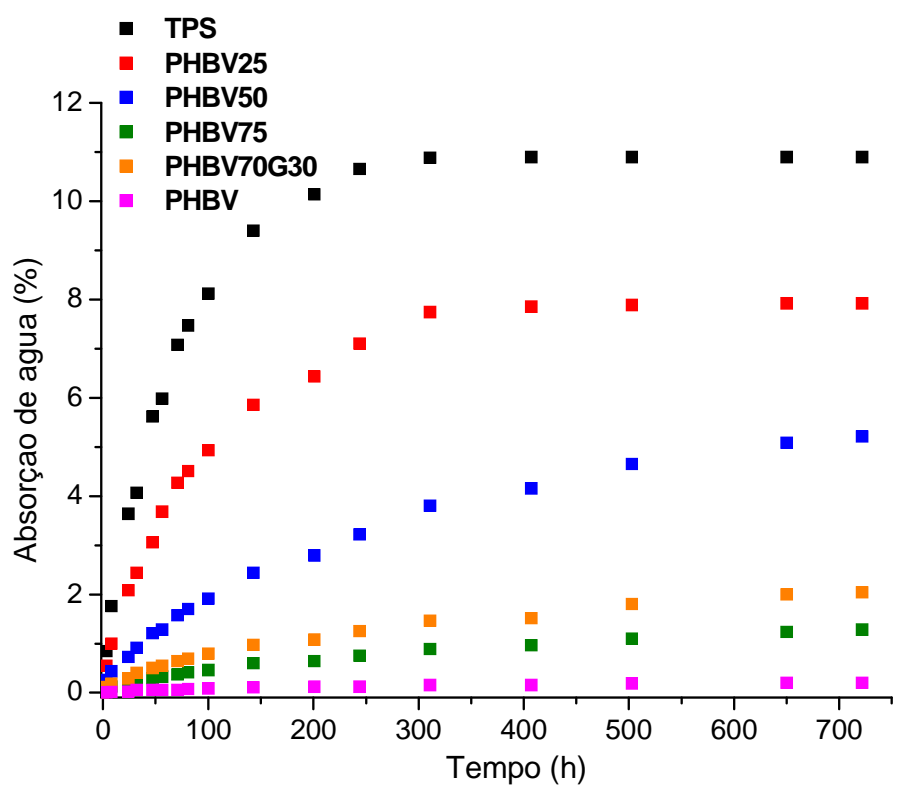

Figura 27 - Curvas de absorção de água (\%) em função do tempo (h) para a amostra TPS, blendas TPS/PHBV e amostras com PHBV, condicionadas em $53 \%$ de umidade.

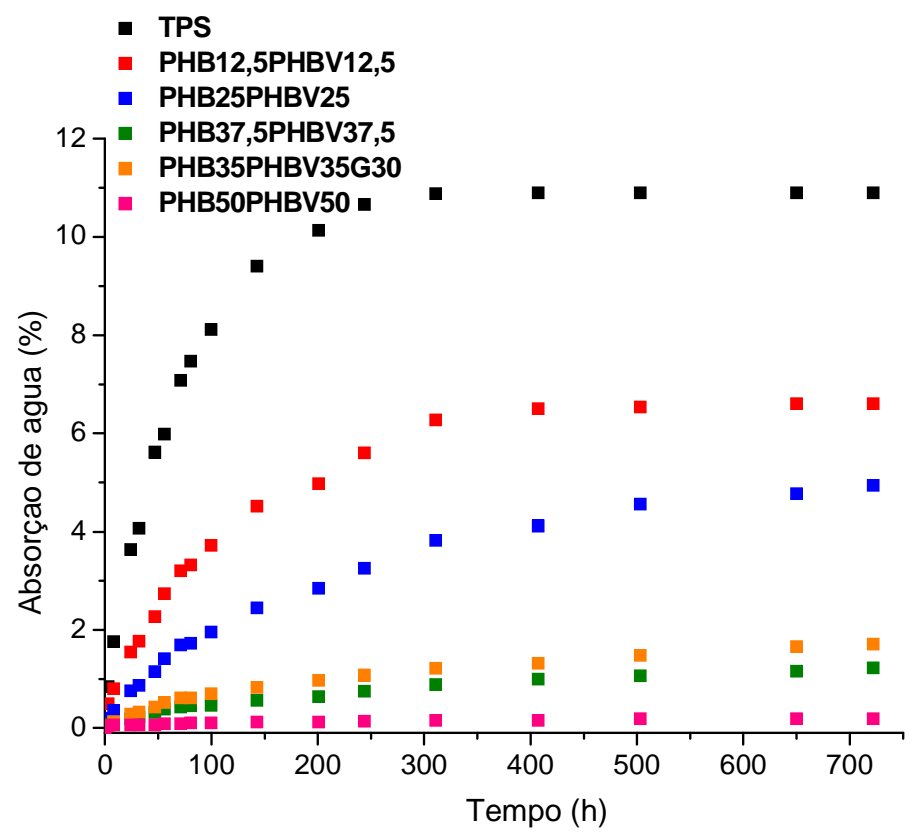

Figura 28 - Curvas de absorção de água (\%) em função do tempo (h) para a amostra TPS, blendas TPS/PHB/PHBV e amostras com PHB/PHBV, condicionadas em $53 \%$ de umidade.

Na Tabela 12 estão representados os valores de absorção máxima de água para as amostras ilustradas nas Figuras 26,27 e 28, em aproximadamente $364 \mathrm{~h}$ de condicionamento para as amostras com PHB e $722 \mathrm{~h}$ para as amostras com PHBV e 
com PHB/PHBV, sendo que as amostras começaram a estabilizar após $315 \mathrm{~h}$ de condicionamento.

Tabela 12 - Valores de absorção máxima de água para a amostra TPS, blendas TPS/PHB, TPS/PHBV e TPS/PHB/PHBV e as amostras de PHB e/ou PHBV.

\begin{tabular}{cccccc}
\hline Amostra & $\begin{array}{c}\text { Absorção } \\
(\%)\end{array}$ & Amostra & $\begin{array}{c}\text { Absorção } \\
(\%)\end{array}$ & Amostra & $\begin{array}{c}\text { Absorção } \\
(\%)\end{array}$ \\
\hline TPS & 10,89 & TPS & 10,89 & TPS & 10,89 \\
PHB25 & 7,64 & PHBV25 & 7,91 & PHB12,5PHBV12,5 & 6,6 \\
PHB50 & 4,40 & PHBV50 & 5,21 & PHB25PHBV25 & 4,94 \\
PHB75 & 1,01 & PHBV75 & 1,28 & PHB37,5PHBV37,5 & 1,22 \\
PHB70G30 & 1,02 & PHBV70G30 & 2,04 & PHB35PHBV35G30 & 1,71 \\
PHB & 0,19 & PHBV & 0,20 & PHB50PHBV50 & 0,18 \\
\hline
\end{tabular}

De acordo com as Figuras 26, 27 e 28 e Tabela 12, observou-se que o maior valor de absorção de umidade foi para a amostra TPS. Como a hidrofilicidade nas amostras foi dependente do teor de amido e glicerol, e a diminuição desta característica dependente dos teores de PHB e/ou PHBV, as amostras PHB25 e PHB50, PHBV25 e PHBV50, PHB12,5PHBV12,5 e PHB25PHBV25 com menores quantidades dos polímeros PHB e/ou PHBV obtiveram comportamentos mais hidrofílicos se comparadas com as amostras PHB e/ou PHBV.

A alta absorção de água ou alta hidrofilicidade pela amostra TPS e a baixa absorção de água pelas amostras PHB e/ou PHBV, podem ser explicadas pela presença de grupos hidrofílicos $(\mathrm{OH})$ presentes nas estruturas químicas do glicerol e do amido, os quais interagem com as moléculas de água e entre si por ligações de hidrogênio.

Ao se comparar as Figuras 26, 27 e 28 e a Tabela 12 observou-se uma diferença bastante significativa nos resultados das amostras PHB70G30, 
PHBV70G30 e PHB35PHBV35G30 com as amostras PHB e/ou PHBV. Esse resultado pode ser justificado pela presença do plasticizante (glicerol), como explicado anteriormente.

Os dados de TG corroboram com os de absorção de água e serão explicados no item 4.6.

\section{Teoria de Fick e Coeficiente de Difusão}

O parâmetro $\mathrm{n}$ (Coeficiente de Fick) fornece informações a respeito do mecanismo envolvido no processo de difusão, e o parâmetro k (Coeficiente de Afinidade) fornece informações sobre a afinidade do material com as moléculas de água. Estes parâmetros estão representados pela Equação 2 (página 49).

O coeficiente de difusão (D) corresponde à capacidade da água se difundir pelo material (COMYN, 1985; ESPERT; VILAPLANA; KARLSSON 2004). Os principais fatores que interferem no processo de difusão da água em um material são a presença de grupos químicos capazes de formar ligações de hidrogênio com a molécula de água, a polaridade de grupos moleculares, temperatura de transição vítrea e cristalinidade.

A Tabela 13 ilustra os valores de $n, K$ e $D$ para a amostra TPS, blendas TPS/PHB, TPS/PHBV, TPS/PHB/PHBV e amostras de PHB e/ou PHBV. 
Tabela 13 - Parâmetros n, k e D (cm2.s-1) para a amostra TPS, blendas TPS/PHB, TPS/PHBV, TPS/PHB/PHBV e amostras de PHB e/ou PHBV.

\begin{tabular}{cccc}
\hline Amostra & $\mathbf{n}$ & $\mathbf{k}$ & $\begin{array}{c}\mathbf{D} \\
\left(\mathbf{1 0 ^ { - 8 }} \mathbf{c m}^{\mathbf{2}} \cdot \mathbf{s}^{-1}\right)\end{array}$ \\
\hline TPS & 0,6 & 0,05 & 3,7 \\
PHB25 & 0,5 & 0,05 & 1,9 \\
PHB50 & 0,5 & 0,04 & 1,5 \\
PHB75 & 0,5 & 0,04 & 1,5 \\
PHB70G30 & 0,6 & 0,04 & 1,5 \\
PHB & - & - & - \\
PHBV25 & & & 2,1 \\
PHBV50 & 0,6 & 0,03 & 0,7 \\
PHBV75 & 0,6 & 0,03 & 0,6 \\
PHBV70G30 & 0,6 & 0,03 & 0,6 \\
PHBV & 0,6 & 0,03 & - \\
& - & - &
\end{tabular}

\begin{tabular}{cccc} 
PHB12,5PHBV12,5 & 0,6 & 0,04 & 1,4 \\
\hline PHB25PHBV25 & 0,6 & 0,02 & 1,1 \\
PHB37,5PHBV37,5 & 0,6 & 0,03 & 0,7 \\
PHB35PHBV35G30 & 0,6 & 0,02 & 0,7 \\
PHB50PHBV50 & - & - & - \\
\hline
\end{tabular}

Como os valores de absorção de água das amostras PHB e/ou PHBV (Figuras 26, 27 e 28 e Tabela 12) foram muito pequenos, erros característicos na determinação dos coeficientes angulares e lineares através dos gráficos para os cálculos de $D$ foram obtidos. Dessa maneira, não sendo corretos os valores de $D$ e, conseqüentemente os valores de $\mathrm{n}$ e $\mathrm{k}$, estes não foram apresentados no presente trabalho. 
A difusão Fickiana ou difusão tipo Caso I é caracterizada pelo valor de $\mathrm{n}$ em aproximadamente 0,5 e pela linearidade nos gráficos de $\left(M_{t} / M_{\infty}\right)$ em função de $t^{1 / 2} / L$ no estágio inicial (CRANK, 1975, COMYN, 1985; ESPERT; VILAPLANA; KARLSSON, 2004). A difusão Fickiana é caracterizada também por apresentar uma velocidade de difusão do solvente muito menor que a velocidade de relaxação das cadeias poliméricas.

De acordo com a Tabela 13 e os gráficos de $\left(M_{t} / M_{\infty}\right)$ em função de $t^{1 / 2} / L$, 0 valor de n aproximou-se de 0,5 e uma linearidade no estágio inicial dos gráficos foram observadas para todas as amostras, concluindo que o comportamento destas aproximaram da Teoria de Fick.

Os valores de $\mathrm{K}$ representam a afinidade dos materiais analisados com a água. Foi observado (Tabela 13) que a afinidade por água para todas as amostras estudadas não obtiveram variações significativas, mas mesmo obtendo poucas variações o valor de $\mathrm{K}$ foi maior para a amostra TPS. Este resultado demonstra que, embora a quantidade dos polímeros PHB e/ou PHBV nas misturas provoquem uma redução na massa de água absorvida pelas amostras, a afinidade destes materiais pela água praticamente não foram alteradas.

Os valores de coeficiente de difusão (D) diminuíram consideravelmente com a presença dos polímeros PHB e/ou PHBV nas blendas PHB25, PHBV25 e PHB12,5PHBV12,5 (Tabela 13), sendo que o maior valor de D foi observado para a amostra TPS. Mesmo aumentando a quantidade de PHB e/ou PHBV nas misturas PHB50, PHB75 e PHB70G30; PHBV50, PHBV75 e PHBV70G30; PHB25PHBV25, PHB37,5PHBV37,5 e PHB35PHBV35G30, os coeficientes de difusão permaneceram praticamente sem variações significativas entre estas amostras. Este resultado pode ser visto como uma indicação que o aumento na concentração dos polímeros em até 
50 \% foi considerável na influência dos coeficientes de difusão, mas acima de 50 \% o valor de D não se altera significativamente.

O maior valor de D para a amostra TPS pode ser explicado pela presença apenas de plasticizantes e amido em relação às amostras com $\mathrm{PHB}, \mathrm{PHBV}$ e PHB e/ou PHBV. Os plasticizantes proporcionam uma diminuição na temperatura de transição vítrea das amostras, aumentando a mobilidade das cadeias e conseqüentemente o volume livre da parte amorfa. Esse efeito provavelmente facilita a migração de moléculas de água dentro do material, aumentando o coeficiente de difusão (PUSHPADASSA; MARX; HANNA, 2008; DA RÓZ, 2004).

Dentre os fatores que podem ter influenciado na diferença de $D$ entre as amostras TPS e blendas PHB25, PHBV25 e PHB12,5PHBV12,5, destaca-se o caráter altamente cristalino dos polímeros PHB e PHBV. A difusão em materiais cristalinos é muito menor que em materiais amorfos, assim o polímero atua como uma barreira para a difusão da água.

\subsection{Termogravimetria - (TG)}

A Termogravimetria (TG) foi empregada para avaliar a estabilidade térmica dos materiais de partida (Amido de Batata, PHB e PHBV), das amostras TPS, PHB e PHBV, das blendas TPS/PHB, TPS/PHBV e TPS/PHB/PHBV e das amostras de PHB e/ou PHBV, observando as perdas de massa desses materiais. 


\section{Materiais de Partida - Amido de Batata, PHB, PHBV e Glicerol}

A Figura 29 ilustra as características das curvas de decomposição térmica (TG) e das derivadas das curvas (DTG) para o amido de batata, PHB, PHBV e glicerol. A Tabela 14 apresenta os eventos de decomposição térmica dos materiais de partida com os respectivos intervalos de temperatura e perda de massa (\%).

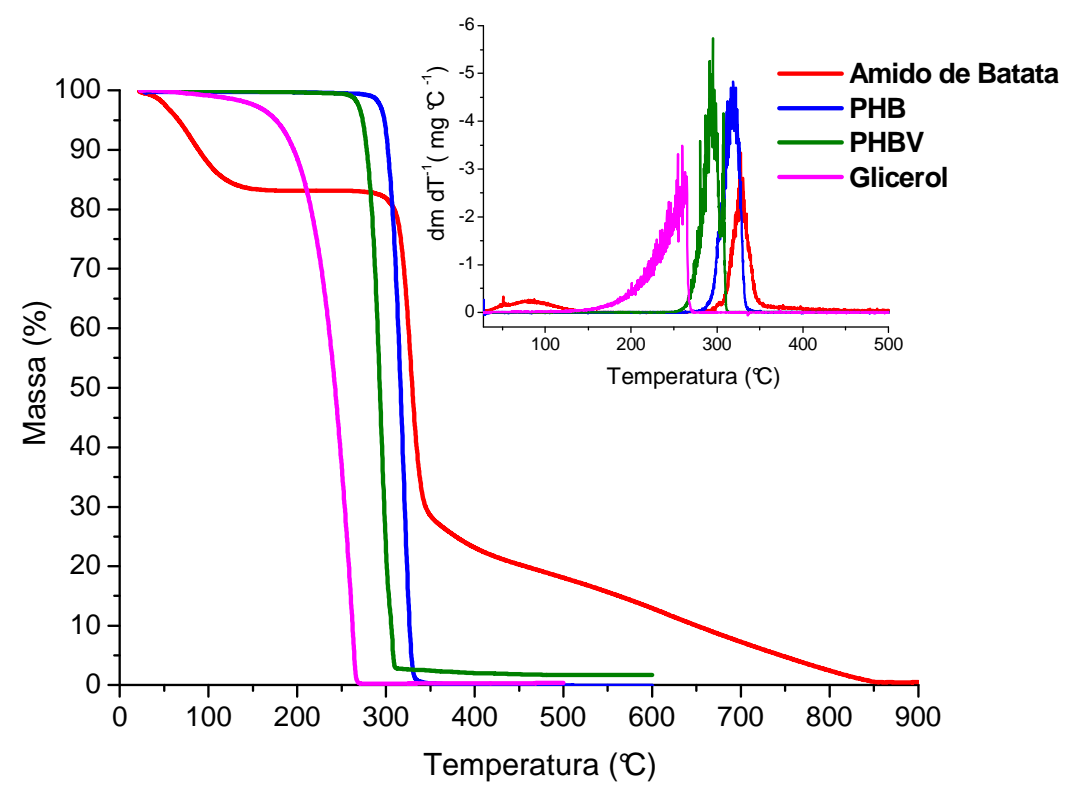

Figura 29 - Curvas TG e DTG para o amido de batata, PHB, PHBV e glicerol. Porta amostra de platina, atmosfera N2 (fluxo: $20 \mathrm{~mL}$ min-1); razão de aquecimento: $10{ }^{\circ} \mathrm{C}$ min-1.

Tabela 14 - Eventos térmicos com os respectivos intervalos de temperatura e perda de massa (\%) das curvas TG para os materiais de partida.

\begin{tabular}{|c|c|c|c|c|c|c|}
\hline \multirow[t]{2}{*}{ Amostra } & \multicolumn{2}{|c|}{$1^{\circ}$ Evento } & \multicolumn{2}{|c|}{ 20 Evento } & \multicolumn{2}{|c|}{ 3 Evento } \\
\hline & $\begin{array}{c}\text { Intervalo } \\
\text { Temperatura } \\
\text { (으) }\end{array}$ & $\begin{array}{c}\text { Perda } \\
\text { Massa } \\
(\%)\end{array}$ & $\begin{array}{c}\text { Intervalo } \\
\text { Temperatura } \\
\left({ }^{\circ} \mathrm{C}\right)\end{array}$ & $\begin{array}{c}\text { Perda } \\
\text { Massa } \\
(\%)\end{array}$ & $\begin{array}{c}\text { Intervalo } \\
\text { Temperatura } \\
\left({ }^{\circ} \mathrm{C}\right)\end{array}$ & $\begin{array}{c}\text { Perda } \\
\text { Massa } \\
(\%)\end{array}$ \\
\hline Amido & $26-163$ & 16,6 & $275-350$ & 54,5 & $350-855$ & 28,0 \\
\hline PHB & - & - & $275-340$ & 98,8 & - & - \\
\hline PHBV & - & - & $255-314$ & 96,6 & - & - \\
\hline Glicerol & - & - & $35-273$ & 99,8 & - & - \\
\hline
\end{tabular}


As análises por TG permitiram avaliar com precisão a umidade contida nos materiais de partida, assim como os estágios de decomposição térmica.

Para o amido de batata, o primeiro evento térmico (Figura 29 e Tabela 14) ocorreu entre $26-163{ }^{\circ} \mathrm{C}$ sendo referente à elimina ção de água. Com base neste evento, o teor de umidade do amido foi de $16,6 \%$.

O segundo evento, entre 275 - $350{ }^{\circ} \mathrm{C}$ com perda de massa de $54,5 \%$ foi referente à etapa máxima de decomposição do amido, sendo a temperatura deste pico na curva DTG de aproximadamente $326{ }^{\circ} \mathrm{C}$. Segund o Aggarwal e Dollimore (1999), esta etapa principal corresponde à eliminação de grupos polihidroxílicos, decomposição e despolimerização das cadeias (AGGARWAL; DOLLIMORE, 1999).

O tratamento térmico em amidos normalmente leva à sua despolimerização quando a temperatura aplicada excede os $300{ }^{\circ} \mathrm{C}$. O a mido passa por uma série de alterações irreversíveis: num primeiro momento a alteração estrutural leva o polímero a formação de pirodextrinas. Em temperaturas mais elevadas ainda, a despolimerização das macromoléculas levam à formação de $\beta-(1-6)$ anidro Dglicopiranose (levoglicosana), 2-furaldeído (furfural), produtos de baixo peso molecular e voláteis, enfim, produtos carbonáceos (cinzas) (AGGARWAL; DOLLIMORE, 1998).

Guinesi e colaboradores (2006), observaram para o amido de batata perda de massa de 56,4 \% entre 294 - 349 C , ou seja, valor próximo observado no segundo evento do presente trabalho. Esses autores relacionaram essa etapa como a despolimerização e degradação do amido em um processo não-oxidativo (GUINESI et al., 2006). 
O terceiro evento, em temperaturas maiores que $350{ }^{\circ} \mathrm{C}$ foi referente à degradação mais complexa de resíduos carbonáceos (carvão e alcatrão) (AGGARWAL; DOLLIMORE, 1999; DA RÓZ, 2004).

Para o PHB e o PHBV, o teor de umidade foi praticamente zero. Os eventos térmicos ocorreram entre $275-340{ }^{\circ} \mathrm{C}$ e $255-314^{\circ} \mathrm{C}$, com perdas de massas de 98,8 e 96,6 \%, respectivamente. A temperatura de pico do PHB, a partir da curva DTG foi de $319^{\circ} \mathrm{C}$ e do PHBV em torno de $295^{\circ} \mathrm{C}$. Com o a temperatura inicial do PHBV foi menor quando comparada com a do PHB, esse polímero apresentou menor estabilidade térmica em relação ao PHB.

Duarte (2004), também relatou um único estágio de perda de massa para o PHB, o que indicou que o processo ocorreu em um único mecanismo de degradação (DUARTE, 2004).

O glicerol apresentou apenas uma etapa de vaporização entre 35 - $273^{\circ} \mathrm{C}$ com 99,8 \% de perda de massa. Pode-se observar que a perda de massa iniciou aproximadamente em $110^{\circ} \mathrm{C}$ e em torno de $270{ }^{\circ} \mathrm{C}$, a s ua vaporização foi praticamente atingida. A temperatura de pico na DTG foi de $262^{\circ} \mathrm{C}$.

\section{TPS}

A Figura 30 ilustra de maneira comparativa, o comportamento de decomposição dos materiais de partida (amido de batata e glicerol) e do TPS. 


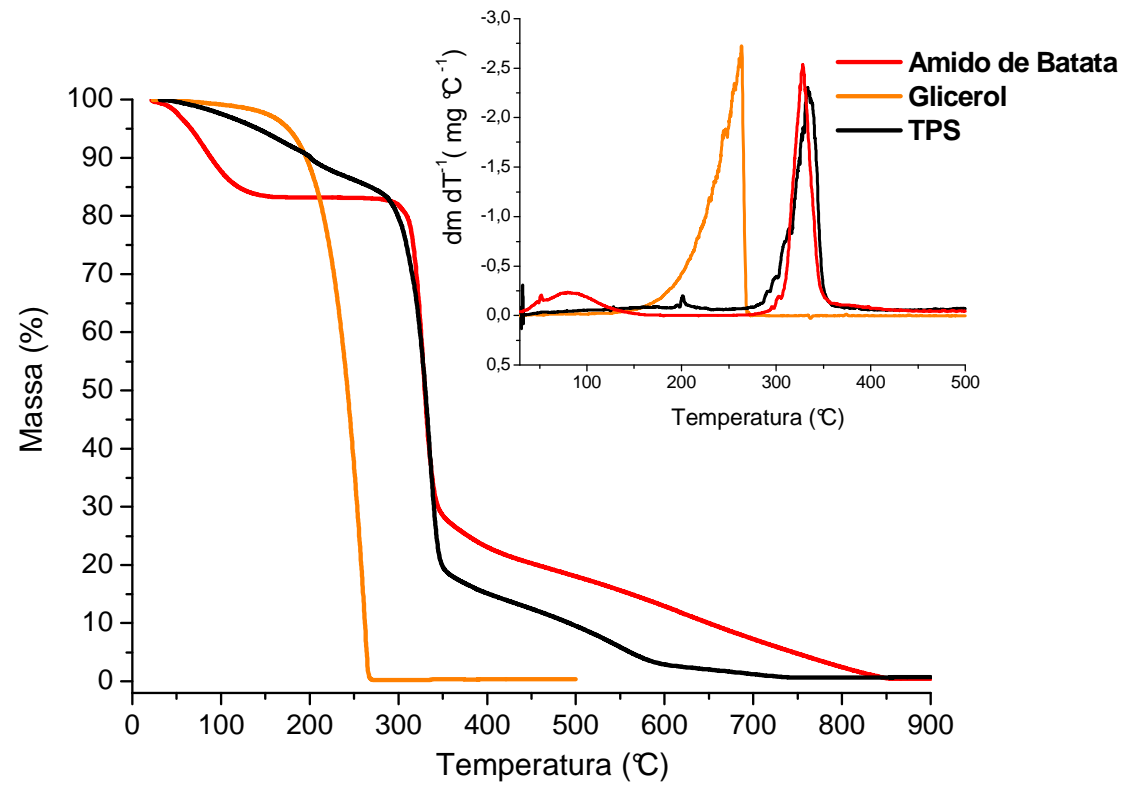

Figura 30 - Curvas TG e DTG para o amido de batata, glicerol e TPS. Porta amostra de platina, atmosfera N2 (fluxo: $20 \mathrm{~mL}$ min-1); razão de aquecimento: $10{ }^{\circ} \mathrm{Cmin}-1$.

A partir da curva TG para a amostra TPS (Figura 30) foi observado três eventos térmicos. O primeiro evento apareceu entre as curvas de amido de batata e glicerol, com perda de massa de $15,5 \%$ entre as temperaturas de $30-275$ C. Este evento foi proveniente da saída de água e parte do glicerol presente no amido.

O segundo evento térmico, entre as temperaturas de 275 - $355^{\circ} \mathrm{C}$ ocorreu uma perda de massa de $65,7 \%$. O perfil termoanalítico da curva TG para o TPS é semelhante aos eventos térmicos observados na curva do amido de batata (Figura 30), ou seja, referente à decomposição do material

O terceiro evento foi observado para a amostra TPS entre as temperaturas de 355 - $745{ }^{\circ}$, com perda de massa de $18,1 \%$. Even to este relacionado com a degradação de resíduos carbonáceos. Este evento também foi observado para 0 amido de batata.

Thiré e colaboradores (2006) observaram o mesmo perfil para a curva TPS, sendo que a temperatura de pico foi de $319,7^{\circ} \mathrm{C}$ e no presente trabalho foi de 332 
`C. O primeiro evento foi corresponde à perda de ág ua absorvida pelo amido. $\mathrm{O}$ segundo evento foi determinado como sendo o mais intenso e foi atribuído à degradação das moléculas de amido, e o último evento foi relacionado aos resíduos, com perda de massa de 7,77 \% (THIRE'; RIBEIRO; ANDRADE, 2006). Lai e colaboradores (2006) também observaram as mesmas características para a amostra TPS (LAI; DON; HUANG, 2006).

Pela análise das curvas das amostras de amido de batata e TPS (Figura 30) pôde-se observar que, de maneira geral, o TPS apresentou estabilidade térmica similar à apresentada pelo amido, evidenciando que o plasticizante não alterou significativamente a estabilidade térmica do amido. Essas observações foram confirmadas também por Da Róz, 2004 (DA RÓZ, 2004).

\section{Blendas TPS/PHB, TPS/PHBV e TPS/PHB/PHBV}

Foram realizadas as análises termogravimétricas (TG) para a amostra TPS, blendas TPS/PHB, TPS/PHBV e TPS/PHB/PHBV e amostras de PHB e/ou PHBV. Todos os corpos de prova foram condicionados em $53 \%$ de umidade.

As Figuras 31, 32 e 33 e a Tabela 15 representam as curvas TG para todas as amostras. 


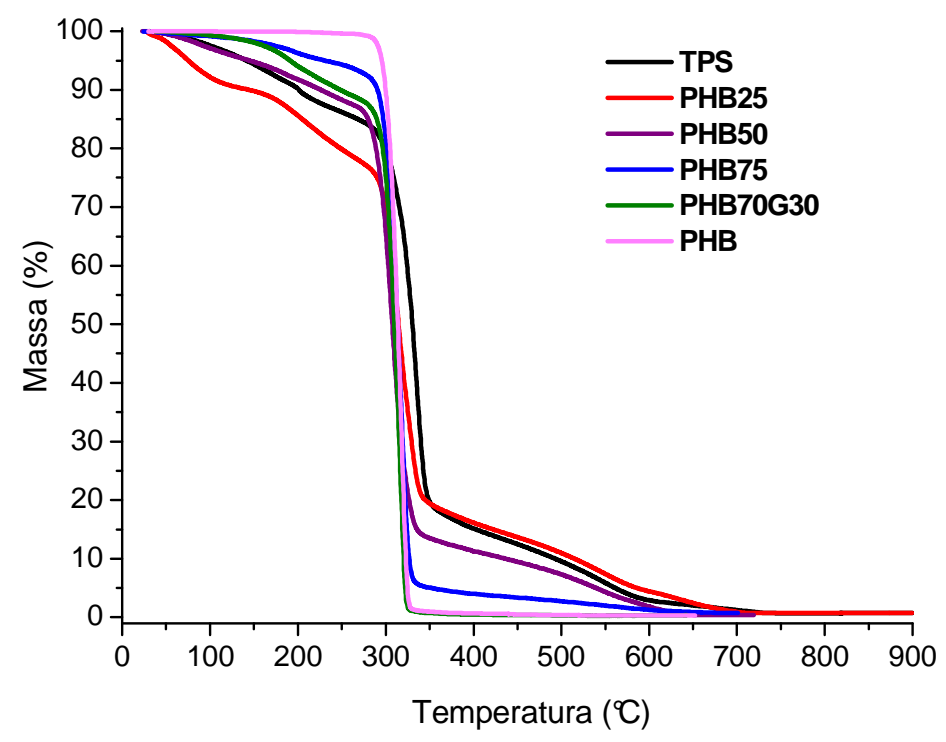

Figura 31- Curvas TG para amostra TPS, blendas TPS/PHB e para amostras de PHB. Porta amostra de platina, atmosfera $\mathrm{N} 2$ (fluxo: $20 \mathrm{~mL}$ min-1); razão de aquecimento: $10{ }^{\complement} \mathrm{Cmin}-1,53 \%$ de umidade relativa.

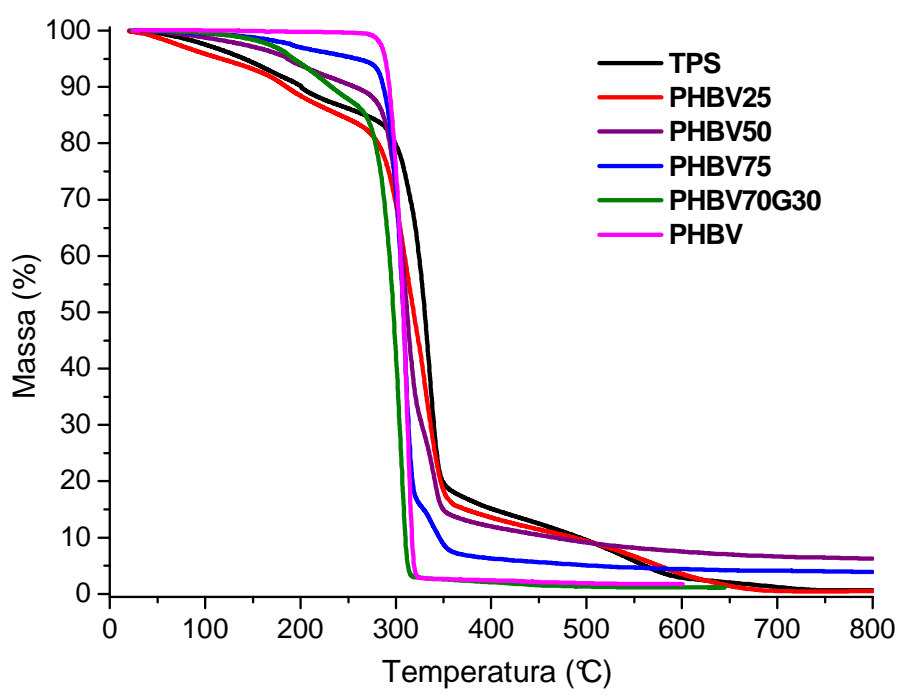

Figura 32 - Curvas TG para amostra TPS, blendas TPS/PHBV e amostras de PHBV. Porta amostra de platina, atmosfera $\mathrm{N} 2$ (fluxo: $20 \mathrm{~mL}$ min-1); razão de aquecimento: $10{ }^{\complement} \mathrm{C}$ min-1, $53 \%$ de umidade relativa. 


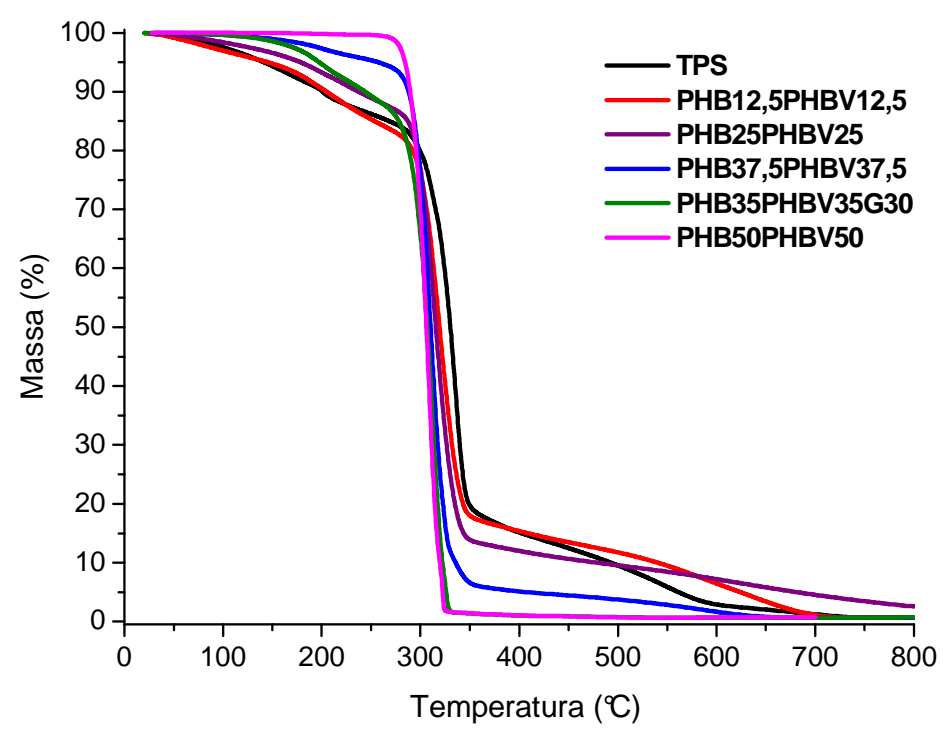

Figura 33 - Curvas TG para amostra TPS, blendas TPS/PHB/PHBV e para amostras de PHB/PHBV. Porta amostra de platina, atmosfera $\mathrm{N} 2$ (fluxo: $20 \mathrm{~mL}$ min-1); razão de aquecimento: $10{ }^{\circ} \mathrm{C}$ min-1, 53 $\%$ de umidade relativa.

Tabela 15 - Intervalos de temperatura e perda de massa (\%) do TPS, blendas TPS/PHB, TPS/PHBV e TPS/PHB/PHBV e amostras de PHB e/ou PHBV.

\begin{tabular}{|c|c|c|c|c|c|c|}
\hline \multirow[t]{2}{*}{ Amostra } & \multicolumn{2}{|c|}{ 10 Evento } & \multicolumn{2}{|c|}{ 20 Evento } & \multicolumn{2}{|c|}{ 3ํㅡㄹ Evento } \\
\hline & $\begin{array}{c}\text { Intervalo } \\
\text { Temperatura } \\
\text { (으) }\end{array}$ & $\begin{array}{c}\text { Perda } \\
\text { Massa } \\
(\%)\end{array}$ & $\begin{array}{c}\text { Intervalo } \\
\text { Temperatura } \\
\left({ }^{\circ} \mathrm{C}\right)\end{array}$ & $\begin{array}{c}\text { Perda } \\
\text { Massa } \\
(\%)\end{array}$ & $\begin{array}{c}\text { Intervalo } \\
\text { Temperatura } \\
\text { (으) }\end{array}$ & $\begin{array}{c}\text { Perda } \\
\text { Massa } \\
(\%)\end{array}$ \\
\hline TPS & $30-275$ & 15,5 & 275 - 355 & 65,7 & $355-745$ & 18,1 \\
\hline PHB25 & $30-275$ & 22,3 & $275-350$ & 58,0 & $350-735$ & 18,7 \\
\hline PHB50 & $30-270$ & 13,1 & $270-345$ & 73,1 & $345-700$ & 13,4 \\
\hline PHB75 & $30-270$ & 6,7 & $270-340$ & 87,8 & $340-700$ & 4,7 \\
\hline PHB70G30 & $30-275$ & 12,0 & $275-340$ & 87,1 & - & - \\
\hline PHB & - & - & $275-340$ & 98,2 & - & - \\
\hline PHBV25 & $30-265$ & 16,7 & $265-360$ & 67,0 & $360-700$ & 15,4 \\
\hline PHBV50 & $30-270$ & 11,1 & $270-355$ & 74,7 & $355-750$ & 7,8 \\
\hline PHBV75 & $30-270$ & 5,5 & $270-360$ & 87,0 & $360-750$ & 3,4 \\
\hline PHBV70G30 & $30-255$ & 12,7 & $255-320$ & 84,3 & - & - \\
\hline PHBV & - & - & $265-325$ & 96,7 & - & - \\
\hline
\end{tabular}




\begin{tabular}{ccccccc}
\hline PHB12,5PHBV12,5 & $30-275$ & 16,7 & $275-355$ & 65,6 & $355-750$ & 16,2 \\
PHB25PHBV25 & $30-275$ & 13,0 & $275-355$ & 73,3 & $355-750$ & 10,0 \\
PHB37,5PHBV37,5 & $30-265$ & 5,4 & $265-355$ & 88,3 & $355-750$ & 5,5 \\
PHB35PHBV35G30 & $30-265$ & 12,4 & $265-335$ & 86,1 & - & - \\
PHB50PHBV50 & - & - & $260-335$ & 98,0 & - & - \\
\hline
\end{tabular}

As curvas das blendas TPS/PHB, TPS/PHBV e TPS/PHB/PHBV apresentadas nas Figuras 31, 32 e 33 demonstraram que a estabilidade térmica e a perda de massa das blendas estão relacionadas diretamente com a quantidade de TPS. Para estas amostras foram observados três eventos térmicos, similares aos eventos da amostra TPS.

O primeiro evento foi relacionado com a perda de água e de glicerol proveniente apenas da amostra TPS, pois para os polímeros PHB e PHBV (Figura 29) não foram visualizados perdas de umidade durante o primeiro evento. Com exceção das blendas contendo $75 \%$ de TPS, o valor de perda de massa neste intervalo de temperatura acompanhou a redução na quantidade de TPS presente nas blendas. Este resultado pode ser atribuído à diminuição na quantidade de água proveniente do amido e do condicionamento das amostras e também da saída do glicerol.

O segundo evento foi proveniente da decomposição das blendas TPS/PHB, TPS/PHBV e TPS/PHB/PHBV (Figuras 31, 32 e 33 e Tabela 15). Foi observado que os comportamentos das curvas variaram de acordo com o aumento do teor de PHB, PHBV e PHB/PHBV sendo uma somatória de eventos térmico dos materiais de partida.

No terceiro evento foi observada uma queima de resíduos carbonáceos até o final do experimento, sendo que maiores perdas de massa foram relatadas para as amostras com maiores quantidades de TPS (Tabela 15). Segundo Thiré e 
colaboradores (2006) essa etapa pode ser atribuída, principalmente à degradação do amido e consequentemente do TPS, pois este é o componente termicamente menos estável das amostras (THIRE'; RIBEIRO; ANDRADE, 2006).

Lai e colaboradores (2006), ao comparar a amostra PHB e as blendas TPS/PHB observaram que para a amostra PHB ocorreu perda de massa em $310^{\circ} \mathrm{C}$ enquanto que para as blendas, a perda de massa foi observada em temperaturas muito menores de aproximadamente $200^{\circ} \mathrm{C}$. Essas obse rvações também foram relatadas no presente trabalho (LAl; DON; HUANG, 2006). Dias e colaboradores (2008) também confirmaram que a degradação do PHB ocorreu em uma única etapa (DIAS et al., 2008).

Segundo Yang e Liu (2004) a degradação do PHBV também ocorreu em uma única etapa, obtendo o mesmo perfil da curva do polímero PHBV do presente trabalho (YANG; LIU, 2004).

As Figuras 34, 35 e 36 apresentam de maneira comparativa, as curvas TG dos materiais de partida (PHB e glicerol) com as amostras PHB e PHB70G30 (Figura 34), dos materiais de partida (PHBV e glicerol) com as amostras PHBV e PHBV70G30 (Figura 35) e dos materiais de partida (PHB, PHBV e glicerol) com as amostras PHB50PHBV50 e PHB35PHBV35G30 (Figura 36). 


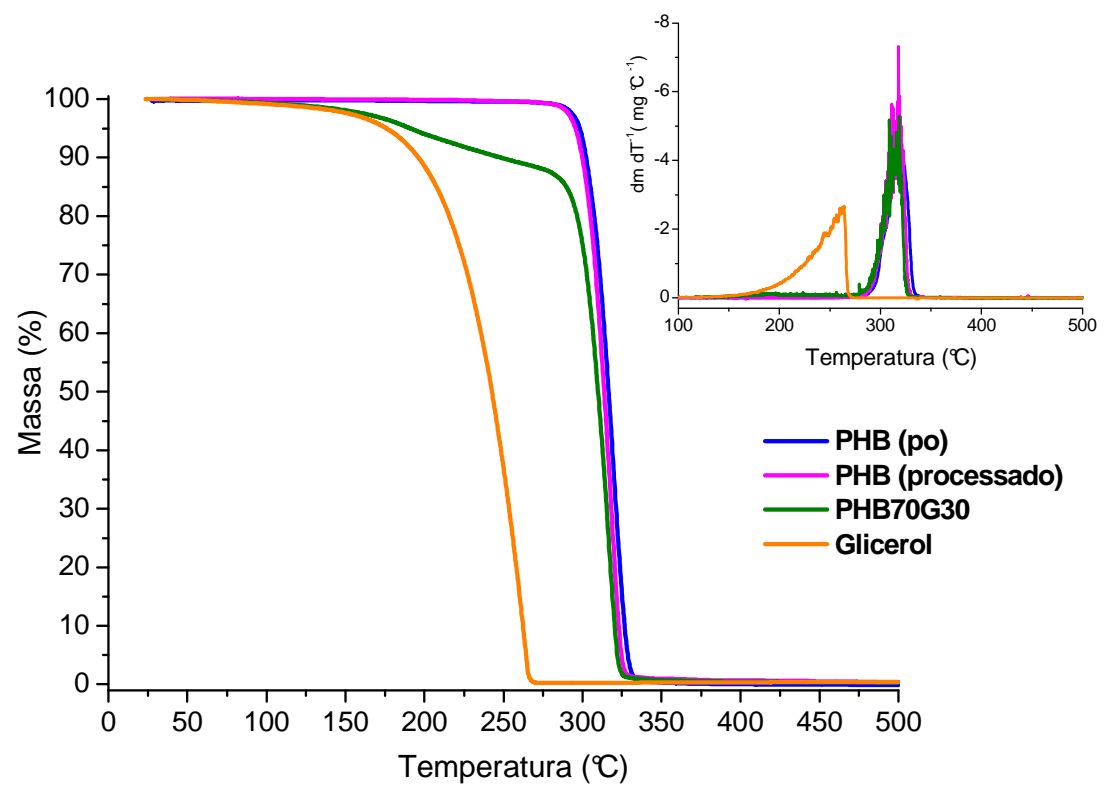

Figura 34 - Curvas TG e DTG das amostras PHB antes e após o processamento, amostras com glicerol e o próprio glicerol. Porta amostra de platina, atmosfera N2 (fluxo: $20 \mathrm{~mL}$ min-1); razão de aquecimento: $10^{\circ} \mathrm{C}$ min-1.

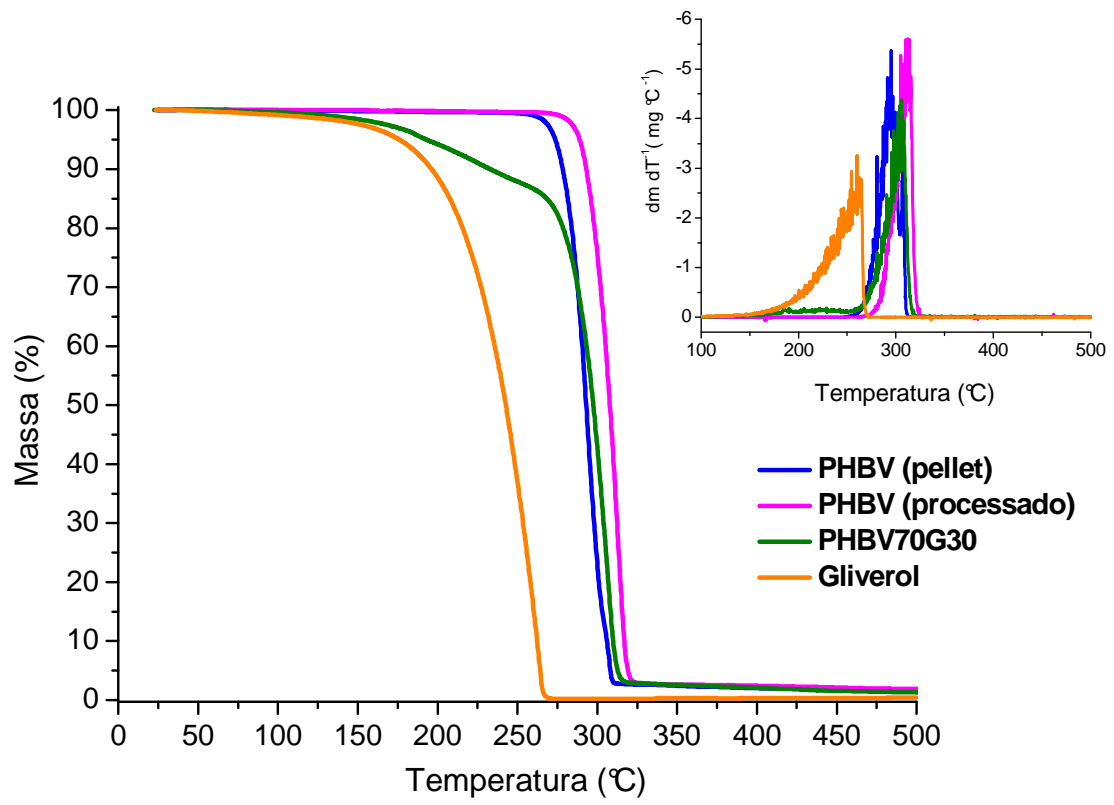

Figura 35 - Curvas TG e DTG das amostras PHBV antes e após o processamento, amostras com glicerol e o próprio glicerol. Porta amostra de platina, atmosfera N2 (fluxo: $20 \mathrm{~mL}$ min-1); razão de aquecimento: $10^{\circ} \mathrm{C}$ min-1. 


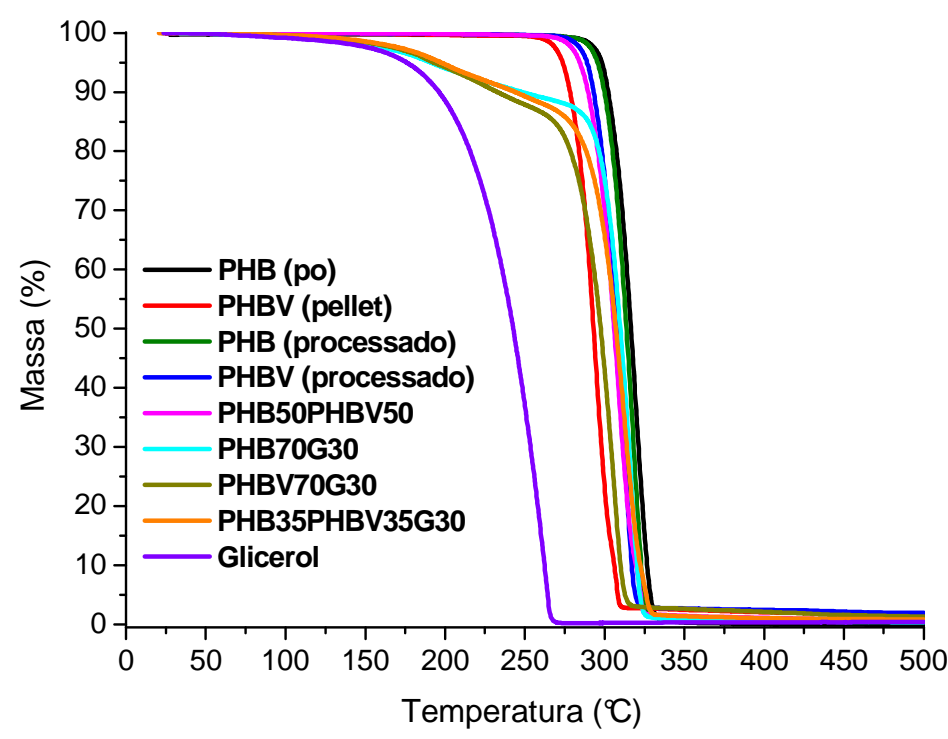

Figura 36 - Curvas TG e DTG das amostras PHB e/ou PHBV antes e após o processamento, amostras com glicerol e o próprio glicerol. Porta amostra de platina, atmosfera N2 (fluxo: $20 \mathrm{~mL}$ min1); razão de aquecimento: $10^{\circ} \mathrm{C}$ min-1.

De acordo com a Figura 34, o PHB (pó) e o PHB (processado), apresentaram um mesmo perfil termoanalítico nas curvas TG. A decomposição térmica ocorreu entre 275 - $340{ }^{\circ} \mathrm{C}$ com perda de massa de 98,8 e $98,2 \%$, respectivamente. Os materiais foram totalmente decompostos, sem resíduos, em uma única etapa.

De acordo com a curva DTG a temperatura máxima foi de $318{ }^{\circ} \mathrm{C}$ para o PHB em pó e para o PHB processado no misturador intensivo (Haake). O perfil da curva PHB (processado) foi confirmado por Thiré e colaboradores (2006) (THIRE'; RIBEIRO; ANDRADE, 2006).

Duarte (2004) confirmou as observações feitas para os polímeros antes e após o processamento, destacando que não houve mudanças significativas na temperatura inicial do PHB extrudado em fase sólida quando comparado com o material não processado, mostrando assim que o PHB praticamente não sofreu degradação durante o processamento (DUARTE, 2004). 
O PHBV (pellet) e o PHBV (processado), Figura 35, apresentaram curvas semelhantes, com perdas de massa de 96,6 e 96,7 \%, respectivamente, em intervalos de temperatura de $255-314^{\circ} \mathrm{C}$ e $265-325^{\circ} \mathrm{C}$, como pode ser observado na Tabela 15. De acordo com a curva DTG (Figura 35) as temperaturas máximas foram de 295 e $310^{\circ} \mathrm{C}$ para o PHBV em pellet e para o PHBV depois de processado.

O PHBV (processado) apresentou uma estabilidade térmica maior em relação ao PHBV (pellet), conforme visualizado na Figura 35, pois a perda de massa deste material teve início a uma temperatura superior.

Segundo Dagnon e colaboradores (2009), Singh e colaboradores (2008) o PHBV degrada em uma única etapa devido à cisão das cadeia que leva a uma redução do peso molecular e formação de produtos voláteis (DAGNON et al., 2009; SINGH et al., 2008).

Foi observado que a degradação térmica da amostra PHB50PHBV50 (Figura 36) ocorreu entre as temperaturas de degradação das amostras PHBV (pellet e processado) e antes das amostras PHB (pó e processado), ou seja, a estabilidade térmica da mistura PHB50PHBV50 foi menor em comparação com os polímeros (PHB e PHBV) processados. E observando as amostras (PHB e PHBV) depois de processadas observou-se que o PHB foi o material que apresentou uma maior estabilidade térmica.

Para as amostras PHB70G30, PHBV70G30 e PHB35PHBV35G30 (Figura 36) foram observados dois eventos térmicos. O primeiro evento foi relacionado à saída de umidade e saída de glicerol e o segundo evento foi relacionado à decomposição térmica dos respectivos polímeros. Pôde observar nitidamente que o primeiro evento 
térmico destas amostras apareceu entre as curvas das amostras dos polímeros (PHB, PHBV e PHB/PHBV) e glicerol.

\subsection{Calorimetria Exploratória Diferencial - (DSC)}

A Calorimetria Exploratória Diferencial (DSC) foi empregada para avaliar os eventos térmicos como temperatura de fusão, transição vítrea, entalpia de fusão, cristalinidade, variação de entalpia entre as amostras, dentre outros. Foram avaliados os materiais de partida (Amido de Batata, PHB e PHBV), amostras TPS, PHB e PHBV, blendas TPS/PHB, TPS/PHBV e TPS/PHB/PHBV e as amostras de PHB e/ou PHBV.

\section{Materiais de Partida:}

\section{Amido de Batata}

A Figura 37 ilustra as características da curva DSC para o amido de batata sem a presença de água. A técnica DSC também foi empregada para determinar a temperatura de gelatinização e teor de amilose do amido, como ilustrada nas Figuras 38 e 39.

As curvas das Figuras 37 e 38 foram obtidas a partir do primeiro aquecimento, pois segundo Talja (2007) a gelatinização não foi observada durante o segundo aquecimento (TALJA, 2007). 


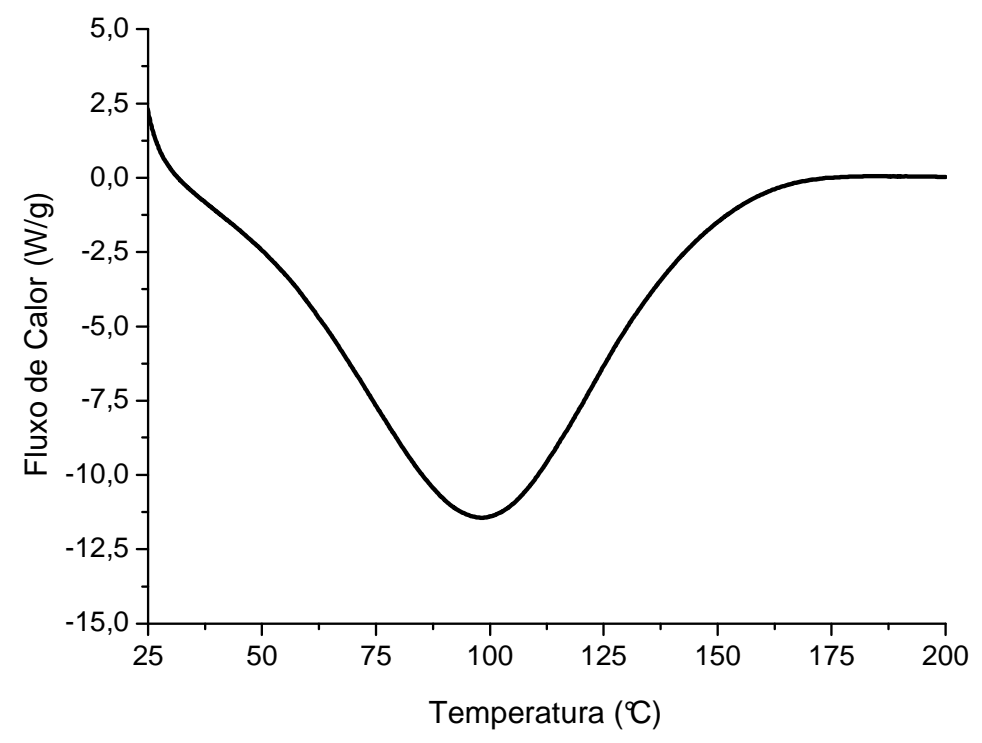

Figura 37 - Curva DSC para o amido de batata sem a presença de água. Porta amostra hermético com furo no centro, atmosfera N2 (fluxo: $20 \mathrm{~mL}$ min-1); razão de aquecimento: 10 C min-1, massa de $10 \mathrm{mg}$ e temperatura ambiente até $250^{\circ} \mathrm{C}$.

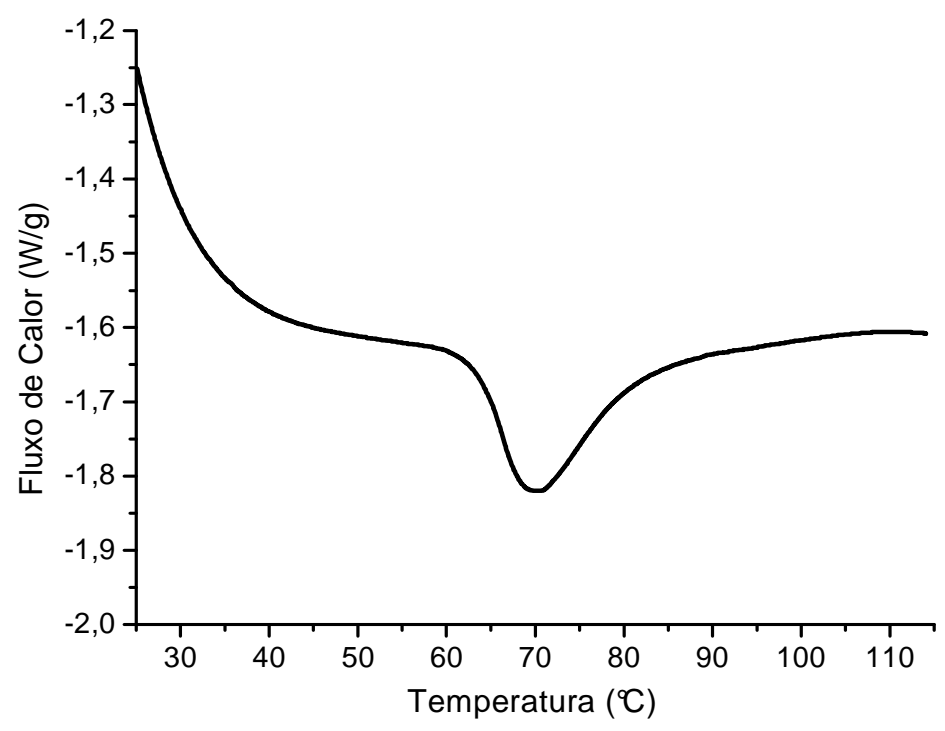

Figura 38 - Curva DSC para a gelatinização do amido de batata. Porta amostra de alumínio de alta pressão, atmosfera $\mathrm{N} 2$ (fluxo: $20 \mathrm{~mL}$ min-1); razão de aquecimento: $10{ }^{\circ} \mathrm{C}$ min-1, massa 1:2 / amido:H2O e temperatura ambiente até $120^{\circ} \mathrm{C}$.

A curva DSC obtida para o amido de batata sem a presença de água (Figura 37) apresenta um pico endotérmico na região de temperatura entre $28-180{ }^{\circ} \mathrm{C}$, 
sendo $98,5^{\circ} \mathrm{C}$ a temperatura de pico. Esse sinal é a tribuído a eliminação de água contida no amido in natura. $O$ calor envolvido no processo foi de $491,4 \mathrm{~J}^{-1}{ }^{-1}$.

A gelatinização é um processo de transformação do amido granular em pasta viscoelástica. Durante o aquecimento do amido em presença de água, inicialmente ocorre o inchamento dos grânulos até temperaturas nas quais ocorre o rompimento destes, com destruição da ordem molecular e mudanças irreversíveis nas suas propriedades. A temperatura na qual ocorre este tipo de transformação é chamada de temperatura de gelatinização (SOUZA; ANDRADE, 2000).

Ao analisar a curva DSC da Figura 38, observou-se que a faixa de temperatura de gelatinização foi entre 48 - $114{ }^{\circ} \mathrm{C}$ para o amido de batata, com temperatura onset e de pico em aproximadamente $62,7{ }^{\circ} \mathrm{C}$ e $70,2{ }^{\circ} \mathrm{C}$, respectivamente. $\mathrm{O}$ calor envolvido no processo foi de $20,4 \mathrm{~J} \mathrm{~g}^{-1}$. Antes de analisar a gelatinização do amido, a mistura foi previamente mantida em repouso, na presença de água, por uma hora.

Moorthy (2002) realizou um estudo amplo em relação à temperatura de gelatinização de diferentes amidos e relatou que os diferentes tipos de amido de batata apresentam temperaturas de gelatinização entre 70,2 e $77,0{ }^{\circ} \mathrm{C}$, ou seja, temperaturas similares a observada no presente trabalho (MOORTHY, 2002). A energia requerida para a separação das moléculas difere entre os grânulos de amido de uma mesma fonte botânica, assim, a gelatinização ocorre em uma faixa de temperatura (CEREDA, 2001).

Alguns autores citam que o evento de gelatinização depende da quantidade de água no sistema, sendo a curva mais definida e a uma temperatura menor obtidas com uma maior quantidade de água (LACERDA, 2006; FUKUOKA; OHTA; WATANABE, 2002; NDIFE; SUMNU; BAYINDIRLI, 1998). 
A entalpia de gelatinização depende de uma série de fatores, tais como cristalinidade, interação intermolecular, dentre outras. Segundo Kaur e colaboradores (2002) e Singh e Singh (2001) a entalpia de diferentes amidos de

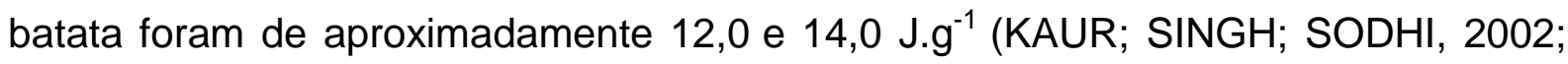
SINGH; SINGH, 2001). Geralmente o tamanho dos grânulos de amido de batata também interfere no aumento da entalpia (TALJA, 2007).

O método utilizado por DSC para a determinação da quantidade de amilose no amido de batata baseia-se na formação de um complexo entre a enzima L- $\alpha$ lisofosfatidilcolina (LPC) e a amilose. A entalpia (pico exotérmico) de formação deste complexo foi observada na curva durante o segundo resfriamento (MESTRES et al., 1996; GUINESI et al., 2006).

Para determinar a porcentagem de amilose foi aplicada a equação 6 (página 54). Segundo Mestres e colaboradores o valor adotado de $\Delta \mathrm{H}$ padrão da amilose de amido de batata foi de 28,50 (MESTRES et al., 1996).

A Figura 39 ilustra as curvas DSC do primeiro e segundo resfriamento obtidas para determinação do teor de amilose do amido de batata. 


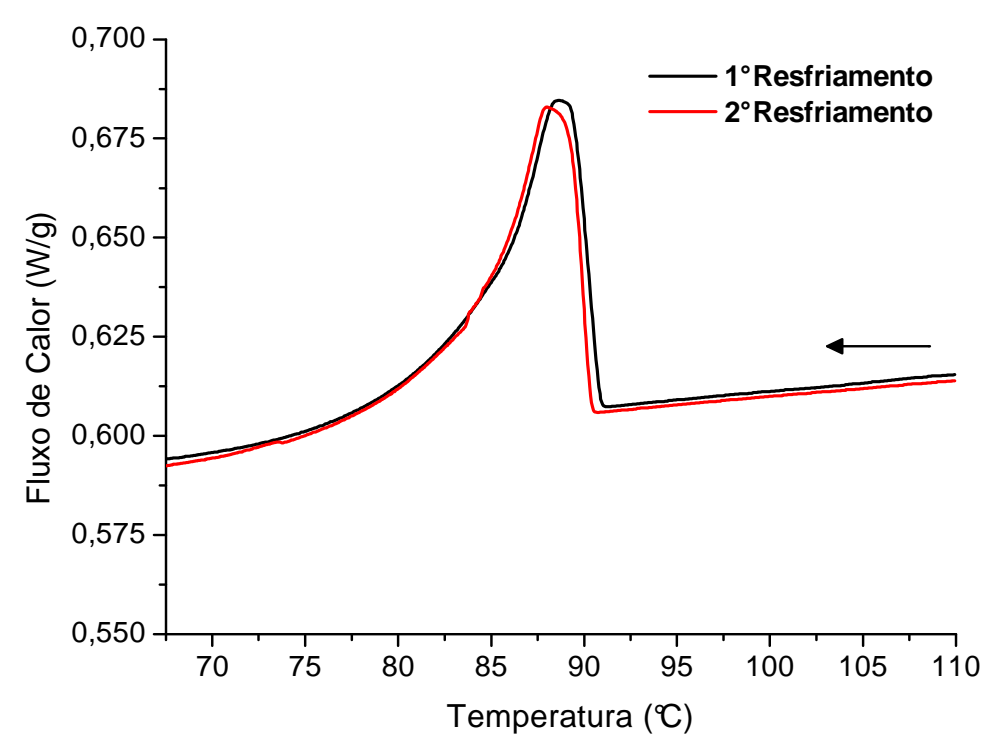

Figura 39 - Curva DSC para a determinação do teor de amilose do amido de batata. Porta amostra de alumínio de alta pressão, atmosfera $\mathrm{N} 2$ (fluxo: $20 \mathrm{~mL}$ min-1); razão de resfriamento: $5{ }^{\circ} \mathrm{C}$ min-1 e razão de aquecimento: $10^{\circ} \mathrm{C}$ min-1.

Através da segunda curva de resfriamento (Figura 39) foi observada para a amostra de amido uma entalpia de 6,8 J.g $\mathrm{g}^{-1}$. Como o valor da entalpia padrão é de 28,50 J.g ${ }^{-1}$, segundo Mestres e colaboradores (1996), a porcentagem de amilose para o amido de batata foi de $23,6 \%$. Gérard e colaboradores (2001) relataram um conteúdo de amilose de $26 \%$ para o amido de batata, utilizando como valor de entalpia padrão 25,0 J.g ${ }^{-1}$. Comparando este valor de amilose com o valor do presente trabalho, utilizando o valor de entalpia padrão segundo Gérard, a amilose do amido de batata seria de $27,2 \%$, semelhante ao obtido neste trabalho (GÉRARD et. al., 2001).

\section{PHB e PHBV}

A Figura 40 ilustra as curvas DSC (primeiro aquecimento, resfriamento e segundo aquecimento) e a Tabela 16 apresenta os intervalos de temperatura 
observados no primeiro e no segundo evento, com as respectivas temperaturas de cristalização $\left(T_{c}\right)$, temperatura de fusão $\left(T_{m}\right)$, entalpia de cristalização $\left(\Delta H_{c}\right)$ e entalpia de fusão $\left(\Delta \mathrm{H}_{\mathrm{m}}\right)$ dos polímeros puros (PHB e PHBV).

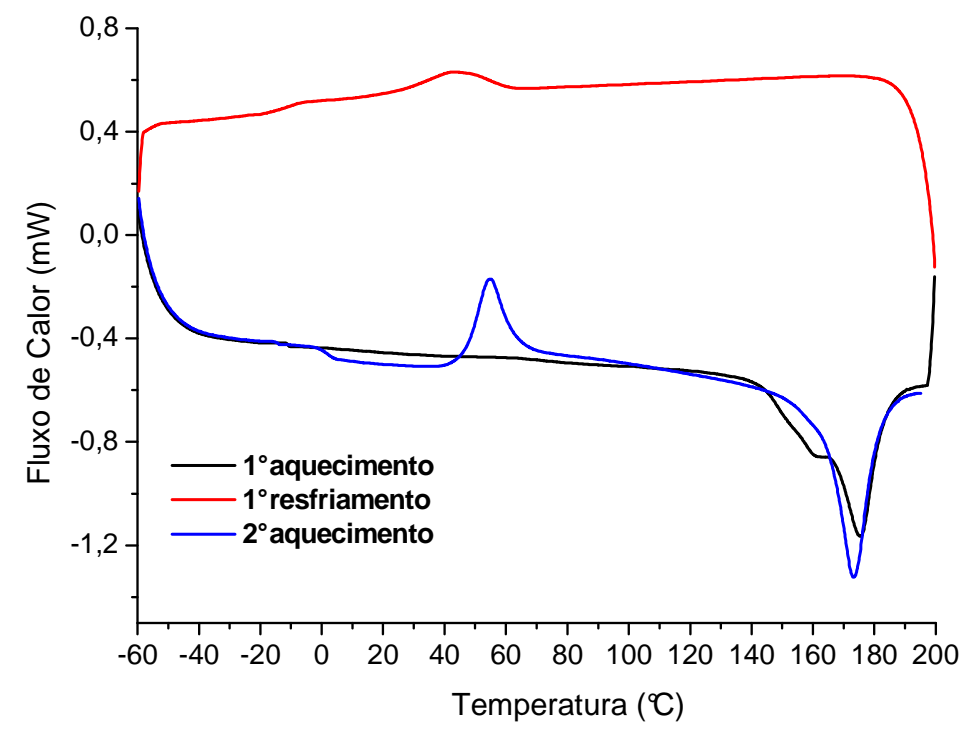

(A)

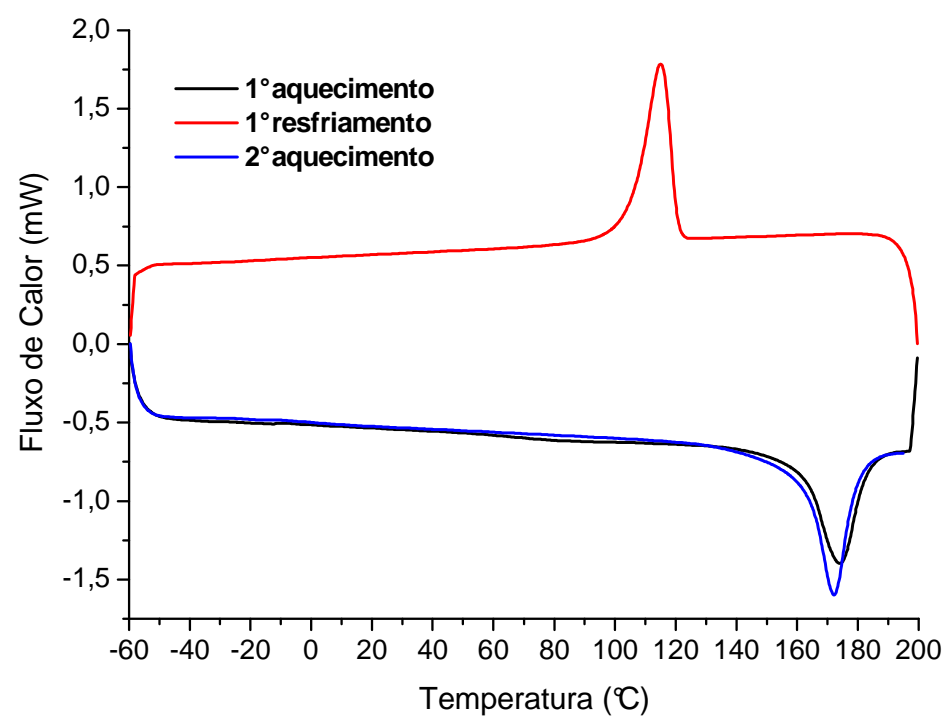

(B)

Figura 40 - Curvas DSC ( $1^{\circ}$ aquecimento, resfriamento, $2^{\circ}$ aqueci mento) para o PHB (A) e PHBV (B). Porta amostra de alumínio de alta pressão, atmosfera N2 (fluxo: $50 \mathrm{~mL} \min -1$ ); razão de resfriamento e aquecimento: $10^{\circ} \mathrm{C}$ min-1, massa: $10 \mathrm{mg}$, temperatu ra ambiente a $200{ }^{\circ} \mathrm{C}$. 
Tabela 16 - Características térmicas (intervalo de temperatura, temperatura de cristalização (Tc) e temperatura de fusão $(\mathrm{Tm})$, entalpia de cristalização $(\Delta \mathrm{Hc})$ e de fusão $(\Delta \mathrm{Hm})$ e grau de cristalinidade) para o PHB e PHBV.

\begin{tabular}{|c|c|c|c|c|c|c|c|c|c|c|}
\hline \multirow{2}{*}{ Amostra } & & \multicolumn{4}{|c|}{ 1을 Evento } & \multicolumn{5}{|c|}{ 2ㅇ Evento } \\
\hline & & $\begin{array}{l}\text { Intervalo } \\
\text { Temp. } \\
\text { (C) }\end{array}$ & $\begin{array}{l}T_{c \text { (pico) }} \\
\left({ }^{\circ}\right)\end{array}$ & $\begin{array}{c}T_{c \text { (onset) }} \\
\left({ }^{\circ} \mathrm{C}\right)\end{array}$ & $\begin{array}{c}\Delta \mathrm{H}_{\mathrm{c}} \\
\left(\mathrm{J} \cdot \mathrm{g}^{-1}\right)\end{array}$ & $\begin{array}{l}\text { Intervalo } \\
\text { Temp. } \\
\text { ('C) }\end{array}$ & $\begin{array}{c}T_{\mathrm{m} \text { (pico) }} \\
\left({ }^{(C)}\right)\end{array}$ & $\begin{array}{c}T_{m \text { (onset) }} \\
\left({ }^{\circ} \mathrm{C}\right)\end{array}$ & $\begin{array}{c}\Delta \mathrm{H}_{\mathrm{m}} \\
\left(\mathrm{J} \cdot \mathrm{g}^{-1}\right)\end{array}$ & $\begin{array}{c}\% \\
\text { Cristal. }\end{array}$ \\
\hline \multirow{3}{*}{ PHB } & $1^{\circ}$ aquec. & - & - & - & - & $134-197$ & 175,3 & 161,1 & 73,0 & 50 \\
\hline & Resfr. & $32-68$ & 41,1 & 60,5 & 24,7 & - & - & - & - & \\
\hline & $2^{\circ}$ aquec. & $39-77$ & 54,7 & 46,6 & 22,0 & $134-195$ & 173,2 & 163,2 & 64,4 & 44,1 \\
\hline \multirow{3}{*}{ PHBV } & $1^{\circ}$ aquec. & - & - & - & - & $133-196$ & 174,0 & 161,5 & 71,6 & 49,0 \\
\hline & Resfr. & $81-133$ & 115,0 & 120,6 & 74,7 & - & - & - & - & \\
\hline & $2^{\circ}$ aquec. & - & - & - & - & $123-195$ & 172,1 & 162,3 & 85,7 & 58,7 \\
\hline
\end{tabular}

Pela curva DSC da amostra PHB (Figura 40 A), durante o primeiro aquecimento foi possível observar a existência de pico de fusão múltiplo, sendo esse fenômeno já observado por Rosário (2005). Durante o resfriamento notou-se um pequeno pico de cristalização, indício de que o PHB possui uma cinética de cristalização lenta, não cristalizando totalmente na razão de resfriamento de $10{ }^{\circ} \mathrm{C}$ $\min ^{-1}$ (ROSÁRIO, 2005).

Segundo Saito e colaboradores (2001) para interpretar picos múltiplos de fusão em um material polimérico, temos que distinguir picos decorrentes da separação de fase dos cristais e picos decorrentes do rearranjo dos cristais (SAITO; INOUE; YOSHIE, 2001).

No segundo aquecimento foi observada mudança na linha base entre -1 e 4 ${ }^{\circ} \mathrm{C}$ com temperatura média em torno de $2,1^{\circ} \mathrm{C}$, relaci onado à transição vítrea $\left(T_{g}\right)$ do PHB. Como a cristalização do polímero durante o resfriamento não foi completa, durante o aquecimento observou-se um pico bem acentuado, com $T_{c \text { (pico) }}$ de $54,7{ }^{\circ} \mathrm{C}$

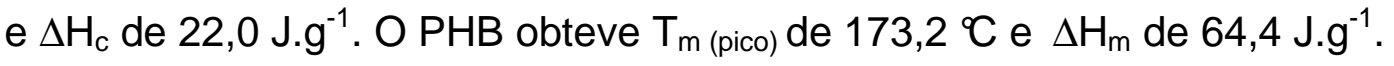


Segundo Lima (2004), a temperatura de transição vítrea $\left(T_{g}\right)$ do PHB ocorre entre 0 a $5^{\circ} \mathrm{C}$ e a temperatura de fusão $\left(T_{\mathrm{m}}\right)$ entre 170 a $180{ }^{\circ} \mathrm{C}$ (LIMA, 2004). Rosário (2005) obteve as temperaturas de fusão no primeiro e segundo aquecimento de 175,2 e $173,4^{\circ}$ C, corroborando com os valores do presente trabalho (ROSÁRIO, 2005).

O grau de cristalinidade do PHB e PHBV pode ser calculado pela razão entre a variação do seu calor de fusão pela variação do calor de fusão do polímero hipoteticamente $100 \%$ cristalino (Equação 5, página 52).

Segundo Pachekoski (2005), Barham e Keller (1985) e Falcone (2004) a cristalinidade do PHB varia entre 50 a $80 \%$, sendo utilizada para o cálculo da cristalinidade a entalpia de fusão do PHB $100 \%$ cristalino com valor igual a $146 \mathrm{J.g}$ 1. Referente à cristalização do PHB em estudo, através da entalpia de fusão (Figura 40) para o primeiro aquecimento e o segundo aquecimento de 73,0 e $64,4 \mathrm{~J}^{-1}{ }^{-1}$, respectivamente, (Tabela 16) as cristalinidades calculadas foram de 50,0 e 44,1\%, valores baixos quando comparados com os da literatura (PACHEKOSKI, 2005; BARHAM; KELLER, 1985; FALCONE, 2004).

Para o PHBV (Figura 40 B) é importante notar que não foi possível determinar as temperaturas de transição vítrea $\left(T_{g}\right)$ durante as análises de DSC e também o pico de cristalinidade no segundo aquecimento, sendo possível determiná-lo apenas no resfriamento, devido às condições experimentais. Brunel (2008) observou o pico de cristalinidade apenas durante o aquecimento, devido à razão de resfriamento rápida de $80{ }^{\circ} \min ^{-1}$ (BRUNEL, 2008).

Analisando a curva DSC do PHBV (Figura 40 B) para o segundo aquecimento, observou-se uma $T_{m \text { (pico) }}$ em 172,1 ${ }^{\circ}$ e $\Delta H_{m}$ de 85,7 J.g ${ }^{-1}$. 
Dagnon e colaboradores (2009), Buzarovska e colaboradores (2007), Scandola e colaboradores (1997) e Buzarovska e Grozdanov (2009) utilizaram para o cálculo da cristalinidade a entalpia de fusão do PHBV $100 \%$ cristalino igual a 109 J.g - $^{-1}$ (DAGNON et al., 2009, BUZAROVSKA et al., 2007, SCANDOLA et al., 1997; BUZAROVSKA; GROZDANOV, 2009). Alguns autores utilizaram a entalpia padrão do PHB para o cálculo de cristalinidade do PHBV, justificando que esta aproximação foi realizada com amostras de PHBV contendo baixa porcentagem de HV (AVELLA et al., 2000b; BARHAM; KELLER, 1985).

No presente trabalho foi utilizado $\Delta \mathrm{H}$ padrão de $146 \mathrm{~J}^{-g^{-1}}$, sendo observado um valor de cristalinidade para o primeiro e o segundo aquecimento de 49,0 e 58,7 $\%$, respectivamente. Pode-se observar que para o PHBV em pellet a porcentagem de cristalinidade obtida no segundo aquecimento foi maior do que a mesma obtida no primeiro aquecimento.

TPS

A Figura 41 ilustra a curva DSC para a amostra TPS, condicionada em $53 \%$ de umidade. 


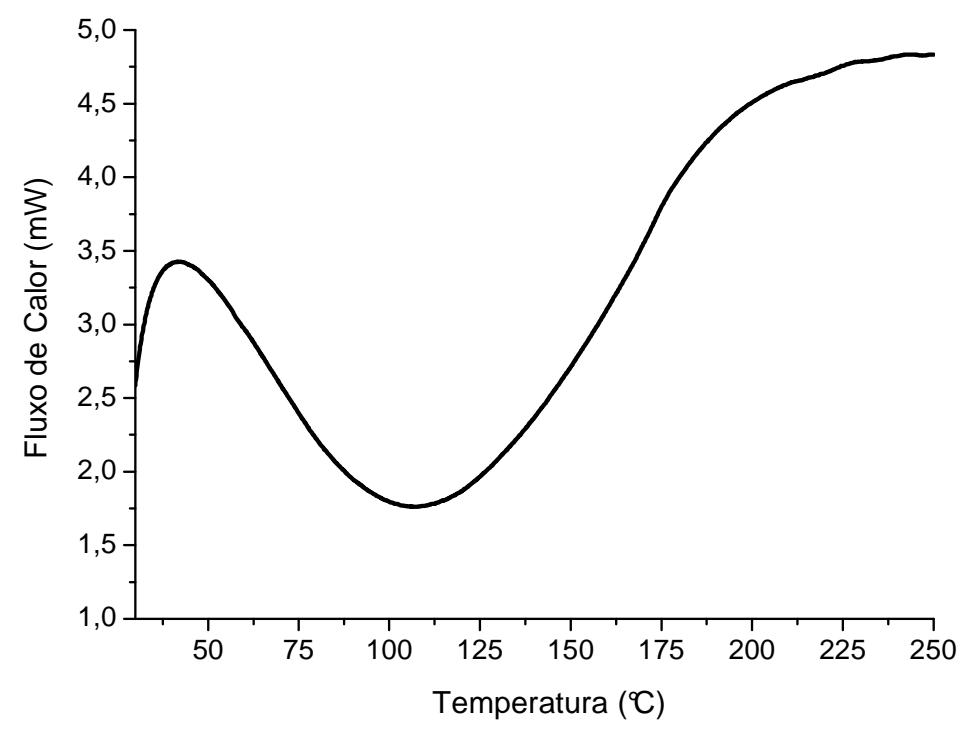

Figura 41 - Curva DSC para amostra TPS. Porta amostra de alumínio, atmosfera N2 (fluxo: $20 \mathrm{~mL}$ min-1); razão de aquecimento: $10^{\circ} \mathrm{C}$ min-1, massa de $10 \mathrm{mg}$ e temperatura ambiente até $250{ }^{\circ} \mathrm{C}$.

Os estudos referentes às condições utilizadas no DSC mostraram que abaixo da temperatura ambiente não foram observados eventos para as amostras, assim os resultados apresentados no presente trabalho foram obtidos a partir do terceiro estudo e do primeiro aquecimento, visto que para a amostra TPS, blendas TPS/PHB, TPS/PHBV e TPS/PHB/PHBV e amostras de PHB e/ou PHBV foram realizadas apenas um aquecimento durante as análises de DSC.

A curva DSC do TPS (Figura 41) apresentou um pico endotérmico entre 40 245 C com variação de entalpia de $112,8{\mathrm{~J} . \mathrm{g}^{-1}}^{-1}$ este evento está relacionado com a saída de água e glicerol. Essas observações podem ser justificadas pela curva TG nesse mesmo intervalo de temperatura para a amostra TPS (Figura 30). 


\section{Blendas TPS/PHB, TPS/PHBV e TPS/PHB/PHBV}

Foram realizadas análises calorimétricas (DSC) para a amostra TPS, blendas TPS/PHB, TPS/PHBV e TPS/PHB/PHBV e amostras de PHB e/ou PHBV. Todos os corpos de prova foram condicionados em $53 \%$ de umidade.

As Figuras 42, 43 e 44 apresentaram as curvas DSC e a Tabela 17 apresenta os intervalos de temperatura, temperatura de pico ( $\left.T_{\text {pico }}\right)$, temperatura onset ( $\left.T_{\text {onset }}\right)$, temperatura de fusão $\left(T_{m}\right)$ e as correspondentes entalpias $(\Delta \mathrm{H})$ para todas as amostras.

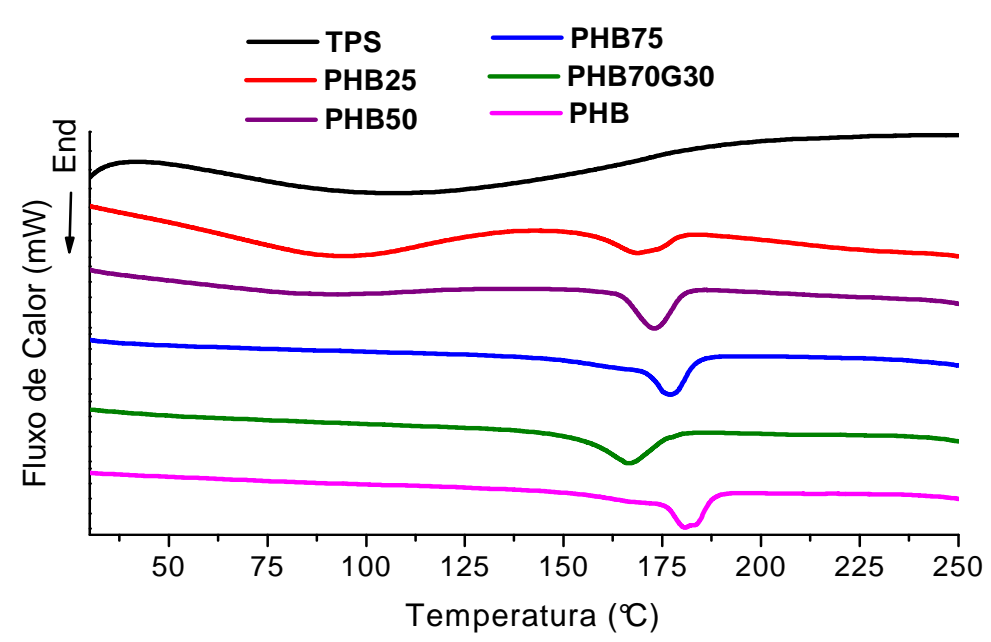

Figura 42 - Curvas DSC para a amostra TPS, blendas TPS/PHB e amostras de PHB. 


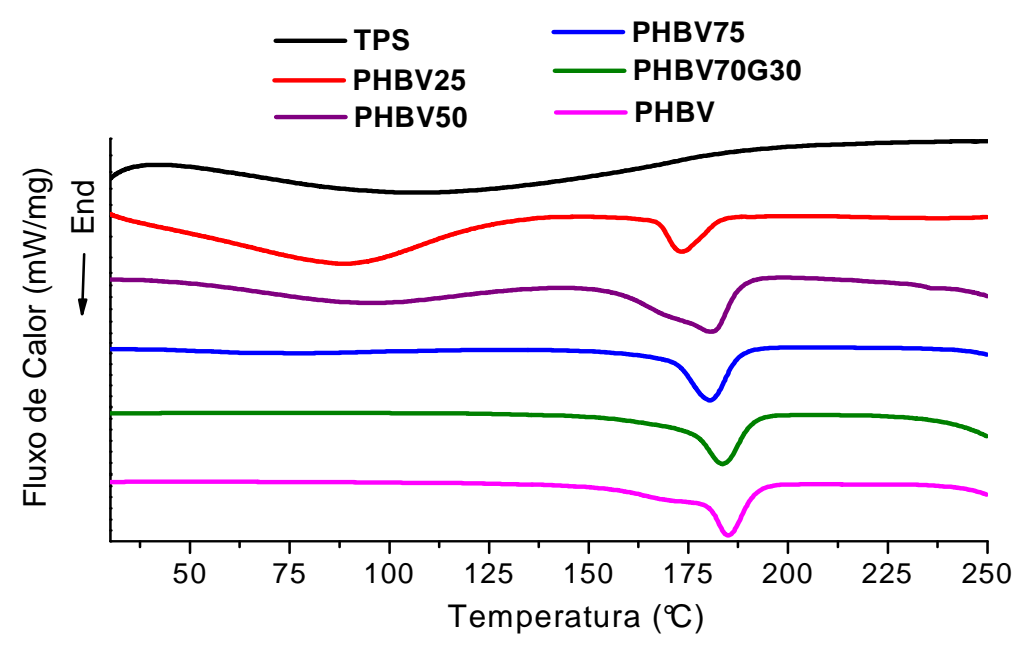

Figura 43 - Curvas DSC para a amostra TPS, blendas TPS/PHBV e amostras de PHBV.

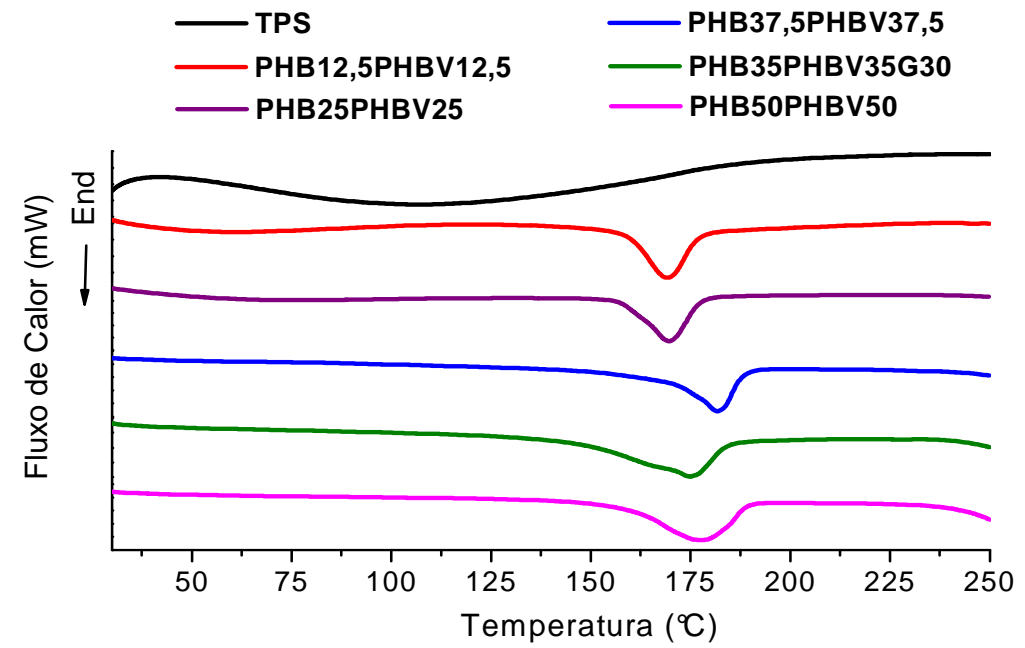

Figura 44 - Curvas DSC para a amostra TPS, blendas TPS/PHB/PHBV e amostras de PHB e/ou PHBV. 
Tabela 17 - Características térmicas (intervalo de temperatura, temperatura de pico e onset e entalpias) para $01^{\circ}$ e $\circ 2^{\circ}$ evento para a amostra TPS, blendas TPS/PHB, TPS/PHBV e TPS/PHB/PHBV e amostras de PHB e/ou PHBV e grau de cristalinidade para as amostras com PHB e/ou PHBV.

\begin{tabular}{|c|c|c|c|c|c|c|c|c|c|}
\hline \multirow[t]{2}{*}{ Amostra } & \multicolumn{4}{|c|}{ 1을 Evento } & \multicolumn{5}{|c|}{ 20 Evento } \\
\hline & $\begin{array}{l}\text { Intervalo } \\
\text { Temp. } \\
\text { ('C) }\end{array}$ & $\begin{array}{l}T_{\text {(pico) }} \\
\left({ }^{\circ} \mathbf{C}\right)\end{array}$ & $\begin{array}{c}T_{\text {(onset) }} \\
\left({ }^{\circ} \mathbf{C}\right)\end{array}$ & $\begin{array}{c}\Delta \mathrm{H} \\
\left(\mathrm{J} \cdot \mathrm{g}^{-1}\right)\end{array}$ & $\begin{array}{l}\text { Intervalo } \\
\text { Temp. } \\
\text { ('C) }\end{array}$ & $\begin{array}{c}T_{m \text { (pico) }} \\
(\stackrel{\circ}{ } \mathbf{C})\end{array}$ & $\begin{array}{c}T_{m \text { (onset) }} \\
\left({ }^{\circ} \mathrm{C}\right)\end{array}$ & $\underset{\left(\mathrm{J} . \mathrm{g}^{-1}\right)}{\Delta \mathrm{H}_{\mathrm{m}}}$ & $\begin{array}{c}\% \\
\text { Cristal. }\end{array}$ \\
\hline TPS & $40-245$ & 107,3 & 46,3 & 112,8 & - & - & - & - & - \\
\hline PHB25 & $40-142$ & 95,1 & 42,5 & 104,6 & $142-200$ & 168,7 & 156,9 & 12,1 & - \\
\hline PHB50 & $40-130$ & 92,3 & 37,1 & 55,6 & $145-200$ & 172,9 & 163,3 & 33,2 & - \\
\hline PHB75 & - & - & - & - & $130-200$ & 177,0 & 167,9 & 84,9 & - \\
\hline PHB70G30 & - & - & - & - & $130-200$ & 166,4 & 152,0 & 85,6 & 58,6 \\
\hline PHB & - & - & - & - & $140-200$ & 180,7 & 171,6 & 86,5 & 59,2 \\
\hline PHBV25 & $30-145$ & 88,7 & 30,1 & 169,0 & $150-200$ & 173,3 & 166,2 & 21,3 & - \\
\hline PHBV50 & $35-143$ & 95,9 & 48,3 & 49,7 & $143-200$ & 180,7 & 156,4 & 47,6 & - \\
\hline PHBV75 & $35-125$ & 77,2 & 40,6 & 20,7 & $135-200$ & 180,5 & 166,7 & 77,6 & - \\
\hline PHBV70G30 & - & - & - & - & $130-200$ & 183,5 & 173,5 & 99,7 & 68,3 \\
\hline PHBV & - & - & - & - & $130-200$ & 185,0 & 176,5 & 107,5 & 73,6 \\
\hline PHB12,5PHBV12,5 & $30-125$ & 61,2 & 30,2 & 31,9 & $125-200$ & 169,2 & 158,2 & 40,0 & - \\
\hline PHB25PHBV25 & $30-125$ & 74,4 & 30,9 & 31,6 & $135-200$ & 169,6 & 158,9 & 40,0 & - \\
\hline PHB37,5PHBV37,5 & - & - & - & - & $135-200$ & 181,7 & 170,0 & 60,7 & - \\
\hline PHB35PHBV35G30 & - & - & - & - & $135-200$ & 177,9 & 157,6 & 73,3 & 50,2 \\
\hline PHB50PHBV50 & - & - & - & - & $130-200$ & 174,7 & 151,0 & 87,9 & 60,2 \\
\hline
\end{tabular}

Pelas medidas de DSC (Figuras 42, 43 e 44 e Tabela 17) foram observados para blendas PHB25 e PHB50, PHBV25, PHBV50 e PHBV75, PHB12,5PHBV12,5 e PHB25PHBV25 dois eventos térmicos. O primeiro evento, endotérmico, está relacionado com a saída de água do amido e da própria água adicionada na mistura e com a saída do glicerol. Os dados de perda de massa nas curvas TG (Figuras 31, 
32 e 33) corroboram com a discussão dos resultados e as temperaturas observadas próximas de 100 Confirmam a saída de água.

O segundo evento foi observado para todas as amostras. Este evento foi relacionado com a fusão dos polímeros PHB e PHBV. Observou-se um deslocamento para maiores valores nas temperaturas de fusão $\left(T_{m}\right.$ (pico) $)$ (Tabela 17), com o aumento da quantidade de PHB e/ou PHBV nas amostras.

Comparando as misturas PHB70G30 e PHBV70G30 com as amostras PHB e PHBV (Figuras 42, 43 e 44 e Tabela 17) observou-se uma diminuição na $T_{m}$ (pico) e $T_{m}$ (onset) das misturas. Segundo Rosário (2005) existe uma influência do plasticizante nas propriedades térmicas do PHB. Em termos dessas propriedades foi observada uma diminuição da $T_{m}$ (pico), $T_{m}$ (onset), $\Delta H_{m}$ e \% Cristalinidade para as misturas PHB/G e PHBV/G. Segundo este autor, as depressões do ponto de fusão aconteceram porque o comportamento do plasticizante é como uma "impureza" que causa uma redução na espessura lamelar dos cristais do polímero (ROSÁRIO, 2005).

Como não foi possível a determinação da $T_{g}$ por DSC, qualquer discussão sobre a miscibilidade baseado no comportamento desta temperatura, torna-se impossível.

Analisando a quantidade de calor nas curvas DSC durante o primeiro evento (Figuras 42, 43 e 44) foi observado que a diminuição de $\Delta \mathrm{H}$ envolvido nos eventos térmicos esteve diretamente relacionado com a diminuição de água nas amostras, assim foi observado uma maior entalpia para a amostra TPS, durante o primeiro aquecimento. Essa constatação foi relatada também por Innocentini-Mei e colaboradores (2003) para blendas de amido e PHB e por Reis e colaboradores (2008) para as blendas de amido e PHBV (INNOCENTINI-MEI; BARTOLI; RODRIGO, 2003; REIS et al., 2008). 
Lima e Felisberti (2006) confirmaram os valores de cristalinidade do PHB de $60 \%$, mesmo a amostra sendo preparada por casting (LIMA; FELISBERTI, 2006). Segundo Reis e colaboradores (2008), a amostra PHBV apresentou pico de cristalização entre 45 e $58{ }^{\circ} \mathrm{C}$, utilizando uma taxa de aquecimento de $20{ }^{\circ} \mathrm{C}$ min $^{-1}$ (REIS et al., 2008).

Foi observada uma redução na entalpia de fusão $(\Delta \mathrm{H})$ para as amostras PHB70G30, PHBV70G30 e PHB35PHBV35G30 quando comparadas com as amostras PHB, PHBV e PHB50PHBV50, como consequência da menor quantidade desses dois polímeros nas misturas.

Saito e colaboradores (2001) estudaram as misturas PHB/PHBV utilizando o polímero PHBV, com 9 e $15 \%$ de HV. Para a mistura PHB/PHBV com $9 \%$ de HV foi observada apenas uma temperatura de fusão. Esse estudo corroborou para a análise do perfil da curva PHB50PHBV50 realizada no presente trabalho. Como especificado anteriormente, o PHBV utilizado no trabalho é composto de 3 a $12 \%$ de HV (SAITO; INOUE; YOSHIE, 2001).

\subsection{Microscopia Eletrônica de Varredura - (MEV)}

Com a aplicação da técnica Microscopia Eletrônica de Varredura (MEV) foram avaliadas as superfícies dos materiais de partida (Amido de Batata, PHB e PHBV) e as superfícies de fratura criogênica da amostra TPS, das blendas TPS/PHB, TPS/PHBV e TPS/PHB/PHBV e das amostras de PHB e/ou PHBV, observando aspectos morfológicos gerais. Para as blendas avaliou-se também a interface (adesão) entre o TPS e os polímeros. 
O tipo específico de padrão morfológico obtido em um dado sistema polimérico está diretamente relacionado às condições de processamento, composição e propriedades reológicas do sistema. Segundo Barra (2003), dependendo dos componentes poliméricos, a mistura pode se apresentar de forma não homogênea. Blendas com esta característica apresentam alta tensão interfacial e fraca adesão entre a matriz e a fase dispersa (BARRA et al., 2003).

\section{Materiais de Partida - Amido de Batata, PHB e PHBV}

As características morfológicas, reológicas e térmicas do amido de batata variam de acordo com o genótipo e origem biológica da batata. As suas propriedades dependem do tamanho e da distribuição dos grânulos, teor de amilose e amilopectina, razão do conteúdo de minerais e entalpia de gelatinização.

A Figura 45 representa as micrografias de MEV para o amido de batata em aumento de 1000x e 5000x. Essas micrografias possibilitaram obter informações sobre a forma e tamanhos dos grânulos de amido.
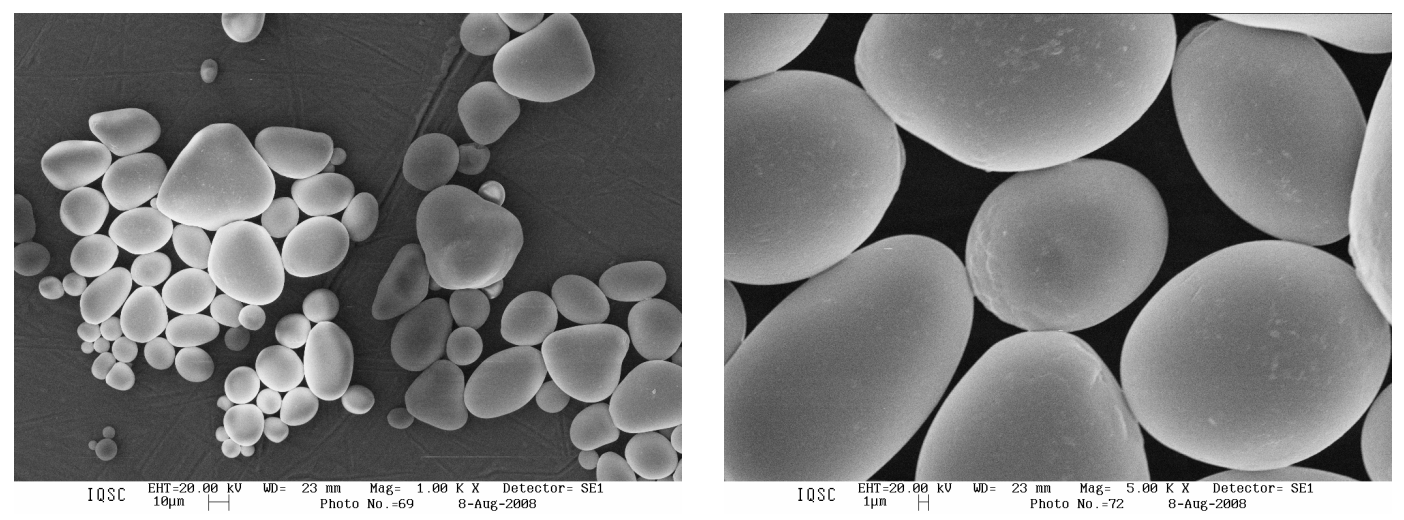

Figura 45 - Microscopia eletrônica de varredura do amido de batata com ampliações de 1000x e 5000x, respectivamente. 
Pelas micrografias apresentadas na Figura 45, notou-se que os grânulos de amido de batata são arredondados e ovais, com tamanhos situados de faixa de 5 a $60 \mu \mathrm{m}$, com maior intensidade nas faixas de, aproximadamente, $10-25 \mu \mathrm{m}$ e 30 $35 \mu \mathrm{m}$ (vide histograma - Figura 46). Segundo Cereda e colaboradores (2001) e Moorthy e colaboradores (2002) dentre os diferentes tipos de amidos, os de batatas são os de maior tamanho, de 5 a $100 \mu \mathrm{m}$ e entre 2 a $72 \mu \mathrm{m}$, respectivamente (CEREDA, 2001; MOORTHY, 2002).

Singh e Singh (2001) analisaram a forma e o tamanho de grânulos de amido de batata (Solanum tuberosum) e observaram diferenças significativas para estes parâmetros entre os diferentes cultivos. Quanto à forma, esta variou de oval para regular ou cuboidal, com diâmetros médios para grânulos pequenos e grandes entre $15-20 \mu \mathrm{m}$ e 20 - $45 \mu \mathrm{m}$, respectivamente (SINGH; SINGH, 2001). Os dados de Singh e Singh corroboram com os do presentre trabalho.

A presença de grânulos com a forma irregular foi predominante dentre todas as formas dos grânulos do amido de batata, sendo observado em menores quantidades grânulos pequenos e ovais. Esse estudo foi confirmado por Kaur e colaboradores (2002) (KAUR; SINGH; SODHI, 2002).

A Figura 46 representa o histograma para determinar a quantidade de grânulos com os seus respectivos tamanhos. 


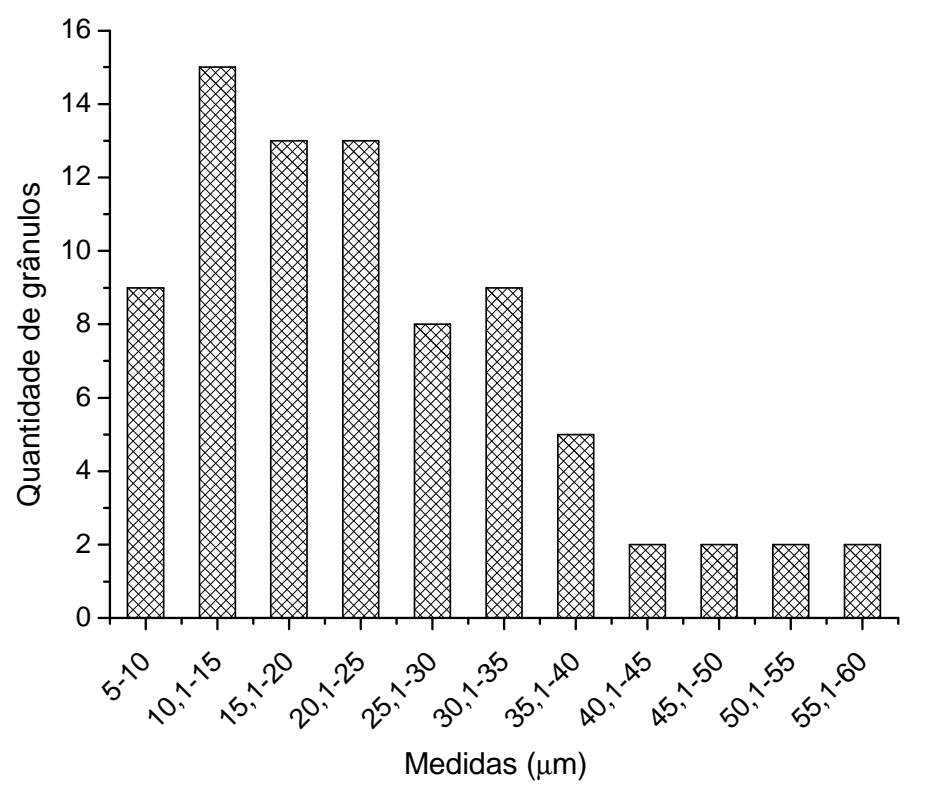

Figura 46 - Histograma das quantidades e tamanhos dos grânulos de amido de batata.

A Figura 47 representa as micrografias de MEV para o PHB (A) e PHBV (B), respectivamente, como materiais de partida, em aumentos de 5.000x.

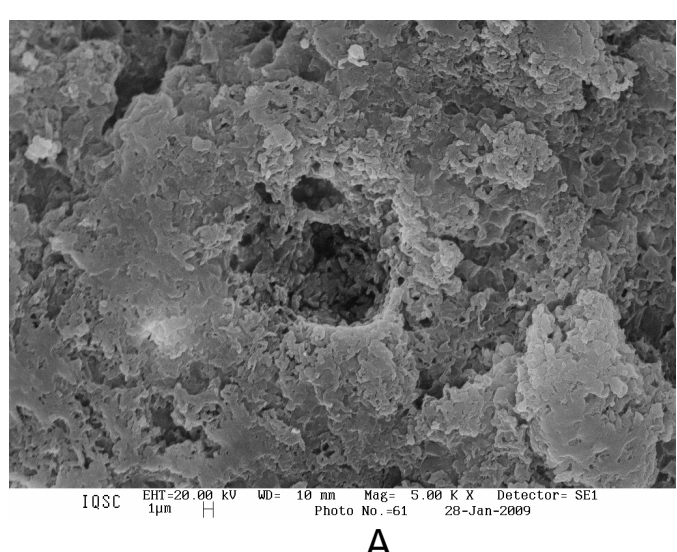

A

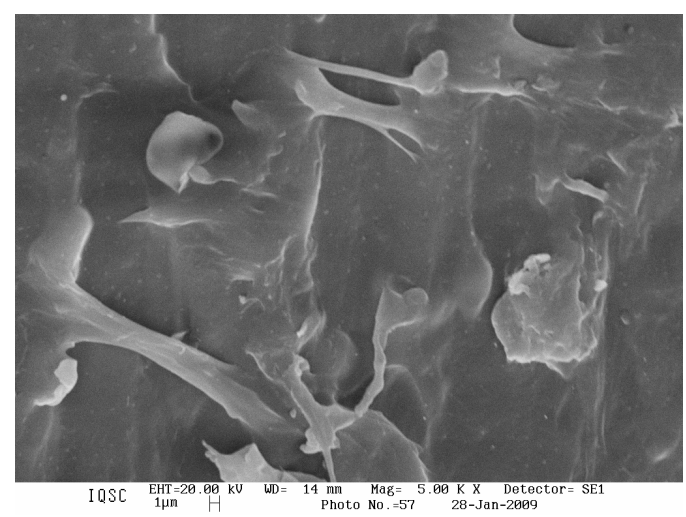

B

Figura 47 - Microscopia eletrônica de varredura do PHB (A) e PHBV (B) com ampliações de 5.000x.

A micrografia do PHB (pó) (Figura 47 A) apresentou aglomerados do polímero na superfície, já o PHBV (pellet) (Figura 47 B) apresentou uma superfície homogênea. 
A Figura 48 ilustra as micrografias de MEV para o amido de batata plasticizado com glicerol e água (TPS) em aumentos de 500x e 1000x.

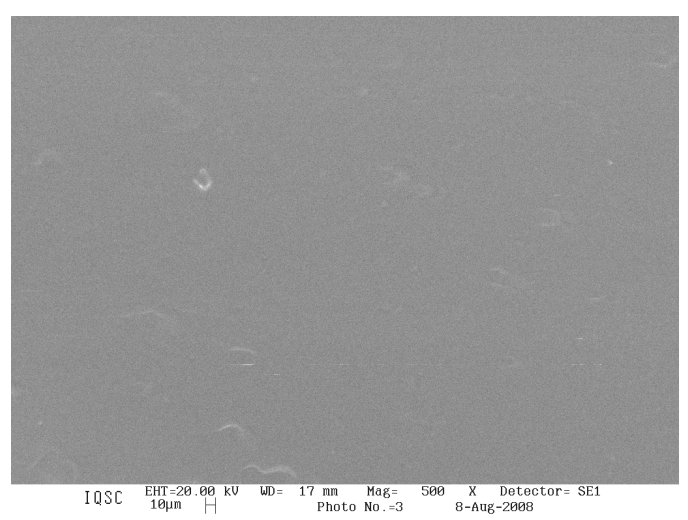

A1

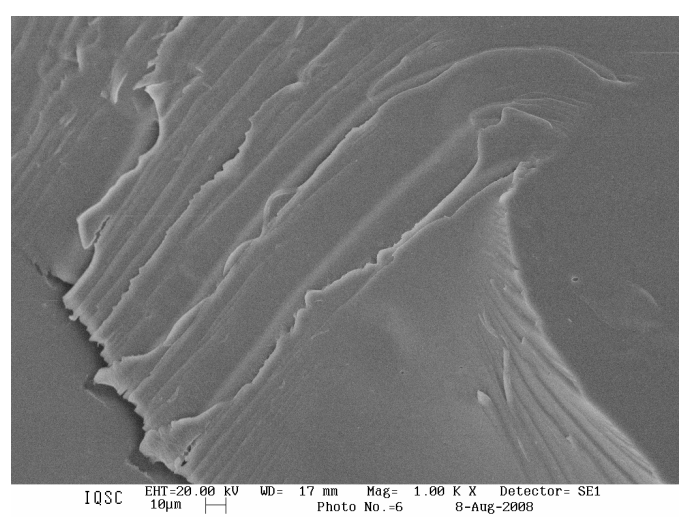

$\mathrm{A} 2$

Figura 48 - Microscopia Eletrônica de Varredura do TPS com aumentos de 500x (A1) e 1000x (A2).

Pelas microscopias da amostra TPS (Figura 48 (A1 e A2)) foi observada uma superfície homogênea e algumas deformações plásticas ocorridas durante a fratura. Esta amostra indicou que o processamento no reômetro de torque foi capaz de promover o rompimento dos grânulos de amido, dando origem a uma matriz polimérica homogênea.

Comparado a microscopia do amido nativo, na forma de grânulos (Figura 45) com o amido plasticizado (TPS) (Figura 48) foi observada uma fase contínua para o TPS, sem grânulos residuais. Wang e colaboradores (2009) confirmaram essas características para a amostra TPS (WANG et al., 2009). 
As Figuras 49, 50 e 51 apresentam as micrografias de MEV para as blendas TPS/PHB, TPS/PHBV, TPS/PHB/PHBV e amostras de PHB e/ou PHBV, em aumento de 1000x.

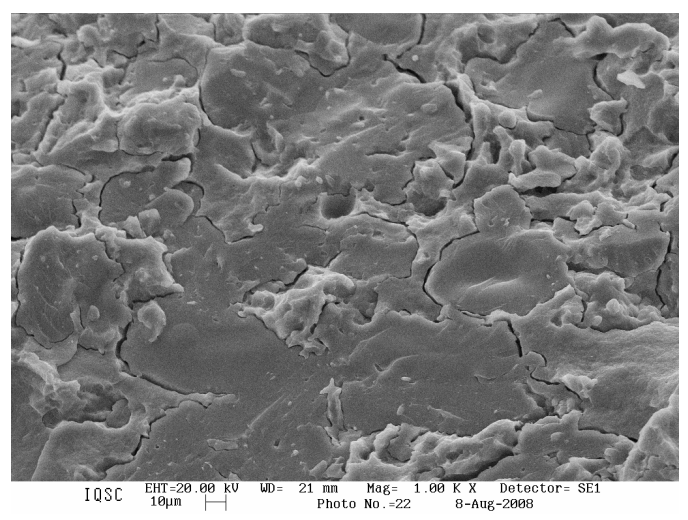

A

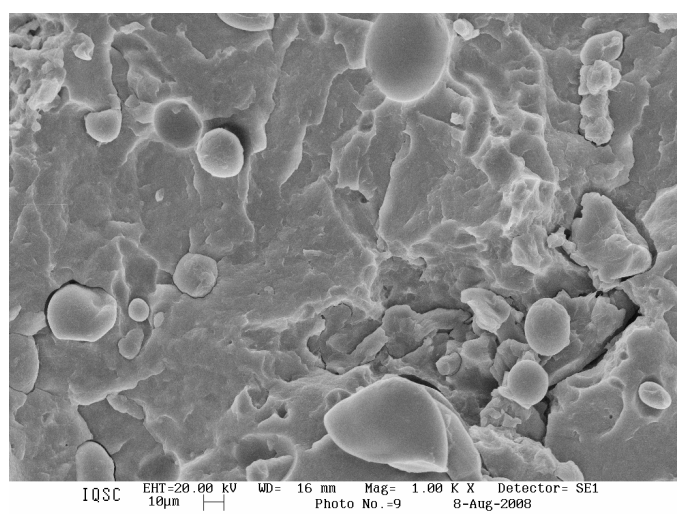

C

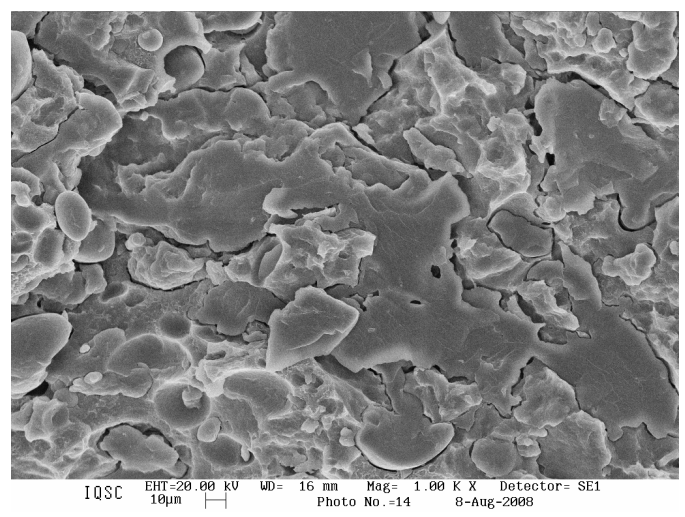

B

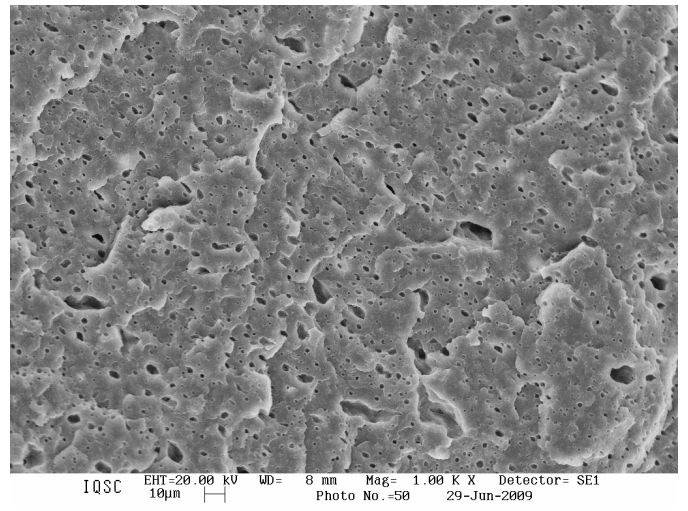

$\mathrm{D}$

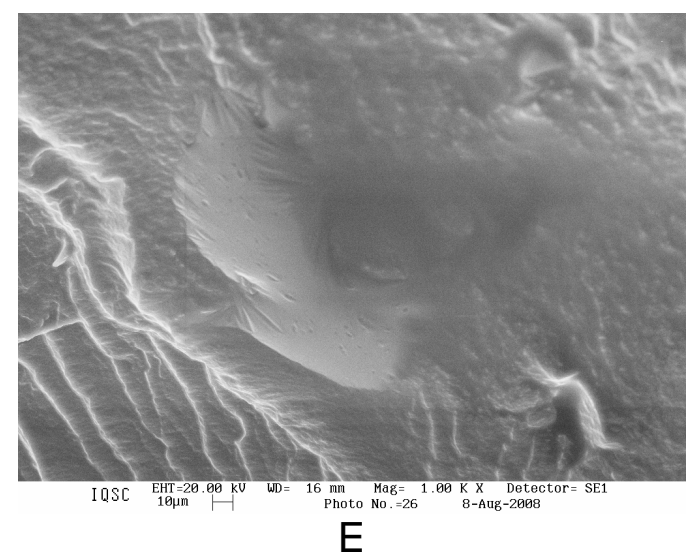

Figura 49 - Microscopia Eletrônica de Varredura das blendas PHB25 (A), PHB50 (B), PHB75 (C), PHB70G30 (D) e PHB (E), com aumentos de 1000x. 


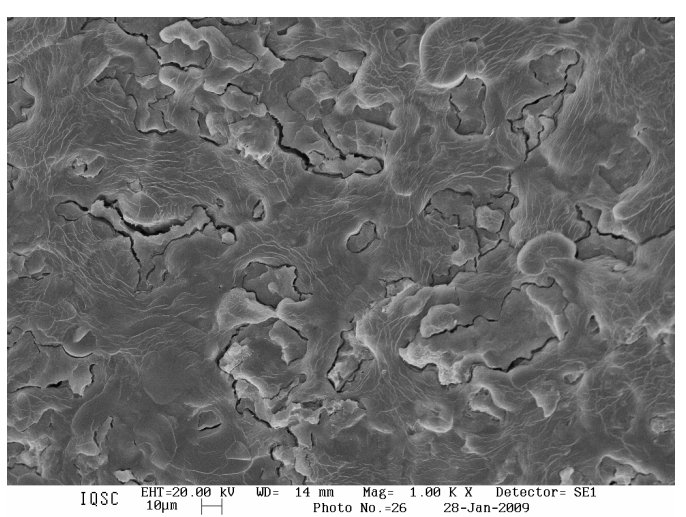

A

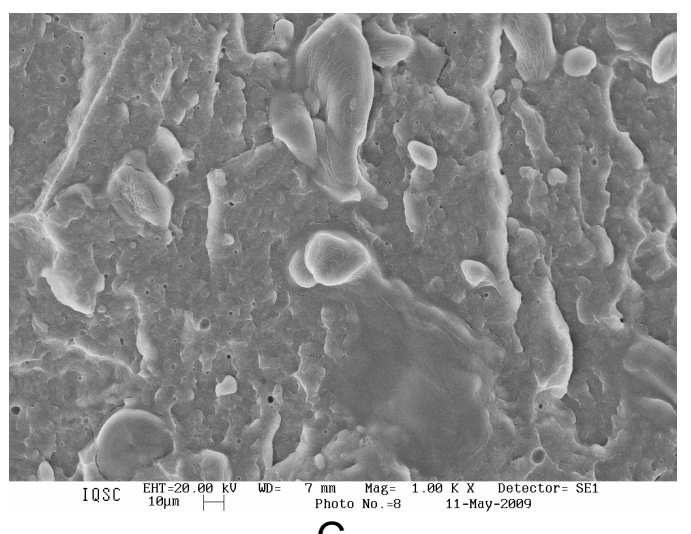

C

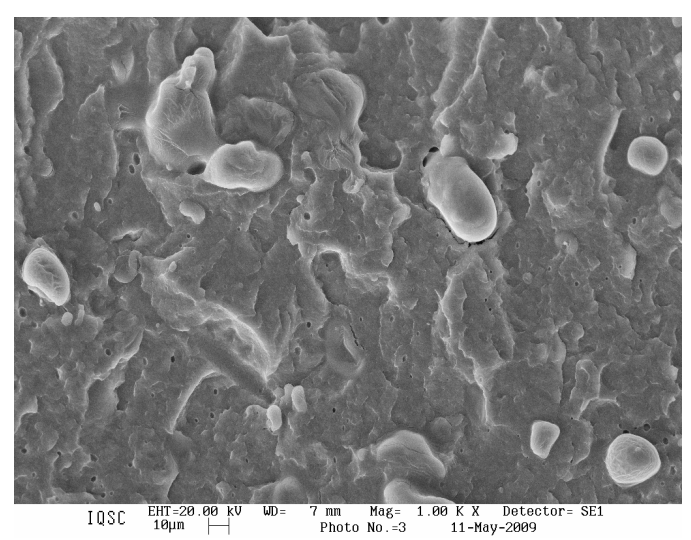

B

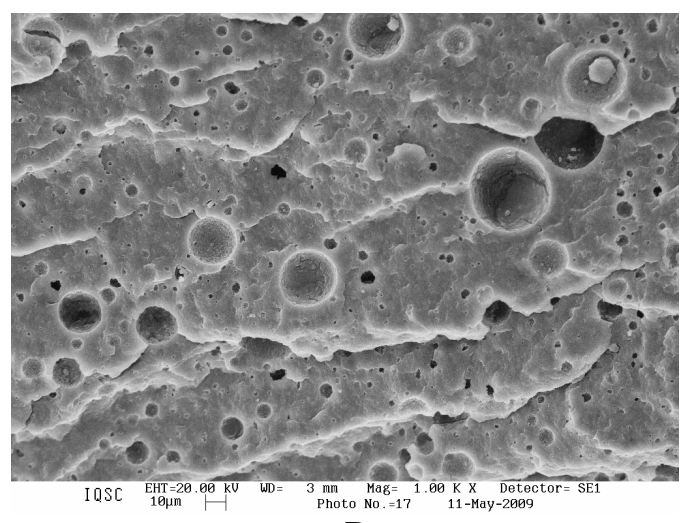

D

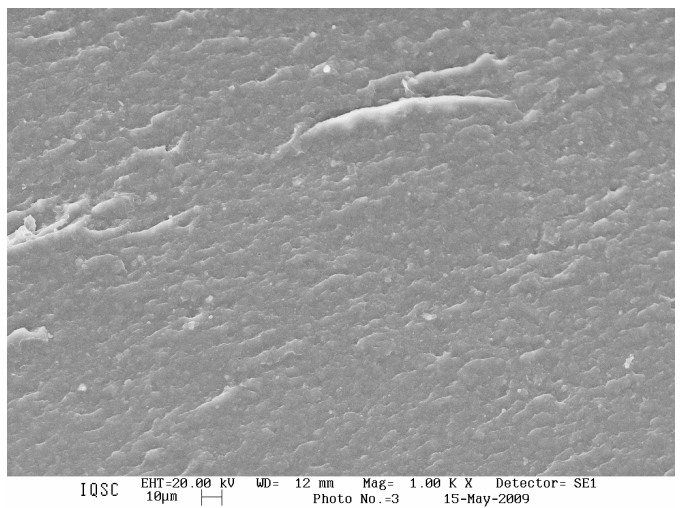

$\mathrm{E}$

Figura 50 - Microscopia Eletrônica de Varredura das blendas PHBV25 (A), PHBV50 (B), PHBV75 (C), PHBV70G30 (D) e PHBV (E), com aumentos de 1000x. 


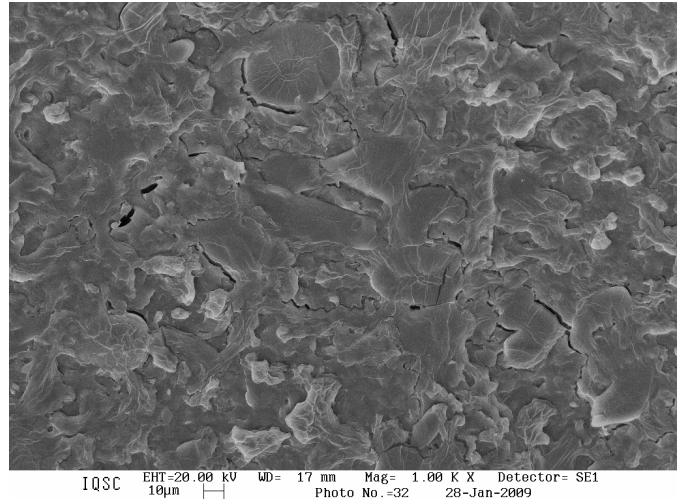

A

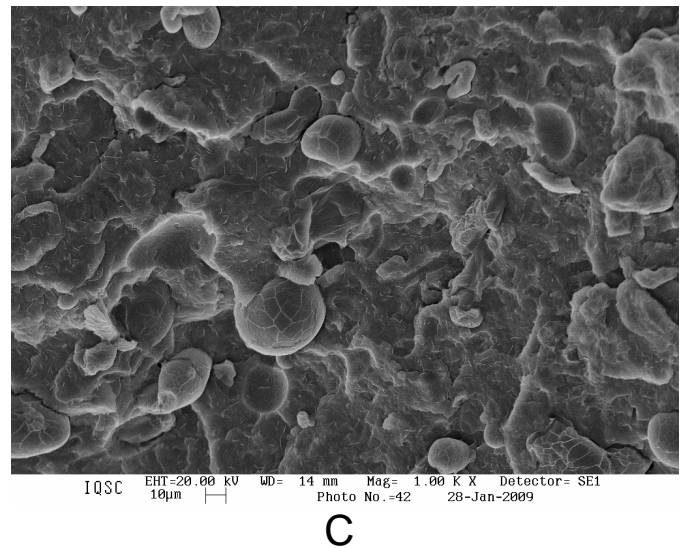

C

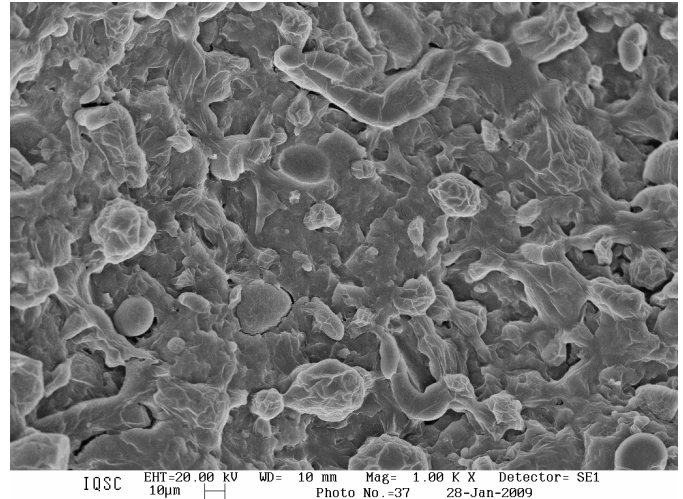

B

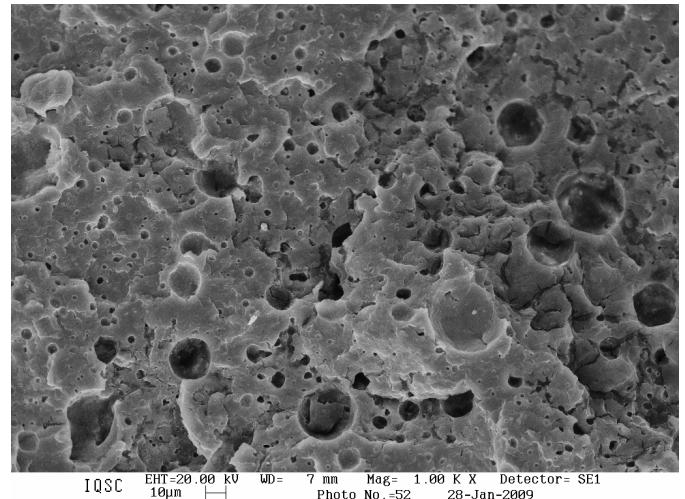

D

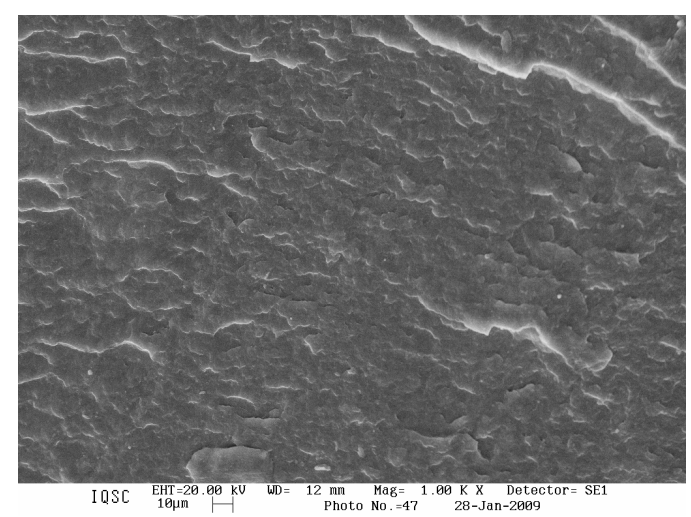

E

Figura 51 - Microscopia Eletrônica de Varredura das blendas PHB12,5PHBV12,5 (A), PHB25PHBV25 (B), PHB37,5PHBV37,5 (C), PHB35PHBV35G30 (D) e PHB50PHBV50 (E), com aumento de 1000x.

Foi relatado anteriormente que os grânulos de amido de batata são arredondados e ovais, com uma ampla distribuição de partículas com diâmetro entre 10-25 $\mu \mathrm{m}$ e 30-35 um (Figura 45). Parece razoável concluir que as amostras apresentaram a presença de grânulos não desestruturados nas superfícies das 
blendas TPS/PHB, TPS/PHBV e TPS/PHB/PHBV (Figuras 49, 50 e 51 (A, B e C)), já que os diâmetros destes grânulos estão dentro da faixa de tamanho dos grânulos de amido nativo.

Para as blendas com menor teor de amido (Figuras 49, 50 e 51 (B e C)), os grânulos mantiveram-se dispersos em toda a matriz. As amostras com maior conteúdo do amido (Figuras 49, 50 e 51 (A) apresentaram-se mais homogêneas e com menor quantidade de grânulos. A partir dessas observações, pôde-se concluir que maiores teores de PHB e PHBV levaram a uma maior dificuldade em desestruturar os grânulos de amido contidos nas blendas TPS/PHB, TPS/PHBV e TPS/PHB/PHBV.

Uma característica bastante visível nas blendas TPS/PHB/PHBV (Figuras 51 ( $A$, B e $C)$ ), que não foi observada nas blendas TPS/PHB e TPS/PHBV, foi o aparecimento de fissuras finas em todas as superfícies poliméricas.

A separação de fases, observada também por Lai e colaboradores (2006), Rosa e colaboradores (2001) e Koller e Owen (1996) pode ser explicada pela dificuldade de dispersão do amido em uma matriz polimérica menos polar, devido à presença de interações de hidrogênio entre as moléculas de amido (LAl; DON; HUANG, 2006; ROSA; FRANCO; CALIL, 2001; KOLLER; OWEN, 1996). Essas características para as amostras TPS/PHBV foram observadas também por Seves e colaboradores (1998) e Reis e colaboradores (2008) (SEVES et al., 1998; REIS et al., 2008).

A Figura 52 ilustra as micrografias de MEV para as amostras PHB, PHBV e PHB/PHBV e amostras PHB70G30, PHBV70G30 e PHB35PHBV35G30 com aumento de 500x e 1000x, respectivamente. 

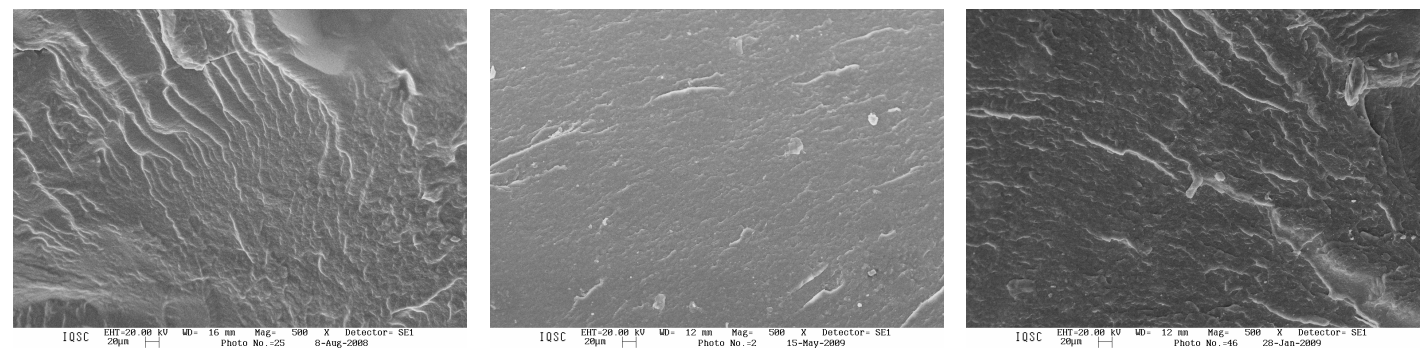

A
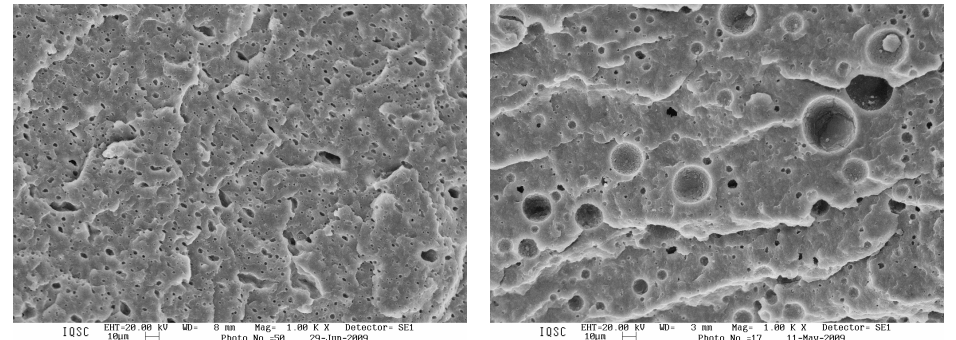

$\mathrm{B}$

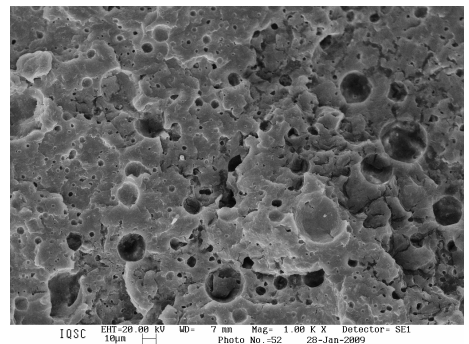

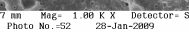

Figura 52 - Microscopia Eletrônica de Varredura das amostras PHB, PHBV e PHB50PHBV50, respectivamente, com aumento de 500x (A). Amostras PHB70G30, PHBV50G30 e PHB35PHBV35G30, respectivamente, com aumento de 1000x (B).

As amostras PHB, PHBV e PHB50PHBV50 (Figura 52 A) apresentaram superfícies de fraturas lisas, típicas de materiais frágeis, coerentes com o comportamento observado no ensaio de tração, apresentando ruptura frágil. Segundo Belem (2008), a superfície de fratura do PHB, exibe características dessas fraturas frágeis possivelmente em função da cristalinidade relativa considerável, com micrografias das amostras apresentando arestas e lascas, mesmo sendo processado na extrusora (BELEM, 2008).

Estas amostras, depois do processamento, mostraram-se mais consolidadas quando comparadas com os respectivos polímeros puros (antes do processamento) (Figura 47), porém com trincas e ranhuras na superfície. As características apresentadas para as amostras deste trabalho foram relatadas por vários autores na literatura (VINHAS et al., 2007; MORAES, 2004; THIRE'; RIBEIRO; ANDRADE, 2006; CORRÊA, 2006). 
Observado a amostra PHB50PHBV50, pôde-se perceber que as características superficiais da mistura dos dois polímeros foram às mesmas relatadas para os polímeros individuais (PHB e PHBV) (Figura $52 \mathrm{~A}$ ).

A adição de glicerol nos polímeros, amostras PHB70G30, PHBV70G30 e PHB35PHBV35G30 (Figura 52 B) apresentaram mudanças nas características superficiais em relação às amostras PHB, PHBV e PHB50PHBV50 sem a adição de glicerol (Figura $52 \mathrm{~A}$ ). Foram observados vazios com lacunas ou fendas distribuídos homogeneamente nas superfícies das amostras. Assim, pôde-se concluir que as misturas apresentaram pouca interação interfacial entre os polímeros e o plasticizante, visto que esses vazios são consequências da perda de glicerol durante o processamento ou durante a termoprensagem para os corpos de prova.

\subsection{Espectroscopia de Absorção na região do Infravermelho com Transformada de Fourier - (FTIR)}

A técnica FTIR foi utilizada na identificação, determinação de grupos funcionais e nos estudos de conformação e estrutura dos materiais de partida (Amido de Batata, PHB e PHBV), da amostra TPS, das blendas TPS/PHB, TPS/PHBV e TPS/PHB/PHBV e das amostras de PHB e/ou PHBV.

\section{Materiais de Partida}

\section{Amido de Batata}


A Figura 53 apresenta o espectro na região de infravermelho do amido de batata. As principais bandas de absorção estão apresentadas na Tabela 18.

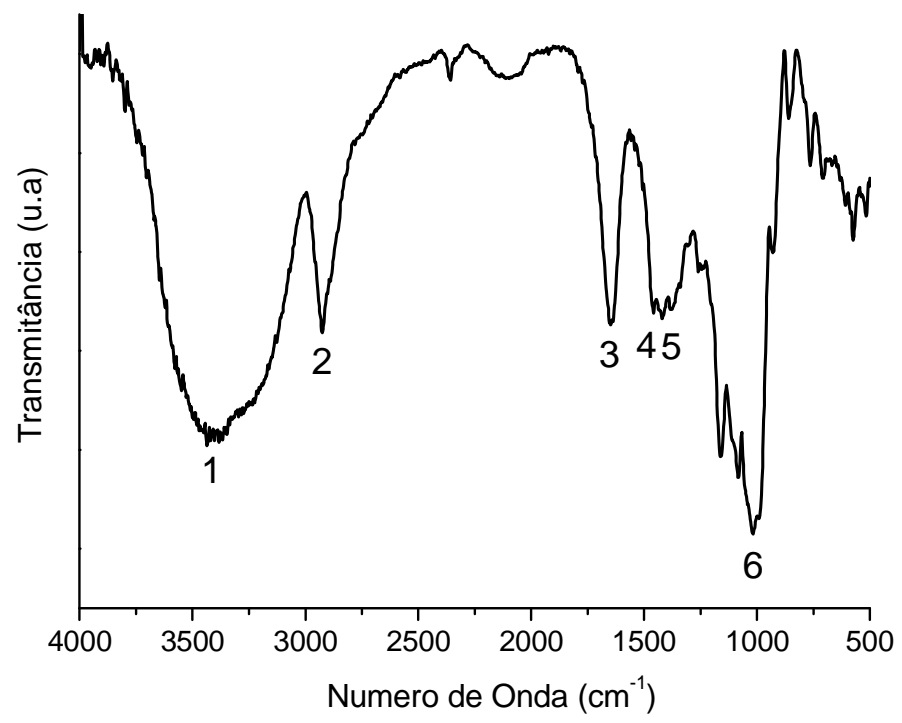

Figura 53 - Espectro na região de infravermelho do amido de batata.

Tabela 18 - Principais atribuições para as bandas de absorção no IV para o amido de batata.

\begin{tabular}{ccc}
\hline Bandas & $\begin{array}{c}\text { Número de onda } \\
\left(\mathbf{c m}^{-1}\right)\end{array}$ & Atribuição \\
\hline $\mathbf{1}$ & 3450 & Deformação axial de O-H \\
$\mathbf{2}$ & 2925 & Deformação axial de $\mathrm{C}-\mathrm{H}$ \\
$\mathbf{3}$ & 1643 & Deformação angular de $\mathrm{O}-\mathrm{H}\left(\mathrm{H}_{2} \mathrm{O}\right)$ \\
$\mathbf{4}$ & 1456 & Deformação angular de $\mathrm{C}-\mathrm{H}$ \\
$\mathbf{5}$ & $1417-1384$ & Deformação angular de C-H \\
$\mathbf{6}$ & $1261-931$ & Deformação axial da ligação éter \\
\hline
\end{tabular}

As principais bandas observadas para o amido de batata (Figura 53 e Tabela 18) são atribuídas à presença de grupos hidroxilas em $3450 \mathrm{~cm}^{-1}$ ou correspondente a deformação axial O-H, deformação axial da ligação $\mathrm{C}-\mathrm{H}$ em $2925 \mathrm{~cm}^{-1}$ e a deformação axial da ligação éter entre 1159 e $1085 \mathrm{~cm}^{-1}$.

O espectro de FTIR do amido (Figura 53) apresentou-se similar ao espectro ilustrado por Ma e Yu (2004), que descrevem uma banda alargada na região de 
$3450 \mathrm{~cm}^{-1}$, correspondente a vibrações de deformação associadas com ligações de hidrogênio (intramolecular e intermolecular) e uma banda em $1645 \mathrm{~cm}^{-1}$ correspondente a deformação angular da $\mathrm{H}_{2} \mathrm{O}$. O espectro não apresentou sinais na região $2600-1800 \mathrm{~cm}^{-1}$ (MA; YU, 2004).

Reis e colaboradores (2008) e Imam e colaboradores (1998) também confirmaram as principais bandas observadas para amostra de amido, sendo destacada por Imam, o conjunto de bandas relacionado a deformação C-O entre 1190 e $960 \mathrm{~cm}^{-1}$ (REIS et al., 2008; IMAM et al., 1998).

\section{PHB e PHBV}

Os espectros de FTIR das amostras de PHB e PHBV estão ilustrados na Figura 54 e as principais bandas de absorção estão apresentadas na Tabela 19.

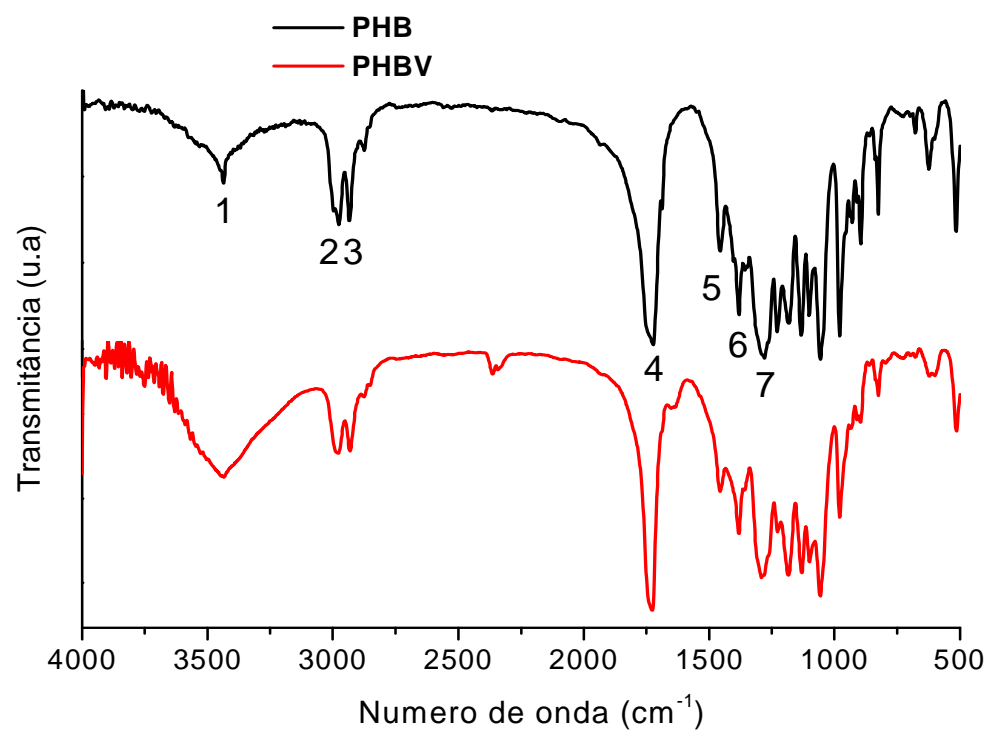

Figura 54 - Espectro na região de infravermelho do PHB e PHBV, respectivamente. 
Tabela 19 - Principais atribuições para as bandas de absorção no IV para os polímeros PHB e PHBV.

\begin{tabular}{crrr}
\hline Bandas & \multicolumn{2}{c}{$\begin{array}{c}\text { Número de onda } \\
\left(\mathbf{c m}^{-1}\right)\end{array}$} & Atribuição \\
\hline $\mathbf{1}$ & PHB & PHBV & \\
$\mathbf{2}$ & 3437 & 3439 & "overtone" da carbonila C=O \\
$\mathbf{3}$ & 2976 & 2981 & Deformação axial assimétrica da ligação C-H \\
$\mathbf{4}$ & 2933 & 2931 & Deformação axial simétrica da ligação C-H \\
$\mathbf{5}$ & 1722 & 1730 & Deformação axial da carbonila C=O \\
$\mathbf{6}$ & 1454 & 1454 & Deformação angular assimétrica do $\mathrm{CH}_{3}$ \\
$\mathbf{7}$ & 1383 & 1380 & Deformação angular simétrica do $\mathrm{CH}_{3}$ \\
\hline
\end{tabular}

Os espectros correspondentes a amostra PHB e PHBV (Figura 54 e Tabela 19) ilustraram bandas de absorção bem intensas e características de poliésteres devido à deformação axial da carbonila $\mathrm{C}=\mathrm{O}$ em 1722 e $1730 \mathrm{~cm}^{-1}$. Essa banda principal foi relatada por Moraes (2004), Duarte (2004), Imam e colaboradores (1998) e Buzarovska e Grozdanov (2009), sendo que este último autor relatou esta banda como modo de estiramento da parte cristalina do polímero (MORAES, 2004; DUARTE, 2004; IMAM et al., 1998; BUZAROVSKA; GROZDANOV, 2009).

Segundo Rosa e colaboradores (2003), o alargamento da absorção da carbonila, em $1730 \mathrm{~cm}^{-1}$ do PHBV em relação ao espectro do PHB é devido à presença dos diferentes monômeros que compõem o PHBV (ROSA; PANTANO FILHO, 2003).

Os picos em 3437 e $3439 \mathrm{~cm}^{-1}$, observados nas amostras PHB e PHBV, respectivamente, foram denominados como overtone da carbonila $\mathrm{C}=\mathrm{O}$ (SOCRATES, 2004), cujas absorções principais foram observadas em 1722 e 1730 $\mathrm{cm}^{-1}$. 
Buzarovska e Grozdanov (2009) destacaram que os picos entre 1290 e 1060 $\mathrm{Cm}^{-1}$ para a amostra PHB e PHBV foram às deformações de C-O-C da parte cristalina dos polímeros, corroborando com os picos do presente trabalho (BUZAROVSKA; GROZDANOV, 2009).

\section{TPS}

A Figura 55 ilustra as características do espectro na região de infravermelho para a amostra TPS. Para melhor visualização das diferenças nas bandas do amido e TPS, o espectro do amido de batata também foi ilustrado nesta Figura 55. As principais bandas de absorção estão apresentadas na Tabela 20.

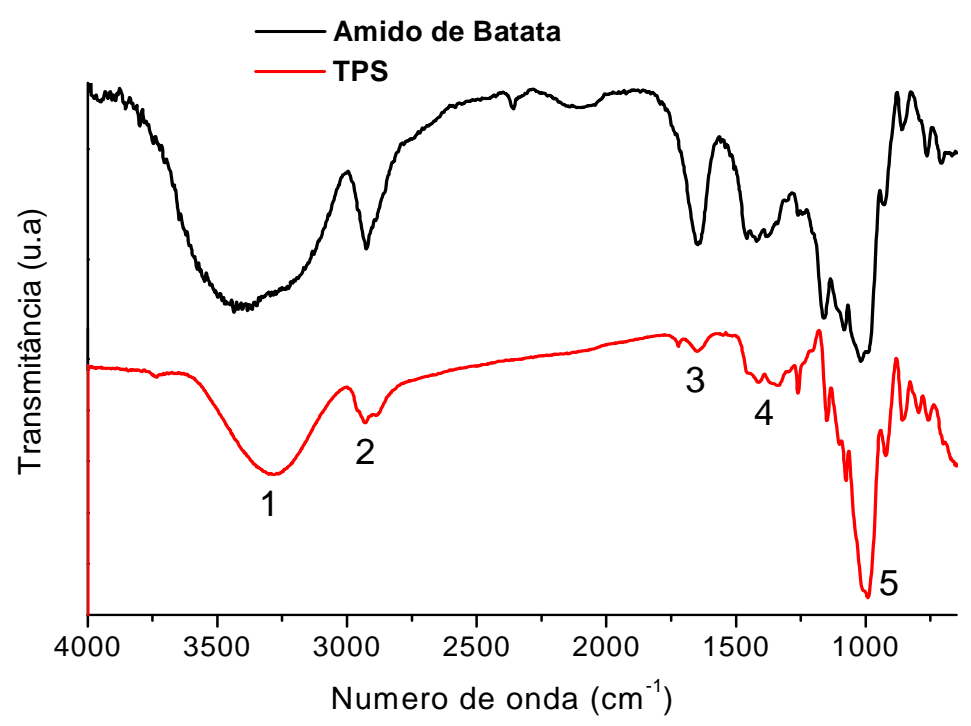

Figura 55 - Espectro na região de infravermelho das amostras amido de batata e TPS, respectivamente. 
Tabela 20 - Principais atribuições para as bandas de absorção no IV para a amostra TPS.

\begin{tabular}{ccc}
\hline Bandas & $\begin{array}{c}\text { Número de onda } \\
\left(\mathbf{c m}^{-1}\right)\end{array}$ & Atribuição \\
\hline $\mathbf{1}$ & 3282 & Deformação axial de O-H. \\
$\mathbf{2}$ & 2930 & Deformação axial de C-H \\
$\mathbf{3}$ & 1650 & Deformação angular de O-H $\left(\mathrm{H}_{2} \mathrm{O}\right)$ \\
$\mathbf{4}$ & $1414-1336$ & Deformação angular de C-H \\
$\mathbf{5}$ & $1259-991$ & Deformação axial da ligação éter \\
\hline
\end{tabular}

Para a amostra TPS (Figura 55 e Tabela 20) foram observadas as principais bandas nos seus respectivos números de onda: $3282 \mathrm{~cm}^{-1}$ determinadas como deformação axial do grupo $\mathrm{OH} ; 2930 \mathrm{~cm}^{-1}$ deformação axial dos grupos $\mathrm{C}-\mathrm{H}$ e entre 1150 e $1076 \mathrm{~cm}^{-1}$ banda correspondente à deformação axial da ligação éter. Todas essas bandas também foram observadas para o amido de batata (Figura 53 e Tabela 18).

As principais diferenças nas bandas verificadas entre as amostras de amido e TPS estão no deslocamento da banda $\mathrm{OH}$, sendo que para o TPS a banda foi observada em $3282 \mathrm{~cm}^{-1}$ e para o amido em $3450 \mathrm{~cm}^{-1}$, indicando modificações no padrão das ligações intermoleculares (ligações de hidrogênio) no sistema TPS (amido/glicerol). Outra diferença entre as amostras foi na intensidade da banda em $1650 \mathrm{~cm}^{-1}$, relacionada à deformação angular do grupo $\mathrm{O}-\mathrm{H}$ da $\mathrm{H}_{2} \mathrm{O}$, sendo que para o amido de batata esta absorção apresentou-se mais intensa.

Foi observado ainda, para a amostra TPS (Figura 55) uma melhor resolução do sinal devido à deformação axial C-H $\left(2930\right.$ e $\left.2885 \mathrm{~cm}^{-1}\right)$. Essa observação também foi relatada por Pushpadass e colaboradores (PUSHPADASS et. al., 2008).

Não existem diferenças significativas na região entre 1414 e $1336 \mathrm{~cm}^{-1}$ para as amostras de amido e TPS, mas entre 1259 e $991 \mathrm{~cm}^{-1}$ (deformação axial C-O) foi 
observado um aumento da intensidade no espectro da segunda amostra, a qual poderia ser devida às interações do plasticizante glicerol com o amido.

Assim, concluiu-se que a conversão de amido em TPS envolveu formação de ligações de hidrogênio de natureza diferente das ligações de hidrogênio encontradas no amido não desestruturado.

\section{Blendas TPS/PHB, TPS/PHBV e TPS/PHB/PHBV}

As Figuras 56, 57 e 58 apresentam as características dos espectros de FTIR para a amostra TPS, blendas TPS/PHB, TPS/PHBV e TPS/PHB/PHBV e amostras de PHB e/ou PHBV. Todos os corpos de prova foram secos antes das análises.

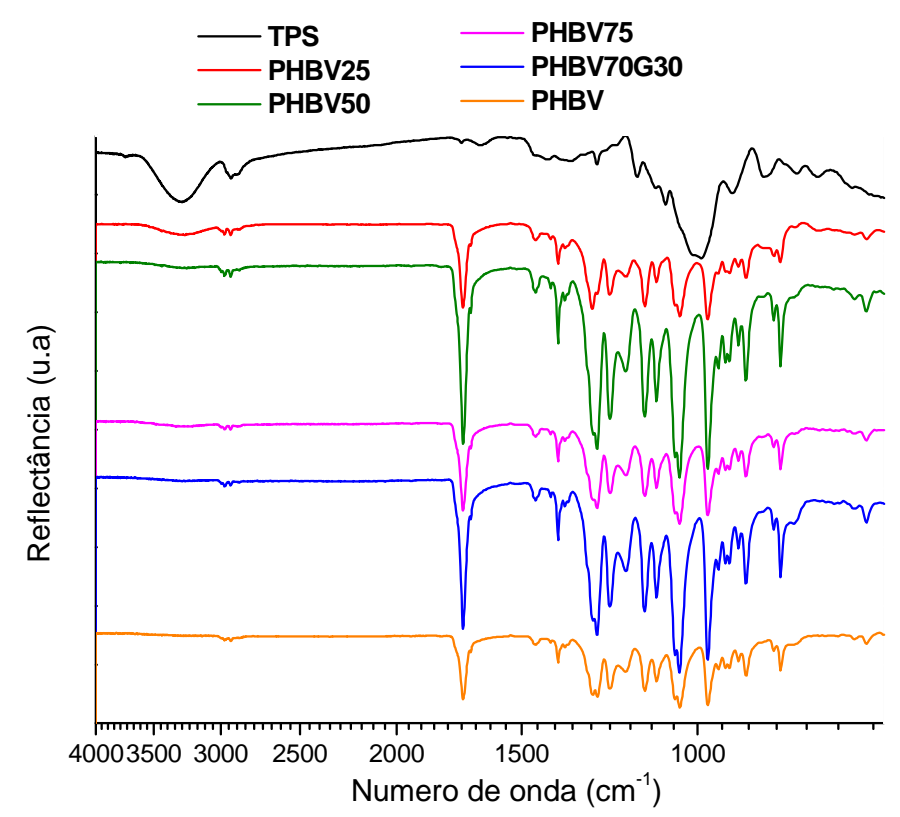

Figura 56 - Espectros de FTIR na região de 4000 a $650 \mathrm{~cm}-1$, para a amostra TPS, blendas TPS/PHB e amostras de PHB. 


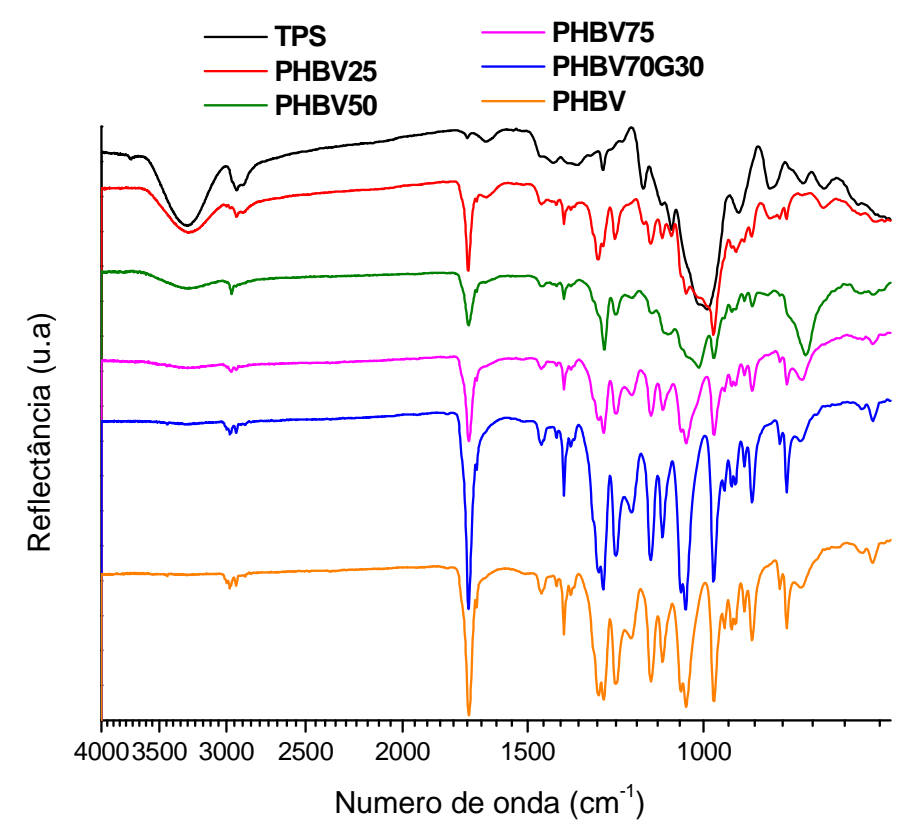

Figura 57 - Espectros de FTIR na região de 4000 a $650 \mathrm{~cm}-1$, para a amostra TPS, blendas TPS/PHBV e amostras de PHBV.

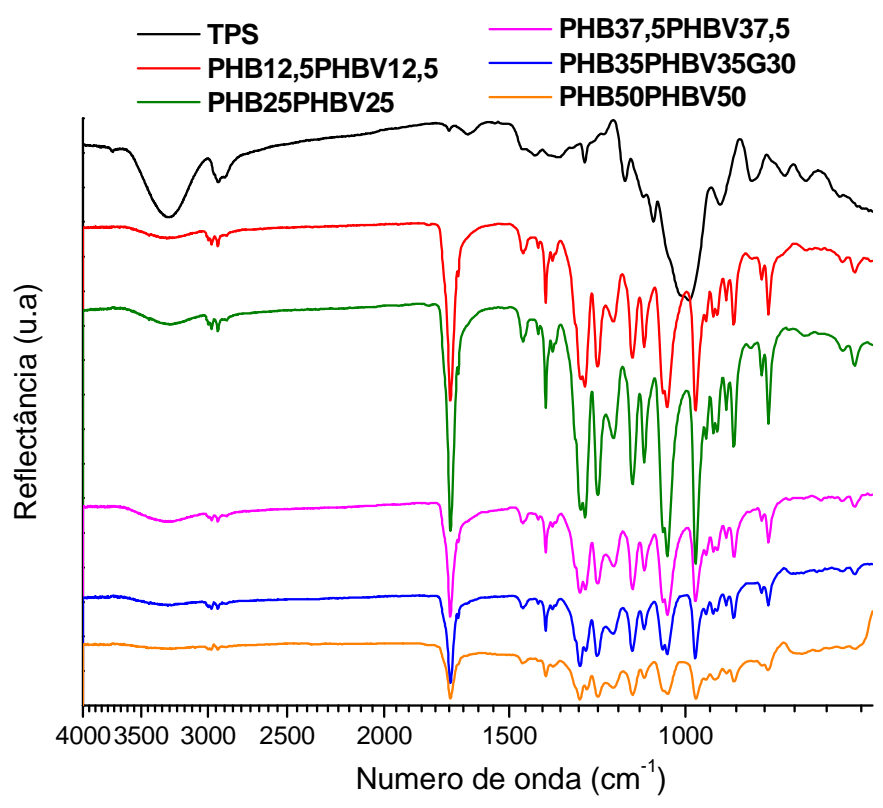

Figura 58 - Espectros de FTIR na região de 4000 a $650 \mathrm{~cm}-1$, para a amostra TPS, blendas TPS/PHB/PHBV e amostras de PHB/PHBV.

De acordo com as Figuras 56, 57 e 58, a banda de deformação axial O-H em aproximadamente $3450 \mathrm{~cm}^{-1}$ foi observada para a amostra TPS e para as blendas 
com maiores conteúdos de TPS, sendo que a medida que aumentou a quantidade de PHB e/ou PHBV nas amostras, a banda foi diminuindo de intensidade.

As bandas em aproximadamente 2933 e $2976 \mathrm{~cm}^{-1}$ para as blendas correspondentes à deformação axial da ligação $\mathrm{C}-\mathrm{H}$ foram observadas em todos os espectros, embora com padrão diferente para as amostras de TPS.

Os picos na região de 1900 a $650 \mathrm{~cm}^{-1}$ ilustraram nitidamente a banda em $1716 \mathrm{~cm}^{-1}$, correspondente a deformação axial da ligação dupla $\mathrm{C}=\mathrm{O}$ nas blendas TPS/PHB, TPS/PHBV e TPS/PHB/PHBV e nas amostras com PHB e/ou PHBV, não sendo relatado para a amostra TPS, conforme esperado. Pushpadass e colaboradores $(2008,2009)$ corroboraram com o presente trabalho (PUSHPADASS et. al., 2008; PUSHPADASS et. al., 2009).

Foi observado um deslocamento desta banda $\left(1716 \mathrm{~cm}^{-1}\right)$ nas blendas TPS/PHBV em relação à amostra PHBV, sendo que para a amostra com menor quantidade de PHBV (PHBV25), o pico foi relatado em $1720 \mathrm{~cm}^{-1}$ e para as amostras PHBV50, PHBV75 e PHBV em 1718, 1716 e $1714 \mathrm{~cm}^{-1}$, respectivamente, confirmando o deslocamento da deformação axial $\mathrm{C}=\mathrm{O}$.

Entre as diversas técnicas para avaliação da miscibilidade de componentes nas blendas poliméricas, tem sido utilizada a verificação de deslocamentos das bandas de absorção no infravermelho em relação ao número de onda, devido às interações entre grupos funcionais. Segundo Buzarovska e Grozdanov (2009), para as blendas miscíveis contendo polímeros com grupo carbonila geralmente observase um deslocamento da banda correspondente à deformação $\mathrm{C}=\mathrm{O}$, como nas blendas das Figuras 56, 57 e 58, mas com apenas esses deslocamentos não foi possível verificar a miscibilidade das blendas (BUZAROVSKA; GROZDANOV, 2009). 
Comparando as amostras PHB, PHBV e PHB50PHBV50 com as amostras PHB70G30, PHBV70G30 e PHB35PHBV35G30 pôde-se observar que não houve deslocamento de bandas, isto é, não foi possível constatar se existem interações específicas entre os componentes (polímeros e plasticizante). Comparando-se as amostras PHB, PHBV com a amostra PHB50PHBV50 também não houve deslocamento de bandas.

\subsection{Difração de Raios-X}

A cristalinidade é um importante parâmetro para definir propriedades físicas e químicas de um material polimérico. Dessa forma, a técnica Difração de Raios-X é tradicionalmente utilizada na determinação do índice de cristalinidade (Ic) ou grau de cristalinidade (\% C) em um material polimérico.

Foram realizadas análises de Difração de Raios-X para os materiais de partida sem nenhum tipo de tratamento prévio (Amido de Batata, PHB, PHBV) e para as amostras TPS, blendas TPS/PHB, TPS/PHBV e TPS/PHB/PHBV e amostras de PHB e/ou PHBV, com umidade relativa controlada de 53\%.

\section{Materiais de partida - Amido de Batata, PHB e PHBV}

Os difratogramas de raios- $X$ para o amido de batata, PHB e PHBV são apresentados na Figura 59. 


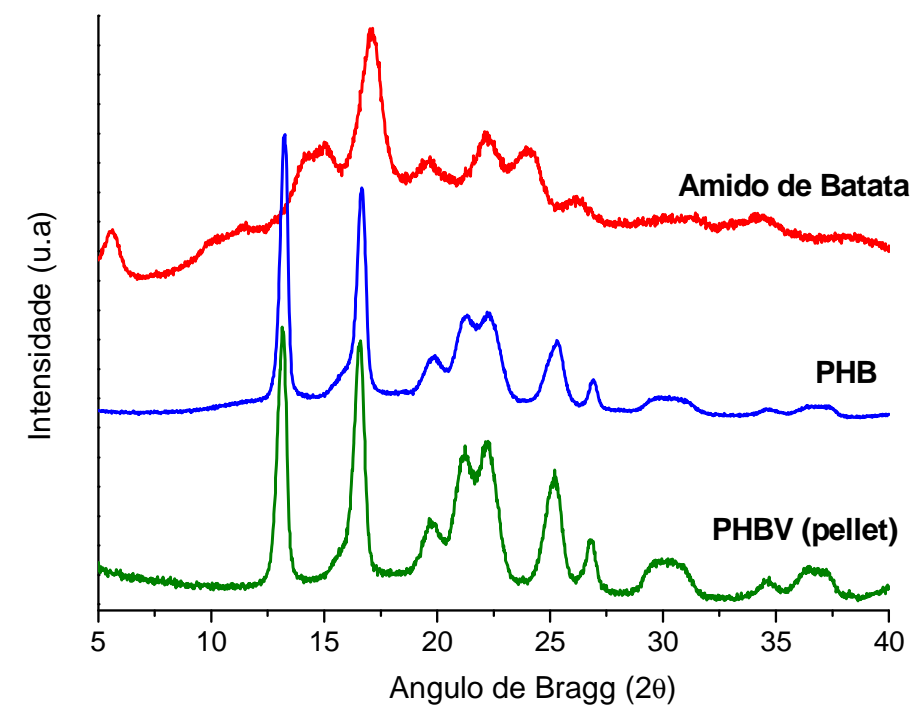

Figura 59 - Difratogramas de raios-X para o amido de batata, PHB e PHBV.

O índice de cristalinidade (Ic) para a amostra de amido de batata foi calculado empregando-se o método utilizado por Hulleman e colaboradores (1999) (Equação 7, página 57) (HULLEMAN et al., 1999).

Os grânulos de amido proporcionam padrões específicos de difração de raios$\mathrm{X}$ e alguns picos de intensidade de refração são característicos do padrão de cristalinidade. Os amidos de batata ou de tubérculos apresentam padrão tipo B. Segundo Hulleman e colaboradores (1999), amidos de padrão tipo B são reconhecidos por apresentarem picos em $2 \theta$ igual a $5^{\circ}$, um pico intenso em $2 \theta$ igual a $17^{\circ} \mathrm{e}$ um dupleto em $2 \theta$ igual a 22 e $24^{\circ}$ (HULLEMAN et al.,1999).

De acordo com a Figura 59, os picos observados foram em $2 \theta$ igual a 5,6 $15,1^{\circ}, 17,1^{\circ}, 19,7^{\circ}, 22,1^{\circ}$ e $24,3^{\circ}$, sendo o pico em $5,6^{\circ}$ de intensidade média e em $17,1^{\circ}$ de intensidade forte, dessa forma concluiu-se que a posição dos picos, bem como suas intensidades, caracterizou o amido de batata como padrão tipo B de cristalinidade. Estes resultados também foram encontrados em trabalhos realizados por outros autores com amido de batata (VAN SOEST et al.,1996b). 
O índice de cristalinidade obtido para o amido de batata pelo pico em $2 \theta$ igual a $17,1^{\circ}$ foi de $45 \%$, segundo o método proposto por Hulleman (1999). O valor de cristalinidade reportado na literatura para amidos de batata é de $59 \%$ ( $\pm 5 \%$ ) (HULLEMAN et al.,1999).

A natureza cristalina do amido depende do controle genético e as condições climáticas durante o crescimento da planta. O comprimento das cadeias envolvidas na fase cristalina e as ramificações das moléculas de amilopectina também influenciam na cristalinidade. Assim, essas características estão na origem da diferença da cristalinidade do amido de batata utilizado no presente trabalho quando comparado com a cristalinidade dos amidos reportados na literatura.

O perfil de difração de raios-X para o PHB é mostrado na Figura 59. Observase um perfil com picos de difração em $2 \theta$ iguais a $13,2^{\circ}$ e $16,7^{\circ}$ representados por dois picos intensos e os picos em $2 \theta$ iguais a $19,8^{\circ}, 21,2^{\circ}, 22,3^{\circ}, 25,3^{\circ}$ e $26,9^{\circ}$ representados pelos picos de intensidades média.

Comportamentos similares foram relatados na literatura (THIRÉ; RIBEIRO; ANDRADE, 2006; SKRBIC; DIVJAKOVIC, 1996). Segundo Thiré (2006), o perfil da amostra de PHB puro exibe picos bem definidos em $2 \theta$ iguais a $13,6^{a}, 17,1^{a}, 21,7^{\circ}$, $22,7^{\circ}$ e 25,6 $6^{\circ}$ que correspondem reflexões $020,110,101,111$ e 121, respectivamente e célula unitária do tipo ortorrômbica.

Segundo o método proposto por Ruland (1974), a cristalinidade do PHB foi de $59,9 \%$ (RULAND, 1974). Observou-se que o PHB é um polímero semicristalino e extremamente quebradiço. A utilização da técnica DSC, durante o primeiro aquecimento, revelou um valor de $50 \%$ para a cristalinidade deste polímero utilizado no presente trabalho. Galego e colaboradores (2000) observaram um valor de 
cristalinidade de 69 \% por Difração de raios-X e Duarte (2004) obteve um valor de 48,5 \% por DSC (GALEGO et al., 2000; DUARTE, 2004).

O perfil de difração de raios-X para o PHBV é mostrado na Figura 59. Observou-se um perfil de difração apresentando picos em $2 \theta$ iguais a $13,4^{\circ}$ e $16,8^{\circ}$ representados por dois picos intensos e picos em $2 \theta$ iguais a $19,9^{\circ}, 21,3^{\circ}, 22,4^{a}$, $25,4^{\circ}$ e $27^{\circ}$, mostrando-se semelhante ao do PHB.

Segundo Rodrigues (2004), o perfil da amostra do copolímero PHBV apresenta picos em $2 \theta$ iguais a $13,5^{\circ}, 16,9^{\circ}, 20^{\circ}, 22^{\circ}, 25,5^{\circ}, 27^{\circ}$ e $30^{\circ} \quad$ (RODRIGUES et al., 2004). Wang e colaboradores (2008) observaram reflexões em 020, 110 e 111 e o mesmo perfil da curva relatada no presente trabalho para a amostra PHBV (WANG et al., 2008).

Segundo o método proposto por Ruland (1974), a cristalinidade do PHBV foi de 62,8 \% (RULAND, 1974). Galego e colaboradores (2000) observaram o grau de cristalinidade para o PHBV entre 58,7 a 54,7\%, para quantidades de HV entre 8 e $24 \%$, respectivamente. Pela técnica DSC durante o primeiro aquecimento, para o presente trabalho, a cristalinidade determinada para a amostra de PHBV foi de 49 $\%$.

A comparação entre o PHB (homopolímero) e PHBV (copolímero) permite verificar a inexistência de novos picos no perfil de difração pela presença da segunda unidade monomérica HV para o copolímero ao homopolímero, indicando que a modificação interna da estrutura molecular impostas ao PHB não determinou o aparecimento de novas simetrias cristalinas. Esta observação também foi relatada por Galego e colaboradores (2000) (GALEGO et al., 2000). 
TPS

A Figura 60 ilustra as características do difratograma de raios- $X$ para a amostra TPS. Para melhor visualização das diferenças que o processamento promove, o difratograma do amido de batata também é ilustrado nesta Figura 60 .

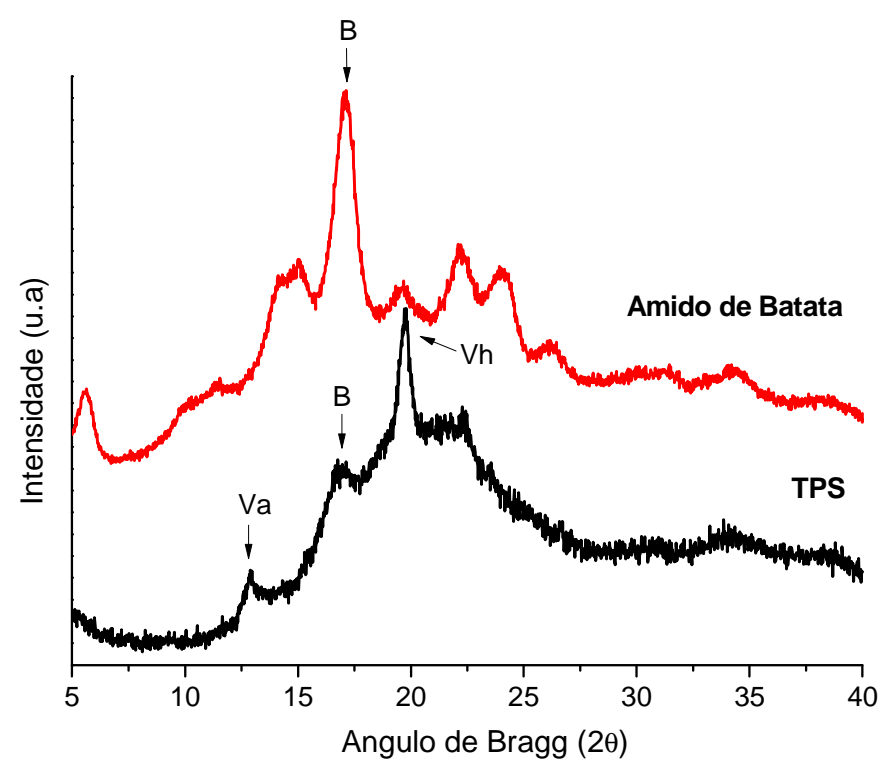

Figura 60 - Difratogramas de Raios-X do amido de batata e amostra TPS.

A amostra TPS foi analisada para determinar as mudanças de cristalinidade e avaliar a extensão da desestruturação do grânulo de amido com plasticizante após o processamento.

Apesar de a amilose encontrar-se no estado amorfo no amido granular e a cristalinidade dos grânulos serem atribuídas à amilopectina, no amido termoplástico a amilose cristaliza-se rapidamente. Essa diferença ocorre porque a amilose possui uma cinética de cristalização maior que a amilopectina, devido à sua estrutura linear. Portanto, a formação das estruturas cristalinas no TPS depende da razão 
amilose/amilopectina e das condições de armazenamento como tempo, temperatura e umidade (BULÉON et al., 1998; PARKER; RING, 2001; CORRADINI et al., 2006).

Dois tipos de padrão cristalino, tipo B e tipo $\mathrm{V}$ podem ser notados em amostra TPS. Os complexos $\mathrm{V}$ podem ser também identificados como $\mathrm{Va}$ (anidro) e Vh (hidratado). Os complexos Va apresentam picos em $12,6^{\circ}$ e $19,4^{\circ}$ e os complexos Vh apresentam picos significativos em $13,2^{\circ}$ e $20,6^{\circ}$. O padrão do tipo Va, é geralmente observado em materiais estocados em ambiente com baixa umidade relativa.

No difratograma da amostra TPS (Figura 54) foram observados os padrões cristalinos tipo B e tipo V. Os picos observados foram em $2 \theta$ igual a $12,9^{\circ}, 17,2^{\circ}$, $19,7^{\circ}, 21,5^{\circ}$, sendo determinado como padrão cristal ino do tipo Va o pico em $12,9^{\circ}$, padrão do tipo B o pico em $17,2^{\circ}$ e padrão tipo $\mathrm{Vh}$ o pico de intensidade forte em $19,7^{\circ}$

O pico referente a cristalinidade do tipo $B$, presente também no amido de batata (Figuras 59 e 60), indicou uma cristalinidade residual do amido ou recristalização da amilopectina durante o processamento e estoque das amostras. Segundo Pushpadass e colaboradores (2009) essa recristalização também pode ser atribuída a amilose (PUSHPADASS et al., 2009). Traços dos padrões de cristalinidade do tipo B também foram relatados em TPS de amido de milho por Forssell e colaboradores (1999) (FORSSELL et al., 1999).

O índice de cristalinidade do TPS calculado pelo pico em $2 \theta$ igual a $19,7^{\circ}$, relacionado ao padrão tipo $\mathrm{Vh}$, foi de $38 \%$ e o pico em $17,2^{\circ}$, relacionado ao padrão tipo $\mathrm{B}$, foi de $12 \%$, esses valores foram calculados segundo o método proposto por Hulleman e colaboradores (1999). 


\section{Blendas TPS/PHB, TPS/PHBV e TPS/PHB/PHBV}

Foram realizadas as análises de Difração de Raios-X para a amostra TPS, blendas TPS/PHB, TPS/PHBV e TPS/PHB/PHBV e amostras de PHB e/ou PHBV. Todos os corpos de prova foram condicionados em $53 \%$ de umidade.

As Figuras 61, 62 e 63 apresentam os difratogramas de raios-X para todas as amostras.

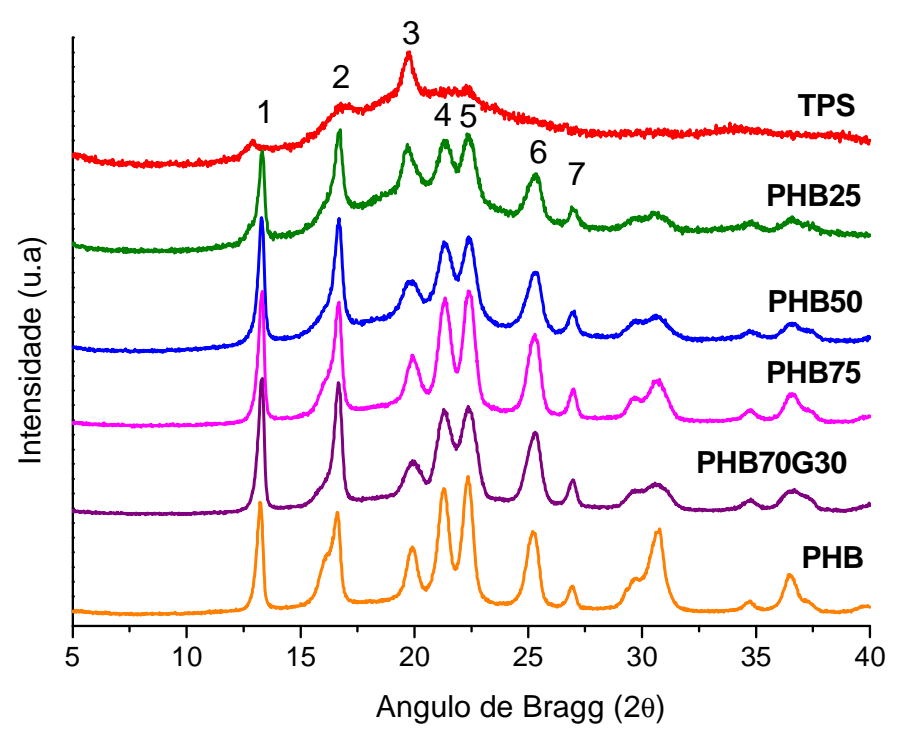

Figura 61 - Difratogramas de raios-X para a amostra TPS, blendas TPS/PHB e para amostras de PHB. 


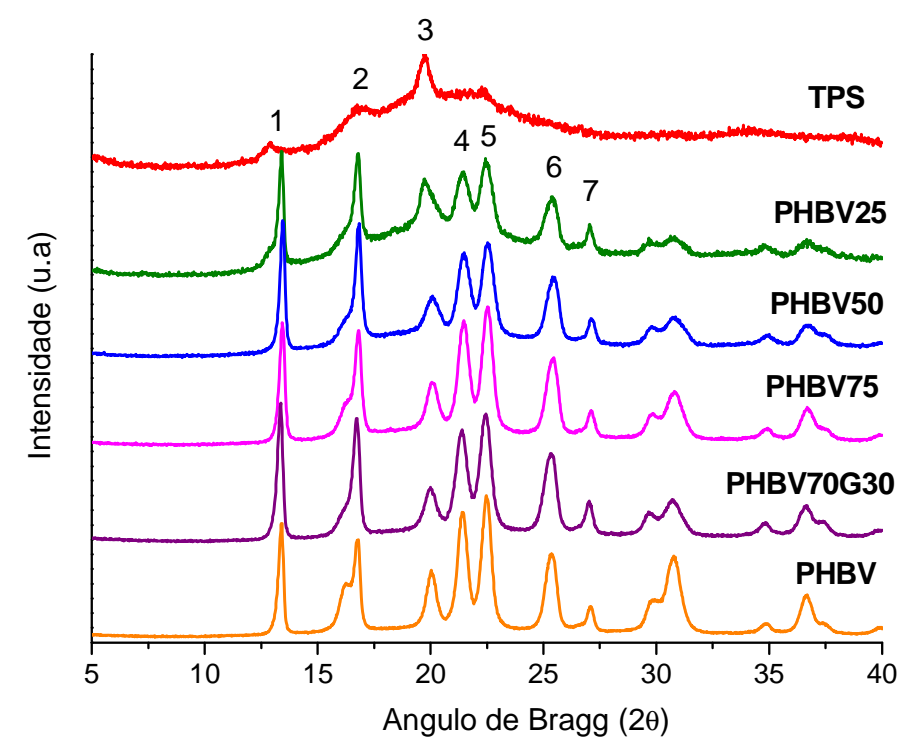

Figura 62 - Difratogramas de Raios-X para a amostra TPS, blendas TPS/PHBV e para amostras de PHBV.

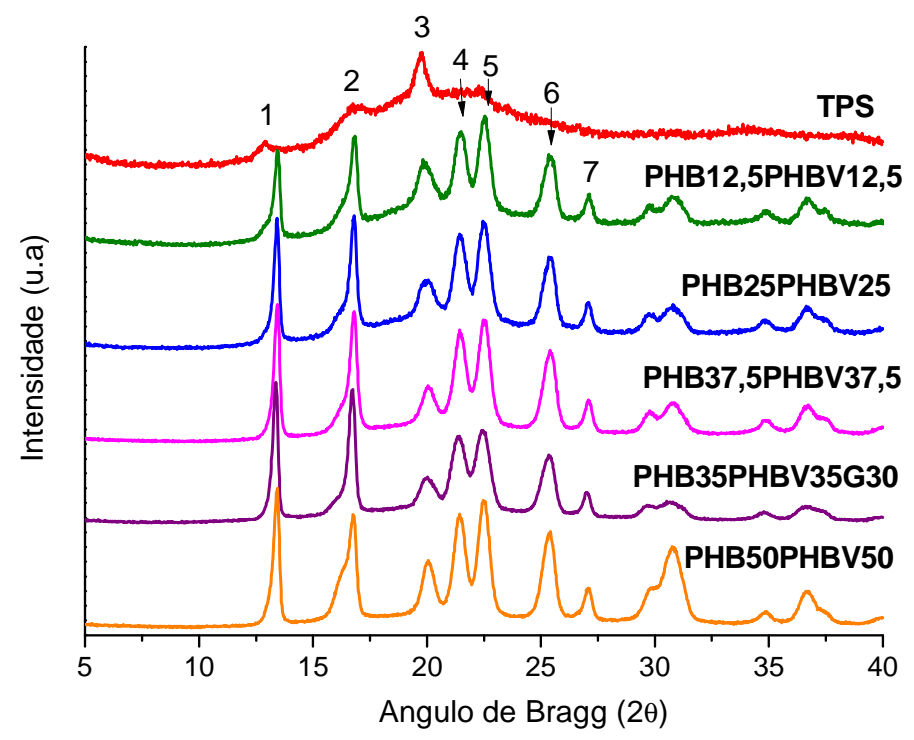

Figura 63 - Difratogramas de Raios-X para a amostra TPS, blendas TPS/PHB/PHBV e para amostras de PHB/PHBV.

Foi observado a partir dos difratogramas de raios-X (Figuras 61, 62 e 63) que os sinais 1 e 2 da amostra TPS se sobrepõem aos sinais dos próprios PHAs (amostras PHB e PHBV) e das blendas correspondentes. 
A conversão do amido nativo em material termoplástico leva à perda da organização natural por causa da gelatinização e/ou fusão dos grânulos de amido. A manuntenção da fase cristalina do PHB e PHBV nas blendas TPS/PHB, TPS/PHBV e TPS/PHB/PHBV (Figuras 61, 62 e 63) é também evidenciado pela intensidade dos picos em $2 \theta$ iguais a $13,3^{\circ} \mathrm{e} 16,7^{\circ}$. Essas observações foram co nfirmadas por Thiré e colaboradores (2006) (THIRÉ; RIBEIRO; ANDRADE, 2006).

As Figuras 64, 65 e 66 ilustram, de maneira comparativa, o comportamento dos difratogramas de raios- $\mathrm{X}$ e a Tabela 21 representa os graus de cristalinidades (\% C) dos polímeros PHB (pó) e PHBV (pellet), polímeros após o processamento (PHB, PHBV e PHB/PHBV) e das misturas com glicerol (PHB/G, PHBV/G e PHB/PHBV/G).

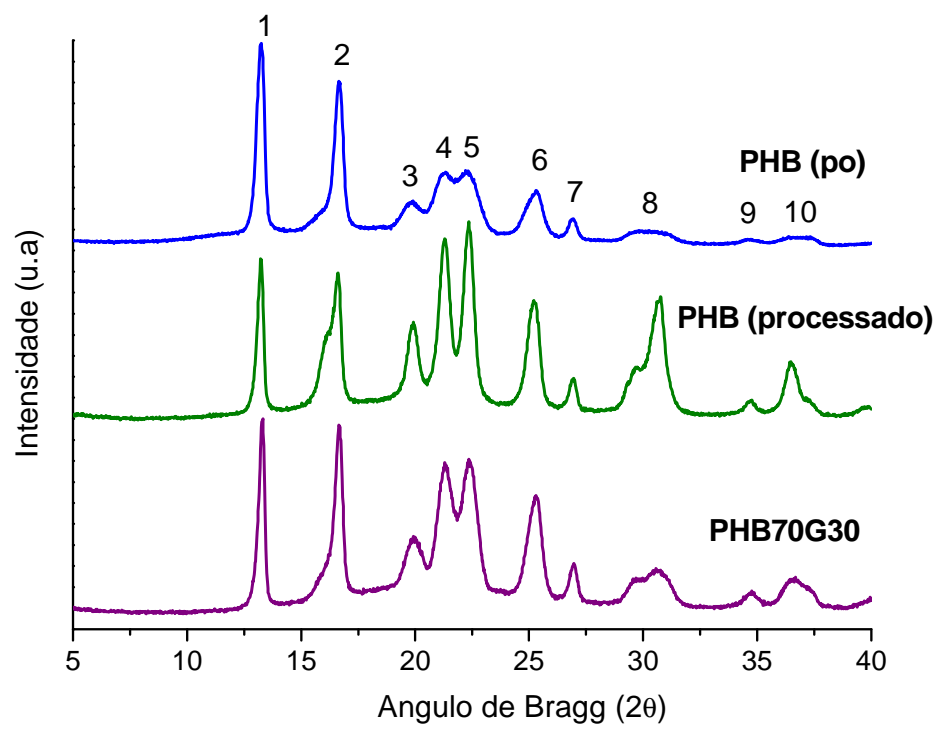

Figura 64 - Difratogramas de Raios-X das amostras PHB antes e após o processamento e amostras de PHB com glicerol. 


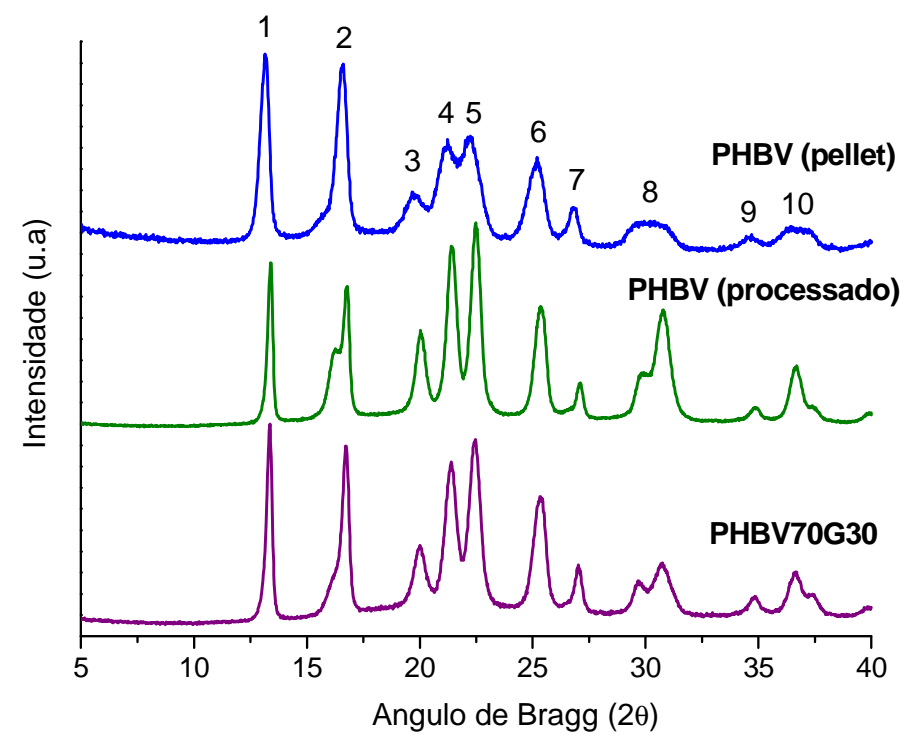

Figura 65 - Difratogramas de Raios-X das amostras PHBV antes e após o processamento e amostras de PHBV com glicerol.

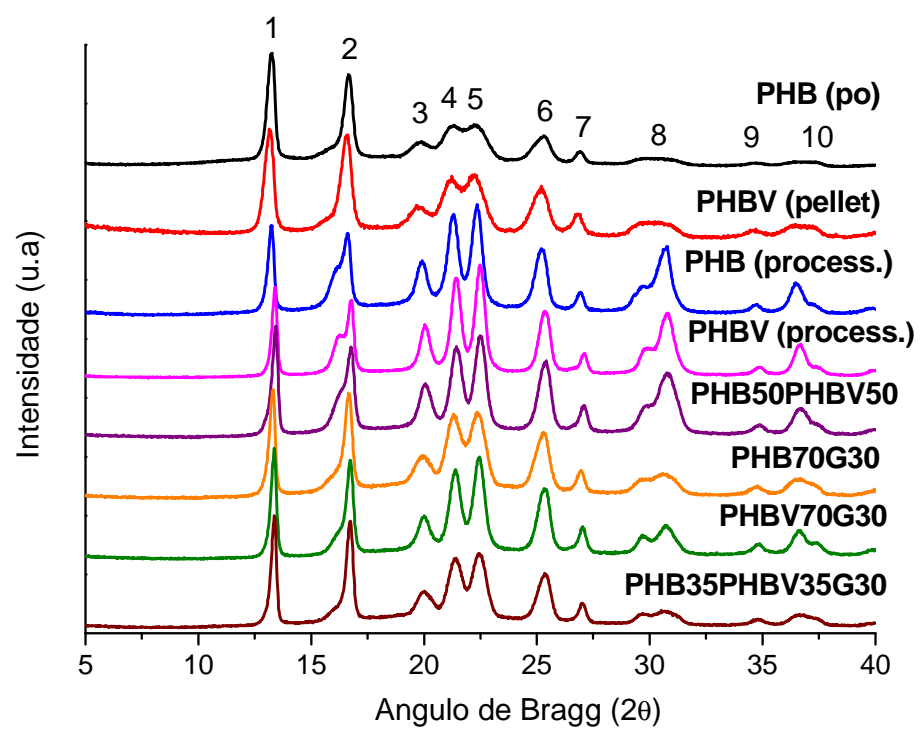

Figura 66 - Difratogramas de Raios-X das amostras PHB e/ou PHBV antes e após o processamento e amostras com glicerol. 
Tabela 21 - Grau de cristalinidade (\% C) obtido por Difração de Raios-X para os polímeros PHB (pó) e PHBV (pellet), amostras de PHB e/ou PHBV e amostras de PHB e/ou PHBV com glicerol.

\begin{tabular}{cccccc}
\hline Amostra & \% Cristal. & Amostra & \% Cristal. & Amostra & \% Cristal. \\
& & & & & \\
\hline PHB (pó) & 59,9 & PHBV (pellet) & 62,8 & - & - \\
& & & & & \\
PHB70G30 & 62,3 & PHBV70G30 & 61,2 & PHB35PHBV35G30 & 61,1 \\
PHB & 68,0 & PHBV & 70,0 & PHB50PHBV50 & 67,6 \\
\hline
\end{tabular}

Foi possível comparar as curvas dos polímeros PHB e PHBV como matérias de partida e depois do processamento a partir das Figuras 64 e 65 e da Tabela 21. Para os polímeros puros (PHB e PHBV) as cristalinidades foram de 59,9 e 62,8 \%, respectivamente, e para as amostras processadas foram de 68 e $70 \%$, indicando que o processamento destes materiais alterou muito pouca a cristalinidade.

As intensidades dos picos de sinais 3 a 6 , nas amostras PHB, PHBV e PHB50PHBV50 (processadas) e PHB70G30, PHBV70G30 e PHB35PHBV35G30 aumentaram em relação aos correspondentes picos 1 e 2 , diferente do observado para as amostras PHB e PHBV como materiais de partida. Observou-se também um grande aumento dos picos de sinais 8 a 10 nas amostras processadas em relação aos polímeros puros e até mesmo nas amostras com glicerol.

A cristalinidade das amostras PHB, PHBV e PHB50PHBV50 (processadas) (Figuras 64, 65 e 66 e Tabela 21) de 68,0, 70,0 e 67,6 \%, respectivamente foram mais elevadas quando comparada com as amostras PHB70G30, PHBV70G30 e PHB35PHBV35G30, com cristalinidade de 62,3, 61,2 e 61,1\%, pois contém em suas composições $100 \%$ do material responsável pela cristalinidade. Essas características com as amostras de PHB e PHBV juntamente com o plasticizante utilizado também foram relatadas por Belem (2008) (BELEM, 2008). 


\subsection{Análise Térmica Dinâmico-Mecânica (DMTA)}

A resposta viscoelástica do material termoplástico pode ser avaliada através da técnica DMTA. Em um material viscoelástico podem se manifestar dois tipos de deformações (elástica e plástica) que se sucedem quando o material é submetido a uma força de tração.

As análises de DMTA da amostra TPS, das blendas TPS/PHB, TPS/PHBV e TPS/PHB/PHBV e das amostras de PHB e/ou PHBV tiveram o objetivo de possibilitar a determinação das temperaturas de transição vítrea dessas amostras.

Na literatura ainda não há um consenso sobre qual variável obtida a partir das análises dinâmico-mecânicas se deve empregar e de que forma determinar a temperatura de uma transição, sendo encontrado vários métodos possíveis, a uso da temperatura do início da queda em E` (módulo de armazenamento), do início ou do pico nas curvas de E“ (módulo de perda) ou em tan $\delta$ (tangente de perda).

Neste trabalho foram utilizadas as temperaturas de pico das curvas de $\tan \delta$ para definir as temperaturas de transição $\left(T_{g}\right)$ das diferentes amostras. Para evidenciar também os fenômenos de relaxação nos polímeros puros e nas misturas estudadas, foram observados os módulos de armazenamento (E').

\section{TPS}

A Figura 67 apresenta as curvas do módulo de armazenamento (E') (em escala logarítmica) ou módulo de estocagem e a tangente de perda (tan $\delta$ ) em função da temperatura para a amostra TPS. 


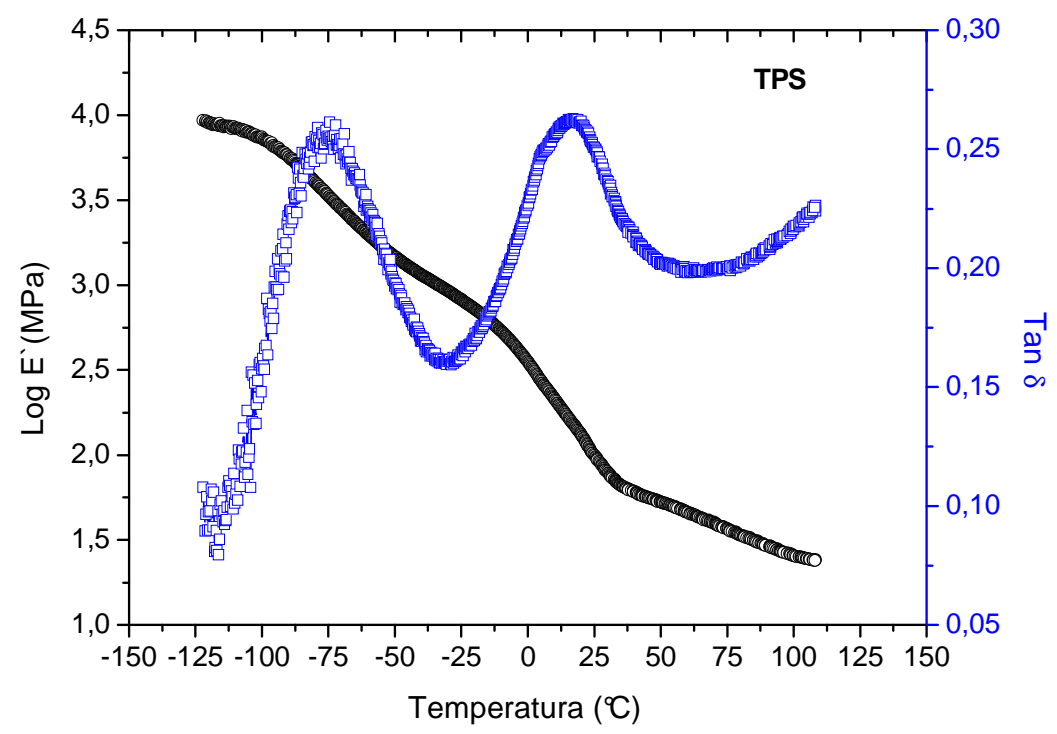

Figura 67 - Curvas de módulo de armazenamento (E’) e tangente de perda (tan $\square$ ) em função da temperatura $\left({ }^{\circ} \mathrm{C}\right)$ para a amostra TPS.

O amido termoplástico (TPS) revelou o aparecimento de duas transições em regiões distintas, estas têm sido relatadas na literatura por vários autores e com diferentes denominações.

Shorgren e colaboradores (1992), Kalichevsky e colaboradores (1993), Lourdin e colaboradores (1997), Carvalho (2002) e Da Róz (2004) relataram as duas transições ou dois picos em tan $\delta$, como transição em região de baixa temperatura (abaixo de $-50^{\circ}$ ) e transição em temperaturas mais elevadas corresponde a transição vítrea ou relaxação $\alpha$ do material (SHORGREN, 1992; KALICHEVSKY; BLANSHARD, 1993; LOURDIN et. al., 1997, CARVALHO, 2002, DA RÓZ, 2004).

Forssell e colaboradores (1997 e 1999), Talja (2007), Pushpadass e colaboradores (2008), Corradini e colaboradores (2006), atribuiram às duas transições como relaxações ocorridas na fase rica em glicerol e relaxações da fase rica em amido (FORSSEL et al., 1997; FORSSELL et al., 1999; TALJA, 2007; PUSHPADASS; MARX; HANNA, 2008; CORRADINI et al., 2006). 
Avérous e Boquillon (2004), Lourdim e colaboradores (1997), Avérous e colaboradores (2000) também observaram duas transições para a amostra TPS, transição denominada como relaxação $\alpha$ e outra como relaxação $\beta$. A principal transição foi a relaxação $\alpha$, associada a um grande pico e relacionada a $T_{g}$ do TPS (AVEROUS; BOQUILLON, 2004; LOURDIN, BIZOT, COLONNA, 1997). A relaxação $\beta$ entre temperaturas de -50 a $-60{ }^{\circ} \mathrm{C}$, segundo Avérous e colaboradores foi dependente da concentração de glicerol e, mais particularmente do glicerol "livre" devido à separação de fases (AVEROUS et al., 2000).

Dessa forma, de acordo com a Figura 67, dois picos em tan $\delta$ foram observados. O primeiro deles apareceu em uma região de mais baixa temperatura, em torno de $-75^{\circ} \mathrm{C}$, correspondente a transições na fase rica do plasticizante glicerol. O outro pico, em temperaturas mais altas, em torno de $16^{\circ} \mathrm{C}$, definiu a temperatura de transição vítrea ou relaxação $\alpha$ do amido plasticizado. PONTES (2008) também observou esses mesmos intervalos de temperatura (PONTES, 2008).

A compatibilidade entre os plasticizantes e as amostras empregadas também pode ser estudada por DMTA. Blendas poliméricas podem ser miscíveis, imiscíveis ou parcialmente miscíveis. A miscibilidade relaciona-se com a capacidade de dois ou mais componentes se misturarem em nível molecular, resultando numa mistura homogênea. Uma forma simples de verificação da miscibilidade pode ser feita através do número e posição das $T_{g}$ `s dos materiais.

Nas blendas miscíveis, os polímeros formam uma única fase e estão intimamente misturados em nível molecular, apresentando uma única $T_{g}$ intermediária aos valores das $T_{g}$ 's dos componentes puros. As blendas imiscíveis apresentam um número de fases relacionado ao número de seus componentes. 
Conseqüentemente, os valores das duas $\mathrm{T}_{\mathrm{g}}$ 's são praticamente iguais às temperaturas de transição vítrea dos componentes puros. As blendas parcialmente miscíveis devem apresentar, então, valores de $\mathrm{T}_{\mathrm{g}}$ 's relativos aos seus componentes, mas situados entre os valores de temperatura de transição vítrea dos polímeros puros (LUCAS; SOARES; MONTEIRO, 2001; SCHLEMMER, 2007; CANEVAROLO JUNIOR, 2004).

Assim, foi determinado que o sistema amido-glicerol é considerado parcialmente miscível (FORSSELL et al., 1999).

De acordo com a curva de log E' em função da temperatura (Figura 67) para a amostra TPS, o módulo de armazenamento ( $\left.E^{\prime}\right)$ cai bruscamente em temperaturas definidas. Os intervalos de temperatura nas quais ocorrem os decaimentos foram próximos das temperaturas de picos em tan $\delta$, ou seja entre -100 e $30^{\circ} \mathrm{C}$ e -10 e 40 C. O módulo inicial de $3,9 \mathrm{MPa}$ diminui significame nte com o aumento da temperatura, sendo que no final das duas $\mathrm{T}_{\mathrm{g}}$ 's, $\mathrm{E}^{\prime}$ reduziu para 1,8 $\mathrm{MPa}$.

\section{Blendas TPS/PHB, TPS/PHBV e TPS/PHB/PHBV}

As Figuras 68, 69 e 70 representam as curvas de tangente de perda (tan $\delta$ ) e módulo de armazenamento (E') em função da temperatura para a amostra TPS, blendas TPS/PHB, TPS/PHBV, TPS/PHB/PHBV e amostras de PHB e/ou PHBV. A Tabela 22 representa os valores das diferentes transições para todas as amostras determinadas a partir das curvas de $\tan \delta$ em função da temperatura. 


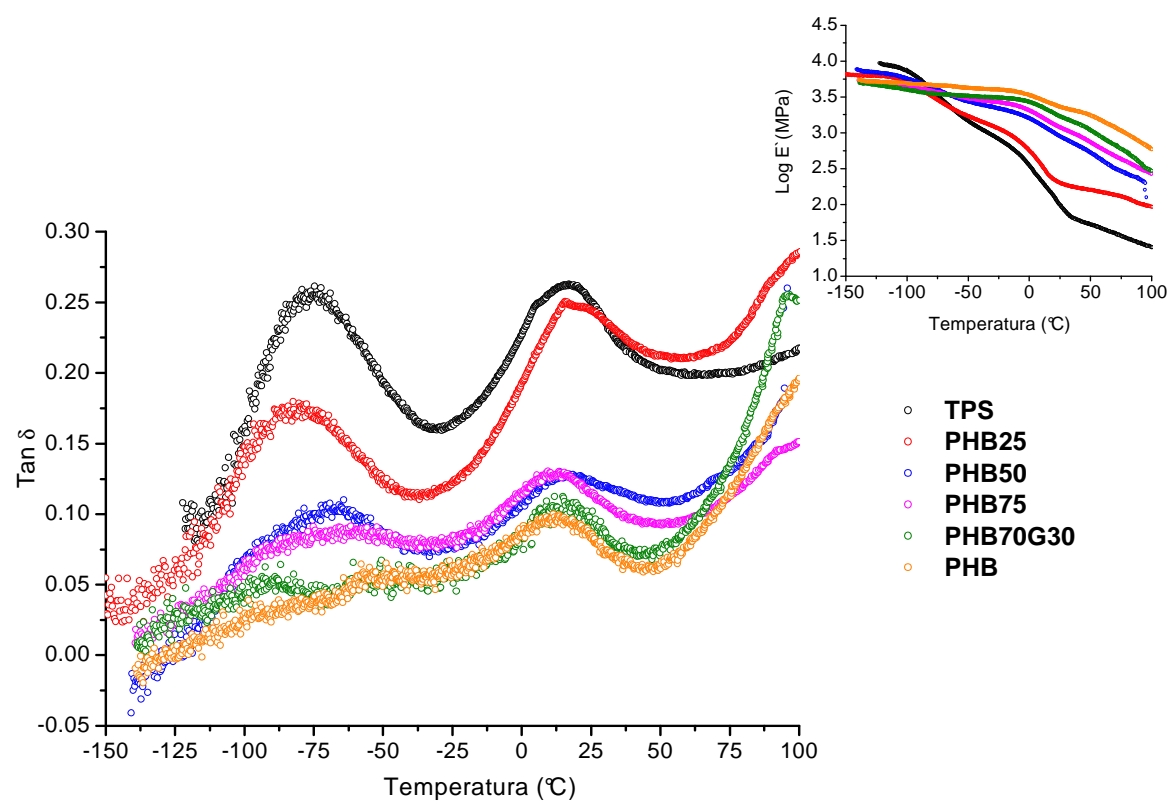

Figura 68 - Gráficos de tan $\delta$ em função da temperatura e gráficos de módulo de armazenamento (E') em função da temperatura para a amostra TPS, blendas TPS/PHB e amostras de PHB.

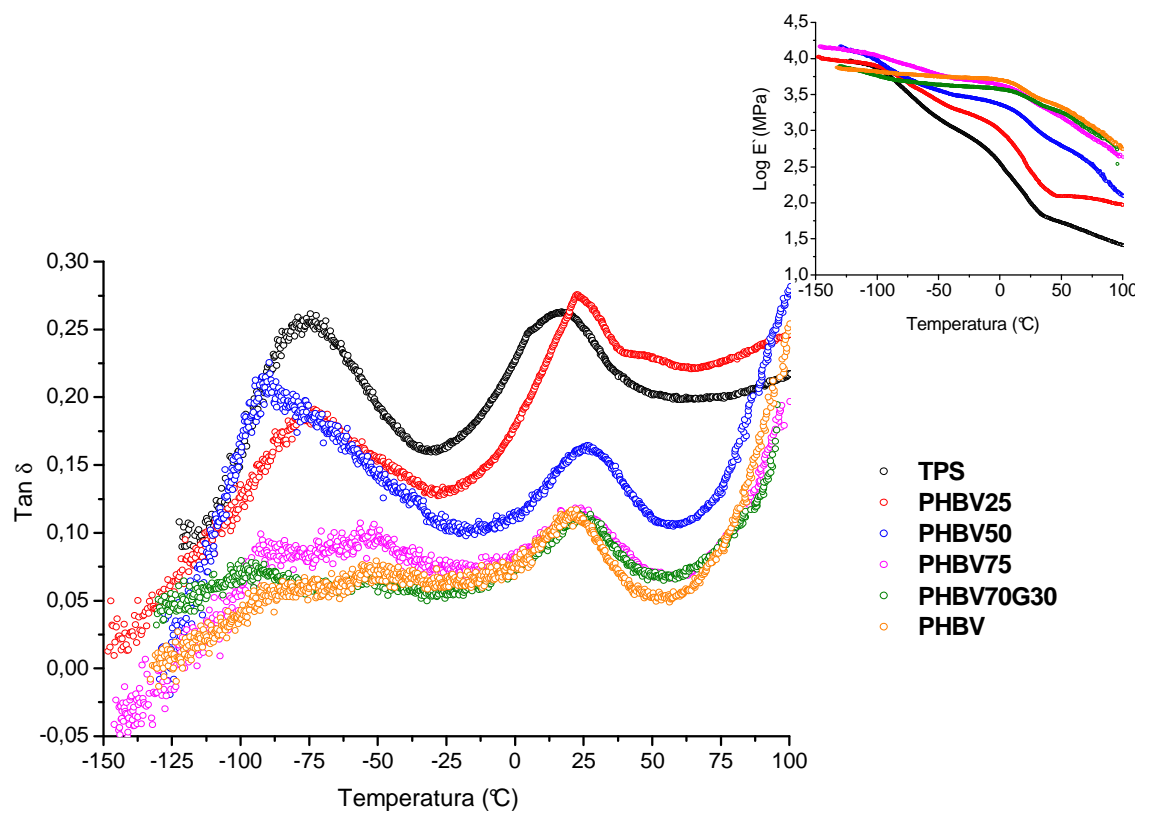

Figura 69 - Gráficos de tan $\delta$ em função da temperatura e gráficos de módulo de armazenamento (E') em função da temperatura para a amostra TPS, blendas TPS/PHBV e amostras de PHBV. 


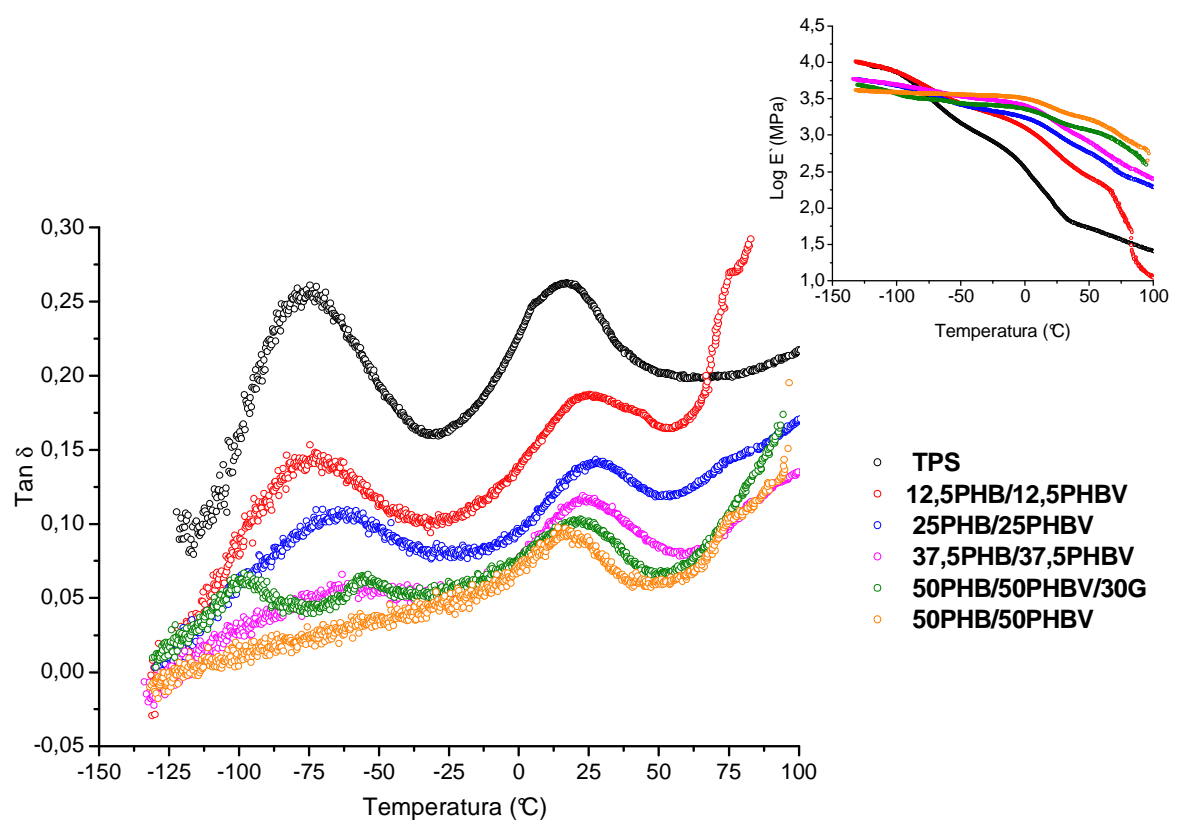

Figura 70 - Gráficos de tan $\delta$ em função da temperatura e gráficos de módulo de armazenamento (E') em função da temperatura para a amostra TPS, blendas TPS/PHB/PHBV e amostras de PHB/PHBV.

Tabela 22 - Valores das temperaturas de transições, a partir das curvas de tan $\delta$ em função da temperatura para a amostra TPS, blendas TPS/PHB, TPS/PHBV e TPS/PHB/PHBV e as amostras de PHB e/ou PHBV.

\begin{tabular}{ccccccc}
\hline \multicolumn{7}{c}{ Temperaturas de transições } \\
& \multicolumn{7}{c}{$\left({ }^{\circ}\right)$} \\
\hline Amostra & PHA=PHB & \multicolumn{1}{c}{ PHA=PHBV } & PHA=PHB/PHBV \\
TPS & -75 & 16 & -75 & 16 & -75 & 16 \\
PHA25 & -81 & 16 & -75 & 22 & -76 & 22 \\
PHA50 & -69 & 14 & -91 & 25 & -65 & 25 \\
PHA75 & -72 & 12 & -91 & 22 & -60 & 22 \\
& & & -54 & & & \\
PHA70G30 & -89 & 12 & -96 & 23 & -99 & 21 \\
& -56 & & -53 & & -56 & \\
PHA & -56 & 12 & -90 & 20 & - & 16 \\
& & & -52 & & & \\
\hline
\end{tabular}

Foi observado para as todas as blendas PHA25, PHA50, PHA75 (Figuras 68, 69 e 70 e Tabela 22) duas transições em tan $\delta$. A primeira transição foi relacionada à 
fase rica em glicerol. A segunda transição foi relacionada com o PHB e PHBV e também com o amido plasticizado, definida em apenas uma temperatura de pico e denominada de $\mathrm{T}_{\mathrm{g}}$ ou relaxações $\alpha$ da blenda.

Apenas para a blenda PHBV75 (Tabela 22) foi observado, além das duas transições já menciondas, uma transição em $-54{ }^{\circ} \mathrm{C}$, relacionada com a relaxação $\beta$ proveniente da amostra PHBV.

Para as blendas PHBV50, PHBV75 e PHBV70G30 (Figura 69 e Tabela 22), principalmente com maiores quantidades de PHBV, foram observadas transições em torno de $-91^{\circ} \mathrm{C}$, ou seja, em temperatura muita baix a quando comparada com as blendas PHB50, PHB75 e PHB70G30, PHB25PHBV25, PHB37,5PHBV37,5 e PHB35PHBV35G30 (Figuras 68 e 70 e Tabela 22). Essas observações podem ser observadas pela curva tan $\delta$ em - $90{ }^{\circ} \mathrm{C}$ do PHBV, denominada como transição $\gamma$.

As transições $\alpha_{a}, \beta$ e $\gamma$ correspondem a transições secundárias, e se referem a fase amorfa. A transição $\alpha_{a}$ corresponde à temperatura de transição vítrea $\left(\mathrm{T}_{\mathrm{g}}\right)$, a transição $\beta$ é normalmente relacionada com relaxações de grupos ou partes de grupos laterias da cadeia polimérica e a transição $\gamma$ refere-se ao movimento (ou relaxação) de pequenos grupos laterais, impurezas diluentes e grupos terminais (CANEVAROLO JUNIOR, 2004).

Como as amostras PHB e PHBV (Figuras 68 e 69 e Tabela 22) contêm uma transição em -56 e -52 C , respectivamente, denomin ada de relaxação $\beta$ e esta está proxima das transições rica em glicerol, não foi possível afirmar para as blendas PHA25, PHA50, PHA75 que as transições em baixas temperaturas foram atribuidas apenas à fase rica em glicerol, podendo ser uma junção da relaxação $\beta$ e desta fase rica em plasticizante. 
Para as amostras PHB, PHBV e PHB50PHBV50 (Figuras 68, 69 e 70) foram observadas, respectivamente, $T_{g}$ 's em 12, 20 e $16{ }^{\circ} \mathrm{C}$, sendo que a $T_{g}$ da mistura PHB50PHBV50 foi observada entre as $\mathrm{T}_{\mathrm{g}}$ `s dos polímeros $\mathrm{PHB}$ e $\mathrm{PHBV}$.

As diferenças observadas para as amostras (PHB, PHBV e PHB50PHB50) foram devidas às transições $\beta$, encontradas apenas para os polímeros puros e com glicerol. Outra diferença foi em relação a uma terceira transição, denominada de transições $\gamma$ observada apenas para o PHBV. Estes resultados mostraram um comportamento diferente do PHBV em relação ao PHB, além de que os valores de $\tan \delta$ nas blendas TPS/PHBV foram altos em relação aos valores do TPS e das blendas TPS/PHB, confirmando assim, a transição $\gamma$ também presente nas blendas.

Para as misturas PHB70G30, PHBV70G30 e PHB35PHBV35G30 foram observadas três transições denominadas como transição rica em glicerol e/ou transição $\gamma$, transição $\beta$ e $T_{g}$ nas curvas de tan $\delta$ em função da temperatura. A primeira transição em torno de -89 a - $99^{\circ} \mathrm{C}$, para as três misturas, foi relacionada a fase rica do plasticizante glicerol e possivelmente a uma transição $\gamma$. A segunda transição em torno de -53 a - $56^{\circ} \mathrm{C}$ e a terceira en tre 12 a $23^{\circ} \mathrm{C}$ foram denominadas de relaxação $\beta$ e transição vítrea $\left(T_{g}\right)$, respectivamente.

O aumento da altura máxima do pico associando a transição vítrea, principalmente na amostra TPS ou amostras com maiores quantidades de TPS pode ser observado na maioria das curvas, isso indica uma consequente diminuição de cristalinidade. De fato, sabe-se que o plasticizante aloja-se preferencialmente na fase amorfa. Assim, um aumento na fração volumétrica da fase amorfa representará uma redução do grau de cristalinidade. Essas caracteristicas pôde ser confirmadas pelas análises de Raio-X. 
No caso do estudo de sistemas de dois ou mais componentes e sua miscibilidade, o DMTA mostra-se como uma técnica bastante eficaz. Como este princípio baseia-se na observação de duas $T_{g}$ 's em sistemas imiscíveis, a análise não será confiável quando o sistema em estudo envolver dois materias cujas $T_{g}$ 's ocorrem em temperaturas iguais ou próximas. Neste caso, será observado apenas uma $T_{g}$ nas blendas poliméricas, e o pesquisador não poderá concluir, baseado somente neste resultado, se amostra apresenta apenas uma $T_{g}$ ou se as duas $T_{g}$ 's estão sobrepostas.

Apenas um pico nos gráficos de Tan $\delta$ em função da temperatura (Figuras 68, 69 e 70), valores próximos da temperatura ambiente, foi observado para as blendas TPS/PHB, TPS/PHBV e TPS/PHB/PHBV, pois as $T_{g}$ 's dos dois materias (TPS e PHB e/ou PHBV) foram muito próximas, não sendo possível definir a miscibilidade das blendas. Dias e colaboradores observaram a mesma dificuldade para as blendas de PHB e PPD (Poli(p-dioxanona)) (DIAS et al., 2008).

As curvas log $E^{\prime}$ em função da temperatura foram representadas para todas as amostras através das Figuras 68, 69 e 70. Para as blendas TPS/PHB, TPS/PHBV e TPS/PHB/PHBV suaves quedas no módulo de armazenamento ( $E^{\prime}$ ) foram observadas, sendo que para as amostras com maiores quantidades de PHB e/ou PHBV, essas quedas foram ainda mais brandas. A comparação entre 0 comportamento dos módulos de armazenamento do TPS e dos polímeros, mostrou a menor cristalinidade e rigidez do TPS em relação a esses polímeros puros, dessa forma a rigidez das blendas TPS/PHA apresenta valor compreendido entre a rigidez do TPS e do respectivo polímero.

Para as amostras PHB e PHB70G30, não foram determinadas mudanças das quedas nas curvas de $E^{\prime}$ em função da temperatura, observando a mesma $T_{g}$ para 
as duas amostras. Tendo a mesma $T_{g}$, conclui-se que não ocorreu relaxações das cadeias na fase amorfa, mesmo com a adição de plasticizante.

Pela Figuras 68, 69 e 70, onde estão representadas todas as amostras com as suas respectivas curvas do módulo de armazenamento em log E', observou-se características similares entre as amostras, pois houve duas quedas entre as faixas de temperaturas das transições da fase rica em glicerol e da fase rica em TPS e polímeros (PHB e/ou PHBV).

A queda mais acentuada do módulo de armazenamento para a amostra PHBV entre as temperaturas de 0 a $50^{\circ} \mathrm{C}$ demonstra ter sido causada por uma diminuição na cristalinidade bastante consistente na comparação entre o homopolímero (PHB) e o copolímero (PHBV). Essas observações foram confirmadas por Belem (2008) (BELEM, 2008).

\subsection{Ensaio Mecânico - Ensaio de Tração}

O comportamento mecânico de um dado material pode ser caracterizado pela resposta que o mesmo apresenta quando submetido ao ensaio de tração. Este ensaio consiste em submeter o material a um esforço que tende a alongá-lo até a ruptura.

A estrutura molecular do polímero é responsável pelo seu comportamento mecânico. De acordo com este comportamento, os materiais poliméricos podem ser classificados em termos de rigidez, fragilidade, dentre outras propriedades.

Foram determinadas neste trabalho características mecânicas, como tensão máxima $(\sigma)$, deformação máxima $(\varepsilon)$, módulo de elasticidade ou módulo de Young (E) da amostra TPS, das blendas TPS/PHB, TPS/PHBV e TPS/PHB/PHBV e das 
amostras de PHB e/ou PHBV frente a ensaios de tração, com amostras condicionadas em ambiente com umidade relativa controlada de 53\%.

TPS

As curvas de tensão em função da deformação para a amostra TPS, obtidas a partir dos ensaios de tração, estão apresentadas na Figura 71.

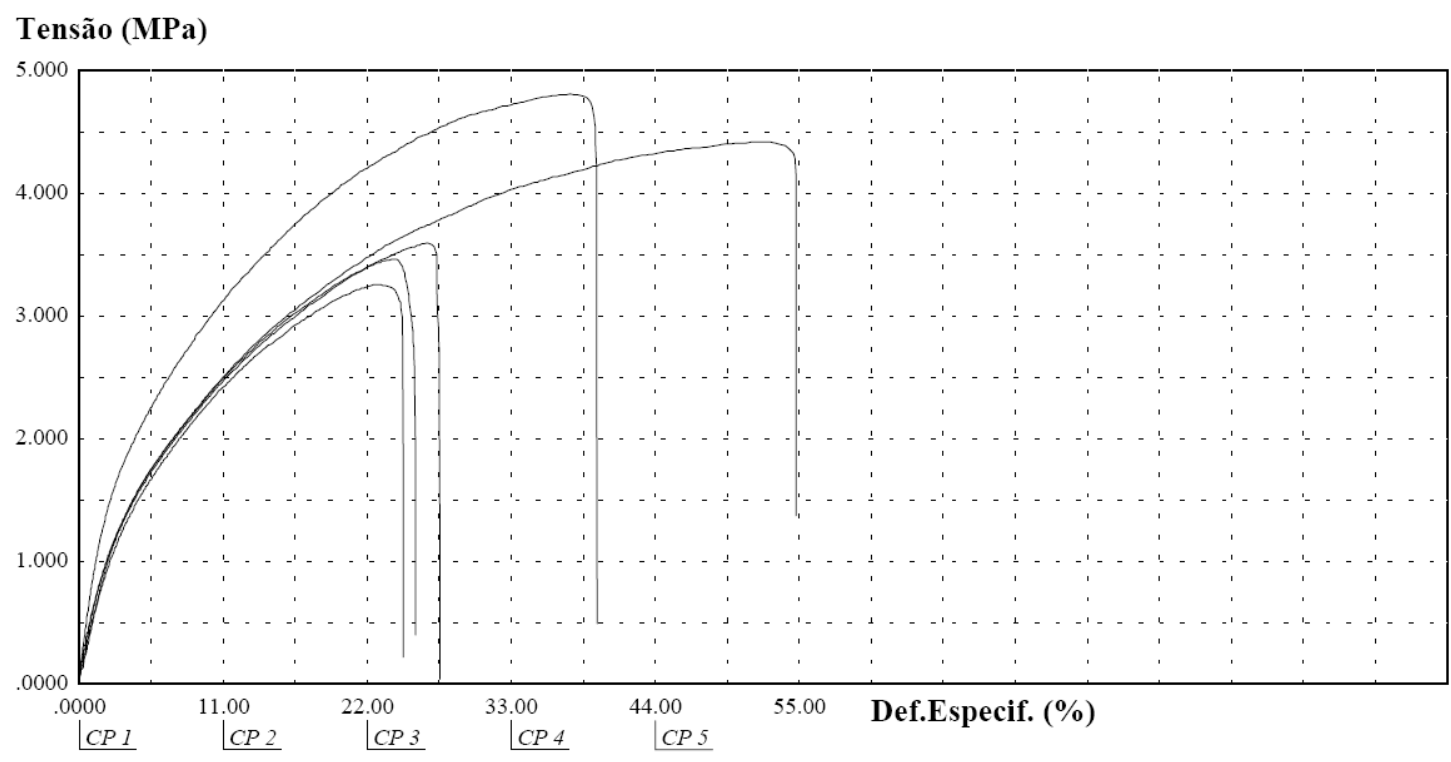

Figura 71 - Curvas representativas de tensão em função da deformação para a amostra TPS.

A amostra TPS (Figura 71) obteve o maior valor de deformação máxima $(\varepsilon)$, menor valor de módulo de elasticidade $(E)$ e baixo valor de tensão máxima $(\sigma)$ quando comparado com as blendas TPS/PHB, TPS/PHBV e TPS/PHB/PHBV e as amostras de PHB e/ou PHBV. Foi observado para o TPS, os valores de $\varepsilon$ igual a $32,5 \pm 12,2 \%$, E igual a $55,1 \pm 25,5 \mathrm{MPa}$ e $\sigma$ igual a $3,9 \pm 0,7 \mathrm{MPa}$. Thire' e colaboradores (2006) observaram os mesmos comportamentos para a amostra TPS, 
corroborando com os dados do presente trabalho (THIRE'; RIBEIRO; ANDRADE, 2006).

Segundo Teixeira (2007) e Carvalho (2002) a amostra TPS com 30\% de glicerol foi caracterizada como um material dúctil. Polímeros com comportamento dúctil apresentam ponto de escoamento nítido e deformam plasticamente (TEIXEIRA, 2007; CARVALHO, 2002).

As propriedades mecânicas do TPS (Figura 71) foram altamente influenciadas pelo teor de água e plasticizante presente nesta amostra. Segundo Souza e Andrade (2000), um material com maior quantidade de água, obtem um comportamento de baixa tensão na ruptura e alta deformação, diferente de um material com menor quantidade de água que se caracteriza como um material termoplástico rígido e quebradiço. Essas características também podem ser confirmadas pela adição do componente glicerol (SOUZA; ANDRADE, 2000).

O menor valor do módulo de elasticidade (E) na amostra TPS quando comparada com as bledas do presente trabalho, pode ser explicado pelo fato do plasticizante se alojar entre as cadeias do polímero, afastando-as umas das outras, o que propicia um menor esforço para que as cadeias possam se movimentar uma em relação às outras, refletindo numa diminuição do módulo do material sob estas condições.

De acordo com Carvalho e colaboradores (2003), Da Róz (2004), Shi e colaboradores (2007), a quantidade e o tipo de plasticizante empregado na preparação da amostra TPS é importante. Nestes trabalhos, os diversos plasticizantes empregados, mesmo que nas mesmas concentrações, apresentaram diferenças significativas nas propriedades do material obtido (CARVALHO et al., 2003b; DA RÓZ, 2004; SHI et. al., 2007). 


\section{Blendas TPS/PHB, TPS/PHBV e TPS/PHB/PHBV}

As curvas de tensão em função da deformação para as blendas TPS/PHB, TPS/PHB e TPS/PHBV e amostras de PHB e/ou PHBV, obtidas a partir dos ensaios de tração, estão apresentadas no Anexo 2.

Os resultados de tensão máxima $(\sigma)$ em $\mathrm{MPa}$, deformação máxima $(\varepsilon)$ em \% e módulo de elasticidade (E) em MPa para todas as amostras estão apresentados nas Figuras 72, 73 e 74 e na Tabela 21.

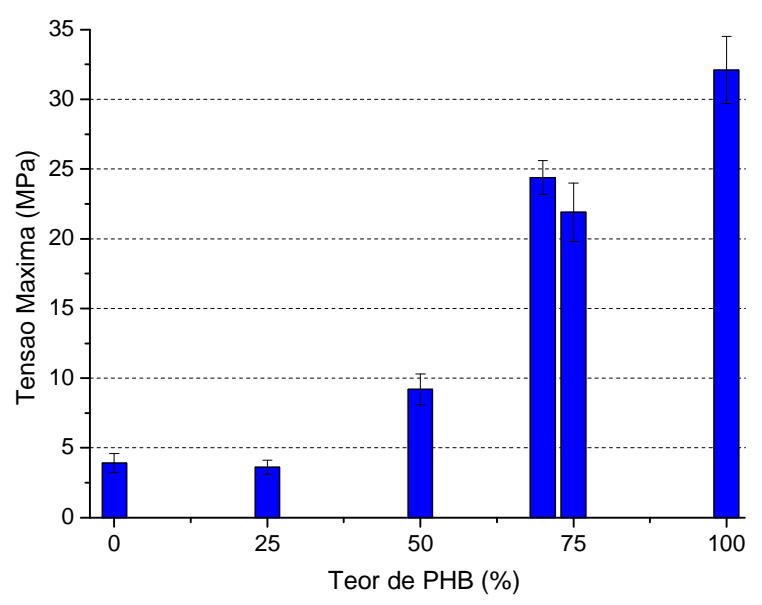

A

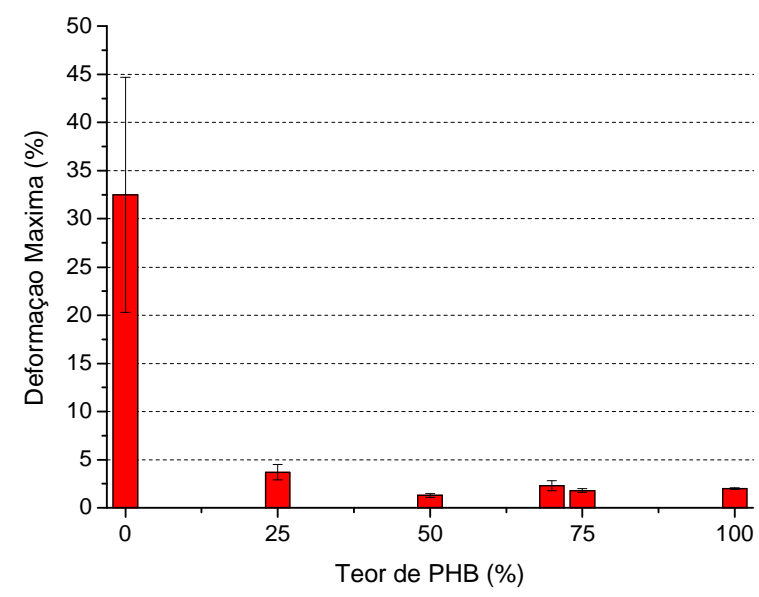

B

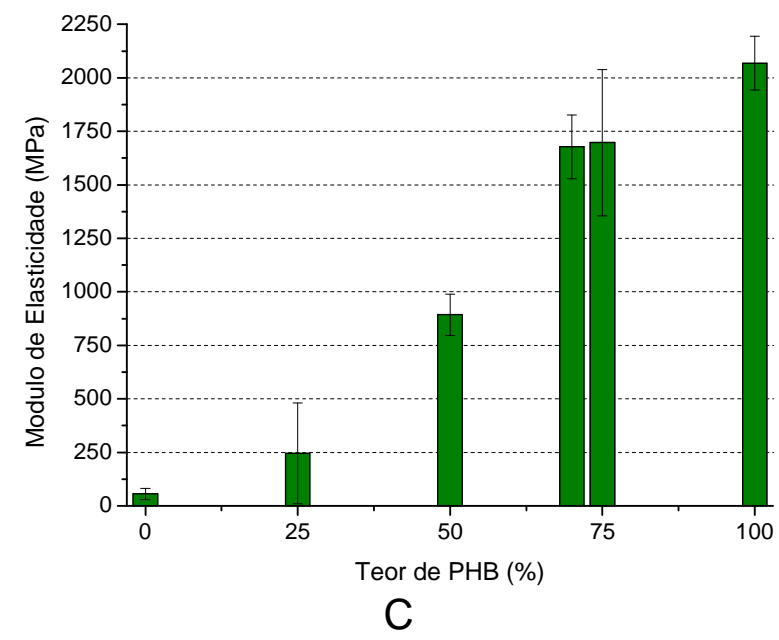

Figura 72 - Gráficos representativo da tensão máxima (MPa) (A), deformação máxima (\%) (B) e módulo de elasticidade (MPa) (C) em função do teor de PHB (\%) para a amostra TPS, blendas TPS/PHB e amostras de PHB. 

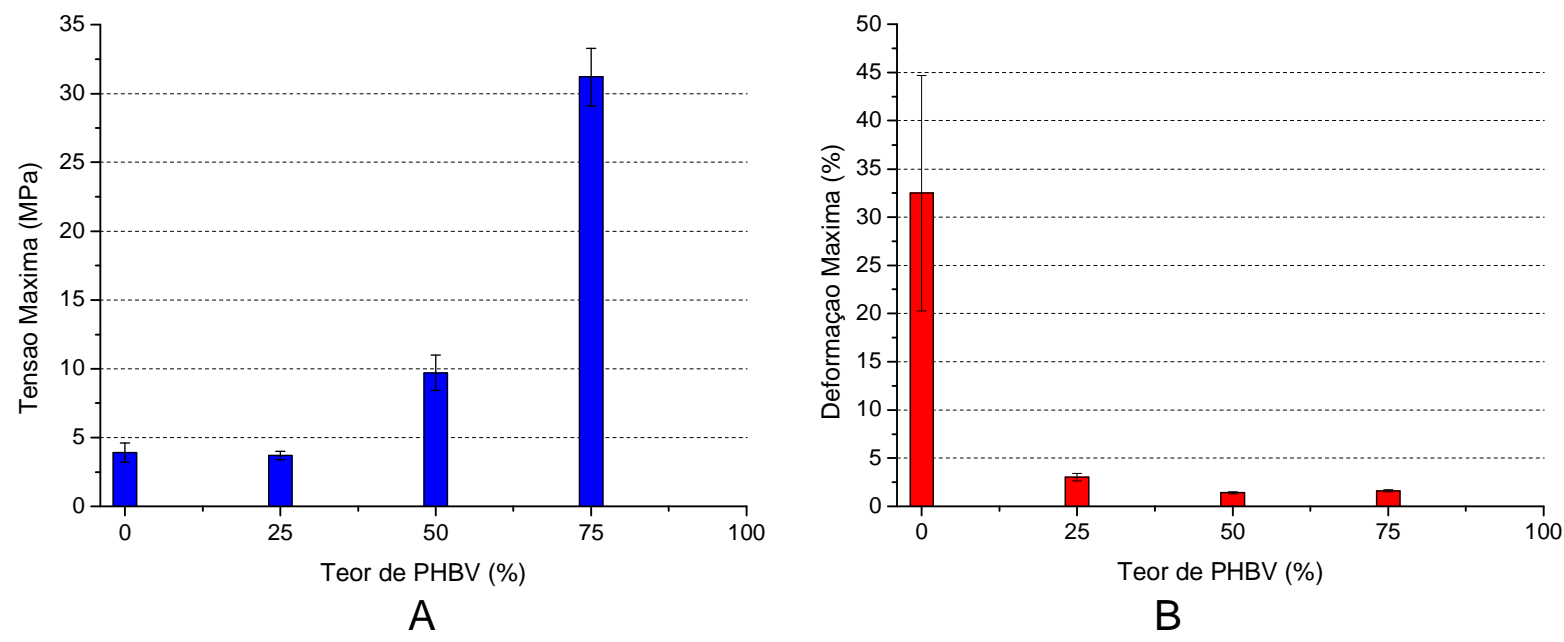

B

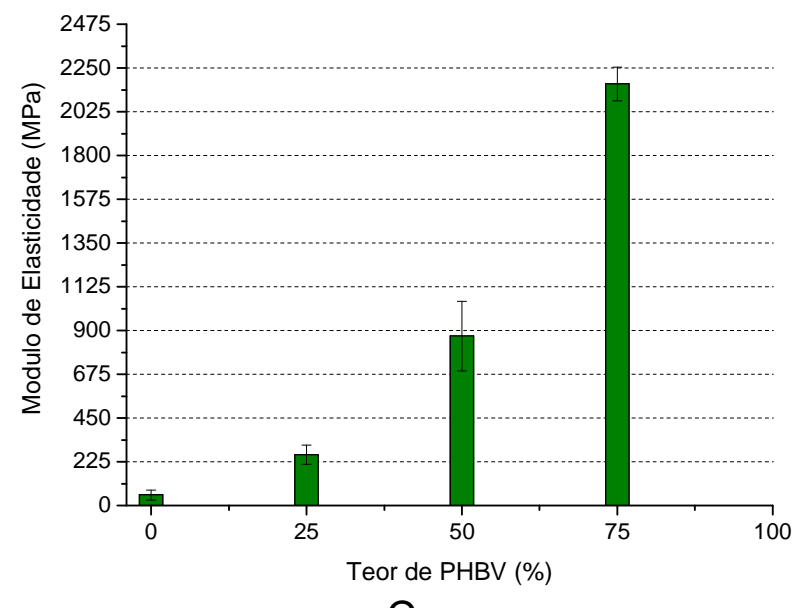

C

Figura 73 - Gráficos representativo da tensão máxima (MPa) (A), deformação máxima (\%) (B) e módulo de elasticidade (MPa) (C) em função do teor de PHBV (\%) para a amostra TPS, blendas TPS/PHBV e amostras de PHBV.

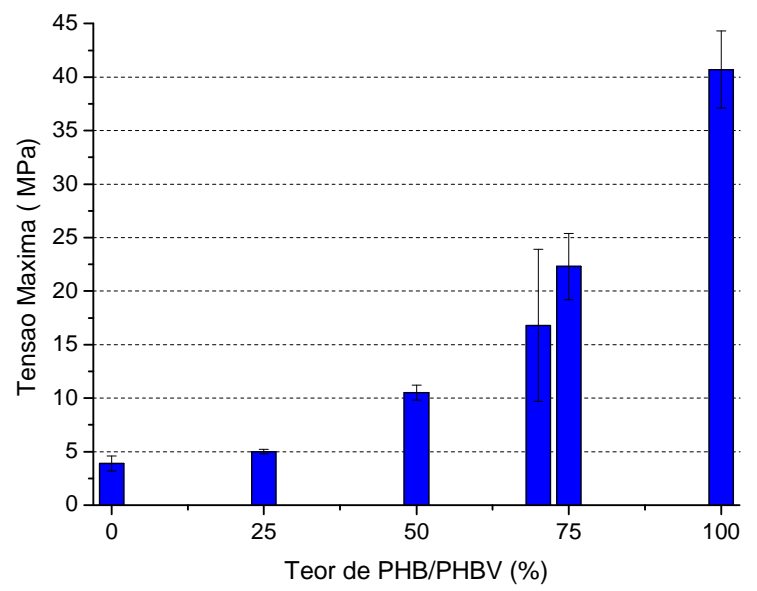

A

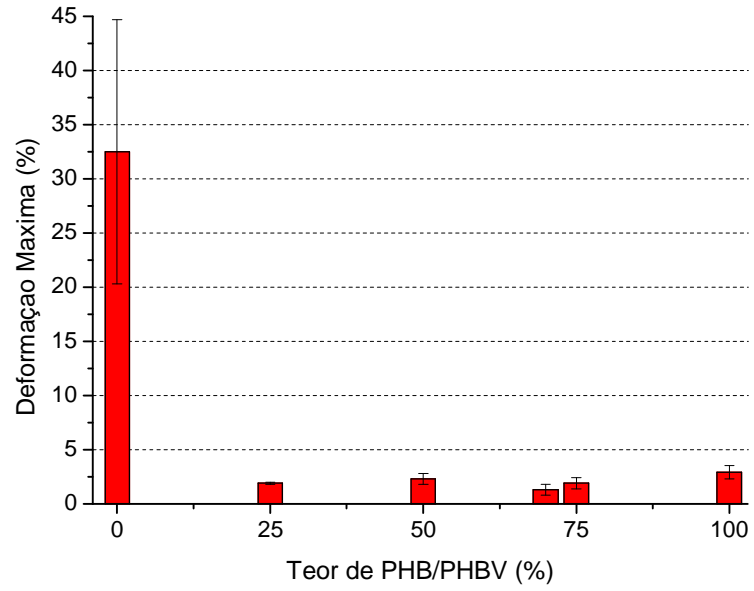

B 


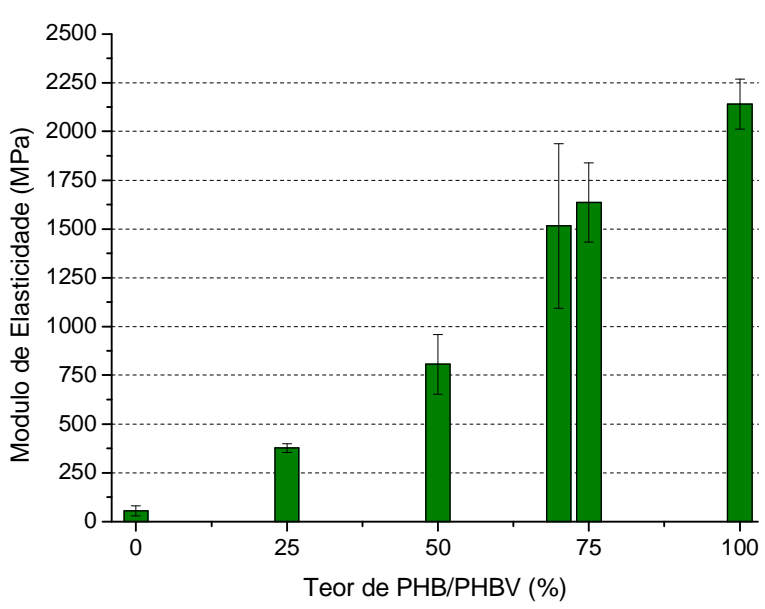

C

Figura 74 - Gráficos representativo da tensão máxima (MPa) (A), deformação máxima (\%) (B) e módulo de elasticidade (MPa) (C) em função do teor de PHBV (\%) para a amostra TPS, blendas TPS/PHB/PHBV e amostras de PHB/PHBV.

Tabela 23 - Valores de tensão máxima $(\sigma)$ em MPa, deformação máxima $(\varepsilon)$ em \% e módulo de elasticidade (E) em MPa, apresentados no ensaio de tração (Figuras de 72 a 74) para as amostras TPS, blendas TPS/PHB, TPS/PHBV e TPS/PHB/PHBV e amostras de PHB e/ou PHBV.

\begin{tabular}{cccc}
\hline Amostra & $\begin{array}{c}\sigma_{\text {máxima }} \\
(\mathrm{MPa})\end{array}$ & $\begin{array}{c}\boldsymbol{\varepsilon} \\
(\%)\end{array}$ & $\begin{array}{c}\mathbf{E} \\
(\mathrm{MPa})\end{array}$ \\
\hline TPS & $3,9 \pm 0,7$ & $32,5 \pm 12,2$ & $55,1 \pm 25,5$ \\
PHB25 & $3,6 \pm 0,5$ & $3,7 \pm 0,8$ & $244,8 \pm 35,9$ \\
PHB50 & $9,2 \pm 1,1$ & $1,3 \pm 0,2$ & $892,3 \pm 97,0$ \\
PHB75 & $21,9 \pm 2,1$ & $1,8 \pm 0,2$ & $1697,0 \pm 342,2$ \\
PHB70G30 & $24,4 \pm 1,2$ & $2,3 \pm 0,5$ & $1678,0 \pm 148,6$ \\
PHB & $32,1 \pm 2,4$ & $2,0 \pm 0,1$ & $2068,0 \pm 124,9$ \\
PHBV25 & $3,7 \pm 0,3$ & $3,0 \pm 0,4$ & $261,7 \pm 49,5$ \\
PHBV50 & $9,7 \pm 1,3$ & $1,4 \pm 0,1$ & $871,7 \pm 178,6$ \\
PHBV75 & $31,5 \pm 2,1$ & $1,6 \pm 0,1$ & $2168,0 \pm 86,9$ \\
PHBV70G30 & - & - & - \\
PHBV & - & - & -
\end{tabular}




\begin{tabular}{cccc}
\hline PHB12,5PHBV12,5 & $5,0 \pm 0,2$ & $1,9 \pm 0,1$ & $376,7 \pm 23,3$ \\
PHB25PHBV25 & $10,5 \pm 0,7$ & $2,3 \pm 0,5$ & $806,3 \pm 153,0$ \\
PHB37,5PHBV37,5 & $22,3 \pm 3,1$ & $1,9 \pm 0,5$ & $1636,0 \pm 202,9$ \\
PHB35PHBV35G30 & $16,8 \pm 7,1$ & $1,3 \pm 0,5$ & $1516,0 \pm 421,4$ \\
PHB50PHBV50 & $40,7 \pm 3,6$ & $2,9 \pm 0,6$ & $2140,0 \pm 128,1$ \\
\hline
\end{tabular}

Os valores de tensão na força máxima $(\sigma)$ aumentaram com o conteúdo de PHB e/ou PHBV nas blendas TPS/PHB, TPS/PHBV e TPS/PHB/PHBV (Figuras 72, 73 e 74 e Tabela 23). Com excessão da amostra PHB25 que obteve $\sigma$ praticamente igual a amostra TPS. Rosa e colaboradores (2001) confirmaram essas observações para blendas com $25 \%$ de amido e $75 \%$ de PHB e blendas com $25 \%$ de amido e 75 $\%$ de PHBV (ROSA; FRANCO; CALIL, 2001).

Innocentini-Mei e colaboradores (2003) encontraram $\sigma$ de $31,0 \pm 0,3 \mathrm{MPa}$ para amostra PHB, ou seja, valor muito próximo ao encontrado no presente trabalho, que foi de 32,1 $\pm 2,4 \mathrm{MPa}$ (INNOCENTINI-MEI; BARTOLI; BALTIERI, 2003). Esses resultados também foram confirmados por Falcone (2004), Thieré e colaboradores (2006), Lai e colaboradores (2006) e El-Hadi e colaboradores (2002) (FALCONE, 2004; THIRE'; RIBEIRO; ANDRADE, 2006; LAI; DON; HUANG, 2006; EL-HADI et al., 2002).

Não foi possível obter corpos-de-prova durante a prensagem para as amostras PHBV e PHBV70G30. Uma possível explicação para esse resultado pode ser a quantidade de vazios nas superfíces dos filmes prensados (conforme observado nas análises de MEV), obtendo menor desempenho mecânico do material.

Segundo valores da literatura (Rosa e colaboradores (2001) e Brunel (2008)), o valor de tensão $(\sigma)$ encontrado para o PHBV foi de $34,2 \pm 1,0 \mathrm{MPa}$ e de $35,6 \pm 0,2$ 
$\mathrm{MPa}$, este último, processado em extrusora e injetora (ROSA; FRANCO; CALIL, 2001; BRUNEL, 2008). Yang e colaboradores (2004) utilizaram o polímero da mesma empresa (Tianan Biological Material Company) do PHBV utilizado no presente trabalho, e observaram valores de $\sigma$ de $28.4 \mathrm{MPa}, \varepsilon$ de $4.2 \%$ e E de 2000 MPa (YANG; LIU, 2004).

As amostras com plasticizante, PHB70G30 e PHB35PHBV35G30 (Figura 72 e 74 e Tabela 21), proporcionaram menores valores de $\sigma$ e $E$, quando comparados às respectivas amostras sem plastificante. Esta redução deve-se exclusivamente ao efeito do agente plasticizante glicerol, o qual se interpõe às cadeias dos polímeros PHB e PHBV propiciando uma redução das interações intermoleculares polímero polímero. Essas características foram confirmadas por Belem (2008) no qual usou o Acetil Tributil Citrato (ATBC) como plasticizante (BELEM, 2008).

O maior valor de deformação máxima $(\varepsilon)$ foi observado para a amostra TPS $(32,5 \pm 12,2 \%)$ quando comparado com as blendas TPS/PHB, TPS/PHB e TPS/PHB/PHBV, sendo que os valores de $\varepsilon$ foram praticamente constantes para estas blendas e para as amostras PHB e PHB/PHBV. Dessa forma, conclui-se que a amostra TPS é mais flexível, pois apresentou maior valor de $\varepsilon$.

Observa-se o caráter frágil do PHB e PHBV devido ao seu baixo valor de deformação, ruptura repentina e alto valor de E, propriedades associadas a alta cristalinidade destes polímeros. Essas características foram observadas também por Brunel (2008) e Belem (2008) (BRUNEL, 2008; BELEM, 2008).

Os valores praticamente constantes de $\varepsilon$ nas blendas TPS/PHB, TPS/PHBV e TPS/PHB/PHBV e até mesmo nas amostras PHB e/ou PHBV podem ser explicados pela baixa aderência interfacial entre o amido e os polímeros PHB e PHBV. Outra explicação para esses valores é devido aos grânulos de amido que não foram 
desestruturados durante o processamento, observados nas análises de MEV. Por tanto, uma boa aderência dos polímeros na matriz polimérica, melhora as propriedades mecânicas (THIRE'; RIBEIRO; ANDRADE, 2006).

Kobayashi (2006) afirmou que a adição de plastificante normalmente diminui a temperatura de transição vítrea e a cristalinidade, onde numerosos cristalitos, pequenos e imperfeitos podem ser formados. Estas propriedades podem explicar o pequeno aumento de $\varepsilon$ para a amostra PHB70G30 quando comparada com a amostra PHB (KOBAYASHI, 2006). Entretanto, para a amostra PHB35PHBV35G30 (Tabela 23) foi observado um menor valor de $\varepsilon$ quando comparado com a amostra PHB50PHBV50.

Os módulos de elasticidade (E) aumentaram com o conteúdo de PHB e/ou PHBV nas blendas TPS/PHB, TPS/PHBV e TPS/PHB/PHBV (Figuras 72, 73 e 74 e Tabela 23). Este comportamento é devido à rigidez intrínseca dos polímeros PHB e PHBV. Reis e colaboradores (2008) também observaram esse comportamento com as blendas TPS/PHBV, mesmo estas sendo preparados por casting (REIS et. al., 2008).

Foram observados para as amostras PHB e PHB50PHBV50 (Tabela 23) valores de $\mathrm{E}$ de $2068,0 \pm 125 \mathrm{MPa}$ e $2140,0 \pm 128 \mathrm{MPa}$, respectivamente, valores mais altos se comparados com a literatura (KOBAYASHI, 2006; EL-HADI et. al., 2002). Brunel (2008) e Rosa e colaboradores (2001) observou para a amostra PHBV valor de $\mathrm{E}$ de $2910 \pm 0,05 \mathrm{MPa}$ e 3940,6 $\pm 323 \mathrm{MPa}$ (BRUNEL, 2008; ROSA; FRANCO; CALIL, 2001). Os diferentes valores observados no presente trabalho foram devido às diferentes origens e características dos polímeros utilizados como materiais de partida. 
As Figuras 75, 76 e 77 e a Tabela 24 ilustram de maneira comparativa os resultados das propriedades mecânicas obtidas a partir dos ensaios de tração para a amostra TPS, blendas PHB25, PHBV25, PHB12,5PHBV12,5 e amostras PHB e PHB50PHBV50.

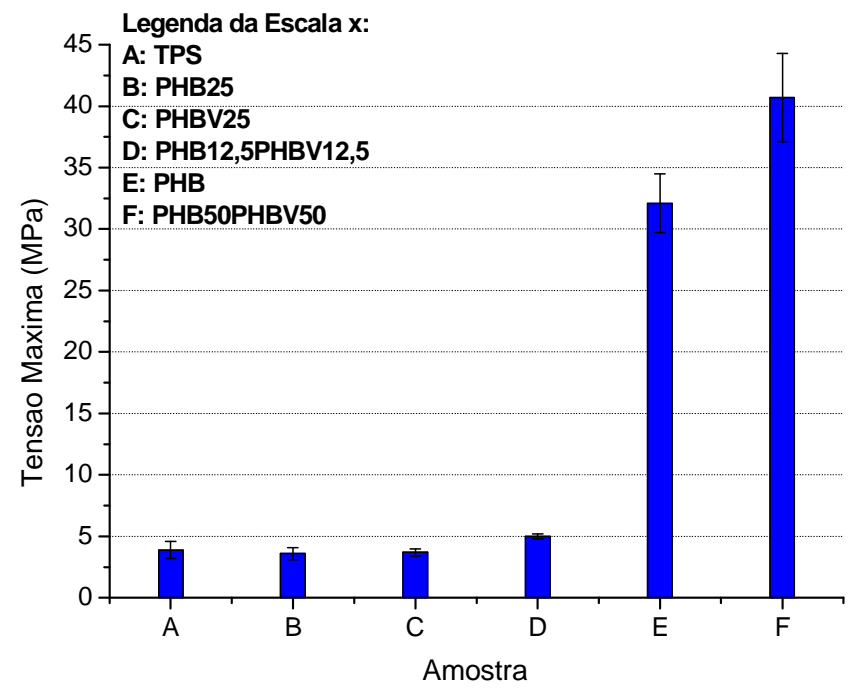

Figura 75 - Gráficos representativo da tensão máxima (MPa) para a amostra TPS, blendas PHB25, PHBV25 e PHB12,5PHBV12,5 e amostras PHB e PHB50PHBV50.

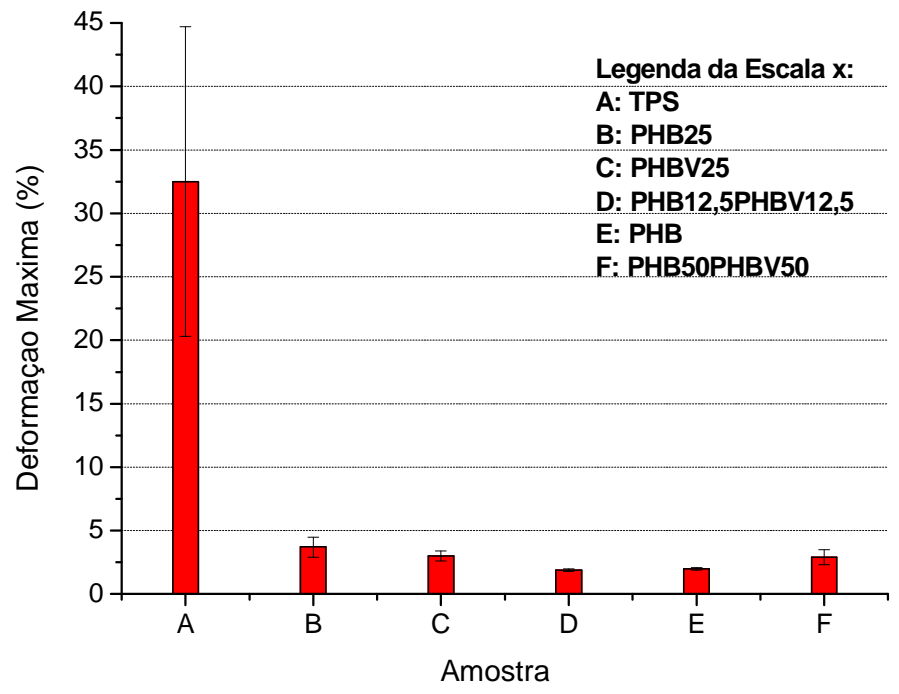

Figura 76 - Gráficos representativo da deformação máxima (\%) para a amostra TPS, blendas PHB25, PHBV25 e PHB12,5PHBV12,5 e amostras PHB e PHB50PHBV50. 


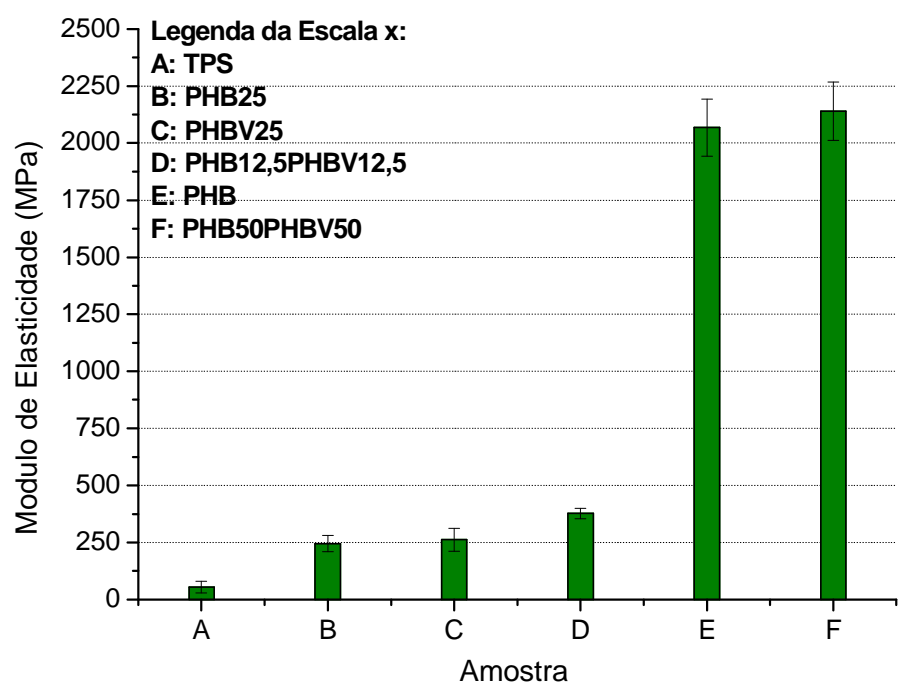

Figura 77 - Gráficos representativo do módulo de elasticidade (MPa) para a amostra TPS, blendas PHB25, PHBV25 e PHB12,5PHBV12,5 e amostras PHB e PHB50PHBV50.

Tabela 24 - Valores de tensão máxima $(\sigma)$ em MPa, deformação máxima $(\varepsilon)$ em \% e módulo de elasticidade (E) em MPa, apresentados no ensaio de tração (Figuras 75 a 77) para as amostras TPS, blendas PHB25, PHBV25 e PHB12,5PHBV12,5 e amostras PHB e PHB50PHBV50.

\begin{tabular}{cccc}
\hline Amostra & $\begin{array}{c}\boldsymbol{\sigma}_{\text {máxima }} \\
(\mathbf{M P a})\end{array}$ & $\begin{array}{c}\boldsymbol{\varepsilon} \\
(\%)\end{array}$ & $\begin{array}{c}\mathbf{E} \\
(\mathbf{M P a})\end{array}$ \\
\hline TPS & $3,9 \pm 0,7$ & $32,5 \pm 12,2$ & $55,1 \pm 25,5$ \\
PHB25 & $3,6 \pm 0,5$ & $3,7 \pm 0,8$ & $244,8 \pm 35,9$ \\
PHBV25 & $3,7 \pm 0,3$ & $3,0 \pm 0,4$ & $261,7 \pm 49,5$ \\
PHB12,5PHBV12,5 & $5,0 \pm 0,2$ & $1,9 \pm 0,1$ & $376,7 \pm 23,3$ \\
PHB & $32,1 \pm 2,4$ & $2,0 \pm 0,1$ & $2068,0 \pm 124,9$ \\
PHB50PHBV50 & $40,7 \pm 3,6$ & $2,9 \pm 0,6$ & $2140,0 \pm 128,1$ \\
\hline
\end{tabular}

Comparando a blenda PHB12,5PHBV12,5 com as blendas PHB25 e PHBV25 (Figuras 75, 76 e 77 e Tabela 24) foi observado que os maiores valores de $\sigma$ e $E$ e o menor valor de $\varepsilon$ foram para a amostra PHB12,5PHBV12,5. Dessa forma, a amostra TPS e as blendas PHB25 e PHBV25 em relação à blenda PHB12,5PHBV12,5 são mais dúcteis, pois as deformações na ruptura foram maiores. 
Conclui-se, de uma maneira geral, que a blenda PHB12,5PHBV12,5 apresentou características mecânicas em tração superiores às blendas PHB25 e PHBV25 e inferiores à amostra PHB e a mistura PHB50PHBV50. 


\section{CAPÍtULO 5}

\section{CONCLUSÃO}

O presente estudo foi de fundamental importância para o planejamento de novos materiais a partir de amido termoplástico e de suas blendas com os polímeros PHB e PHBV.

O estudo da plasticização do amido com $30 \%$ de glicerol foi realizado em um misturador intensivo e os parâmetros de processo determinados (160 C, 10 min e $60 \mathrm{rpm}$ ) mostraram-se eficientes para a preparação das amostras de TPS. Essa eficiência foi comprovada pela técnica de Difração de Raios- $X$, onde a estrutura cristalina de padrão tipo $\mathrm{B}$, original do amido de batata, foi modificada com a desestruturação do grânulo durante o processamento. Os resultados deste técnica também mostraram que os dois polímeros estudados, PHB e PHBV, apresentam elevados graus de cristalinidade.

Os ensaios de absorção de água, realizados em ambientes com umidade contralada, revelaram que as amostras e blendas apresentaram ganho de massa de até $37 \%$. As blendas preparadas com maiores teores do polímero (PHB e/ou PHBV) apresentaram maior resistência à absorção de água. Resultado muito interessante, particularmente para aplicações do bioplástico em ambientes úmidos. A partir dos valores do coeficiente de difusão (D) e dos parâmetros $n$ e k, pode-se concluir que o comportamento das amostras segue a Lei de Fick. A partir dos resultados de absorção, adotou-se o condicionamento em $53 \%$ de umidade para o estudo do comportamento térmico e das propriedades mecânicas do TPS e das blendas. 
As análises térmicas (TG e DSC) forneceram informações de grande valia para a compreensão do comportamento dos materiais preparados. Para as blendas TPS/PHB, TPS/PHBV e TPS/PHB/PHBV foi possível observar 2 estágios de perda de massa, proveniente do TPS e dos polímeros. O PHB e PHBV apresentaram apenas um estágio na degradação. A partir destes resultados, observou-se que a estabilidade térmica e o comportamento de perda de massa das blendas estão relacionadas diretamente com a quantidade de TPS presente nas amostras.

Dados de DSC demonstraram que o amido de batata neste trabalho possui teor de amilose de $23,6 \%$, muito próximo ao valor reportado na literatura. A curva DSC do TPS revelou apenas eventos relacionados à eliminação de água e glicerol. Para as blendas foram observados dois eventos térmicos, sendo o primeiro evento, endotérmico, relacionado à saída de água e glicerol do TPS e o segundo evento, também endotérmico, relacionado à fusão dos polímeros PHB e PHBV.

A técnica de Microscopia Eletrônica de Varredura evidenciou a formação de misturas homogêneas, tanto para a matriz (TPS) como para as blendas TPS/PHB, TPS/PHBV e TPS/PHB/PHBV. Entretanto, a análise das micrografias de algumas composições reveleram a presença de grânulos residuais, indicando que 0 processamento não levou à desestruturação total do amido de batata. A adição de glicerol aos polímeros, amostras PHB/G, PHBV/G e PHB/PHBV/G, levou a misturas que apresentaram pouca interação entre os polímeros e o plasticizante.

A partir da técnica FTIR foi possível identificar os principais grupos funcionais presentes nos materiais de partida e nas blendas. Comparando-se os espectros da amostra de amido e do TPS, observou-se que a conversão de amido em TPS envolveu formação de ligações de hidrogênio de natureza distinta das observadas para o amido não desestruturado. 
As análises por Difração de Raios-X permitiram calcular a cristalinidade dos materiais de partida e dos polímeros, antes e após o processamento. A posição dos picos, bem como suas intensidades, permitiu caracterizar o amido de batata como possuindo padrão tipo B de cristalinidade. Para a amostra TPS foram observados padrões cristalinos tipo B e tipo V. A análise dos materiais contendo PHB e PHBV revelou a manutenção dos perfil de difração e da cristalinidade dos mesmos, após o processamento realizado.

As análises de DMTA forneceram picos em tan $\delta$ para todas as amostras. Para a amostra TPS, foi obervado um pico correspondente a transições na fase rica do plasticizante glicerol e um outro pico definido como $T_{g}$ do amido plasticizado. Foi observado para as todas as blendas duas transições em tan $\delta$, sendo que a primeira transição foi relacionada à fase rica em glicerol e a segunda transição foi relacionada com o PHB e PHBV e também com o amido plasticizado, manifestadas em um mesmo intervalo de temperatura. Para as amostras PHB e PHBV foram observadas relaxação $\beta$ e $T_{g}$.

Os Ensaios Mecânicos de Tração mostraram para a amostra TPS o maior valor de deformação máxima $(\varepsilon)$, menor valor de módulo de elasticidade $(E)$ e baixo valor de tensão máxima ( $\sigma$ ), quando comparado às blendas TPS/PHB, TPS/PHBV e TPS/PHB/PHBV e às amostras de PHB e/ou PHBV. A propriedade mecânica do TPS foi fortemente influenciada pelo teor de água e de plasticizante presente nesta amostra, sendo assim, os dados de Absorção de Água corroboraram para esta discussão. A incorporação do polímero nas amostras, de uma maneira geral, aumentaram os valores de tensão na força máxima e os valores do módulo de elasticidade das blendas TPS/PHB, TPS/PHBV e TPS/PHB/PHBV. As amostras com 
plasticizante, PHB70G30 e PHB35PHBV35G30, proporcionaram menores valores de $\sigma$ e $E$, quando comparados às respectivas amostras sem plastificante.

Assim, o estudo da obtenção de amidos termoplásticos (via estado fundido) a partir do amido de batata mostrou-se que, além dos já conhecidos TPS oriundos de outras fontes de amido, foi possível a obtenção de TPS a partir desta matéria prima. Como esperado, a constituição de cada material de partida influenciou, especialmente, na performance mecânica dos TPS gerando materiais dúcteis, enquanto que os poliésteres apresentaram comportamento de material frágil.

Em relação às estratégias adotadas para melhorias nas propriedades mecânicas e de resistência à absorção de água do TPS, as mesmas revelaram-se eficientes.

A combinação, por mistura de polímeros da família dos polihidroxialconoatos, como o PHB e PHBV com o amido termoplástico apresentou-se como uma alternativa para a obtenção de materiais satisfatórios para algumas aplicações, sendo possível o processamento das amostras, uma vez que o PHB e o PHBV sofre degradação térmica em temperaturas superiores a $200{ }^{\circ} \mathrm{C}$ e o processamento das blendas ocorreu em temperatura máxima de $170{ }^{\circ} \mathrm{C}$.

Comparando os resultados obtidos neste trabalho, com os resultados descritos na literatura, observa-se a importância das características intrínsecas das materiais primas utilizadas para a adequada formulação de novos materiais visando atender as crescentes exigências do mercado, tanto do ponto de vista econômico como ambiental. 


\section{CAPÍTULO 6}

\section{SUGESTÕES PARA TRABALHOS FUTUROS}

- Estudar as características de biodegradabilidade da amostra TPS e das amostras de PHB e/ou PHBV;

- Desenvolver formas de melhorar a adesão e a interação entre o amido e os polimeros PHB e PHBV;

- Fazer um estudo mais aprofundado nas condições de processamento, incluindo outras formas de processamento, com o uso da extrusora e injetora.

- Utilizar alguns modificadores naturais, como fibras por exemplo, e modificadores do PHB e PHBV, como novos plasticizantes, nas amostras estudadas, visando melhores as propriedades das blendas poliméricas. 


\section{CAPÍTULO 7}

\section{REFERÊNCIAS BIBLIOGRÁFICAS}

AGGARWAL, P.; DOLLIMORE, D. A thermal analysis investigation of partially hydrolyzed starch. Thermochimica Acta, v. 319, p. 17-25, 1998.

AGGARWAL, P.; DOLLIMORE, D. A method of comparison between corn starch and its products using thermal analysis. Instrumentation Science \& Technology, v. 27, p. 191-197, 1999.

AMASS, W.; AMASS, A.; TIGHE, B. A review of biodegradable polymers: Uses, current development in the synthesis and characterization of biodegradable polyesters, blends of biodegradable polyesters and recent advances in biodegradable studies. Polymer International, v. 47, p. 89-144, 1998.

AMERICAN SOCIETY FOT TESTING AND MATERIALS. Standard specification for compostable plastics. Philadelphia: ASTM, 1999. D 6400-04.

AMERICAN SOCIETY FOT TESTING AND MATERIALS. Standard test method for determining aerobic biodegradation of plastic materials under controlled composting conditions. Philadelphia: ASTM, 1998. D 5338-98.

AMERICAN SOCIETY FOT TESTING AND MATERIALS. Standard practice for maintaining constant relative humidity by means of aqueous solutions. Philadelphia: ASTM, 1985. E104-02.

AMERICAN SOCIETY FOT TESTING AND MATERIALS. Requirements for packaging recoverable through composting and biodegradation. Philadelphia: DIN, 2000. DIN EN 13432-00.

AVELLA, M.; LA ROTA, G.; MARTUSCELLI, E.; RAIMO, M. Poly (3-hydroxybutyrateco-3-hydroxyvalerate) and wheat straw fibre composites: thermal, mechanical properties and biodegradation behavior. Journal of Materials Science, v. 35, p. 829-836, 2000a. 
AVELLA, M.; MARTUSCELLI, E.; RAIMO, M. Review Properties of blends and composites based on poly (3-hydroxy)butyrate (PHB) and poly(3-hydroxybutyratehydroxyvalerate) (PHBV) copolymers. Journal of Materials Science, v. 35, p. 523$545,2000 b$.

AVÉROUS, L. Biodegradable multiphase systems based on plasticized starch: a review. Journal of Macromolecular Science, v. C44, n. 3, p. 231-274, 2004.

AVEROUS, L.; BOQUILLON, N. Biocomposites based on plasticized starch: thermal and mechanical behaviours. Carbohydrate Polymers, v. 56, p. 111-122, 2004.

AVEROUS, L.; MORO, L.; DOLE, P.; FRINGANT, C. Properties of thermoplastic blends: starch-polycaprolactone. Polymer, v. 41, p. 4157-4167, 2000.

BARHAM, P. J.; KELLER, A. The relationship between microstructure and mode of fracture in polyhydroxybutyrate. Journal of Polymer Science. Part A: Polymer Chemistry. v. 24, p. 69-77, 1985.

BARRA, G. M. O.; ROEDER, J.; SOLDI, V.; PIRES, A. T. N.; AGNELLI, J. A. M. Blendas de Poliamida 6/Elastômero: Propriedades e Influência da Adição de Agente Compatibilizante. Polímeros: Ciência e Tecnologia, v. 13, n. 2, p. 94-101, 2003.

BASTIOLI, C. Global status of the production of biobased packaging materials. Starch/Stärke, v. 53, p. 351-355, 2001.

BELEM, Lauriberto Paulo. Biodegradação, Degradação Hidrolítica e Cinética de Cristalização do P(HB-co-HV) e do PHB, puro ou com os plastificantes dos tipos Citrato e Ftalato. 2008. 232 f. Tese (Doutorado em Ciências e Engenharia de Materiais) - Departamento em Ciências e Engenharia de Materiais, Universidade de São Carlos, São Carlos, 2008.

BHARDWAJ, R.; MOHANTY, A. K.; DRZAL, L. T.; POURBOGHRAT, F.; MISRA, M. Renewable Resource-Based Green Composites from Recycled Cellulose Fiber and Poly (3-hydroxybutyrate-co-3hydroxyvalerate) Bioplastic. Biomacromolecules, n. 7, p. 2044-2051, 2006.

BRUNEL, Daiana Gomes. Influência da incorporação de aditivos nas propriedades do Poli (hidroxivalerato)-PHBV. 2008. 153 f. Dissertação (Mestrado em Ciências e Engenharia de Materiais)-Departamento em Ciências e Engenharia de Materiais, Universidade de São Carlos, São Carlos, 2008. 
BULÉON, A.; COLONNA, P.; PLANCHOT, V.; BALL, S. Starch granules: structure and biosynthesis. International Journal of Biological Macromolecules, v. 23, n. 2 , p. 85-112, 1998.

BUZAROVSKA, A.; GROZDANOV, A. Crystallization kinetics of poly (hydroxybutyrate-co-hydroxyvalerate) and poly (dicyclohexylitaconate) PHBV/PDCHI blends: thermal properties and hydrolytic degradation. Journal of Materials Science, v. 44, p. 1844-1850, 2009.

BUZAROVSKA, A.; BOGOEVA-GACEVA, G.; GROZDANOV, A.; AVELLA, M.; GENTILE, G.; ERRICO, M. Crystallization behavior of poly (hydroxybutyrate-covalerate) in model and bulk PHBV/kenaf fiber composites. Journal of Materials Science, v. 42, p. 6501-6509, 2007.

CALLISTER JUNIOR, W. D. Ciência e engenharia de materiais: uma introdução. 5. ed. Rio de Janeiro: LTC, 2002. p. 310-336.

CANEVAROLO JUNIOR, S. V. Técnicas de caracterização de polímeros. São Paulo: Artliber, 2004. p.17-361.

CARVALHO, Antonio José Felix. Compósitos de amido termoplástico e fibras celulósicas: preparação, caracterização e estudo do efeito dos teores de plastificante e reforço. 2002. 166 f. Tese (Doutorado em Ciências e Engenharia de Materiais) - Departamento em Ciências e Engenharia de Materiais, Universidade de São Paulo, São Carlos, 2002.

CARVALHO, A. J. F.; ZAMBON, M. D.; CURVELO, A. A. S.; GANDINI, A. Size exclusion chromatography characterization of thermoplastic starch composites. 1. Influence of plasticizer and fibre content. Polymer Degradation and Stability, v. 79, p. 133-138, 2003a.

CARVALHO, A. J. F.; JOB, A. E.; ALVES, N.; CURVELO, A. A. S.; GANDINI A. Thermoplastic starch/natural rubber blends. Carbohydrate Polymers, v. 53, p. 9599, 2003b.

CEREDA, M. P. Propriedades gerais do amido, agricultura. São Paulo: Fundação Cargill, 2001. v. 1, p. 13-204. (Culturas de tuberosas amiláceas latino americanas).

COMYN, J. Polymer permeability. New York: Springer, 1985. p. 1-35. 
CORRADINI, E.; MEDEIROS, E. S.; CARVALHO, A. J. F; CURVELO, A. A. S.; MATTOSO, L. H. C. Mechanical and Morphological Characterization of Starch/Zein Blends Plasticized with Glycerol. Journal of Applied Polymer Science, v. 101, p. 4133-4139, 2006.

CORRÊA, Maria Clara Silveira. Caracterização da superfície de Poli (3hidroxibutirato) - PHB submetido à biodegradação. 2006. 84 f. Dissertação (Mestrado em Ciências e Engenharia de Materiais) - Departamento em Ciências e Engenharia de Materiais, Universidade de São Carlos, São Carlos, 2006.

CRANK, J. S. The mathematics of diffusion. Oxford: Claredon Press, 1975. 414 p.

DA RÓZ, Alessandra Luzia. Preparação e caracterização de amidos termoplásticos. 2004. 171 f. Tese (Doutorado em Ciências e Engenharia de Materiais) - Interunidades em Ciências e Engenharia de Materiais, Universidade de São Paulo, São Carlos, 2004.

DAGNON, K. L.; CHEN, H. H.; INNOCENTINI-MEIB, L. H.; D'SOUZA, N. A. Poly [(3hydroxybutyrate)-co-(3-hydroxyvalerate)]/layered double hydroxide nanocomposites. Polymer International, v. 58, p.133-141, 2009.

DIAS, M.; ANTUNES, M. C. M.; SANTOS JR. A. R.; FELISBERTI, M. I. Blends of poly (3-hydroxybutyrate) and poly (p-dioxanone): miscibility, thermal stability and biocompatibility. Journal of Materials Science: Materials in Medicine, v.19, p. 35353544, 2008.

DUARTE, Márcia Adriana Tomaz. Estudo do processamento e da degradação térmica do poli (3-hidroxibutirato) e de suas blendas com poli ( $\varepsilon$-caprolactona). 2004. 94 f. Dissertação (Mestrado em Ciência e Engenharia de Materiais) Departamento de Engenharia Mecânica, Universidade do Estado de Santa Catarina, Santa Catarina, 2004.

DUFRESNE, A.; DUPEYRE, D.; VIGNON, M. R. Cellulose Microfibrils from Potato Tuber Cells: Processing and Characterization of Starch/Cellulose Microfibrils Composites. Journal of Applied Polymer Science, v. 76, p. 2080-2092, 2000.

EL-HADI, A.; SCHNABEL, R.; STRAUBE, E.; MULLER, G.; HENNING, S. Correlation between degree of crystallinity, morphology, glass temperature, mechanical properties and biodegradation of poly (3-hydroxyalkanoate) PHAs and their blends. Polymer Testing, v. 21, p. 665-674, 2002. 
ESPERT, A.; VILAPLANA, F.; KARLSSON, S. Comparison of water absorption in natural cellulosic fibres from wood and one-year crops in polypropylene composites and its influence on their mechanical properties. Composites: Part A, v. 35, p. 12671276, 2004.

FALCONE, Daniele Maria Bruno. Influência da incorporação de Poli (Ácido Lático)-PLA, de pó de madeira e outros aditivos no comportamento físicomecânico do Poli (hidroxibutirato)-PHB. 2004. 200 f. Dissertação (Mestrado em Ciência e Engenharia de Materiais) - Departamento de Engenharia de Materiais, Universidade Federal de São Carlos, São Carlos, 2004.

FORSSELL, P. M.; HULLEMAN, S. H. D.; MYLLARINEN, P. J.; MOATES, G. K.; PARKER, R. Ageing of rubbery thermoplastic barley and oat starchs. Carbohydrate Polymers, v. 39, p. 43-51, 1999.

FORSSELL, P. M.; MIKKILÃ, J., M.; MOATES,G.K.; PARKER, R. Phase and glass transition behavior of concentrated barley starch-glycerol-water mixtures, a model for thermoplastic starch. Carbohydrate Polymers, v. 34, p. 275-282, 1997.

FUKUOKA, M.; OHTA, K.; WATANABE, H. Determination of the terminal extent of starch gelatinization in a limited water system by DSC. Journal of Food Engineering, v. 53, p. 39-42, 2002.

GALEGO, N.; ROZSA, C.; SÁNCHEZ, R.; FUNG, J.; VÁZQUEZ, A.; TOMÁS, J. S. Characterization and application of poly ( $\beta$-hydroxyalkanoates) family as composite biomaterials. Polymer Testing, v. 19, p. 485-492, 2000.

GÉRARD, C.; BARRON, C.; COLONNA, P.; PLANCHOT, V. Amylose determination in genetically modified starches. Carbohydrate Polymers, v. 44, p. 19-27, 2001.

GUINESI, L. S.; DA RÓZ, A. L.; CORRADINI, E.; MATTOSO, L. H. C.; TEIXEIRA, E. M. CURVELO, A. A. S. Kinetics of thermal degradation applied to starches from different botanical origins by non-isothermal procedures. Thermochimica Acta, v. 447, p. 190-196, 2006.

HUANG, J.; SHETTY, A. S.; WANG, M. Biodegradable plastics: a review. Advances in Polymer Technology, v. 10, n. 1, p. 23-30, 1990. 
HULLEMAN, S. H. D.; KALISVAART, M. G.; JANSSEN, F. H. P.; FEIL, H. VLIEGENTHART, J. F.G. Origins of B-type crystallinity in glycerol-plasticizer, compression-moulded potato starches. Carbohydrate Polymers, v. 39, p. 351360, 1999.

INNOCENTINI-MEI, L. H.; MARIANI, P. D. S. C. Visão geral sobre polímeros ou plásticos ambientalmente degradáveis (PADs). Campinas: Flamboyant, 2005. 41 p.

INNOCENTINI-MEI, L. H.; BARTOLI, J. R.; BALTIERI, R. C. Mechanical and thermal properties of poly (3-Hydroxybutyrate) blends with starch and starch derivates. Macromolecular Symposium, v. 197, p. 77-87, 2003.

IMAM, S. H.; CHEN, L.; GORDON, S. H.; SHOGREN, R. L.; WEISLEDER, D.; GREENE, R. V. Biodegradation of Injection Molded Starch-Poly (3-hydroxybutyrateco-3-hydroxyvalerate) Blends in a Natural Compost Environment. Journal of Environmental Polymer Degradation, v. 6, n. 2, p. 91-98, 1998.

INTERNATIONAL ORGANIZATION FOR STANDARDIZATION. Determination of the ultimate aerobic biodegradability of plastic materials in an aqueous medium Method by measuring the oxygen demand in a closed respirometer. ISO 14851:1999.

INTERNATIONAL ORGANIZATION FOR STANDARDIZATION. Determination of the ultimate aerobic biodegradability of plastic materials in an aqueous medium Method by analysis of evolved carbon dioxide. ISO 14852:1999.

INTERNATIONAL ORGANIZATION FOR STANDARDIZATION. Determination of the ultimate aerobic biodegradability of plastic materials under controlled composting conditions. ISO 14855:1999

KALICHEVSKY, M. E.; BLANSHARD, J. M. V. The effect of fructose and water on the glass transition of amylopectin. Carbohydrate Polymers, v. 20, p. 107-113, 1993.

KAUR, L.; SINGH, N.; SODHI, N. S. Some properties of potatoes and their starches II. Morphological, thermal and rheological properties of starches. Food Chemistry, v. 79, p. 183-192, 2002.

KAZIMIERCZAK, J.; CIECHAŃSKA, D.; WAWRO, D.; GUZIŃSKA, K. Enzymatic Modification of Potato Starch. Fibres \& Textiles, v. 15, n. 2, p. 100-1-4, 2007. 
KOBAYASHI, Marcio. Desenvolvimento do compósito de PHB modificado com fibra de bagaço de cana de açúcar e caracterização de seu comportamento sob biodegradação. 2006. 121 f. Dissertação (Mestrado em Ciências e Engenharia de Materiais) - Departamento em Ciências e Engenharia de Materiais, Universidade de São Carlos, São Carlos, 2006.

KOENIG, M. F.; HUANG, S. J. Biodegradable blends and composites of polycaprolactone and starch derivaties. Polymer, v. 36, p. 1877-1882, 1995.

KOLLER, I.; OWEN, A. J. Starch-Filled PHB and PHB/HV Copolymer. Polymer International, v. 39, p. 175-181, 1996.

LACERDA, Luiz Gustavo. Uso de Técnicas Termoanalíticas na Caracterização da Hidrólise Enzimática Parcial de Amidos de Matérias-Primas Tropicais. 2006. 81 f. Dissertação (Mestrado em Ciência e Tecnologia de Alimentos) - Universidade Estadual de Ponta Grossa, Ponta Grossa, 2006.

LAI, S. M.; DON, T. M.; HUANG, Y. C. Preparation and Properties of Biodegradable Thermoplastic Starch/Poly(hydroxy butyrate) Blends. Journal of Applied Polymer Science, v. 100, p. 2371-2379, 2006.

LIMA, Juliana Aristéia. Blendas de Poli (hidroxibutirato) e Elastômeros de Epicloridrina. 2004. 104 f. Dissertação (Mestrado em Físico-Química) - Instituto de Química de Campinas, Universidade Estadual de Campinas, Campinas, 2004.

LIMA, J. A.; FELISBERTI, M. I. Poly (hydroxybutyrate) and epichlorohydrin elastomers blends: Phase behavior and morphology. European Polymer Journal, v. 42, p. 602-614, 2006.

LOURDIN, D.; BIZOT, H.; COLONNA, P. Antiplasticization" in starch-glycerol films? Journal of Applied Polymer Science, v. 63, p. 1047-1053, 1997.

LUCAS, E. F.; SOARES, B. G.; MONTEIRO, E. Caracterização de polímeros. determinação de peso molecular e análise térmica. Rio de Janeiro: e-papers, 2001. 366p.

MA, X.; YU, J.; KENNEDY, J. F. Studies on the properties of natural fibers-reinforced thermoplastic starch composites. Carbohydrate Polymers, v. 62, p. 19-24, 2005. 
MA, X.; YU, J. The plasticizers containing amide groups for thermoplastic starch.

Carbohydrate Polymers, v. 57, p. 197-203, 2004.

MALI, S.; GROSSMANN, M. V. E.; GARCÍA, M. A.; MARTINO, M. M.; ZARITZKY, N. E. Barrier, mechanical and optical properties of plasticized yam starch films.

Carbohydrate Polymers, v. 56, n. 2, p.129-135, 2004.

MESTRES, C.; MATENCIO, F.; PONS B.; YAJID, M.; FLIEDEL, G. A rapid method for the determination of amylose content by using differential scanning calorimetry. Starch/Stärke, v. 48, p. 2-6, 1996.

MYLLARINEN, P.; BULEON, A.; LAHTINEN, R.; FORSSEL, P. The crystallinity of amylose and amylopectin films. Carbohydrate Polymers, v. 48, p. 41-48, 2002.

MOORTHY, S. N. Physicochemical and Functional Properties of Tropical Tuber Starches: A Review. Starch/Stärke, v. 54, p. 559-592, 2002.

MORAES, Maria Flávia Vanucci. Produção e Caracterização da blenda polimérica biodegradável Poli (hidroxibutirato) [PHB] / co-poliéster alifático aromático [ecoflex] para aplicação em embalagens. 2004. 115 f. Dissertação (Mestrado em Engenharia de Materiais) - Rede Temática em Engenharia de Materiais, Universidade Federal de Ouro Preto, Belo Horizonte, 2004.

NDIFE, M.; SUMNU, G.; BAYINDIRLI, L. Differential Scanning Calorimetry Determination of Gelatinization Rates in Different Starches due to Microwave Heating. Lebensmittel Wissenschaft und Technologie, v. 31, p. 484-488, 1998.

PACHEKOSKI, Wagner Mauricio. Desenvolvimento de blendas biodegradáveis constituídas de Poli (hidroxibutirato)-PHB e Poli (ácido lático)-PLA para a fabricação de filmes. 2005. 157 f. Tese (Doutorado em Ciências e Engenharia de Materiais) - Departamento em Ciências e Engenharia de Materiais. Universidade de São Carlos, São Carlos, 2005.

PALMA, E. J.; CICHELLO, M. S. F.; PAVANELLI, A. P. Emulsificantes em panificação. Disponível em:

<http://www.oxiteno.com.br/aplicacoes/mercados/doc/documento.asp?artigotecnico= 1\&segmento=0100\&idioma=PO\&r=.pdf > . Acesso em: 03 fev. 2009.

PARKER, R.; RING, S. G. Aspects of the Physical Chemistry of Starch: mini review. Journal of Cereal Science, v. 34, p. 1-17, 2001. 
PONTES, Bárbara Regina Bouças. Avaliação do amido de batata na preparação de materiais termoplásticos. 2008. Trabalho de Conclusão de Curso (Graduação em Química) - Instituto de Química de São Carlos, Universidade de São Paulo, São Carlos, 2008.

POTHAN, L. A.; THOMAS, S. Effect of Hybridization and Chemical Modification on the Water-Absorption Behavior of Banana Fiber-Reinforced Polyester Composites. Journal of Applied Polymer Science, v. 91, p. 3856-3865, 2004.

PUSHPADASSA, H. A.; MARX, D. B.; HANNA, M. A. Effects of Extrusion Temperature and Plasticizers on the Physical and Functional Properties of Starch Films. Starch/Stärke, v. 60, p. 527-53, 2008.

PUSHPADASS, H. A.; MARX, D. B.; WEHLING, R. L.; HANNA, M. A. Extrusion and Characterization of Starch Films. Cereal Chemistry, v. 86, n. 1, p. 44-51, 2009.

RAMACHANDER, T. V. N.; ROHINI, D.; BELHEKAR, A.; RAWAL, S. K. Synthesis of PHB by recombinant $E$. coli harboring an approximately $5 \mathrm{~kb}$ genomic DNA fragment from Streptomyces aureofaciens NRRL 2209. International Journal of Biological Macromolecules, v. 31, p. 63-69, 2002.

RAMSAY, B. A.; LANGLADE, V.; CARREAU, P. J.; RAMSAY, J. A. Biodegradability and Mechanical Properties of Poly-( $\beta$-Hydroxybutyrate-Co- $\beta$-Hydroxyvalerate) Starch Blends. Applied and Environmental Microbiology, v. 59, n. 4, p. 12421246, 1993.

REDDY, C. S. K.; GHAI, R.; RASHMI; KALIA, V. C. Polyhydroxyalkanoates: an overview. Bioresource Technology, v. 87, n. 2, p. 137-146, 2003.

REIS, K. C.; PEREIRA, J.; SMITH, A. C.; CARVALHO, C. W. P.; WELLNER, N.; YAKIMETS, I. Characterization of polyhydroxybutyrate-hydroxyvalerate (PHB$\mathrm{HV}$ )/maize starch blend films: Review. Journal of Food Engineering, v. 89, p. 361369, 2008.

RIBEIRO, E. P.; SERAVALLI, E. A. G. Química de alimentos. São Paulo: Edgard Blucher, 2003. p. 58-67.

RODRIGUES, R. C.; FIORESE, M. L.; ARNOSTI, E. P.; RAMOS, R. A. W.; PEZZIN, A. P. T.; ARAGÃO, G. M. F. Produção e Caracterização de Poli (3-hidroxibutiratoco-3-hidroxivalerato) por Ralstonia eutropha Utilizando Resíduo da Indústria de Arroz. Revista Matéria, v. 9, n. 4, p. 378-385, 2004. 
ROSA, D. S.; FRANCO, B. L. M.; CALIL, M. R. Biodegradabilidade e Propriedades Mecânicas de Novas Misturas Poliméricas. Polímeros: Ciência e Tecnologia, v. 11, n. 2, p. 82-88, 2001.

ROSA, D. S.; PANTANO FILHO, R. Biodegradação: um ensaio com polímeros. Itatiba: Moara Editora, 2003. 112 p.

ROSÁRIO, Francisco. Modificação do PHB com PCL, farinhas de madeira e plastificantes. 2005. 187 f. Tese (Doutorado em Ciências e Engenharia de Materiais) - Departamento em Ciências e Engenharia de Materiais, Universidade de São Carlos, São Carlos, 2005.

ROSSELL, C. E. V.; MANTELATTO, P. E.; AGNELLI, J. A. M.; NASCIMENTO, J. Sugar-based biorefinery - technology for integrated production of poly (3hydroxybutyrate), sugar, and ethanol. In: Kamm, B.; Gruber, P. R.; Kamm, M. (Eds.). Biorefineries industrial processes and products: status quo and future directions. Weinheim: Wiley-VCH, 2006. v. 1, p. 209-226.

RULLAND, W. International tables of $\mathbf{x}$ ray crystallography. Birmingham: Kinoch Press, 1974. 85 p.

SAITO, M.; INOUE, Y.; YOSHIE, N. Cocrystallization and phase segregation of blends of poly (3-hydroxybutyrate) and poly (3-hydroxybutyrate-co-3hydroxyvalerate). Polymer, v. 42, p. 5573-5580, 2001.

SCANDOLA, M.; FOCARETE, M. L.; ADAMUS, G.; SIKORSKA, W.; BARANOWSKA, I.; SWIERCZEK, S.; GNATOWSKI, M.; KOWALCZUK, M.; JEDLINSKI, Z. Polymer Blends of Natural Poly (3-hydroxybutyrate-co-3hydroxyvalerate) and a Synthetic Atactic Poly (3-hydroxybutyrate). Characterization and Biodegradation Studies. Macromolecules, v. 30, p. 2568-2574, 1997.

SCHLEMMER, Daniela. Preparação, caracterização e degradação de blendas de poliestireno e amido termoplástico usando glicerol e óleo de buriti (mauritia flexuosa) como plastificantes. 2007. 80 f. Dissertação (Mestrado em Química) Universidade de Brasília, Brasília, 2007.

SEVES, A.; BELTRAME, P. L.; SELLI, E.; BERGAMASCO, L. Morphology and thermal behaviour of poly (3-hydroxybutyrateco-hydroxyvalerate)/starch valerate blends. Die Angewandte Makromolekulare Chemie, v. 260, p. 65-70, 1998. 
SHI, R.; LIU, Q.; DING, T.; HAN, Y.; ZHANG, L.; CHEN, D.; TIAN, WEI. Ageing of Soft Thermoplastic Starch with High Glycerol Content. Journal of Applied Polymer

Science, v. 103, p. 574-586, 2007.

SHOGREN, R. L. Effect of moisture on the melting and subsequent physical aging of cornstarch. Carbohydrate Polymer, v. 19, p. 83-90, 1992.

SILVERSTEIN, R. M.; BASSLER, G. C.; MORRILL, T. C. Identificação

Espectrométrica de Compostos Orgânicos. 5. ed. Rio de Janeiro: LTC,1994. p. 93120.

SINGH, S.; MOHANTY, A. K.; SUGIE, T.; TAKAI, Y.; HAMADA, H. Renewable resource based biocomposites from natural fiber and polyhydroxybutyrate-covalerate (PHBV) bioplastic. Composites: Part A, v. 39, p. 875-886, 2008.

SINGH, J.; SINGH, N. Studies on the morphological, thermal and rheological properties of starch separated from some Indian potato cultivars. Food Chemistry, v. 75, p. 67-77, 2001.

SKRBIC, Z.; DIVJAKOVIC, V. Temperature influence on changes of parameters of the unit cell of biopolymer PHB. Polymer Communications, v. 37, n. 3, p. 505-507, 1996.

SOCRATES, G. Infrared and Raman Characteristic Group Frequencies: Tables and Charts. New York: John Wiley, 2004. 366 p.

SOUZA, R. C. R.; ANDRADE, C. T. Investigação dos Processos de Gelatinização e Extrusão de Amido de Milho. Polímeros: Ciência e Tecnologia, v. 10, n. 1, p. 24$30,2000$.

ST-PIERRE, N.; FLAVIS B. D.; RAMSAY, B. A ; RAMSAY, J. A .; VERHOOGT, H. Processing and characterization of thermoplastic starch/polyethylene blends.

Polymer, v. 38, p. 647-655, 1997.

TALJA, RIKU A. Preparation and characterization of potato starch films plasticized with polyols. 2007. $57 \mathrm{f}$. Dissertation (Department of Food Technology) - Faculty of Agriculture and Forestry, University of Helsinki, Helsinki, 2007. 
THIRE', R. M. S. M.; RIBEIRO, T. A. A.; ANDRADE, C. T. Effect of Starch Addition on Compression-Molded Poly (3-hydroxybutyrate)/Starch Blends. Journal of Applied Polymer Science, v. 100, p. 4338-4347, 2006.

TEIXEIRA, Eliangela de Moraes. Utilização de amido de mandioca na preparação de novos materiais termoplásticos. 2007. 201 f. Tese (Doutorado em Química) Departamento em Físico-Química, Universidade de São Paulo, São Carlos, 2007.

VAN SOEST, J. J. G.; HULLEMAN, S. H. D.; WIT, D.; VLIEGENTHART, J. F. G. Changes in the mechanical properties of thermoplastic potato starch in relation with changes in B-type crystallinity. Carbohydrate Polymers, v. 29, p. 225-232, 1996a.

VAN SOEST, J. J. G.; ESSER, P. Influence of amylose-amylopectin ratio on properties of extruded starch plastics sheets. Journal of Macromolecular Science. Part A, v. 34, p. 1665-1689, 1997.

VAN SOEST, J. J. G.; HULLEMAN, S. H. D.; WIT, D.; VLIENGENTHART, J. F. G.; Crystallinity in starch bioplatics. Industrial Crops and Products, v. 5, p. 11-22, 1996b.

VAN SOEST, J. J. G.; BENES, K.; WIT, D.; VLIEGENTHART, J. F. G. The influence of starch molecular mass on the properties of extruded thermoplastic starch.

Polymer, v. 37, n. 16, p. 3543-3552, 1996c.

VINHAS, G. M.; ALMEIDA, Y. M. B.; LIMA, M. A. G. A.; SANTOS, L. A. Study of the properties and biodegradability of polyester/starch blends submitted to microbial attack. Química Nova, v. 30, n. 7, p. 1584-1588, 2007.

WANG, H.; SUN, X. Z.; SEIB, P. Mechanical properties of poly (lactic acid) and wheat starch blends with methylenediphenyl diisocyanate. Journal of Applied Polymer Science, v. 84, p. 1257-1262, 2002.

WANG, N.; JIUGAO, Y.; XIAOFEI, M.; CHUNMEI, H. An Investigation of the Physical Properties of Extruded Glycerol- and Formamide-Plasticized Cornstarch. Journal of Thermoplastic Composite Materials, v. 22, p. 291-273, 2009.

WANG, W.; ZHANG, Y.; ZHU, M.; CHEN, Y. Effect of Graft Modification with Poly (Nvinylpyrrolidone) on Thermal and Mechanical Properties of Poly (3-hydroxybutyrateco-3-hydroxyvalerate). Journal of Applied Polymer Science, v. 109, p. 1699-1707, 2008. 
YANG, H.; LIU, J. Thermal analysis of poly (3-hydroxybutyrateco-3-hydroxyvalerate) irradiated under vacuum. Polymer International, v. 53, p. 1677-1681, 2004. 


\section{Anexo 1}

\section{Absorção de Água}

Regressão linear dos resultados de absorção de água para a amostra TPS, para determinação do coeficiente de difusão (D) e os parâmetros n e k.
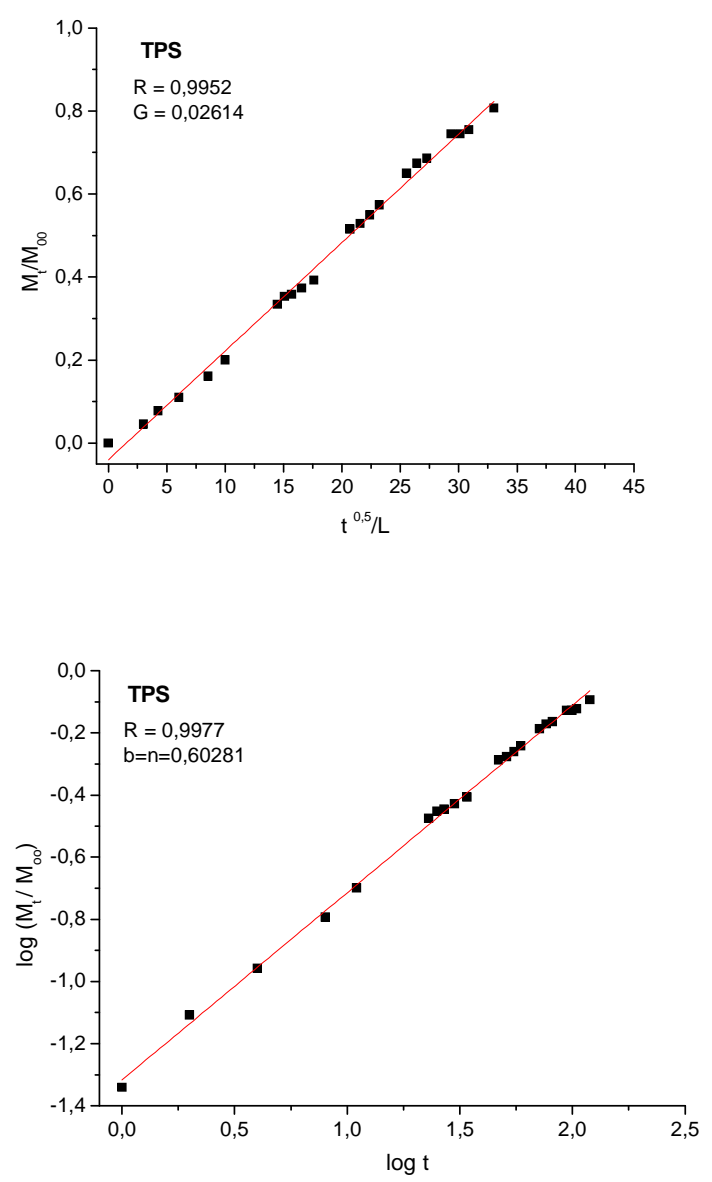

Figura 1 - Gráficos para o cálculo de Difusão Fickiana (D) e para os parâmetros n e k. 


\section{Anexo 2}

\section{Ensaio Mecanico}

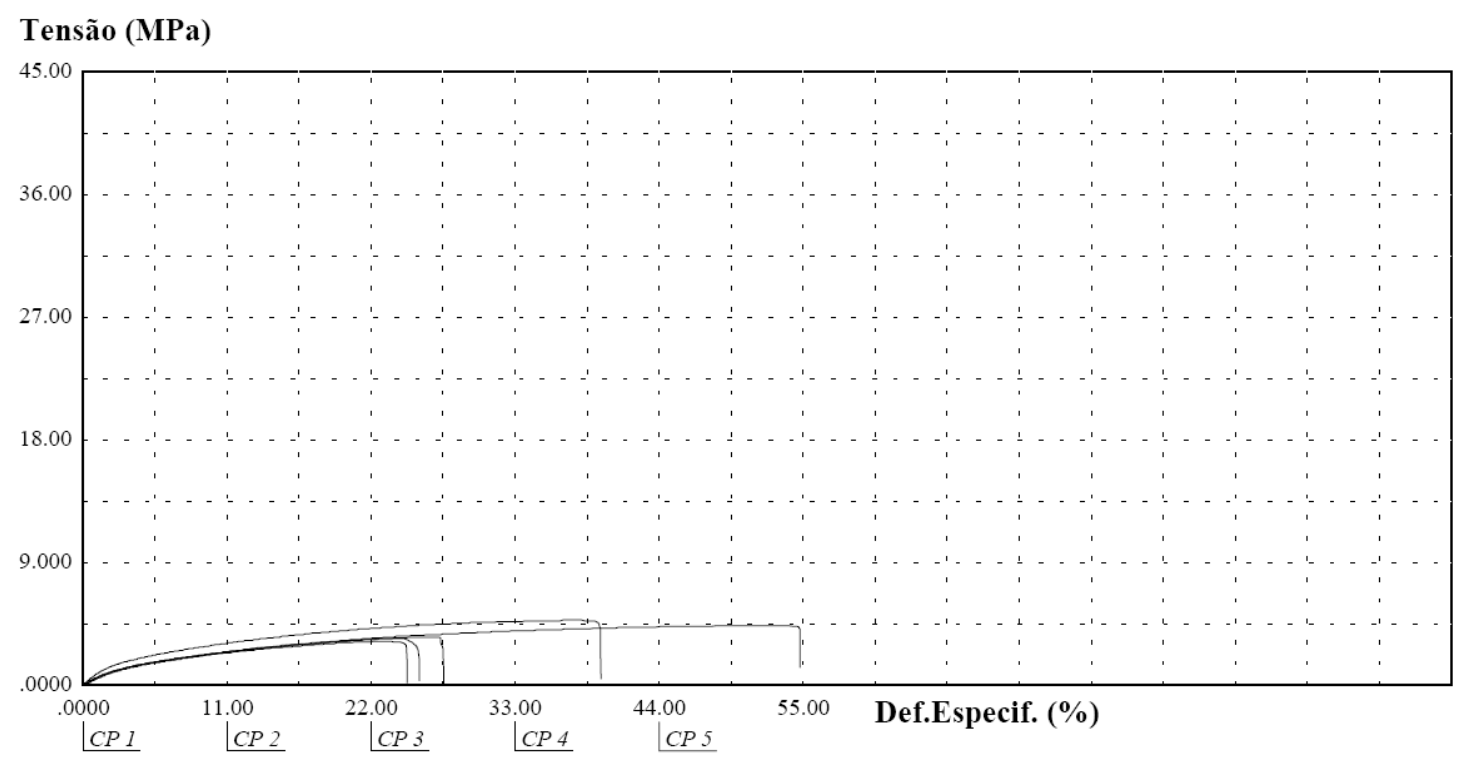

Tensão (MPa)

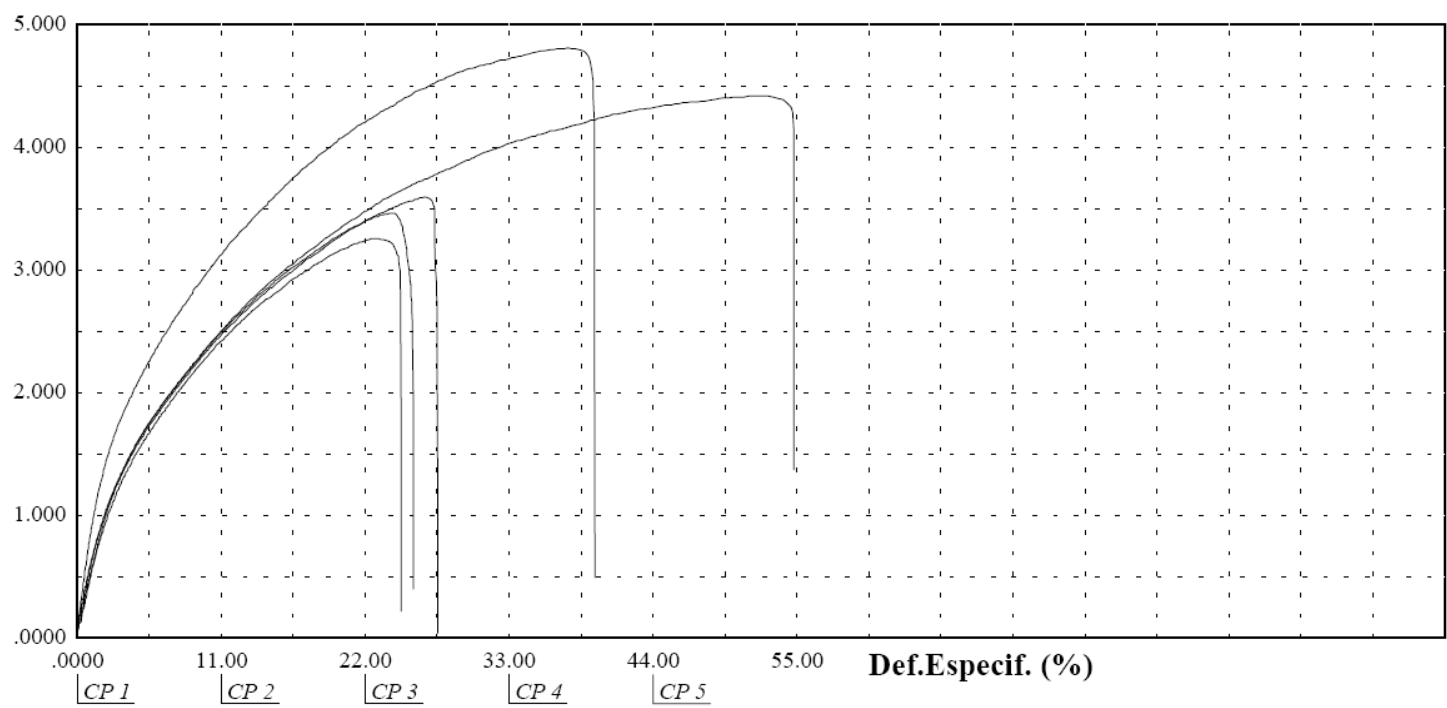

Figura 1- Curvas representativas de tensão x deformação para a amostra TPS. 
Tensão (MPa)

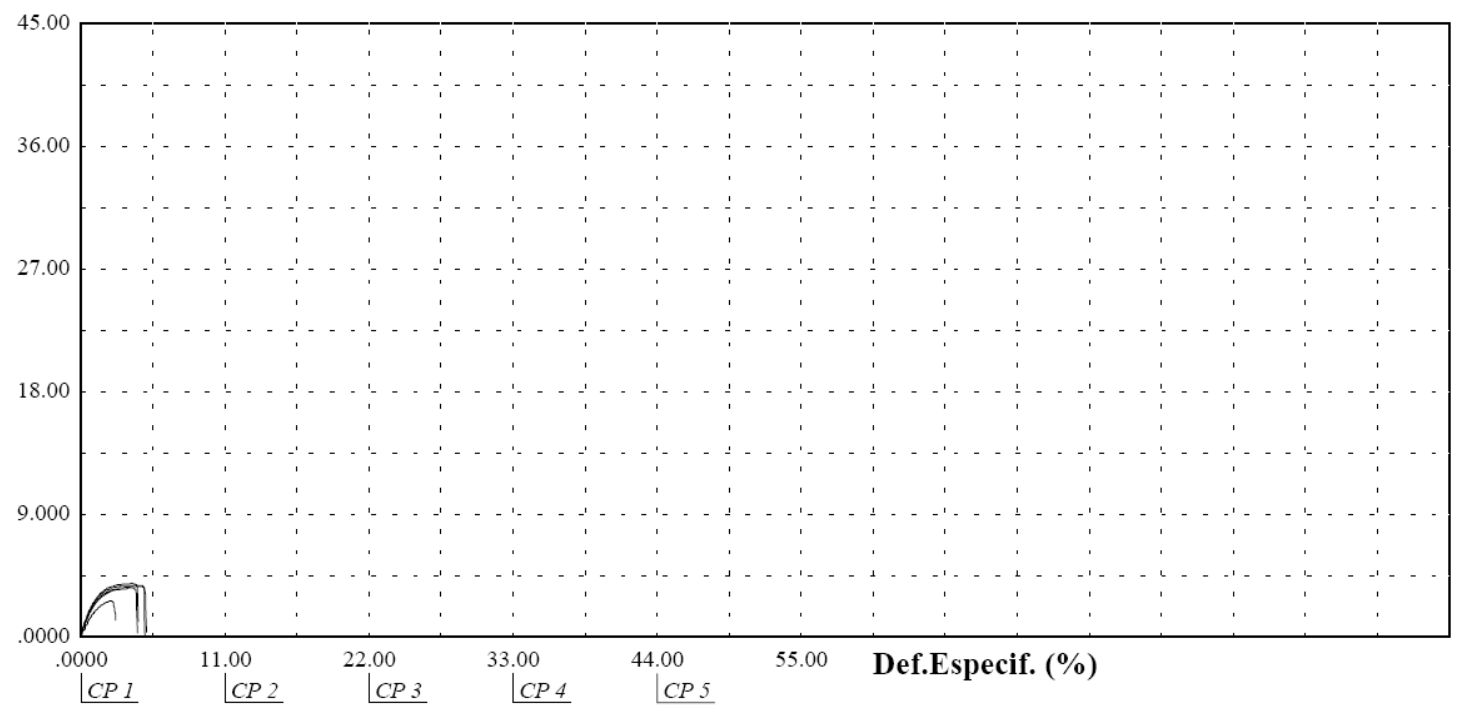

Tensão (MPa)

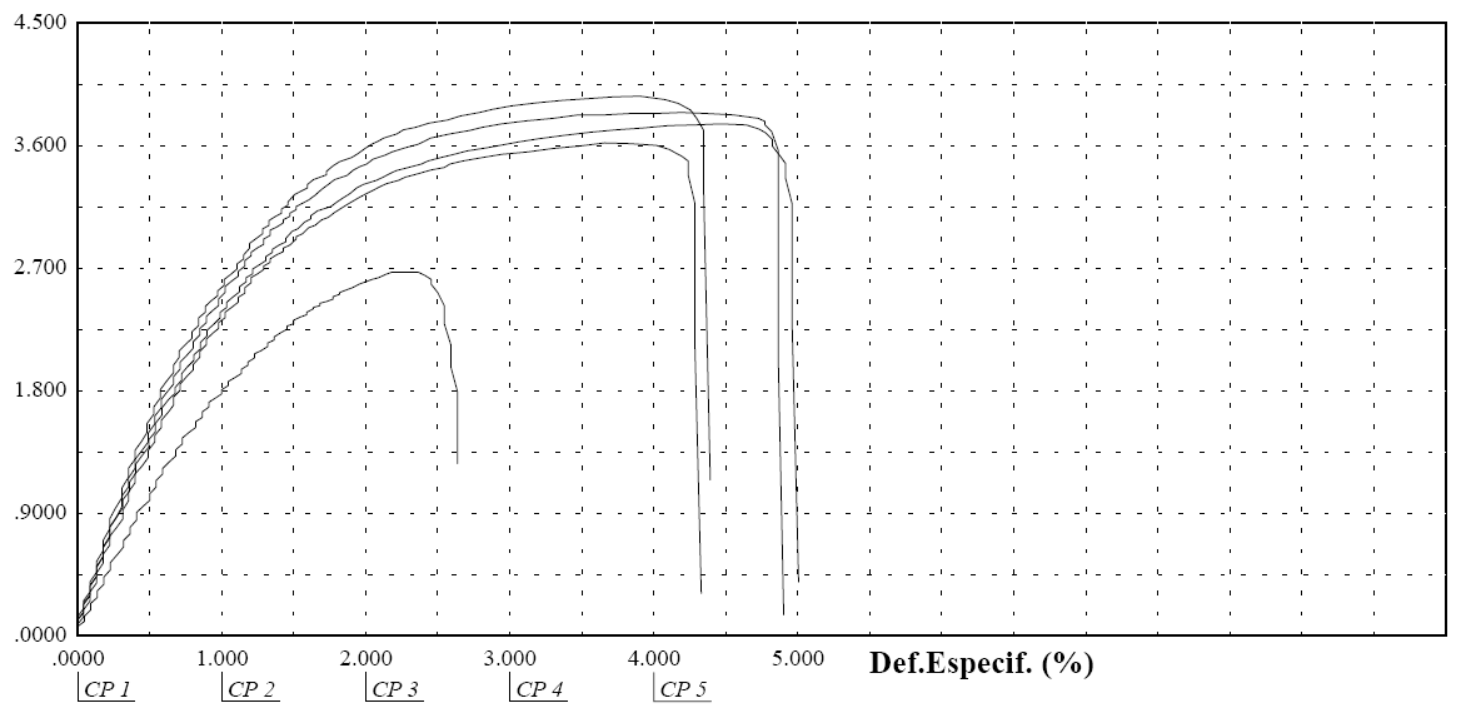

Figura 2 - Curvas representativas de tensão x deformação para a blenda PHB25. 
Tensão (MPa)

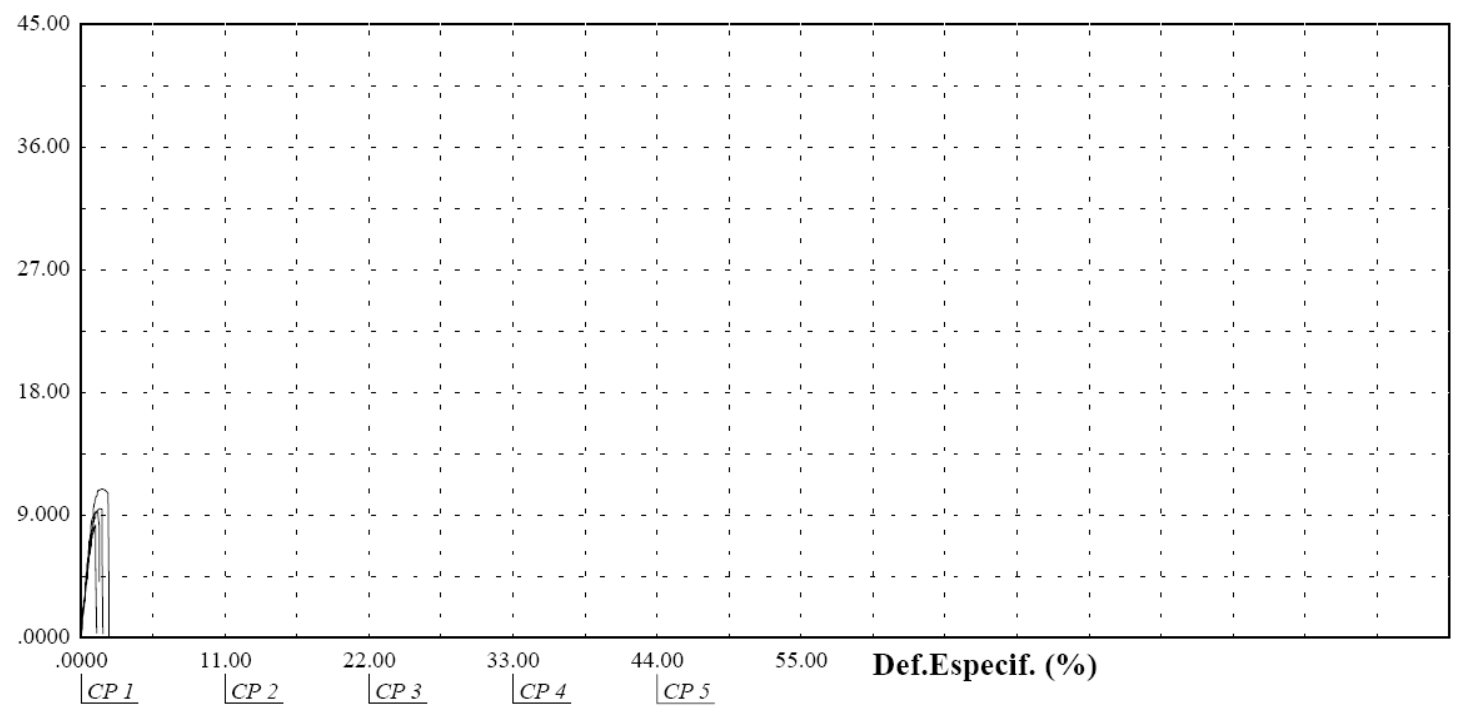

Tensão (MPa)

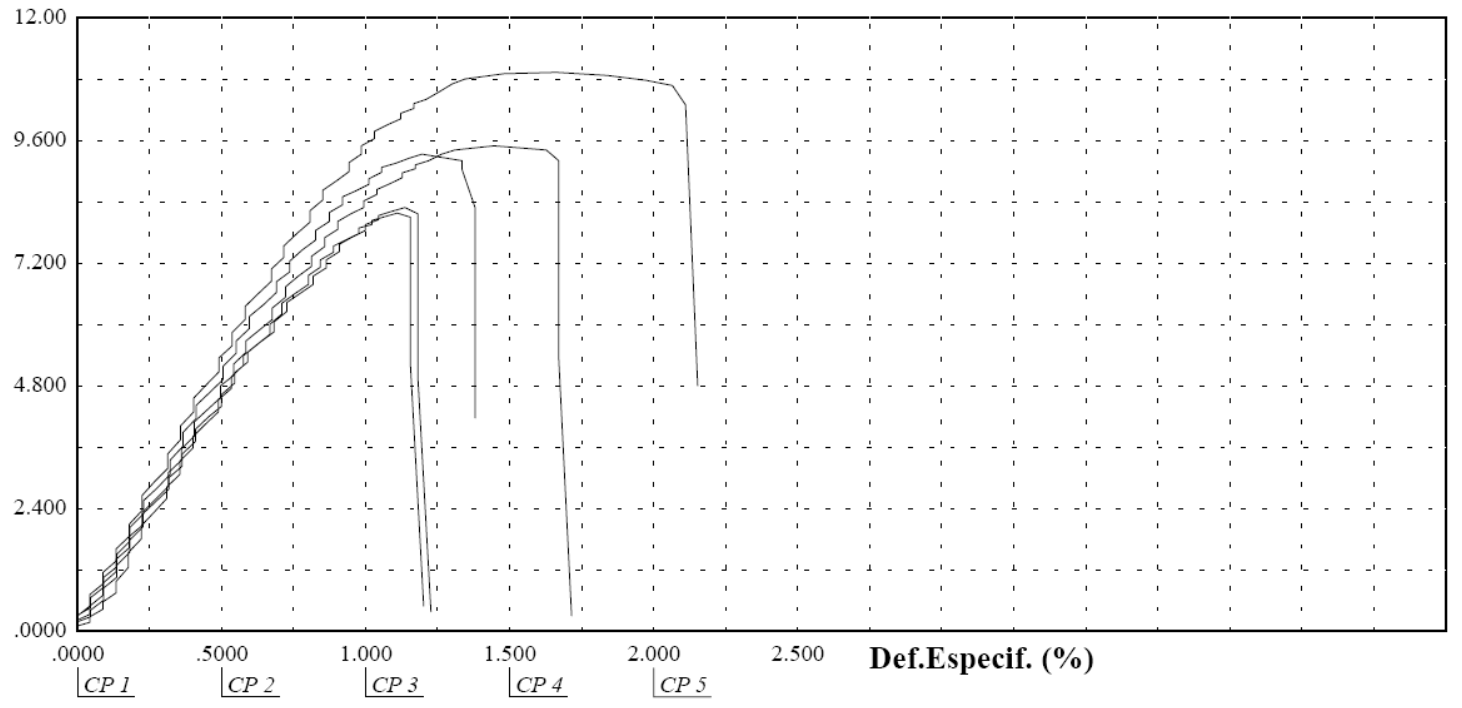

Figura 3 - Curvas representativas de tensão x deformação para a blenda PHB50. 

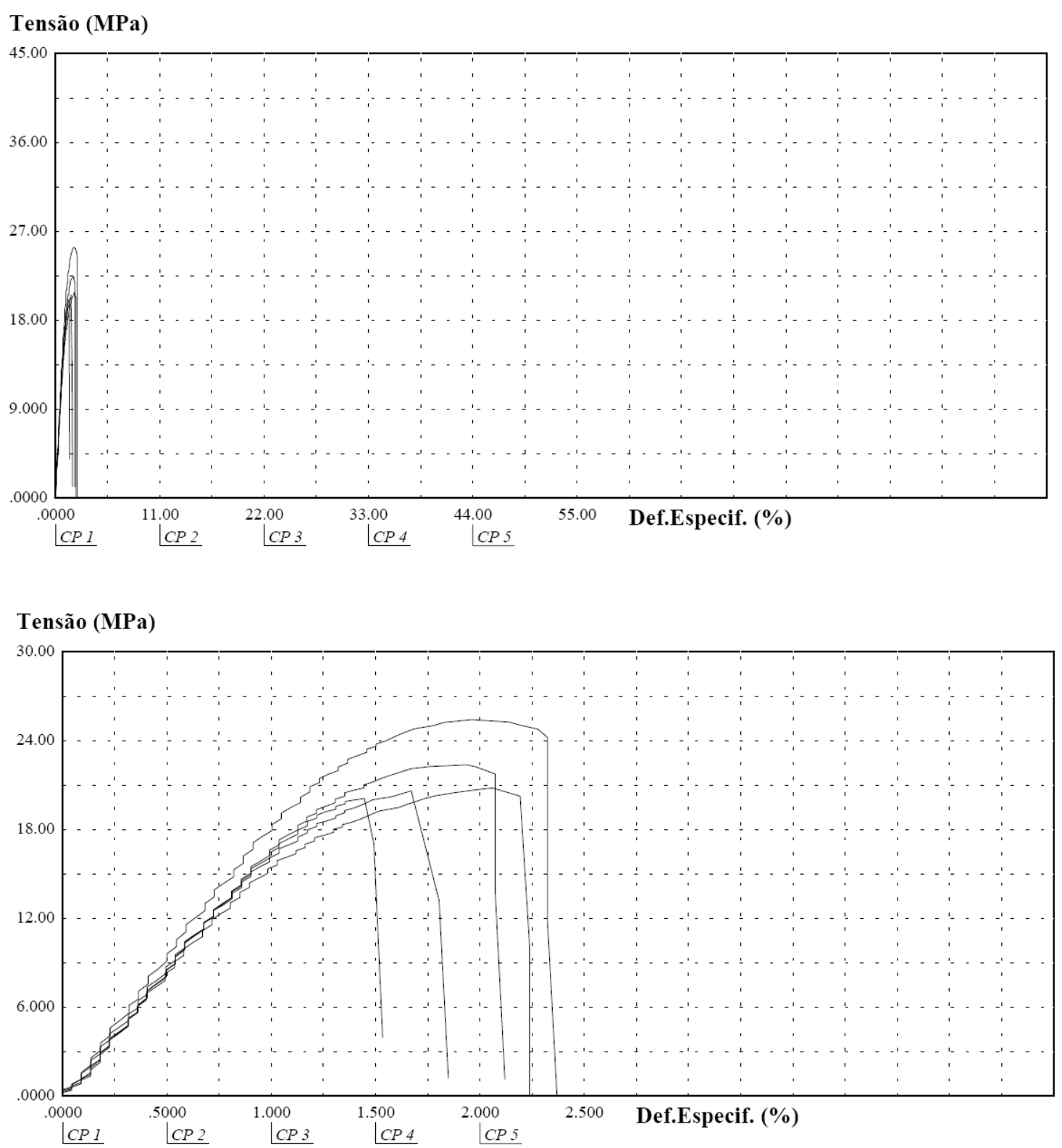

Figura 4 - Curvas representativas de tensão x deformação para a blenda PHB75. 

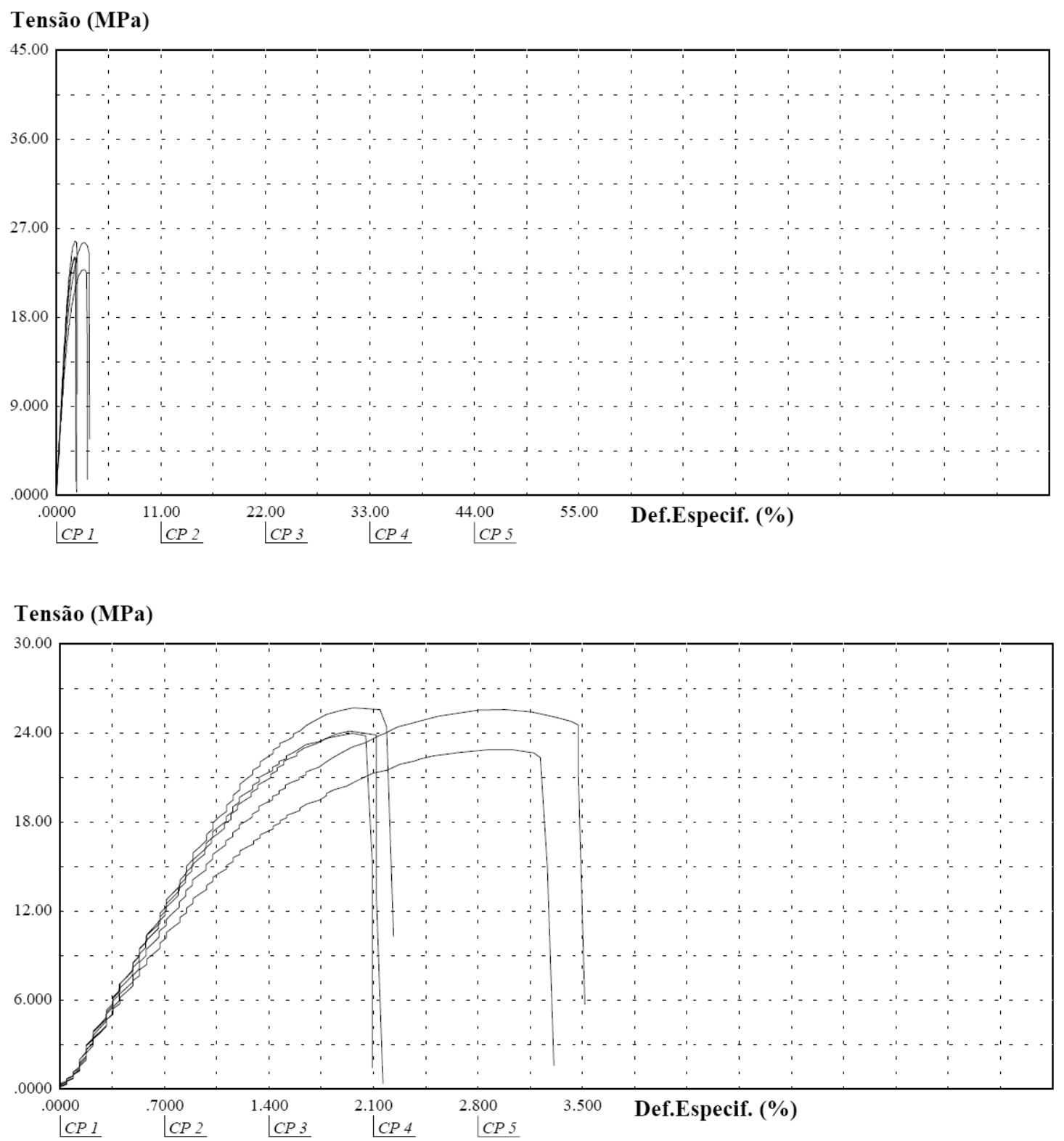

Figura 5 - Curvas representativas de tensão x deformação para a amostra PHB70G30. 

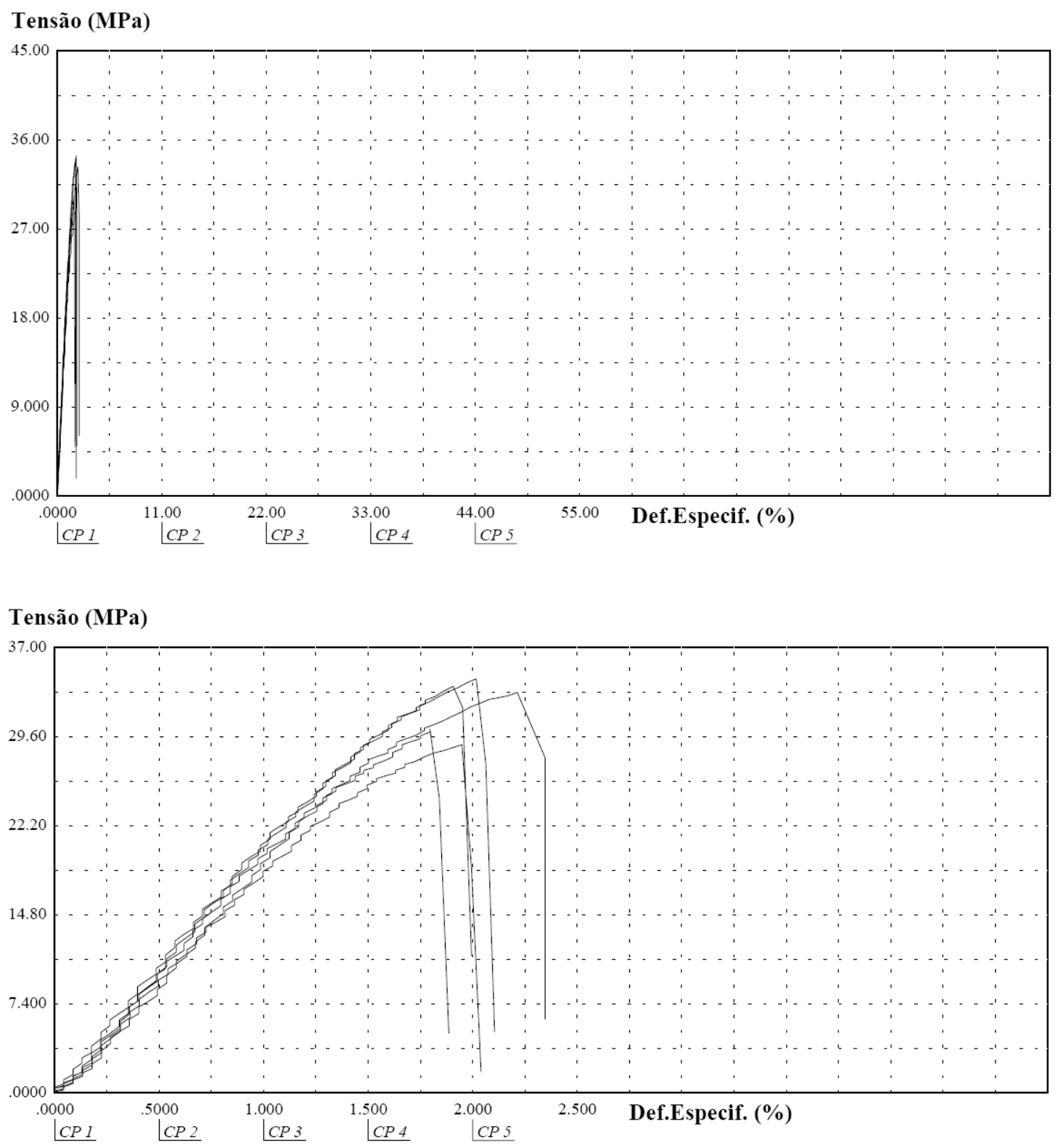

Figura 6 - Curvas representativas de tensão x deformação para a amostra PHB. 


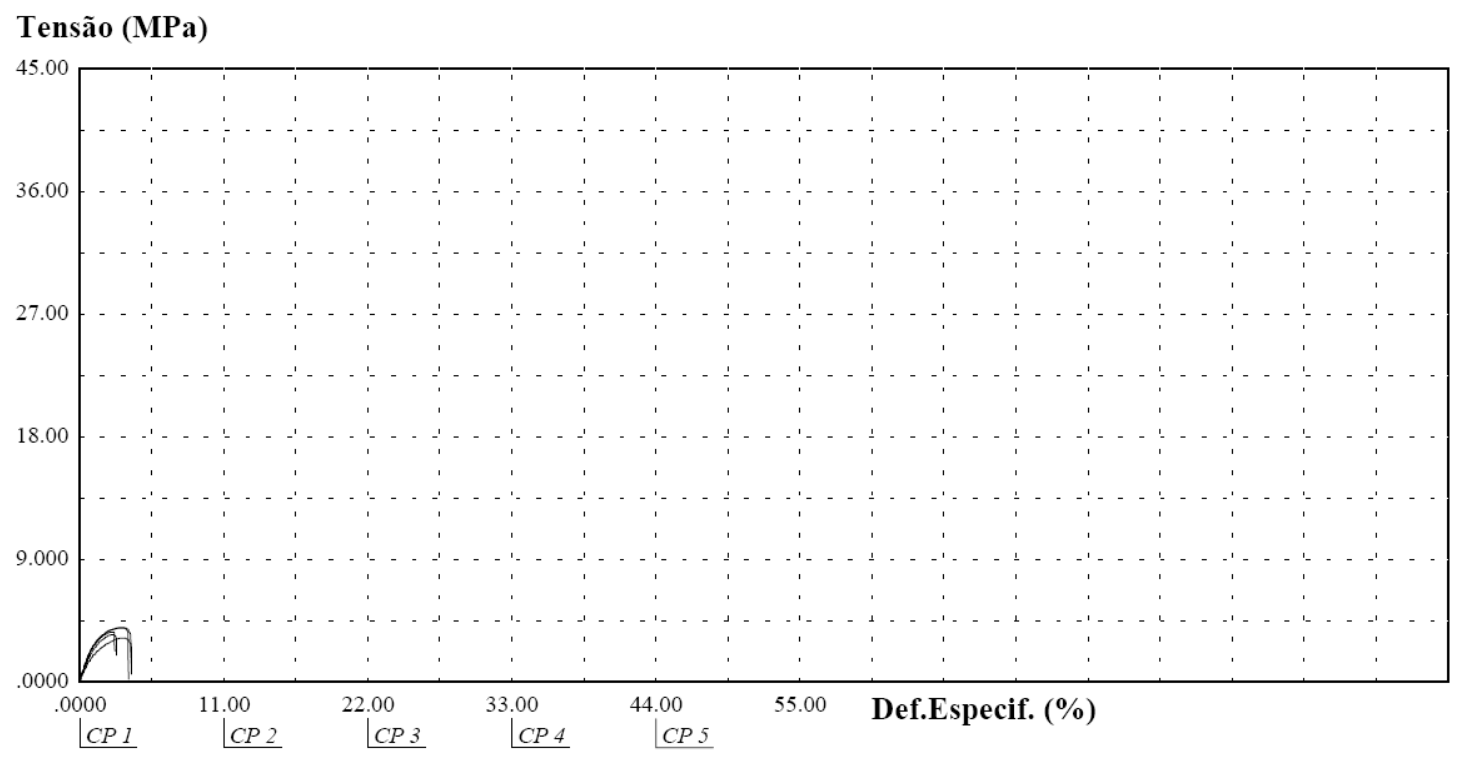

Tensão (MPa)

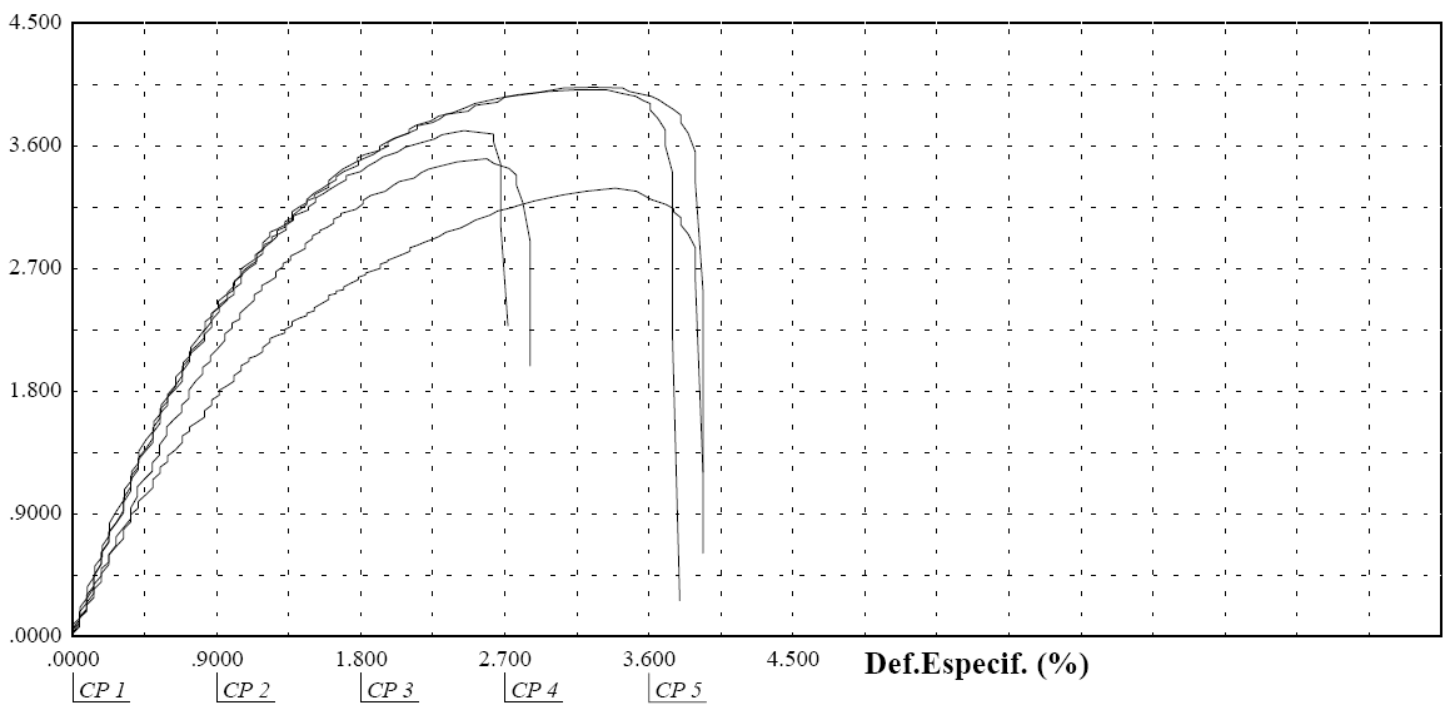

Figura 7 - Curvas representativas de tensão x deformação para a blenda PHBV25. 

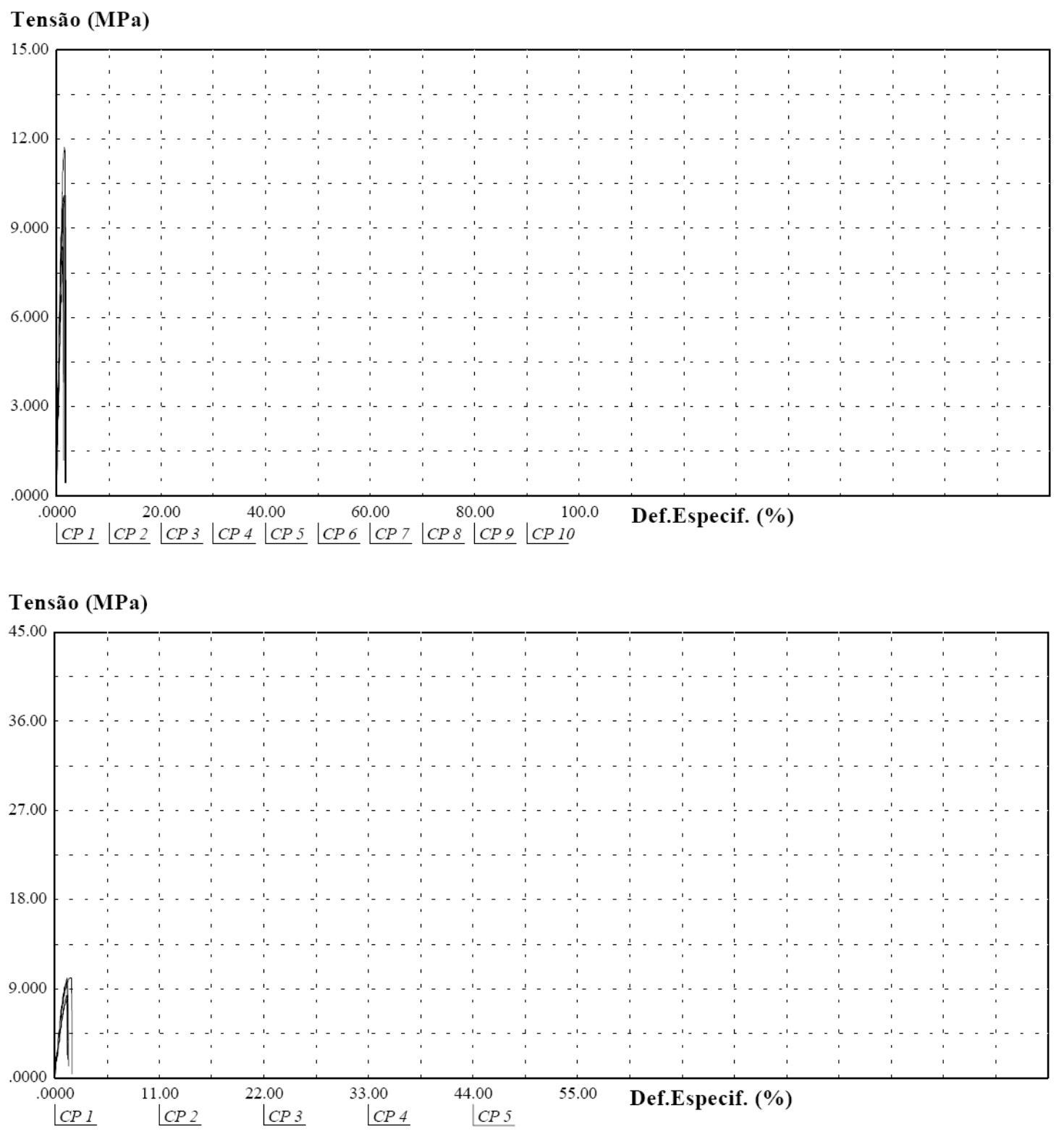

Figura 8 - Curvas representativas de tensão x deformação para a blenda PHBV50. 


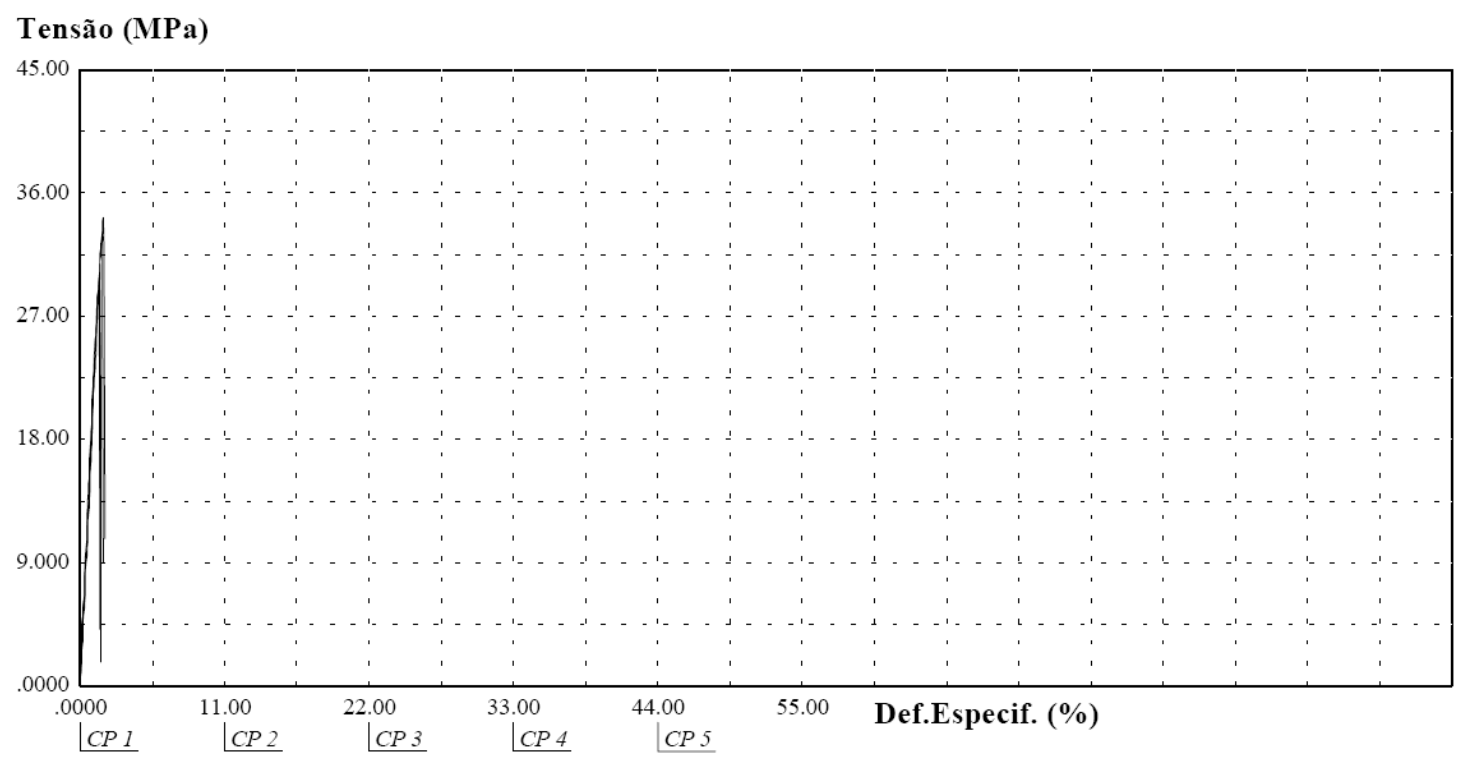

Figura 9 - Curvas representativas de tensão x deformação para a blenda PHBV75. 

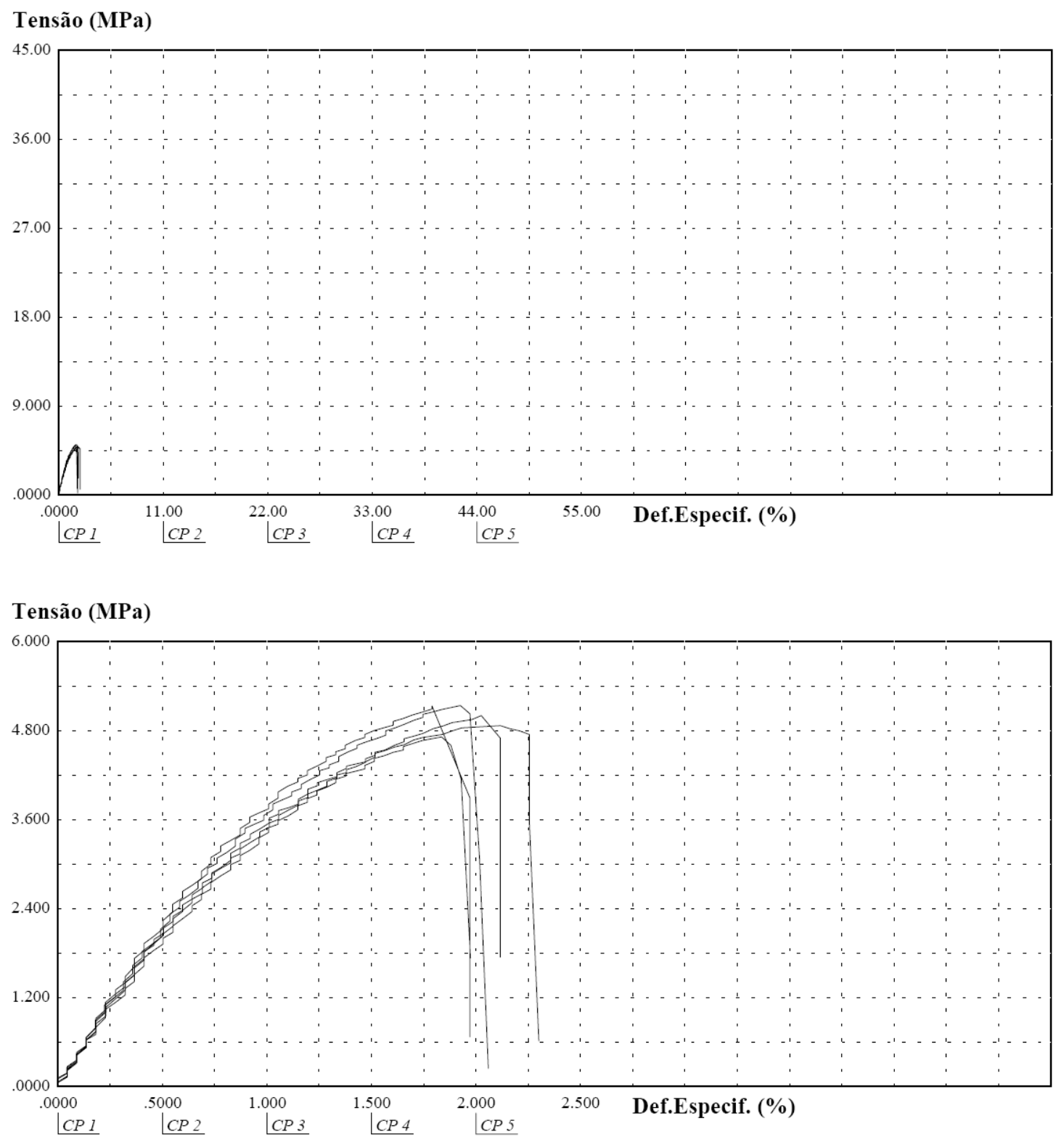

Figura 10 - Curvas representativas de tensão x deformação para a amostra PHB12,5PHBV12,5.

194 


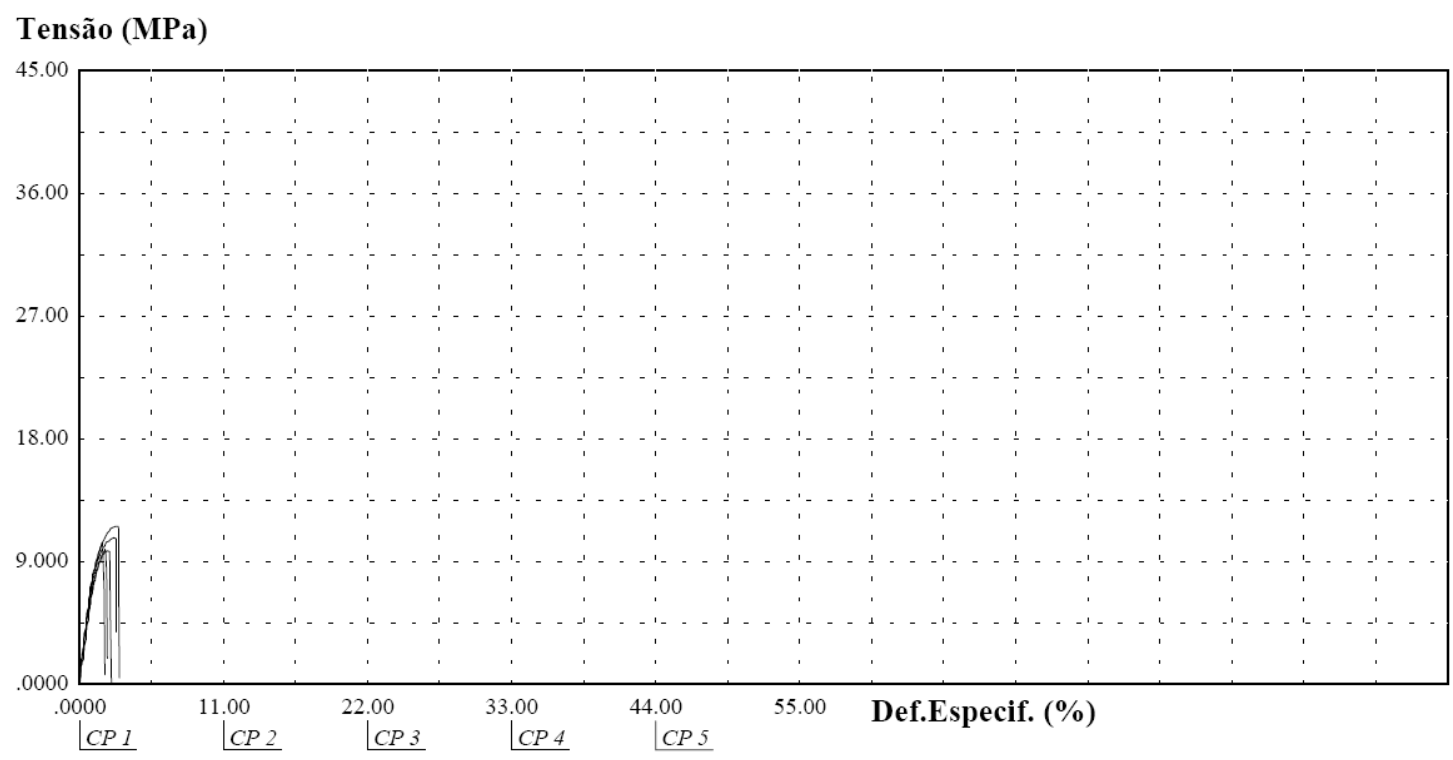

Tensão (MPa)

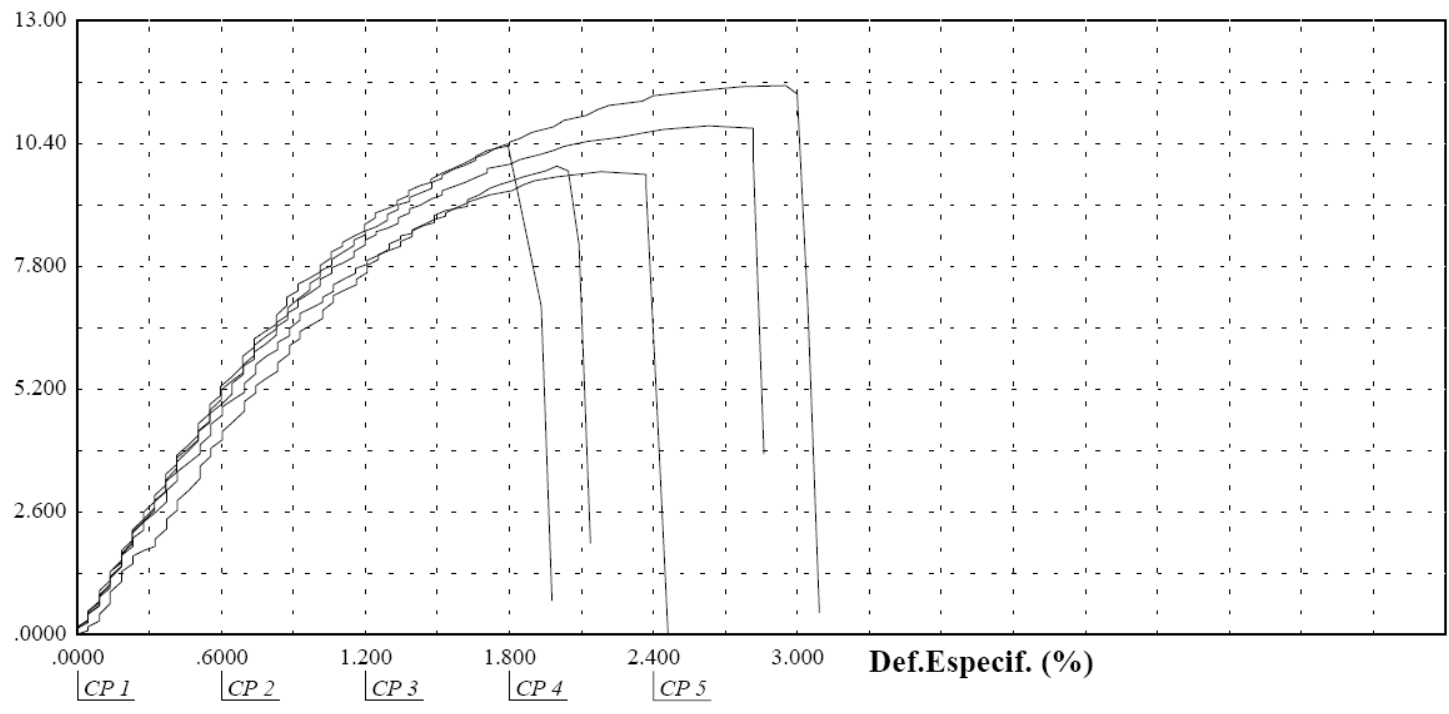

Figura 11 - Curvas representativas de tensão x deformação para a amostra PHB25PHBV25. 

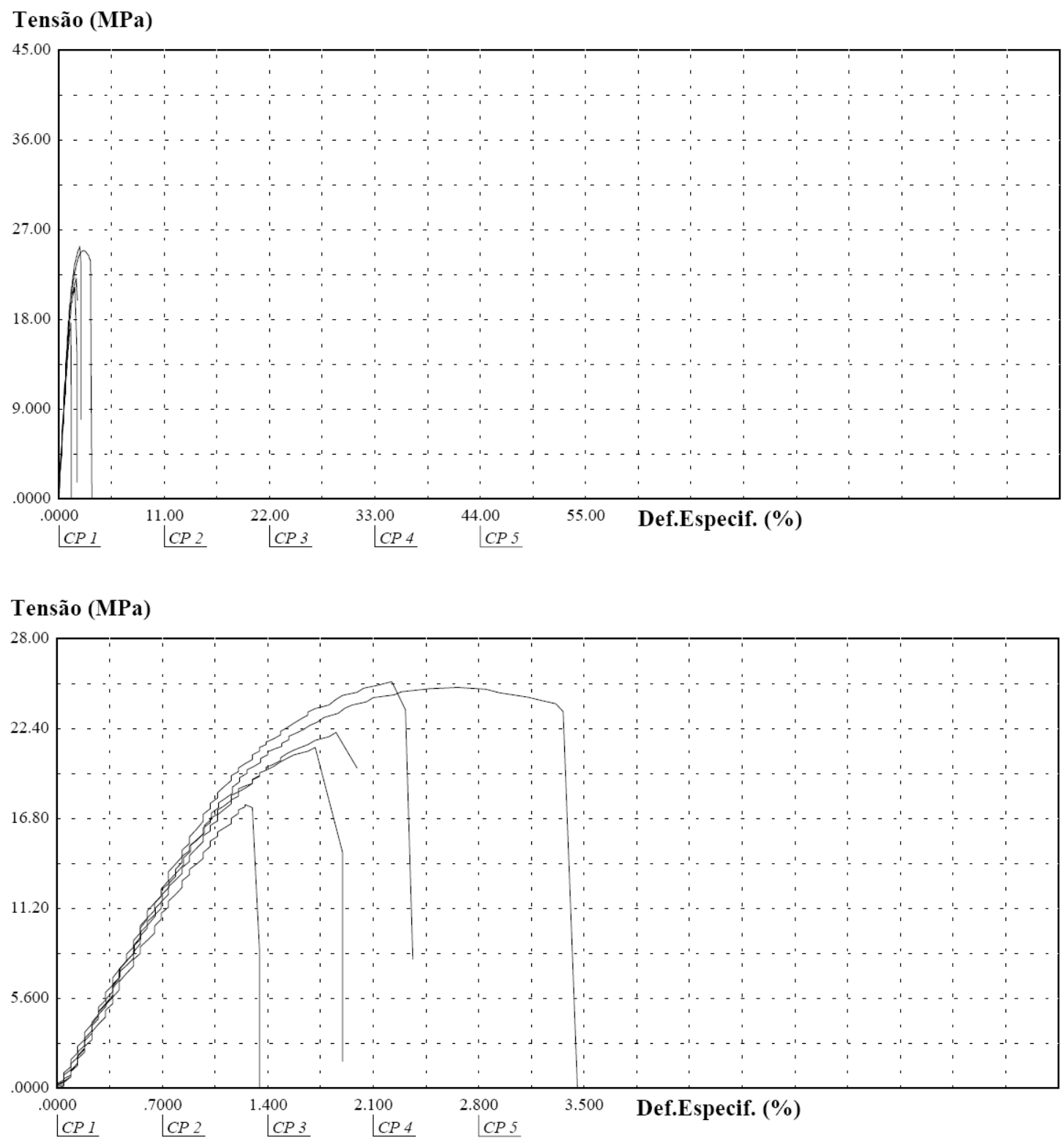

Figura 12 - Curvas representativas de tensão x deformação para a amostra PHB37,5PHBV37,5. 


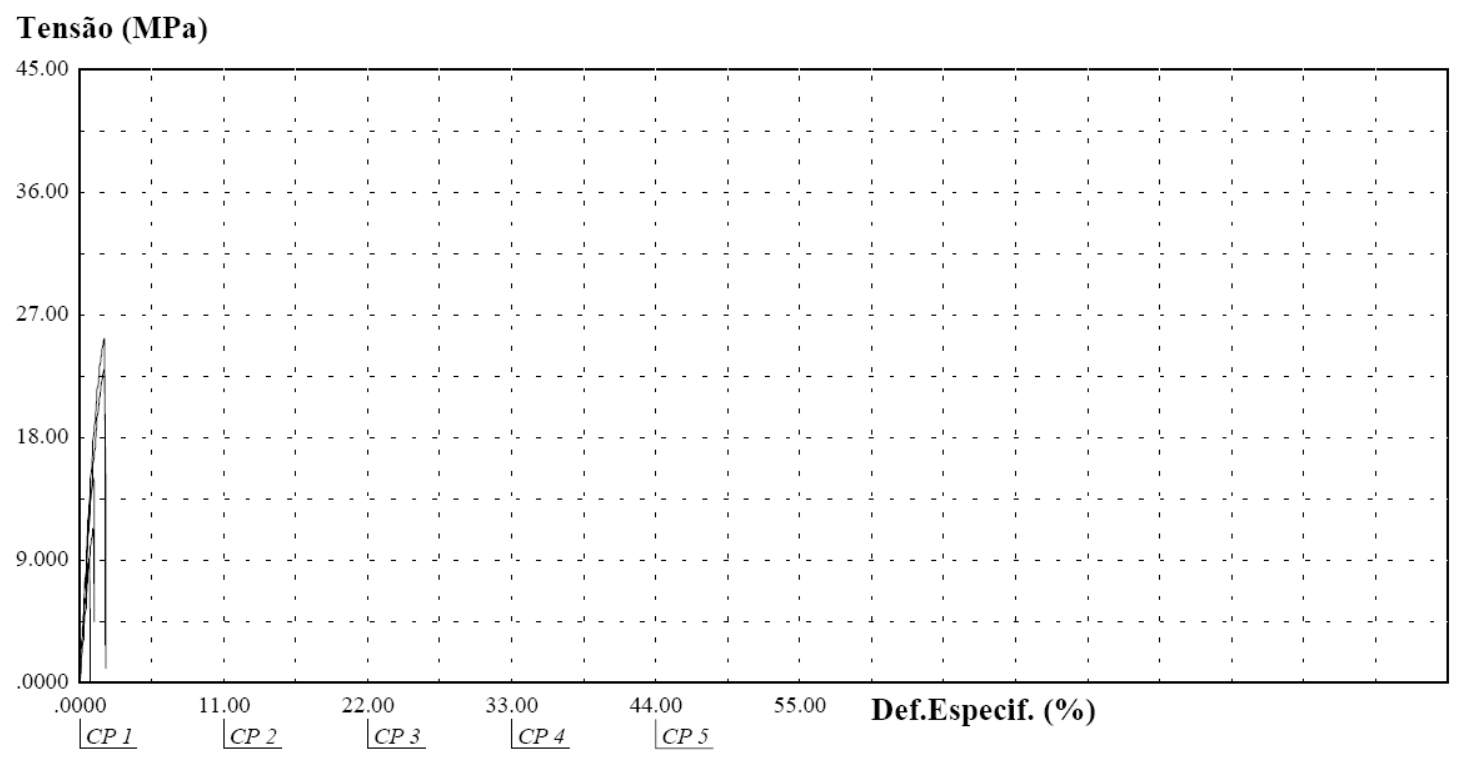

Tensão (MPa)

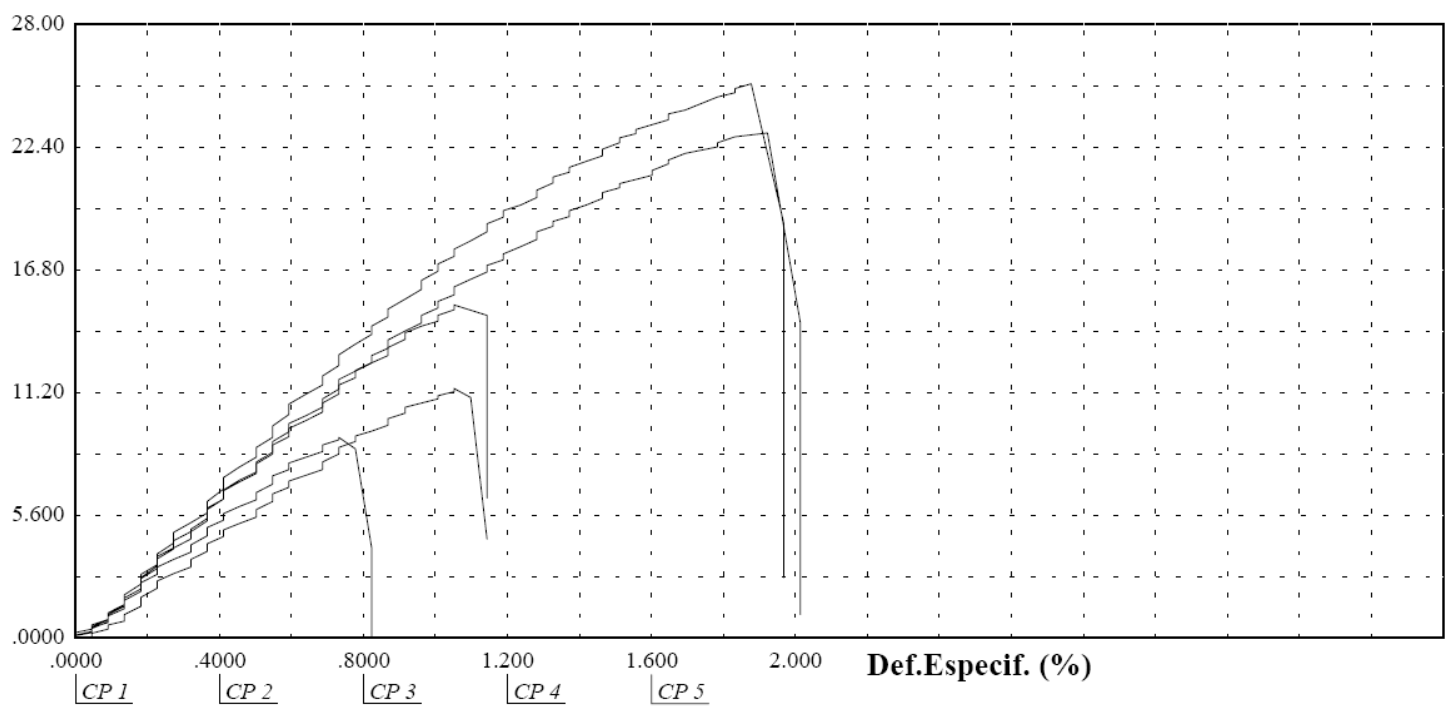

Figura 13 - Curvas representativas de tensão x deformação para a amostra PHB35PHBV35G30. 

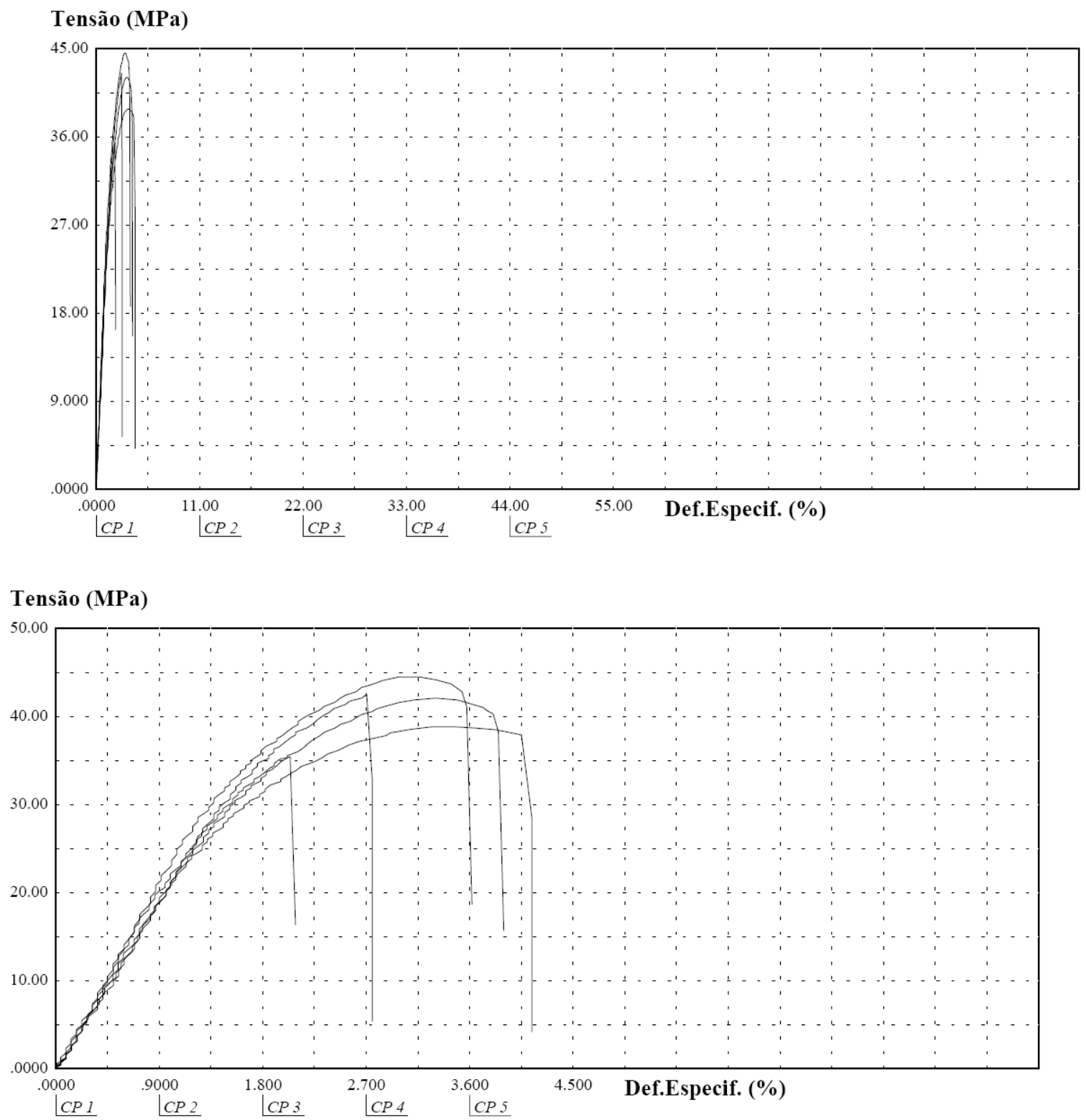

Figura 14 - Curvas representativas de tensão x deformação para a amostra PHB50PHBV50. 